\title{
THE SGOTTISH PHILOSOPHY OF COMMON SENSE
}

B Y

S. A. GRAVE

OXFORD

AT THE GLARENDON PRESS

I960

\section{DISCARDED}

A1: 46 


\section{PREFACE}

T wist to thank especially Professor A. D. Woozley, under whose supervision this book was 1 written in substance at the University of St. Andrews, for a number of valuable suggestions, and for helping me to correct mistakes that I had made. I am of course entirely responsible for all the book's remaining defects. And I wish to thank also the librarians and staffs of the four universities of Scotland and of the National Library of Scotland for making available to me manuscripts or books or for giving me information I needed; and, in general, to acknowledge assistance of one kind or another from too many people to mention individually.

Perth, Western Australia

S. A. G. 


\section{NOTE}

GONTENTS

Hamilton's edition of Reid's Works (7th ed., Edinburgh, 1872, 2 vols.) has been used and his edition of Stewart's Works (Edinburgh, 1854-6o, II vols.); the third edition of Beattie's Essay on the Nature and Immutability of Truth (London, I772); the ninth edition of Locke's Works (London, 1 794, 9 vols.); the Luce-Jessop edition of Berkeley's Works (London, I 948-57, 9 vols.); Selby-Bigge's edition of Hume's Treatise of Human Nature (Oxford, 1896) and his edition of Hume's Enquiries (2nd ed., Oxford, 1902). Books by these and some other authors are mentioned under abbreviated titles. The complexities of division and sub-division in two of Stewart's books, the Elements and the Active and Moral Powers, have been simplified for easier reference. Thus, for example, Elements, mi. iii. 3, gives volume, chapter, and section; Active and Moral Powers, III. iii. 3, gives book, chapter, and section.

The manuscripts referred to as 'Aberdeen MSS.' (with a cataloguing number) are: (I) papers of Reid's from the collection formerly in the possession of Miss Hilda Paterson of Birkwood, Banchory, and now in the library of King's College, Aberdeen; (2) items from the collection of Beattie manuscripts also at King's College, Aberdeen. The Reid collection is at present unclassified in boxes numbered 2131.1-213I.7.

Many of Stewart's papers were destroyed soon after his death (Works, vol. viii, Editor's Introduction), and most of what survived seems to have disappeared subsequently. The library of the University of Edinburgh has students' copies of his lectures on moral philosophy and political economy, a travel-diary, a scrap-book, an essay on Sanskrit and a few of his letters.

\section{INTRODUCTION}

I. THE SCEPTICAL PRINGIPLE

1. Ideas

2. Direct Objects

II. THE SGEPTIGAL DEDUGTION

I. The Logical Deduction

2. The Historical Deduction

3. The Sceptical Conclusion

III. COMMON SENSE (I)

1. Plain Truth and Strange Doubt

- 2. The Metaphysical Commitment of Common Sense

IV. GOMMON SENSE (2)

1. Reason and Common Sense

2. Philosophy and the Philosophy of Common Sense

V. THE LANGUAGE OF SENSATION

1. Natural Signs

2. Sensation and Perception

151

3. Perceptual Relativity

I6I

183

VI. PERSONAL IDENTITY AND FREE WILL

1. Personal Identity

2. Free Will

VII. MORAL DISTINCTIONS

. I. Matter of Fact and Moral Fact

2. The Principles of Action

242

INDEX 


\section{INTRODUCTION}

THE philosophy of Common Sense became 'the Scottish philosophy' and schooled several generations of Scotsmen. 1 It 'permeated the universities', Victor Cousin wrote, looking back as its patron in France over its history in Scotland, 'spread among the clergy, among the lawyers, among men of letters and men of the world; and, without producing a movement as vast as that of the German philosophy, had a similar effect within narrower limits'. I Its history in Scotland began at Aberdeen with Thomas Reid's teaching at King's College and his papers to the Aberdeen Philosophical Society. Reid, who was born in I 710 and educated at Marischal College, Aberdeen, was appointed professor of philosophy at King's College in 1752. The society, important both for the origin and expansion of the philosophy of Common Sense, was formed in $175^{8}$ and during its early years gravitated in a distant orbit round Hume. ${ }^{2}$ It became more than locally famous as the 'Wise Club' and included several men, very friendly with Reid, who wrote books which counted in their day: George Campbell, the author of The Philosophy of Rhetoric, Alexander Gerard, the author of essays On Taste and On Genius, and James Beattie.

Beattie ( $1735^{-1803}$ ) popularized the notion of a philosophical appeal to common sense. His Essay on the Nature and Immutability of Truth in opposition to Sophistry and Scepticism (first published in I 770) was a great and immediate success in Scotland and England. Reynolds celebrated its success with a huge picture of Sophistry, Scepticism, and Infidelity fleeing before the face of Truth, Beattie at her side with the Essay on Truth under his arm. The considerable reputation as a poet in the fashionable mood of mournful and Gothic romance which Beattie acquired with The Minstrel, recommended him as a philosopher. His philo645.

' Cours de l'histoire de la philosophie moderne (nouvelle édition, Paris, 1846-47), iv.

'A title philosophical society here', Reid wrote to Hume, 'is much indebted to tians, be entainment. Your company would, although we are all good Chris you upon the bench, you are brought oftener than any other man to the bar, accused and defended with great zeal, but without bitterness.' (Reid's Works, i. 92.) 
sophy had some domestic permanence. In 1841 Alexander Bain, assistant to Dr. Glennie, Beattie's successor at Marischal College, was reluctantly reading out its doctrines in class from Glennie's ancient lectures.

Reid's Inquiry into the Human Mind on the Principles of Common Sense, based on his papers to the Aberdeen Philosophical Society, was published in 1764 . In the same year he was appointed professor of moral philosophy at Glasgow, in succession to Adam Smith. He published nothing while he was teaching at Glasgow except $A$ Brief Account of Aristotle's Logic, as an appendix to Lord Kames's ${ }^{1}$ History of Man (I774). The Essays on the Intellectual Powers of Man and the Essays on the Active Powers of Man, incorporating, along with other material, the substance of his lectures, appeared in 1785 and 1788 . Reid died in 1796. He never thought grandly of himself and would not have countenanced the wording of part of his epitaph: 'in Scientia Mentis Humanae, ut olim in Philosophia Naturali illustris ille Baconius Verulamius, omnia instauravit'. We shall be concerned later on with the not very obvious connexion between a philosophy of common sense and a Baconian reformation of the philosophy of the mind.

Dugald Stewart (1753-1828) brought the philosophy of Common Sense from Glasgow to Edinburgh. He had gone to study under Reid on the advice of one of Hume's friends, Adam Ferguson. After his return to Edinburgh he taught mathematics in the university for some years, and in 1785 he succeeded Ferguson as professor of moral philosophy. Stewart always saw his work as an extension of Reid's and especially as continuing the reformation of the philosophy of the mind. He published the first volume of the Elements of the Philosophy of the Human Mind in 1792 (the second volume in 1814 and the third in 1827 ), the Philosophical Essays in 1810, and the Philosophy of the Active and Moral Powers of Man in 1828 . Stewart was most eminent in his pupils. Among those who attended his lectures were Sydney Smith, Francis Jeffrey, Henry Brougham, and Francis Horner

I Henry Home (1696-1 782), a judge of the Court of Session with the title Lord Kames, was variously distinguished, as a jurist, as an agriculturalist, and as a philosopher. He was a close and early friend of Hume and later his critic in the Essays on the Principles of Morality and Natural Religion (175I). He came to know Reid very well, shared some of his opinions but, as a 'necessitarian', differed from him strongly over the question of the freedom of the will. (the men who founded the Edinburgh Review), Scott, James Mill, Palmerston, Lord John Russell, and Thomas Chalmers who led the Disruption in the Church of Scotland.'

The whole of English and French philosophy in the eighteenth century comes from Locke and its principle is the tabula rasa. Reid grounded Scottish philosophy on the contrary principle and in so doing he raised himself above his century and from Scotland reached across to Königsberg. Kant in fact proposed, as Reid did, to establish in metaphysics and morals speculative and practical laws which depend on the constitution of human reason itself, laws which are not derived from experience and which alone make experience possible. It is the same enterprise differently carried out. ${ }^{2}$

They were very different enterprises, as Cousin elsewhere recognizes, though both repudiated the tabula rasa. When RoyerCollard (about I81o) brought the philosophy of Common Sense into France, he did so because, along with this repudiation, it maintained that the principles of common sense, imposed upon us by the constitution of the human mind, are principles by which our cognition is conformed to its objects, to things as they really are in themselves.

The Baconian appraisal of Reid's work appears again in the school Royer-Collard gathered around him. Reid's demand for an inductive philosophy of the mind could be used in argument against what this school regarded as the aprioristic sensationism riveted by Condillac to French philosophy. It opposed opinions which had already lost much of their authority under criticism from Catholic philosophers such as de Bonald and de Maistre and from a philosopher whose thought had come to approximate in some respects fairly closely to Reid's. Maine de Biran rejected the notion that there is nothing in the intellect which was not first in the senses and with it, 'hypothetical explanations of inexplicable facts', reasserted 'personal individuality' against its dissipation into mental states and denied that the passivity of desire could be transformed into the activity of the will.

Maine de Biran and Reid between them supplied RoyerGollard with most of what he needed for his attack on the decaying orthodoxy of 'Condillacisme'. Cousin was his pupil, and the principal architect of the Eclecticism which replaced it as

$$
\begin{aligned}
& \text { I J. McCosh, Scottish Philosophy (London, 1875), p. } 283 . \\
& 2 \text { Cousin, Hist. phil. moderne, p. } 5^{81} \text {. }
\end{aligned}
$$


the new orthodoxy. As the constant foundation upon which Eclecticism built its shifting structures, essential doctrines of the philosophy of Common Sense became, through Cousin's influence on French education, part of the 'official' philosophy of France-Cousin was for a time minister of public instructionand, as part of this philosophy, were still being taught in the colleges late in the nineteenth century. Until after the middle of the nineteenth century, the philosophy of Common Sense was, with or without borrowed or invented modifications, the philosophy which professors of philosophy in America were as likely as not to be teaching. And besides being for so long so established in France and America as well as in Scotland, it impressed philosophers of some distinction in other countries, notably Rosmini in Italy and, much more deeply, the Belgian 'Ontologists' at Louvain.

The philosophy of Common Sense arose as an 'answer' to Hume. No past philosopher is more our contemporary than Hume. And the insistence on the authority of common sense is a topical commonplace. The Common Sense philosophers thought that Hume's characteristic opinions contradicted this authority. They were perhaps not mistaken in thinking so. If they were mistaken, it was instructively; if they were right, there is all the more reason for what they said to be heard again. They thought that common sense had metaphysical commitments which it is no longer generally regarded as having, but which perhaps it has.

The philosophy of Common Sense was historically important and is again of some consequence. Its history is for the most part the uneventful history of established teaching, and we shall not go into it any further. Nor shall we be concerned with its influence on other philosophies any further than is necessary for the definition of its boundaries. In particular we shall be mentioning only very incidentally its continental influence. What is worth consideration in Eclecticism is the peace of complementarity it tried to impose on warring philosophies, and to discuss this would take us too far afield. The philosophers at Louvain who about the middle of the nineteenth century occupied themselves with Reid, did so because of his argument for the proposition that no 'ideas' come between the mind and its objects. The use they made of this proposition in the construc- tion of an ontologistic doctrine of the knowledge of $\operatorname{God}^{\mathrm{I}}$ is a matter of minor and technical interest.

The purpose of this book is to piece together in some detail the philosophy of Common Sense from its fragmentary state in the writings of Reid and the other members of his school, to consider it in relation to Hume and to try and show the significance of its account of the nature and authority of common sense for present-day discussion.

We have to decide who are members of Reid's school. The label 'Common Sense' and their dependence on Reid, bracketed James Beattie and James Oswald with Reid as members of a school. And collective denunciation by Priestley, the chemist, theologian, and philosopher-who spoke of Reid, Beattie, and Oswald as 'a set of pretended philosophers', 2 by Kant-who spoke of them as appealing to the 'judgement of the crowd', 3 and by an anonymous critic, charging them all with plagiarism, tightened the brackets. Beattie's philosophy is to a large extent part of Reid's philosophy vulgarized, with the most vulgar misunderstanding of the philosophers he along with Reid was opposing. Oswald was the author of An Appeal to Common Sense in behalf of Religion (the first volume published in 1766 and the second in 1772). Oswald is more independent of Reid than Beattie, because his claims for common sense are more extravagant than Beattie's. His misunderstanding of the philosophers he regarded as attacking common sense is on a level with Beattie's. Beattie now and then makes a point which Reid has not made, or makes a point better than Reid makes it. These small contributions can be worked into the fabric of the philosophy of Common Sense. It would be hard to find contributions from Oswald.

George Campbell would count as a member of Reid's school, if his concern with the philosophy of Common Sense had been less marginal. He gave it a general assent, and in The Philosophy of Rhetoric ( 1776$)$ briefly defended Reid against Priestley. As philosophers, Gerard and Ferguson are still more peripherally associated with Reid. Stewart is Reid's acknowledged successor.

\footnotetext{
I J. Henry, 'Le Traditionalisme et l'ontologisme à l'Université de Louvain (18351865)', Annales de l'Institut suptrieur de philosophie, v (Louvain, 1924).

2 Examination of Dr. Reid's 'Inquiry' etc. (London, 1 774), p. 5 .

3 Prolegomenc to any Future Metaphysics, tr. P. G. Lucas (Manchester, 1953), p. 8.
} 
We shall treat the philosophy of Common Sense as ending with Stewart.

Two other philosophers are sometimes reckoned as belonging to Reid's school. Thomas Brown (1778-1820), Stewart's pupil, and for ten years conjoint-professor of moral philosophy with him at the University of Edinburgh, attacked Reid openly and Stewart by unconcealed implication. There was rather more of a family quarrel in Brown's disagreement with Reid and Stewart than he supposed, since Brown was not prepared to dispense altogether with intuitive beliefs, but the differences between his philosophy and theirs were nevertheless more than sufficient to make his philosophy another philosophy. The most important of these differences will be indicated when we have their contexts.

Sir William Hamilton (1788-1856), Reid's editor and Stewart's, regarded himself as continuing the philosophy of Common Sense and giving it a powerful new development. The extent of the development would perhaps be enough to make Hamilton's philosophy another philosophy, even without a break with any of Reid's principles. If Hamilton's axiom of the relativity of all knowledge is a significant principle, he breaks, as we shall see, decisively with Reid.

By the 'Common Sense philosophers' we shall mean, as a rule, Reid, Beattie, and Stewart. When (in deference to the traditional grouping) Oswald is included, his name will be expressly mentioned. The opinions of Reid, Beattie, and Stewart on the power of common sense to settle disputed questions need the contrast of an opinion which travesties them, and we shall then find Oswald useful. More frequently the contrast will be between Reid and Stewart on the one hand and Beattie and Oswald on the other.

Something may be said here on the question of Reid's sources. Cousin and subsequent commentators on Reid have noticed that he never mentions George Turnbull who had been his teacher. Reid was not concealing a heavy debt. He had learnt from Turnbull that the method of inquiry into the mind was to be the same as the method of inquiry into 'any part of nature':

I While Royer-Collard was introducing Scottish philosophy into France as something to put in place of Condillac, Brown was introducing French philosophy something to put in place of Condillac, Brown was introducing French pritosophy philosophie de Thomas Brown (Paris, 1863), p. v. the method of observation, inductive inference, and the rigorous proscription of conjecture. Cousin quotes one of a number of passages he might have chosen from Turnbull's Principles of Moral Philosophy (published I 740) and asks whether it is Reid or Turnbull. It could be either. Reid may have felt that he had made the proper acknowledgements in making them to Bacon and Newton, as Turnbull had made his to Newton. 'And if natural Philosophy in all its Parts, by pursuing this Method, shall at length be perfected, the Bounds of Moral Philosophy will be also enlarged.' Many philosophical works in the eighteenth century contain puzzling echoes of Newton's prophecy and propose, as Hume did, some application of 'experimental philosophy' to 'moral subjects'. The application is rarely obvious even after the books have been studied. We shall need to have gone some distance with Reid before we shall be in a position to understand how he supposes that the rules of method, which he had learnt from Turnbull and held on the authority of Bacon and Newton, are relevant to a philosophy of common sense and to philosophy in general.

Reid lays great emphasis on the distinction between 'metaphysical' and 'physical' causes, between 'real agents' and the 'laws of nature' according to which they act. The distinction is to be found in Turnbull. Reid makes no proprietary claims for it, treats it as Newtonian and appears to regard it as a commonplace in natural philosophy, and as an equally familiar distinction when the meaning of 'physical' cause is changed to 'something which, by the laws of nature, the effect always follows'.2 We shall be concerned later on with Reid's account of causation, and shall also have occasion to notice a partial similarity between his views and those of Turnbull on the philosophical importance of common language. Turnbull's own thought was moulded by Locke and Shaftesbury, and the vague Platonism to be met with now and then in Reid might well have come from Shaftesbury in the first instance, and if a source has to be provided for Reid's idea of an appeal to common sense in philosophical controversy, there is none more probable than Shaftesbury. ${ }^{3}$

Newton, Opticks, IIr. i. $3^{1}$ (4th ed. reprinted, London, 193I), p. 405.

2 'Letter to James Gregory', Reid's Works, i. 67.

3 'Sensus Communis', I. vi, 1v. iii; Characteristics (5th ed., London, 1732), i. 78, 147. In the Intellectual Powers (vi. ii; Works, i. 423-4) Reid quotes with approval several passages from this essay. 
The anonymous translator of Father Buffier's Traité des premières vérités profixed to his translation (published i780) a 'detection of the plagiarism' of 'the Doctors Reid, Beattie and Oswald'. He had found the book behind their books. They had paraphrased Buffier and corruptly paraphrased him.

Before there was a charge of plagiarism to answer, and about ten years after he had written the Inquiry, Reid had remarked casually that he had 'lately' become acquainted with Buffier's treatise. In the Intellectual Powers, published after the translation of Buffier, he mentions, without mentioning himself, that he had reason to believe that neither Beattie nor Oswald had known Buffier. ${ }^{\text {I }}$

Buffier's opinions, if stolen by Oswald, are unrecognizable in his work. There are verbal coincidences between Beattie's definition of common sense and Buffier's which do not look coincidental, but his heavy borrowings are from Reid. There are strong resemblances in places between the philosophies of Reid and of Buffier, but no indication of any independence on Reid's part. (No dependence of anything in the Inquiry on Buffier; Reid's later books show some signs of Buffier's influence.) A philosophy of common sense is a reaction to philosophical paradox and scepticism. The doctrines of common sense are the same in Reid and in Buffier; they could hardly be doctrines of common sense unless they were. Their doctrine of common sense is substantially the same, with just the amount of variation to be expected from their independence. The polemical features of a philosophy of common sense will alter according to circumstances. The philosophical situation is constituted for Buffier-his Treatise was published in 1724-by an emergence from Cartesian doubt which had been unable to get beyond subjective certainties to anything objective; for Reid, by the inevitability of Hume after Locke. Common sense, they both agree, is the only remedy for a situation which has resulted from a break with common sense. An obvious break, as Buffier sees it: the 'first truths' of common sense, without which we are cut off from everything beyond the present states of our con-

3 Reid's Works, note A, ii. 789 , where Hamilton gives the references. The 1776 edition of the Essay on Truth has a preface in which Beattie says that when he first wrote his book he had not read Buffier, though he had heard that there were similarities between Buffier's use of the notion of common sense and his own. sciousness, have been simply rejected for want of proof. An unobtrusive break in Reid's opinion: the principle that perceiving, remembering, and thinking have ideas for direct objects looked as innocent as the Trojan horse and had 'death in its belly'. By itself, in Reid's opinion, even without the further sceptical premiss which Locke made its companion, it has as a necessary consequence the situation which Buffier found. Buffier accepted the principle.

The primary, as well as secondary qualities of matter, cause, effect, connexion, extension, duration, identity, and almost all about which knowledge is conversant, have been represented as only qualities of our minds; truth itself, and belief, or knowledge, represented as a species of sensation: The idea confounded with its object: The esse and the percipi maintained to be universally the same, and the impossibility asserted of any thing different from impressions, or various kinds of weak and lively sensation. ${ }^{\mathrm{I}}$

This is Price, and might equally well be Reid summarizing the final consequences of the 'theory of ideas'. 'I know nothing that can be said or done to a person, who professes to deny these things [the necessity of a cause for every event, the impossibility of something coming from nothing], besides referring him to common sense and reason.' This is again Price. ${ }^{2}$ The Review of Morals was published six years before Reid's Inquiry. Mr. Segerstedt ${ }^{3}$ has detailed the very considerable resemblances between Reid and Price, leaving the question of derivation open. In spite of the resemblances there is no more evidence in the Inquiry for Reid's dependence on Price than for his dependence on Buffier.

The doctrines of common sense, the doctrine, for example, of the necessity of a cause for every event, do not have to be borrowed by one philosopher from another. Price has no doctrine of common sense itself. Reid claimed to have an explanation for the development of philosophy into paradox and scepticism and claimed originality for the more important half of it. Paradox and scepticism were implicit in the 'theory of ideas'. Part of this theory Reid held to be as old as philosophy and part

'Price, Review of the Principal Questions in Morals, r. iii (1st ed., London, 1758), p. 88.

Ibid. I., ii, p. 35 .

3 The Problem of Knowledge in Scottish Philosophy (Lund, 1935), pp. 21-30. 
modern. Its two parts were the two parts of Locke's fundamental teaching; Locke's principles were the premisses for Hume's conclusions. One of these principles, Reid thought, was logically sufficient and he gave it his main attention. Price did not examine the consequences of the principle that the mind's direct objects are always ideas. He did examine the secondary principle that we have no ideas which we do not have from sensation or reflection. But there is no trace of any borrowing here in Reid from Price. And for Price, it is the relativity of the senses applied to all knowledge that ends in the way described. Hume, Price appears to be saying, is Protagoras over again. Alternatively, for Price, it is Berkeley's principles which Hume takes to their sceptical conclusion.

Reid was taught the philosophical method he professed. His philosophy of common sense is substantially his own, owing something to Aristotle, something to Bacon, Descartes, and Turnbull, more to Berkeley than to anyone else, and something to Hume. 'I once believed this doctrine of ideas so firmly as to embrace the whole of Berkeley's system in consequence of it.' Berkeley's influence on Reid was permanent and is obvious. And when Reid told Hume that he would always consider himself Hume's 'disciple in metaphysics', he was perhaps acknowledging that he had learnt more from Hume than the consequences of the theory of ideas. ${ }^{2}$

I Intellectual Powers, II. x; Works, i. 283.

2 Reid's Works, i. gr. Beattie was shocked at the tone in which Reid and Campbell conducted their controversies with Hume when the interests of 'truth, virtue, and religion' were at stake. There was a story current to the effect that Hume and his adversaries had acted in concert in order 'to promote the sale of one another's works'. The story was false, but themut and peple before publication gave it colour; and people 'may be excused for mistaking the meaning of actions that have really an equivocal appearance'. (Beattie to Blacklock in Forbes's Life of Beattie, London, 1824, p. 73.

\section{I}

\section{THE SCEPTICAL PRINCIPLE}

I. IDEAS

$\mathrm{H}$ UME is the vast figure in Reid's intellectual world. With few exceptions, other philosophers do not greatly matter to him except in so far as they are implicitly Humian. And they all are, he believes, if they have any opinions at all on our knowledge of things other than ourselves; at least he knows of no clear exceptions. They all leave common sense at one and the same point and are on the road to Hume. Whether they speak of eidola with Democritus, or of 'sensible and intelligible species' with the Schoolmen, or, since Descartes and Locke, of 'ideas', they all, according to Reid, accept the 'ideal hypothesis' in one form or another. They all hold the theory which is summed up in the proposition that the immediate object of every sort of 'external' cognition is a representative substitute for what we would ordinarily say that we saw or touched, that we remembered, or in any way thought of. According to this theory, as Reid understood it, when we look at a distant mountain what we directly see, leaving out all inference and interpretation, is not something miles away, but its image at no distance from us. When we remember yesterday's bitter wind, what we are directly aware of is something now present doing duty for something that was once present but now is past and gone, and so no longer there to be directly accessible. When we think of happenings historically and geographically remote, the alternative to supposing that the soul reaches out ectoplasmically through time and space to immediate contact with them is to suppose that what it contemplates is here and now their mediatory ideas within itself.

The ruin of worlds, the Dedication to the Inquiry declares, with virtue brought down in the general catastrophe, is in the principle that ideas are the mind's only immediate objects. Sun, moon, and stars, body and soul, 'all things without exception' dissolve into subjective atoms as fugitive as the experience of 
them. For the necessary consequence of the principle that ideas are the mind's only immediate objects is that they are its only objects, the only things that there are at all. The Treatise of Human Nature showed what the principle hid, laid bare the universal scepticism 'implicit' in the 'ideal system' and 'reared along with it'. Half the credit, therefore, for the reformation in philosophy that would make Hume impossible is unintentionally Hume's. So Reid says in effect in a letter to him, the letter in which he acknowledges himself Hume's 'disciple in metaphysics'. Reid's share in the credit was to have seen that 'ideas' had been invented by philosophers, and therefore that the philosophers' principle from which Hume had validly deduced absurd consequences was a sophisticated illusion. 'The merit of what you are pleased to call $m y$ philosophy', he writes to James Gregory, 'lies, I think, chiefly in having called in question the common theory of ideas. . . I I think there is hardly anything that can be called mine in the philosophy of the mind, which does not follow with ease from the detection of this prejudice.'I

By the 'theory of ideas' (the 'ideal system', the 'ideal hypothesis') Reid usually refers to the theory which assigns ideas to the mind as its immediate objects. Sometimes he makes this theory part of the 'theory of ideas', with a theory of conceptual limitation as its other part. The 'theory of ideas', when we use the phrase without qualification, will have the commoner of the two references Reid gave it.

Reid's critics never disparaged his work-as Stewart, ${ }^{2}$ who thought he could see the theory of ideas decaying into an historical curiosity, was afraid they might-on the ground that to refute something so obviously false was a trivial achievement. Reid had critics who simply defended the theory of ideas. He had others, notably Priestley and Brown, who maintained that what he called the 'theory of ideas' was something he had made up himself out of his misunderstandings of the philosophers he attacked. Or, if (Brown allowed) the Aristotelians had to some extent anticipated him in its construction, and there were latterday eccentrics whose meaning for 'ideas' was more or less the same as his, Reid had tried to fasten on to the whole of philo-

Reid's Works, i. 88.

2 Life of Reid, $\mathrm{II}$; Works, x. 291. (The Life of Reid is also printed in Reid's Works (vol. i) as a prefatory memoir.) sophy opinions which it was one of the characteristics of modern philosophy to have rejected. Reid had astonishingly acquired the reputation of having been 'the overthrower of a mighty system of metaphysical illusion', when all he had done was to show that the metaphorical language of philosophers was intended to be metaphorical. The old words having become mere figures of speech, his whole attack on 'images in the mind' was as pointless as a theological refutation of the poetaster who 'still talks, in his rhymings to his mistress, of Cupid and the Graces'. Nothing like what Reid thought of as 'the common theory of ideas' was held by anybody of any consequence, except Malebranche and Berkeley, after the emergence from Aristotelian darkness. I

Brown's and Priestley's criticisms of Reid have one point in common, that Reid took philosophical metaphors literally. We shall begin with Priestley's criticism, and as there is not a great deal of Priestley, we shall use what he says mainly as an occasion for an exposition of Reid. We shall be principally occupied throughout this section with ideas as objects of perception.

Priestley has Reid standing in foolish triumph over the theory of ideas, simplified, for simple refutation, to the view that perception is by means of literal images, mirror-pictures, replicas of things in the outside world. As Priestley construes him, Reid thought that all he had to do to refute the theory was to meet its assertion of similarity between things and the ideas of them, with a denial. And Priestley refutes Reid by denying that this similarity is asserted, or needed for a causal theory of perception. Quoting the passage in which Reid proposes an 'experimentum crucis by which the ideal system must stand or fall', he remarks that everyone knows that when philosophers called ideas 'images of external things' they were using a 'figurative expression, denoting not that the actual shapes of things were delineated in the brain, or upon the mind, but only that impressions of some kind or other were conveyed to the mind by means of the organs of sense and their corresponding nerves'. The theory of ideas, as the philosophers have held it, is the theory that external things cause sensations or ideas in the mind, and

1 Lectures on the Philosophy of the Human Mind, xxvi-xxvii (1 $4_{\text {th }}^{\text {th }}$ ed., Edinburgh, 1844), pp. 168-74. Nothing else that Brown said marked so deliberately his break with Reid's school as this denial of a great part of its historical justification. 
thus are perceived inferentially. To suppose that this theory is destroyed by the observation that sensations are not like anything external, is to suppose absurdly that an effect has to be like its cause. ${ }^{I}$

Extension, figure, or motion, 'any one, or all of them', Reid says, may be chosen for the crucial experiment.

Either they are ideas of sensation, or they are not. If any one of them can be shewn to be an idea of sensation, or to have the least resemblance to any sensation, I lay my hand upon my mouth, and give up all pretence to reconcile reason to common sense in this matter, and must suffer the ideal scepticism to triumph. But if, on the other hand, they are not ideas of sensation, nor like to any sensation, then the ideal system is a rope of sand, and all the laboured arguments of the sceptical philosophy against a material world, and against the existence of every thing but impressions and ideas, proceed upon a false hypothesis. ${ }^{2}$

Priestley excusably misunderstood the experiment. It ambiguously ends a sprawling argument which contains the plain enough statement that in all this debate about the existence of a material world, it hath been taken for granted on both sides, that this same material world, if any such there be, must be the express image of our sensations' (p. 127). One can see that Priestley has misunderstood the experiment, and remain puzzled as to its correct interpretation. It seems from its context to want rewording into an argument not about extension, figure, and motion, but about the ideas of extension, figure, and motion, 'idea' throughout meaning 'concept'. Take it, however, as it stands, and with Reid's meaning for 'sensation' gathered from the context, it perhaps comes to this: The theory of ideas supposes extension, figure, and motion, in so far as they are matters of direct experience, to be 'ideas of sensation', that is, sensations. They cannot be. For what are sensations? They are feelings. Run your finger lightly along the edge of a table and you get a sensation; press it hard against the table and you get a different sensation; press it harder still and you get a different sensation -this time one of pain. Extension, figure, and motion are not sensations and are utterly unlike sensations. ${ }^{3}$ Therefore the

Examination, pp. 28-31.

2 Inquiry, v. vii; Works, i. 128.

3 'It has been pertinently asked ... what were the experiments by which $\mathrm{Dr}$. Reid made this pretended comparison? Whether in comparing, as he supposed, the external world of our direct experience is not constructed out of sensations and the images of sensations which are their fainter copies.

The philosophers may have given a peculiar meaning to the word 'sensation' and Reid may have used it up to a point more correctly-up to a point, since he elsewhere speaks of 'sensations' of colour, sound, taste, and smell. But the difference, it might be said, between his meaning for 'sensations' and theirs, the difference between, for example, feelings in the finger-tips and felt shapes, is a difference that will not allow his argument to begin. Reid's argument cannot be disposed of so easily. Why does the theory of ideas assert that the direct objects of the senses have no existence apart from sensation? The short answer is that the distinction between object and sensation is a distinction within an identity: they can no more be divided than a thing from itself. And Reid's implicit answer to this is that the object and the sensation show themselves to our experience to be two different things, entirely dissimilar.

The experimental argument may, however, have been directed primarily against the other aspect of the theory of ideas. It is introduced by a discussion in which the emphasis is on 'the conception of extension, motion, and the other attributes of matter' (with a clear reference to Locke's account of the origin of these conceptions). The disputants who agree that if there is a material world it must be the 'express image of our sensations', do so apparently because they agree 'that we can have no conception of any material thing which is not like some sensation in our minds'. And completing the preparations for the experiment, Reid says that the 'very existence of our conceptions of extension, figure, and motion, since they are neither ideas of sensation nor reflection, overturns the whole ideal system, by which the material world hath been tried and condemned'.

Here, and perhaps in the experiment itself, Reid is trying to turn the conceptual empiricism, which he regarded as an aspect of the ideal theory, into a refutation of it. According to this qualities of matter with his sensations, he did not merely compare one set of these sensations or ideas with another? And indeed whether he could possibly do any thing else?' Reid copied this out with no comment on a scrap of paper. (Aberdeen MSS. 2131.3.) It comes from a very favourable account of Priestley's Examination in the London Review for Jan. 1775. 
feature of the theory, all our ideas (concepts) are, or are complications of, ideas of sensation or of reflection. What is beyond sense or introspective experience is conceptually blank; there is no meaning in the words in which we talk about it. And Reid argues: Sensations are feelings, such as those of contact and pressure. Our ideas of extension, figure, and motion are not ideas of sensation, nor of any of the operations of our minds. They are ideas of things as different from sensations as anything can be. Therefore the theory that lays it down that we have no ideas except those of sensation and of reflection is false, and its consequence, the inconceivability of any world independent of ourselves, the meaninglessness of any description of it, groundless.

Some damage is done, even with Reid's partial misunderstanding of what had been meant by 'sensations'. Reid is attacking the theory that the immediate objects of sense are sensations, are, at any rate, objects indivisible from sensation. If they are, and the principle of conceptual empiricism is added, it follows that we have no conception of extension and the other qualities of bodies as existing unsensed. Of course, with sufficient resolution, Reid's incredulity could be met with the insistence that in fact we have none. But this is clear: these premisses cannot be true and the conclusion false. Locke at least is a casualty even if Berkeley is not.

Was it Reid's opinion that the theory of ideas held that we perceive the qualities of external things by means of their facsimile reproductions within the mind? He thought that this was the doctrine of the old pre-Cartesian form of the theory. The dissimilitude between ideas and anything in the material world he regarded as the characteristic feature of the new theory, and one which hurried it on to its sceptical conclusion. Locke had not fully realized the implications of the ideal nature, and Reid watched with polemical satisfaction his distinction between ideas which resemble material qualities and those which do not dissolve under the criticism that nothing like an idea could be in any material thing. The old theory made two mistakes in its account of perception and was comparatively harmless. The new theory made only one and was deadly. Both made the mistake of supposing that ideas are the immediate objects of perception. But the old theory cancelled the effect of its mistake with another, maintained that our ideas are like whatever it is that they are ideas of. The new theory saw that no idea could be like anything that was not an idea. We are made necessarily ignorant of any world beyond our ideas. ${ }^{\mathrm{I}}$

'Ideas of sensation' and 'sensations'; the difference between them is a matter of words, Reid says at the beginning of the section dealing with the difference between the old and the new theory of ideas. He was not speaking carelessly: 'sensations' is the word he uses throughout the section, and our substitution of the word 'ideas' for it does not alter his statements. Now Reid does not think that sensations are philosophers' inventions, but that ideas are. He can never find ideas when he looks for them, but has no trouble in finding sensations. How can ideas be sensations and fictitious entities?

Reid might have answered that ideas in perception are not so much fictitious entities, as fictitous functions assigned to real entities. There are sensations, but they are not direct objects of perception mediating indirect objects. When ideas are identified with sensations, the theory of ideas, as a theory of perception, is the theory that sensations function as mediatorial objects.

Although Reid distinguishes between the old and the new forms of theory of ideas, he very often ignores the distinction, and his discussion of the second of two alternative locations proposed for 'ideas'- 'in the mind' or 'in the brain'-takes it for granted that ideas in the brain are supposed to be images.

The physiological theories of perception which went beyond systematizing the results of experimental investigations into what occurs in the body when perception occurs, and purported to explain perception, were, in Reid's opinion, guesses at the macbinery which performed the impossible function of shifting images of things from the sense organs to the brain, in order to have them contemplated there by the mind and mistaken for things outside. After a list of the physiologists' conjectural 'engines'-hydraulic machines operating with animal

I Inquiry, vi. vi. Apart from the sceptical consequences which the change carried with it, the hieroglyphic ideas, Stewart remarks, were 'at least an attempt to solve the problem about the means by which the mind carries on its intercourse with things external'. The substitution for them of ideas, which have no more resemblance to things than alphabetical characters have, left the problem altogether untouched. (Elements, r, note S; Works, ii. 502.)

6228 
spirits, stringed systems of vibrating chords, wind instruments causing disturbances in an 'elastic aether'-Reid goes on:

Since, therefore, a blind man may guess as well in the dark as one that sees, I beg leave to offer another conjecture touching the nervous system. ... Why may not the optic nerves, for instance, be made up of empty tubes, opening their mouths wide enough to receive the rays of light which form the image upon the retinae, and gently conveying them safe, and in their proper order, to the very seat of the soul, until they flash in her face? . . . It is a peculiar advantage of this hypothesis, that, although all philosophers believe that the species or images of things are conveyed by the nerves to the soul, yet none of their hypotheses shew how this may be done. For how can the images of sound, taste, smell, colour, figure, and all sensible qualities, be made out of the vibrations of musical chords, or the undulations of animal spirits, or of aether? We ought not to suppose means inadequate to the end. ${ }^{x}$

What, Reid asks, can anyone possibly be supposed to mean by 'images' of heat, cold, hardness, softness, sound, smell, and taste 'in the brain'? The shape of a thing might possibly be able to have an image there, but with regard to 'most objects of sense, the phrase is absolutely unintelligible, and conveys no meaning at all'. And that we perceive 'images in the brain, and external objects only by means of them' is 'as improbable as that there are such images to be perceived. If our powers of perception be not altogether fallacious, the objects we perceive are not in our brain, but without us.'2

Newton spoke of the 'sensible Species' of things, of their 'Images', as being brought through the nerves to the sensorium 'that there they may be perceived by their immediate presence's to the mind. The brain, Locke said, is 'the mind's presenceroom' to which ideas are admitted in 'audience'. 4 It is incredible that they could have meant that seeing is seeing small pictures painted on flesh, that tastes and smells are copied under the skull. Reid was grossly mistaken..$^{5}$ Anyone who might have said that the 'images' of things are perceived in the brain did not really mean images. Still Reid's objection remains that nothing

Inquiry, vi. xix; Works, i. 179. 2 Intellectual Powers, n. iv; Works, i. 257.

3 Opticks, mI. i. 28, p. 370. $\quad{ }^{4}$ Essay, II. iil. I; Works, i. 98.

5 Reid was always convinced that he had to deal with cerebral replicas of sensible qualities. See also Philosophical Orations, p. 35. (These are Latin orations delivered by Reid at graduation ceremonies in King's College, Aberdeen. They have been edited by W. R. Humphries, 1937, Aberdeen University Studies, 1 13.) is perceived in the brain. 'Images' or 'ideas' in the brain mean, no doubt, impressions of some kind or other on the brain. But what does it mean to say that these are 'perceived'? When this word in turn gets a plausible sense given to it, all that is left of the original mystery is the banality that certain modifications of the brain are causal antecedents of perception. 'Ideas in the brain' are no longer alternatives to 'ideas in the mind' as the direct objects of perception.

Reid would go further and reject all talk of 'causal antecedents to perception' if more than 'constant conjunction' is intended, if it includes the suggestion that anything that goes on in the body does anything to the mind. We know nothing whatever about the nature of the connexion between body and mind, and any ways of speaking that mask this ignorance have to be repudiated. In particular, Reid will not have 'impressions' made upon the mind. There is no neutrality in this word as a philosopher's word. It is dangerous long before it acquires the formidable powers it has in Hume's vocabulary. Impressions are made on wax and things like wax, and what Reid is resisting is the suggestion that the mind is in any way a thing like wax. If impressions are made on the mind, we shall next be hearing how this is done, and it will be in one of the ways in which body acts on body. With the corporealization of the mind, the uniqueness of its activity moves out of sight.

Ordinary language has a metaphorical use for 'impression on the mind': something or other made a great (little, or no) impression on somebody's mind. And this use will not allow us to say that something which is seen 'with perfect indifference' 'makes an impression upon' the mind. We know the literal paraphrases of the everyday metaphor according to the context in which it occurs. The philosophical metaphor has us baffled. 'If philosophers mean no more but that I see the object, why should they invent an improper phrase to express what every man knows how to express in plain English?'I It is, of course, theory which drives them into strange speech, theory which 'contradicts the common sense of mankind'. Common sense does not think of perception as anything's action on the mind or as the mind's action on anything. It thinks of perception as an action of the mind certainly-the verbs for perceiving are

Intellectual Powers, I. iv; Works, i. 254. 
active verbs-but as an 'immanent' and not as a 'transitive' action. ${ }^{I}$

We do not perceive ideas in the brain, and if our powers of perception are not altogether fallacious, we are not in employing them contemplating ideal objects in the mind either. The reason why ordinary people 'look upon it as perfect lunacy to call in question the existence of external objects' is that they never doubt that they see and handle them. ${ }^{2}$ It makes no difference whether the supposed mediators are regarded as separate both from what they represent and from the perceptual act, or whether they are regarded as inseparable aspects of the perceptual act. It is their presence at all that common sense cannot understand.

In the 'perception of an external object, all languages distinguish three things - the mind that perceives, the operation of that mind, which is called perception, and the object perceived.... Philosophers have introduced a fourth thing in this process, which they call the idea of the object.' 3 The same three-termed structure of agent, act, and object is the framework for our speech when it is concerned with memory, imagination, and thought. Here again the philosophers, Reid says, have wedged in a 'fourth thing' between the second and third terms.

There is no 'fourth thing', except as an optical illusion of Reid's, in the standard teaching of modern philosophy, Brown maintains. Turning to modern philosophy after looking hard at ancient philosophy, Reid saw double. And having dislocated ideas from their unity with the act of cognition, he proved that there are no ideas. The truth is, Brown continues, that Reid could not recognize his own opinion when he found it in other philosophers. In the matter of perception, for example,

so far is Dr. Reid from having the merit of confuting the universal, or even general illusion of philosophers with respect to ideas in the mind, as images or separate things, distinct from the perception itself, that his own opinions as to perception, on this point at least, are precisely the same as those which generally prevailed before. From the time of the decay of the Peripatetic Philosophy, the process of perception was generally considered as involving nothing more than the presence of an external object, an organic change or series

Intellectual Powers, II. xiv; Works, i. 301.

Ibid., I. viii; Works, i. 274.

3 Ibid., II. xii; Works, i. 293 of changes, and an affection of the mind immediately subsequent, without the intervention of any idea as a fourth separate thing between the organic and the mental affection. I have no doubt that, with the exception of Berkeley and Malebranche, who had peculiar and very erroneous notions on the subject, all the philosophers whom Dr. Reid considered himself as opposing, would, if they had been questioned by him, have admitted, before they heard a single argument on his part, that their opinions, with respect to ideas, were precisely the same as his own. ${ }^{\mathrm{P}}$

Reid's words usually suggest that he thought that philosophers regarded ideas as separate entities-separate from the acts of the mind to which they are direct objects as well as, of course, from the indirect objects they represent. It is unlikely that he distinguished with any cut-and-dried precision between what Hamilton called the 'gross' and the 'subtle' form of the theory of ideas. (The distinction is first emphasized, one may risk saying, in comment upon Reid.) He did allow for the subtlety which identifies act and object in ideas and meant his arguments to reach it. ${ }^{2} \mathrm{He}$ was denying the existence of ideas not merely as separate objects, but as objects, and therefore denying something that philosophers had been asserting, whether they held the theory of ideas in gross or subtle form. Ideas under another name perhaps do figure as direct objects in Reid's own theory of perception. If they do-we shall be considering this question in the fifth chapter-it would have been no justification for Reid to claim that no one could say that the ideas in his theory were separate entities.

'Idea' is a word in ordinary, everyday use, Reid remarks. 'To have an idea' of something is to think of it, to conceive of or imagine it. Men's 'ideas' are their opinions. Nobody would

Lectures, p. 174

2 "That the object perceived is one thing, and the perception of that object another, I am as certain as I can be of anything. The same may be said of conception, of remembrance, of love and hatred, of desire and aversion. In all these, the act of the mind about its object is one thing, the object is another thing. ... Now, if in these operations the idea be a fourth thing different from the three $I$ have mentioned, I know not what it is, nor have been able to learn from all that has been written about ideas. And if the doctrine of philosophers about ideas confounds any two of these things which I have mentioned as distinct-if, for example, it confounds the object perceived with the perception of that object, and represents them as one and the same thing - such doctrine is altogether repugnant to all that I am able to discover of the operations of my own mind; and it is repugnant to the common sense of mankind, expressed in the structure of all languages.' (Intellectual Powers, II. xi; Works, i. 292.) 
trouble to assert or could bring himself to deny that we have 'ideas', when the word is used in one of these familiar ways. The word has, however, another meaning in the vocabulary of philosophers. In this other meaning it does not signify that act of the mind which we call thought or conception, but some object of thought', some object even of perception. I These ideaobjects are the illusory ideas; ideas as that which we think about'. ${ }^{2}$ The double meaning of 'idea' gives the denial that there are ideas an irritating sound of paradox, when its sense is a protest against paradox.

Since the word 'idea' was, in the language of philosophers, clouded with this act and object ambiguity and the word 'perception' was often given a widely extended meaning, it is not always clear how to interpret such statements as 'I take ... the idea of an object and the perception of an object to be the same thing.' 3 They may be expressing Reid's own doctrine; that is rejecting altogether ideas as objects, while allowing them as ideas of objects, 'having an idea of an object' meaning nothing but thinking of it, or imagining it, or remembering it-all of these being different ways of 'perceiving' it in the extended use of the word. On the other hand, they may be doing something quite different. They may be multiplying entities while appearing to reject their multiplication, rejecting ideas as objects distinct from 'perception' in order to reassert them as objective components of 'perception'. The opposite meanings of which such statements are capable partly explains why Reid was unsure as to whether or not he was encountering the ideal theory when he encountered them in Arnauld.

When thought, imagination, and memory, but not perception, are being supplied with ideas, ideas as separate entities are profitably replaced by ideas in which act and object have been fused together. The standard teaching of modern philosophy, Brown says, is 'the unity of the idea and the perception itself'; idea and act in perception are not distinct, but 'the same, a modification of the mind and nothing more'.4 What is meant? Surely not the nonsense that when we see something red and

I Intellectual Powers, 1. i; Works, i. 225. Cf. ibid. Ir. xiv; Works, i. 298.

2 'Lectures on Pneumatology', Aberdeen MSS. 2131.5

3 A. Arnauld, Des vraies et des fausses idées, v; CEuvres (Paris and Lausanne, 1775-83), xxxviii. 198. round, the seeing of it is red and round. 'Modification' does not have its ordinary, everyday meaning of 'alteration' here. It is a technical term, and according to the traditional conventions in metaphysics for its technical employment, anything of which red, for example, is a 'modification' is red. If the ideas which are direct objects of perception are modifications of the mind in this sense, they have moved so completely into the mind that 'in the mind' is a phrase without any sense left to it at all.

The identity, then, of the act of perception and its ideal object is not an identity that allows the transposition of predicates. What kind of unity or identity is it? What corrections does the subtle theory of ideas want to make in the crude theory? The dependence of ideas for existence on their being perceived is common to both, so the language of identification cannot be merely an extravagant way of asserting this dependence. What more is it asserting? No plausible meaning appears to replace the obvious and impossible one.

If, however, the view that identifies ideas and perception, in order to become intelligible, turns into the view that separates them, the view that separates them, in order to become intelligible, turns into the view that identifies them. Separate from the act of perception, they are still 'in the mind'. What can 'in the mind' mean in this context except 'modification' of the mind? Contained in the mind? The mind has no dimensions. Perhaps it is only an extravagant way of asserting that ideas depend for their existence on being perceived. If it is, the reason for their dependence seems to have gone. One had supposed that the reason why ideas had no existence when unperceived was that they were 'in the mind', the only 'place' where ideas could be. One had construed these metaphors to mean that an act of perception and its ideal object were not two things, but one and the same thing, that an idea can be no more separated from the perception of it than a thing can be separated from itself. Difficulties are proposed about the unity of contraries, about the identity of unextended acts with extended objects. Hylas cannot understand how there can be room in the mind for so many houses and trees. What is it to be 'in the mind'? Philonous explains that for an object to be 'in the mind' is no more than for it to be perceived. I Hylas does not ask him to go

\footnotetext{
I Berkeley, Three Dialogues, In; Works, ii. 249-50.
} 
over once again the reasons for holding that what is perceived must be perceived in order to exist.

\section{DIRECT OBJECTS}

We have so far been mainly concerned with ideas as related to the mind and as perceptual objects. We have now to consider their mediatorial necessity and the other capacities in which they function as objects.

... philosophers have been led to think that, in every act of memory and of conception, as well as of perception, there are two objectsthe one, the immediate object, the idea, the species, the form; the other, the mediate or external object. The vulgar know only of one object, which, in perception, is something external that exists; in memory, something that did exist; and, in conception, may be something that never existed. But the immediate object of the philosophers, the idea, is said to exist, and to be perceived in all these operations. $^{\mathrm{I}}$

What is it that has led philosophers to think in this way? We shall have to answer with a very rough and partial summary. For perception, there have been all the reasons that can be listed under 'perceptual relativity': the coin showing a different appearance to different observers; the jaundiced landscapes viewed through sick eyes, coinciding with the blue, green, and brown world of the healthy. Considerations of this sort have seemed to many philosophers to point unmistakably to the conclusion that the immediate objects of sense experience are private objects. We have false memories and these have no intrinsic marks to distinguish them from true memories. While the object of a true memory could perhaps be a past event as it actually was, the object of a false memory could not be a past event as it actually was. The false object must be an idea. And how could an idea of an event be mistaken for an event? We can only suppose that the direct objects of both true and false memories are ideas, the one corresponding and the other failing to correspond to something that actually happened. Ideas, under a variety of names, came in similarly to provide objects for false beliefs and, since true and false beliefs are psychologically indistinguishable, immediate objects for true beliefs. We make mistakes in perception, memory, and belief which we

$$
\text { I Intellectual Powers, rv, ii; Works, i. } 369 \text {. }
$$

could not make if in perception we were face to face with physical objects, in memory with the past, and in even true belief with facts. Finally, ideas provide imaginary objects for the mind which cannot think without objects, but can think of what does not exist.

Most of these familiar reasons for a theory of ideas were curiously ignored by the philosophers of the Common Sense school. They are all silent about the objects of false beliefs and memories. Reid and Beattie saw that perceptual relativity was a difficulty which a doctrine of direct perception had to meet, and proceeded to meet it without anxiety. It was the assumption that ideal substitutes had to be found for non-existent objects of thought which was really significant in Reid's eyes, and he fastened on to this as one of the two great persuasives towards the theory of ideas. The other is the assumption which, to give it a name, might be called the 'principle of cognitive contact'. Together, Reid says, they 'carry us into the whole philosophical theory of ideas' and, he adds (forgetting the perceptual variations), 'furnish every argument that ever was used for their existence'. ' The two assumptions, he maintains, are not independent; the second is not true if the first is false, and the first is false.

We shall be concerned later in this section with Reid's elimination of ideal substitutes for non-existent objects of thought, and shall now consider the principle of cognitive contact. It is the epistemological analogue of 'no action at a distance', ideas doing something similar to the work done by the medium between remote interacting bodies. Nothing further from the mind than the mind itself can be its direct object, nothing at a different time from the mind's cognitive act; anything there and then must be mediated by something here and now in order to be perceived, remembered or in any way thought of.

It is hard to believe that this assumption was taken seriously by many philosophers (except perhaps in explanation of the possibility of memory). It was. To give one or two instances. It weighs heavily with Locke. The following passage from his second reply to Stillingfleet is particularly interesting, as it shows ideas at their double work of annihilating distance and providing objects for false beliefs:

$$
\text { I Ibid., rv. ii; Works, i. } 3^{69}
$$


Not thinking your Lordship therefore yet so perfect a convert of Mr. J. S.'s [John Sergeant], that you are persuaded, that as often as you think of your cathedral church, or of Des Cartes's vortices, that the very cathedral church at Worcester, or the motion of those vortices, itself exists in your understanding; when one of them never existed but in that one place at Worcester, and the other never existed anywhere in 'rerum natura'; I conclude, your Lordship has immediate objects of your mind, which are not the very things themselves existing in your understanding.

These immediate objects, Locke says, can be called indifferently 'representations' or 'ideas'.

Sergeant opposed to Locke's theory of ideas a version of the Thomist interpretation of the Aristotelian opinion that the mind 'becomes' the thing it knows. The thing known exists in the understanding and outside it. Ideally in the understanding, really outside it, Reid would insist that Sergeant meant, and therefore he is opposing the theory of ideas to the theory of ideas. The 'self same thing', Sergeant says, in two different modes of existence; and existence, non-existence, and mode of existence are logically accidental to the nature of everything except God; so that the external thing is identical with the thing in the understanding. ${ }^{2}$

In so far as the theory of ideas is a straightforward doctrine of double objects, the Thomist doctrine reproduced by Sergeant is plainly not a form of the theory of ideas, but what interests us here is the way it conforms to the principle of cognitive contact: if not a representative of the thing, then the thing itself must be in the mind in order to be known.

Malebranche supposes that he can take for granted that distant objects are perceived by means of ideas. It is quite improbable that the soul moves out of the body to where the objects are, and impossible that remaining where it is, it could perceive them across distance. ${ }^{3}$

Reid's examples are from Newton and Clarke. Clarke says:

Without being present to the images of the things perceived, it [the soul] could not possibly perceive them ... a living substance can only there perceive, where it is present either to the things themselves, (as the omnipresent God is to the whole universe;) or to the images I Works, iii. 390-1.

2 Solid Philosophy Asserted (London, 1697), pp. $3^{8} \mathrm{ff}$.

3 Recherche de la vérite, uI. ii. I. of things, (as the soul of man is in its proper sensory.) Nothing can any more act, or be acted upon, where it is not present; than it can be, where it is not. ${ }^{x}$

A final example from Price. It seems to Price, and he mentions his reluctance to disagree with Reid, that Reid annihilates perception by denying the existence of ideas as its immediate objects. 'External' objects 'themselves not being present, if perceived, they must be perceived by ideas of them'.2

The principle of cognitive contact is behind the theory of ideas. Behind the principle is the false analogy between the behaviour of bodies and minds, the analogy which, according to Reid and Stewart, is always devastating the philosophy of the mind, and here persuading us to look at cognition after the model of a physical transaction, involving like it contiguity in space and time. Then when the damage is done, the analogy, Reid thinks, is arbitrarily given up. We can admittedly love and hate what is absent. Why must the mind in its intellectual operations, though not in its affections and desires, be always in immediate contact with its objects, acting on them or being acted on by them $?^{3}$

We do not know, of course, how we perceive things out of immediate contact with the mind. Reid is more than willing to admit our ignorance and to remind us of its extent. We do not know how things would be perceived if they were in immediate contact with the mind. The mind's consciousness of its own operations is as inexplicable as its external perception. It might be added to Reid's comment on the failure of the principle of cognitive contact to make perception more intelligible, that memory mediated by ideas is not any more intelligible than memory without them. Ideas are contemporaneous with the act of remembering, but not with the past events they represent. The difficulty, if it is one, is exactly what it was before. Thought about what is separated from us in space and time is not explained by doubling up its objects into direct and indirect; distance now lies between these. Apply the principle of cognitive contact rigorously, and the world shrinks in duration

I The Leibniz-Clarke Correspondence, ed. H. G. Alexander (Manchester, 1956), pp. 21-22; Reid, Intellectual Powers, it. iv; Works, i. 255-6.

${ }^{2}$ Review of Morals, Appendix, note C in 3rd ed., 1787 (ed. D. D. Raphael, Oxford, 1948, pp. 280-1).

${ }^{3}$ Intellectual Powers, Iv. ii; Works, i. 369 . 
to the present and in dimensions to the circumference of the mind. Apply it only until objects are split into direct and indirect, and the original difficulty is not touched.

No light from the theory of ideas on the mechanics of perception, memory, and thought, and in addition, Reid says, these familiar things become unrecognizable. Let us look at memory when the theory of ideas has been to work on it. '. . . the mind has a power in many cases to revive perceptions, which it has once had, with this additional perception annexed to them, that it has had them before.'I We would not have known that this was memory unless Locke had told us that it was.

We find by experience, that when any impression has been present with the mind, it again makes its appearance there as an idea; and this it may do after two different ways: either when in its new appearance it retains a considerable degree of its first vivacity, and is somewhat intermediate betwixt an impression and an idea; or when it entirely loses that vivacity, and is a perfect idea. ${ }^{2}$

Reid repeats the comment that he made on Locke: we have to be told that these are memory and imagination. The definitions 'convey no notion of the thing defined' and 'they may be applied to things of a quite different nature from those that are defined'. 'Suppose a man strikes his head smartly against the wall, this is an impression ... he can repeat this impression with less force, so as not to hurt him ... he can just touch the wall with his head, so that the impression entirely loses its vivacity'perception, memory, and imagination. ${ }^{3}$

Is memory unrecognizable in these descriptions of it by Locke and Hume because they are fragments torn off complete descriptions? No, the rest can be added, the Lockian metaphors-the mind a repository, its power to repaint its perceptions upon itself -all that Hume has to say about the images being tied down in an invariable order and even about their feeling of authenticity. The descriptions still need sign-posting. Do we just not understand the technical language in the descriptions? (Reid's comment on Hume gets its satirical edge from pretending not to.) It is not that either. When we have learnt the new uses for 'perception', 'impression', and 'idea', the descriptions remain opaque. Is the trouble perhaps that we are looking for

I Locke, Essay, ir. x. 2; Works, i. 128.

3 Intellectual Powers, II. vii; Works, i. 357.
2 Hume, Treatise, I. i. 3, p. 8. less than we are being given? Locke and Hume are not trying to tell someone who does not know what memory is what it is; they are analysing memory, disclosing the structure of a familiar thing. But as descriptions or analyses, these accounts of memory are equally baffling. 'The mind reviving a perception with the additional perception of having had it before', 'an impression again making its appearance'; taken literally, as Reid points out, ${ }^{1}$ these are self-contradictions, since, by definition, perceptions and impressions disappear for ever as soon as the experience of having them is over. Then they are not to be taken literally.

There are two real possibilities of a meaning for them that will survive examination, and an illusory third. To 'revive a perception' (or to 'repeat an impression') might be a completely unilluminating synonym for 'to remember'. Completely unilluminating, because no explanation of the meaning of the phrases is forthcoming except that they mean the same as 'to remember'. That is one possibility.

The phrases may be intended to convey the statement that memory is knowing the past indirectly through its present representative image. But this statement breaks down on examination. Reid's criticism of a theory of double objects for any thought of the past can be applied with some adaptation to a theory of remembering by representative images. Either we do know the past in memory or we do not. If we do, we have got through and beyond present images to it. It was only temporarily an indirect object. Once this is realized, it becomes clear that there never was any indirection in remembering. (We may fumble through images towards memory; there may be this mediation, and it must be temporary to be successful; but while we are on the way to remembering we are not remembering.) There never was any indirection in the sense required by the theory, because indirection in this sense is logically impossible. We either get through the present image and beyond it to the past or we fail to, and the theory requires both success and failure. Whatever the object, a man 'either thinks of it, or he does not. There is no medium between these. If he thinks of it, it is an immediate object of thought while he thinks of it. If he does not think of it, it is no object of thought at all.'2

Ibid., In. vii; Works, i. 357 .

2 Ibid., vi. iii; Works, i. 427. 
The other possibility is that we do not know the past, or if you like, that knowing the past is nothing but having a present experience which has a certain special quality ('vivacity'whatever this means, unless it means simply 'remembering'). There are not two objects, one present, one past, direct and indirect. There is one object, something present. But memory has gone even if its name is being kept. The evolution of the theory of ideas shows itself in the passage quoted from Hume with its Lockian beginning and Humian end.

The knowledge which he has of the past by his memory, seems to Reid to be 'as unaccountable as an immediate knowledge would be of things to come'.1 Memory has disappeared when the theory of ideas has finished explaining how it is possible. We are in no great danger of taking the impressions on the brain, spoken of in physiological theories of memory, as surrogate memory-objects. These impressions are supposed to function causally in memory. And there may be tracings on the brain left from our past experiences, for all Reid knows, and (Reid never lets an opportunity pass for expressing his physiological scepticism) for all the theorist who has conjectured their existence knows. Let us agree that there are. How does their presence make memory any more intelligible? Perhaps if we knew more about their nature the question would be answered. We know all there is to know about the impression which a pin makes in the hand when it pricks it. But can any philosopher say how pain is caused by this impression? If we had a complete description of the state of the brain which is supposed to cause memory 'we should still be as ignorant as before how that state contributes to memory. We might have been so constituted ... that the prick of a pin in the hand, instead of causing pain, should cause remembrance; nor would that constitution be more unaccountable than the present.'2

Reid has an analysis of perception into a complexity of sensation, conception, and belief. Without needing to know any more about it at the moment, we can see that it will not fit easily into a theory of direct perception. Memory and imagination he left simple. Memory involves belief (in the past existence of what is remembered) as a consequence, not as a separable

Intellectual Powers, mir. ii; Works, i. $34^{\circ}$

2 Ibid., w. vii; Works, i. 354 . component. There is no belief in imagination. Stewart breaks up the simplicity of memory and adds belief to imagination.

[The] remembrance of a past event is not a simple act of the mind ... the mind first forms a conception of the event, and then judges from circumstances of the period of time to which it is to be referred ... if we have the power, as will not be disputed, of conceiving a past event without any reference to time, it follows that there is nothing in the ideas or notions which memory presents to us, which is necessarily accompanied with a belief of past existence, in a way analogous to that in which our perceptions are accompanied with a belief of the present existence of their objects, and therefore, that the refer. ence of the event to the particular period at which it happened, is a judgment founded on concomitant circumstances. ${ }^{x}$

The ideal version of memory seems to be vaguely back again. ${ }^{2}$

This, however, would almost certainly be to misinterpret Stewart. Although he occasionally uses the language of representation (as in the definition of 'conception' in the Outlines of Moral Philosophy), ${ }^{3}$ when he speaks of conceiving a thing, all he means is thinking of it, not thinking of it through an intermediary. In memory something is first thought of without any location in time and subsequently dated. Why does there have to be this succession? Stewart has no other explanation than the one which ends the passage just quoted. It is as though he thought that all remembering begins with the hesitancy of 'Yes, it was Wednesday because ...', only more so, so much more so that to begin with it is only conception becoming memory. But Stewart does not want to deny the 'apparent instantaneousness' of memory judgements. The analogy he finds illuminating is with the 'estimates of distance we learn to form by the eye' (p. $35 \mathrm{I}$ ).

There is no conception and no imagination, in Stewart's opinion, without a temporary belief that what is conceived or imagined is real. We should perhaps have the distinction he draws between conception and imagination before us. 'The business of conception ... is to present us with an exact transcript

I Stewart, Elements, r. vi. i; Works, ii. 350-1.

2 With Hamilton, explicitly. An 'immediate knowledge of the past [Reid's phrase] is a contradiction in terms'. 'Nothing but Reid's superstitious horror of the ideal theory' could have prevented him from seeing that the faculty of memory is necessarily 'mediate' and 'representative'. (Discussions, and ed., London, 1853, pp. 49-53.) I. iv; Works, ii. 21. 
of what we have felt or perceived' ('conception' implying 'no idea of time whatever'). Imagination is the power 'to form new wholes' out of these transcribed materials. 'I I am at a loss to know', Reid wrote, 'whether according to your meaning of the word conception, I may conceive a golden mountain, a centaur, or a man only a foot high. These are not exact transcripts of what I have perceived. I think it is memory only that gives us exact transcripts of what we have perceived or felt. ${ }^{2}{ }^{2}$ Stewart is clear enough. (He is not claiming that his meaning for 'conception' and 'imagination' is their 'proper English meaning'.) The gold mountain is 'imagined'. Ben Nevis is 'conceived' if it is pictured as it was when seen on some past occasion. It is remembered if the thought and belief of the past occasion are added to the conception. Added to the conception, they destroy a belief which flickers into existence with every conception, the belief that what is being conceived exists at that moment.

Why does Stewart think that conception and imagination always carry temporary belief with them? The characteristics of any form of mental activity, he says, stand out clearly when nothing interferes with it, and we find that when imagination wholly absorbs our attention, as in dreams or at the theatre, we cannot help being swept into belief. ${ }^{3}$ Reid is completely sceptical. 'I can conceive the steeple of the cathedral church of Glasgow standing upon its point. . . . I cannot find a vestige of belief accompanying it. If there be any', he adds (referring to another of Stewart's theories which he disliked), 'it must be one of those hidden operations which are accompanied with no memory.'4

Memory and imagination, in Stewart's account of them, thus seem to move close together. The materials presented by experience are reorganized in imagination. There is the time reference in memory. Otherwise memory and imagination are separated only by a difference in the relative strength and permanence of the belief involved in them. Include the ambiguous analysis of perception into sensation-conception-belief, which Stewart shared with Reid, and Stewart can be seen to be some distance

Elements, 1. iii; Works, ii. 144-5.

2 'Criticism and Remarks on Stewart's Elements', Aberdeen MSS. 2131.4 .

3 Elements, I. iii; Works, ii. $149 \mathrm{ff}$.

4 'Criticism and Remarks on Stewart's Elements'. along the road to what Reid regarded as the final scepticism implicit in the theory of ideas: the real, the remembered, and the imagined as higher and lower on a single scale of intensity.

The ordinary man thinks that he can think of what does not exist. He has, according to Reid, the authority of philosophy ancient and modern against him. 'The philosopher says, Though there may be a remote object which does not exist, there must be an immediate object which really exists; for that which is not, cannot be an object of thought.'I

This is the second of the two assumptions which Reid believed lay behind the theory of ideas, and its falsity infects the first. Contact with an object cannot be a cognitive necessity if we can think of something which does not exist, and which is therefore incapable of acting on the mind or being acted on by it. The ordinary man is content with the fact that he can remember things that did exist, perceive things that do exist, and imagine things that do not exist. He is not interested in how this is done. Philosophers are. And looking about for explanations, they found the too obvious models. For cognition in general there was the modification of bodies by mutual contact and impulse (with, Stewart remarks, its illusory appearance of transparent intelligibility). And an everyday experience was there to illuminate the supposition of representative ideas. We are 'accustomed to see objects by their images in a mirror, or in water; and hence are led, by analogy, to think that objects may be presented to the memory or imagination in some similar manner'.2 For conception and imagination specifically, the analogy with painting was to hand, and the whole apparatus of metaphor derived from it. The real and the unreal can be painted and conceived. Many of the adjectives that describe a painting-clear, distinct, vague, blurred, accurate-describe a conception.

It is important, Reid says, to see where the analogy breaks down. When a man is painting, his action is bringing something into existence. When he has finished painting, there is a picture there. Painting is a 'transitive act, which produces an effect distinct from the operation'. Suppose a man merely conceives his picture and does not go on to paint it. 'What is this

\footnotetext{
Intellectual Powers, rv. ii; Works, i. 369 .
}

2 Ibid., II. xiii; Works, i. 296. 
conception? It is an act of the mind, a kind of thought.' Does it produce some object? None at all. When we conceive of something, there is nothing in the mind except the act of conceiving. 'An image of a thing in the mind'; the phrase is familiar enough. Very often the easiest way in which we come to have a conception of something is by having it illustrated for us, by seeing some picture or 'image' of it. 'Hence by a figure common in language, conception is called an image of the thing conceived. But to show that it is not a real but a metaphorical image, it is called an image in the mind.' 'Having an image of a thing in the mind' means no more than 'having a conception' of it, and that means no more than conceiving it. I To claim the sanction of ordinary language for objective images in the mind is to misunderstand the language just 'as if, from the phrases of deliberating and balancing things in the mind, we should infer that there is really a balance existing in the mind for weighing motives and arguments'.2

Every conception 'must have an object', because every conception is of something. ${ }^{3}$ When it is a conception of Rome, Rome is the object. When it is a conception of Caesar crossing the Rubicon, Caesar crossing the Rubicon is its object. Reid is convinced that the city and the historical event are the direct and only objects of these conceptions. 4 When something which never existed is conceived of, a centaur, for example, what is the object of the conception?

The philosopher says, I cannot conceive a centaur without having an idea of it in my mind. I am at a loss to understand what he means. He surely does not mean that I cannot conceive it without conceiving it. This would make me no wiser. What then is this idea? Is it an animal, half horse and half man? No. Then I am certain it is not the thing I conceive. Perhaps he will say, that the idea is an image of the animal. ... This one object which I conceive, is not the image of an animal-it is an animal. I know what it is to conceive an image of an animal, and what it is to conceive an animal; and I can distinguish the one of these from the other without any danger of mistake. ${ }^{5}$

By all means say that when you conceive of a centaur, you

1 Intellectual Powers, Iv. i; Works, i. $3^{62-3}$. There is a qualification to be introduced here: imagination is 'one species of conception'. We shall come to this point later in the chapter.

3 Ibid., Iv. i; Works, i. 368.

2 Ibid., Iv. ii; Works, i. 373 .

5 Ibid., iv. ii; Works, i. 373 . have its image in your mind-so long as you remember that to have an image of a centaur in the mind, is just to conceive of a centaur. If you insist that No, by 'having an image' of a centaur, you do not mean merely that you conceive of it; you mean that to conceive of it is to have its image as the object of the conception, then, up to a point, Reid could understand you. $\mathrm{He}$ knows what it is to think of an image of a centaur. Imagining a drawing of a centaur would be the sort of thing that should be meant. What Reid does not understand is your implication that things and their representations are identical. Thinking of the image of a centaur is quite different from thinking of the thing itself-nothing can be its own image. If you again correct him, and say that the image is not on paper but in the mind (especially if you add that the act of conception and its object are identical), then, again, it is a centaur and not its representation that is being thought of, and nothing in the mind is half man and half horse, nothing in it is remotely like a centaur.

The 'immediate and the only object' of a conception of the circle is the circle, Reid says. 'But where is this circle? It is nowhere. If it was an individual, and had a real existence, it must have a place; but, being an universal, it has no existence, and therefore no place.' 'Is it not', Reid asks, 'in the mind of him that conceives it?' And he answers: the 'conception of it is in the mind, being an act of the mind,' but the conception is not the circle and has no resemblance to it-'no two things can be more perfectly unlike, than a species of thought and a species of figure'. ${ }^{\mathrm{I}}$

The circle is ruled out of existence for Reid, as he explains, because it is a universal. (Though on Reid's view of the nature of universals, it will turn out to be as misleading to say that universals which have instances do not exist as to say that they do.) A centaur, however, is clearly selected for consideration because anyone would accept it as an example of a nonexistent object. Only philosophers ask questions about the existence of universals. The fact that a Euclidean circle, from the definition of the line describing its circumference, has no real existence is not directly under discussion here. But the discussion applies to it, as to everything else that is thought of and does not exist.
I Ibid., rv. ii; Works, i. 374 . 
What does Reid mean when he says that a centaur is the direct object of the conception of a centaur and that there are no centaurs, that the circle does not exist and is the direct object of the conception of it? One would like to be quite sure that Reid himself knew even vaguely. He goes on to speak of our conception of objects that do exist as if he had said something perfectly straightforward, as though there was no appearance of self-contradiction in it which needed to be explained away. The meaning he might have had has to be worked out from obscure and conflicting materials.

Is Reid providing non-existent objects of conception with a 'subsistence' somewhere between being and nonentity? It is not what one would expect from Reid with his down to earth mind, yet a touch would bring the more probable of two interpretations of his statements (or the stronger of two inconsistent views that he held) very close to it.

We shall begin with the less probable interpretation (or the weaker view). We learn the meaning of some general words, Reid says, by being given definitions. 'The meaning of other general words we collect, by a kind of induction, from the way in which we see them used on various occasions by those who understand the language.'I 'I have a notion of pain', 'signifies no more than that I understand what is meant by the word pain'. ${ }^{2}$ From these isolated statements and half-hints elsewhere, one might possibly take Reid's view to be that to conceive of $X$ (where $X$ is not an individual) is to understand the word ' $X$ ', and to understand the word, to know its meaning, is to know how it is used. ${ }^{3}$ And to conceive of an $X$, knowing that there are no $X \mathrm{~s}$, would be to understand the meaning of the word ' $X$ ', and know that it is a word without application to anything.

What becomes of the principle which Reid regards as axiomatic, the principle that every act of conception must have an object? When we are thinking of what does not exist, there is necessarily no object which is the non-existent thing we are thinking of. And if the principle will not be satisfied with something else instead, it has to be given up. All that can be done is

Intellectual Powers, v. vi; Works, i. 409. Cf. rv. i; Works, i. 365.

2 Ibid., II. xi; Works, i. 291.

3 '. . by conceiving universals, Dr. Reid means nothing more than understanding the meaning of propositions involving general terms.' (Stewart, Elements, 1. iv. 3; Works, ii. 192.) to explain the feeling that there must be what there cannot be. The demand for an object when something unreal is thought of is the shadow of the necessity for an object when something real is thought of. The linguistic forms 'thought of a . . ', \&c., appropriate in the one case, persist inappropriately in the other. The demand cannot be satisfied, and no analysis of the notion of imaginary being or ens rationis can take away all the uneasiness that results from its frustration.

It might be said that the mind does have objects when we think of non-existent things, though not the impossible objects of the demand. It is, to widen slightly the application of a remark of Stewart's, words with which our attention is then occupied. ${ }^{\text {I }}$ The plain man believes that he can think of what does not exist, and he has a plain way of expressing his disbelief in something alleged to exist: he calls it mere words.

The questions, however, which Reid had for the ideal objects, proposed as substitutes for non-existent real objects, are waiting for these word-objects. Is the word 'centaur' (or its use) half horse and half man? And the plain man can express his disbelief in something by calling it a mere idea. The only commitment common sense has in the matter is that we can think of what does not exist.

The interpretation of Reid which we sketched out cannot claim much support from anything that he says, and it is contradicted by such statements as these, which have a number of parallels in the chapters where they occur: 'To conceive the meaning of a general word, and to conceive that which it signifies, is the same thing.' A general word signifies what is 'common to many individuals'. 'The meaning of the word is the thing conceived.' 3

We may notice incidentally that this identification of the meaning of a word with the thing it applies to is a crude expression of Reid's view that the word is directly related to the world; that there is no psychological entity, its 'meaning', floating in between. He eliminates the ideas signified by words and in turn signifying things, though without any formal announcement that ideas in yet another of their mediatorial capacities

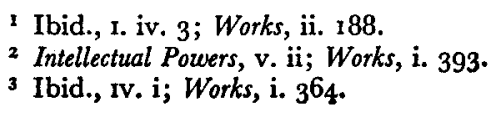


have gone.' There is no direct polemic in Reid against the Lockian theory of signification, and no comment on its parallel with the Lockian theory of perception.

Reid's other explanation of what it is to think of objects that do not exist (or the other interpretation of his one explanation) is implicit in his views on the nature of universals. In the second of three chapters of the Intellectual Powers with 'general conceptions' as their topic, Reid lists by way of illustration a few of the 'innumerable attributes that are really common to many individuals', and adds the remark that 'if this be what the schoolmen called universale a parte rei', there certainly are such universals. He then begins to speak obscurely of the nonexistence of universals. He is dealing with an objection to the notion of common attributes, which he expresses by saying that 'every subject hath its own qualities, and that which is the quality of one subject cannot be the quality of another subject'.

To this I answer, that the whiteness of this sheet is one thing, whiteness is another; the conceptions signified by these two forms of speech are as different as the expressions. The first signifies an individual quality really existing .... the second signifies a general conception, which implies no existence, but may be predicated of everything that is white, and in the same sense. On this account, if one should say that the whiteness of this sheet is the whiteness of another sheet, every man perceives this to be absurd; but when he says both sheets are white, this is true and perfectly understood. The conception of whiteness implies no existence; it would remain the same though everything in the universe that is white were annihilated. ${ }^{2}$

There is another passage from a few pages farther on which can usefully be put beside this one:

... universals have no real existence. When we ascribe existence to them, it is not an existence in time or place, but existence in some individual subject; and this existence means no more but that they are truly attributes of such a subject. Their existence is nothing but predicability, or the capacity of being attributed to a subject (p. 407).

A minor difficulty, and an important feature, in the first passage is the meaning of 'conception'. Reid has, however,

I In the Philosophical Orations there is a brief hostile reference to the teaching which holds 'Verba esse non rerum sed idearum signa' (p. 32).

Intellectual Powers, v. iii; Works, i. 395. warned us during the previous chapter that 'conception' may be used for 'thing conceived' (for the thing, not for an idea of it, when the word refers to the object instead of the act), and it is used in this way here. The stubborn difficulty is with the general whiteness which does not imply existence and would remain the same even though there was nothing white. In the second passage Reid seems to change his mind in between sentences as to the sense in which universals can be said to exist. In spite of this, it is possible to make out something from it of his assertions with regard to their existence, and enough to help a little with the interpretation of the previous passage.

This seems to be the doctrine which emerges from the two passages taken together: Universals exist, when they exist, as attributes of individual subjects, as their predicates, sharing their incommunicable individuality - the whiteness of this sheet cannot be the whiteness of another sheet. They exist then as particulars. Not as universals? Their universality is multiple predicability. But since an attribute is locked in existence to its own subject, its predicability of a number of subjects is merely the fact that a number of subjects have or could have attributes which, though individually different, are qualitatively identical. Facts of predicability, unlike the attributes about which they are facts, are not existents in space and time. And facts of predicability survive the disappearance of actual predicates. The universal whiteness would remain though there was nothing white. What would remain is the fact that there could be things that were white.

In a later passage than the two we have been considering, Reid seems to claim for attributes some kind of numerical identity in their different subjects. An attribute 'may be in, or affirmed of' many different individuals, 'and be the same in all, without division or multiplication'. Reid quotes the phrase 'without division or multiplication' as one which the Platonists use, and approves of it. It is not possible to decide how he would himself elucidate it; whether when he repeats the phrase, he no longer construes 'common' to many individuals as 'individually different and qualitatively identical' in each. His main concern throughout the context of the passage is with the status of universals apart from any instances they may have as predicates of actual subjects. They are conceived and do not exist; 
they are 'objects of conception' to any mind conceiving them, and are therefore not in any mind conceiving them. They are immutable and their relations are immutable. Among them are to be found the objects of geometry. ${ }^{\mathrm{I}}$

Reid has said earlier that our conception of an individual is a conception of various attributes referred to a subject. ${ }^{2}$ When we think of some individual thing which does not exist, a centaur for example, we are presumably combining pure universals in thought and giving them this reference.

The impression finally left by the language in which Reid speaks of the status of universals apart from their instances is that he thought of them as ownerless abstractions, like the Platonic Ideas but non-existent. His remarks on the Platonic Ideas themselves confirm it. If Plato had denied existence to his Ideas, had regarded them as 'things barely conceived', he would have spoken with truth of their timelessness and immutability, and in a way 'level to the human understanding' ${ }^{3}$ One looks carefully through Reid for something that makes intelligible the notion of a world, populated by abstract entities or possible predicates in timeless relations and deprived of any kind of being. There is nothing at all.

A brief indication here of Reid's views on the nature of 'abstract general conceptions' in relation to Locke and Berkeley, whom he criticizes, and to Stewart who criticizes him, will emphasize both his and Stewart's rejection of concepts as psychical entities. Against Berkeley, Reid insists that we do have 'abstract general conceptions'. Stewart complains that Reid is manufacturing mystery where everything is plain and straightforward. Everyone agrees that we can, for example, reason 'concerning a figure considered merely as triangular', without attending to its particularities. What additional light does it throw on the subject to tell us in 'scholastic language' that we are enabled to do so because of the power which the mind has of forming 'abstract general conceptions'?4 Stewart, however, has no deep quarrel with Reid's views; the words 'abstract general conceptions' prevented him from seeing how shallow it

I Intellectual Powers, vi. iii; Works, i. 428-9.

2 Ibid., v. ii; Works, i. 392.

${ }^{3}$ Ibid., v. v; vI. iii; Works, i. 404, 429.

4 Elements, II. ii. 2 ; Works, iii. 83 . was. ${ }^{\mathrm{I}}$ The words are almost Locke's, but Reid does not use them in Locke's sense; he is much closer to Berkeley than he thinks; and he does not make mistakes which Stewart corrects.

An 'abstract conception' for Reid, is the conception of some attribute of a thing in isolation from its other attributes, with no implication that what is conceived apart could exist apart. ${ }^{2}$ (To have a conception of anything is simply to think of it.) An 'abstract general conception' is the conception of such an attribute as predicable of a number of individuals. There is nothing general in the mind: the act of conception is an 'individual act', and there are no ideas (in Locke's phrases) particular 'in their existence' and general 'in their signification'. Generality belongs to the objects of conception, whether or not these exist. 'The generality is in the object conceived, and not in the act of the mind by which it is conceived. Every act of the mind is an individual act, which does or did exist. But we have power to conceive things which neither do nor ever did exist. We have power to conceive attributes without regard to their existence.' 3

It seems to Reid that Berkeley himself shows that we have 'abstract general conceptions'. For Berkeley admits that in considering, for example, a triangle, he can consider it merely as such, without attending to its differences from other triangles. And you cannot consider what you do not conceive. So Berkeley does conceive a triangular figure merely as such. 'I know no more that is meant by an abstract general conception of a triangle. ${ }^{4}$ Locke meant more, and Berkeley did not mean less by the abstraction he allowed. And Reid does not confront Berkeley with any inconsistency: the proposition that nothing can be considered unless it is conceived is tautological, with 'conception' used as Reid used it.

Against Berkeley's view that the particular is given a functional universality by being made representative of a class, Reid objects that the use of a member of a class as its representative implies a conception of the defining properties of the class. It does, but it is open to Berkeley to reply that the class properties

I Reid and Stewart are usually contrasted as 'conceptualist' and 'nominalist'. Part of Reid's attack on the theory of ideas is the denial that there are concepts with the mental status conceptualism has traditionally assigned to them. 'Mr. Locke... I think, may be accounted a Conceptualist' (Intellectual Powers, v. vi; Works, i. 406).

4 Ibid., v. vi; Works, i. 408. 
are in the first place determined by a decision to take into consideration some properties of a particular and to leave others out of consideration. The class properties are calculated from the degree of abstraction applied to the particular, not the other way round. There is no reason why Reid should regard this reply as unsatisfactory.

'Generalization', Reid says in a draft of part of the Intellectual Powers, 'is nothing else in my apprehension than observing some attribute or circumstance to be common to two or more objects, and giving it a name which must of consequence be applicable to all the individuals in which the thing signified by it is found.' $t$ It is nothing else in Stewart's opinion, but his emphasis is on the second half of the sentence. Unfortunately no more than hints and fragments of Stewart's heavily linguistic view of the nature of general conceptions emerge from pages of exposition, divided between the first two volumes of the Elements. Language, or at any rate, a system of signs, is the indispensable instrument of abstraction and general reasoning, which cannot begin without primitive signs and cannot develop successfully without a

class of signs, expressive of all the circumstances which we wish our reasonings to comprehend; and, at the same time, exclusive of all those which we wish to leave out of consideration. The word triangle, for instance, when used without any additional epithet, confines the attention to the three angles and three sides of the figure before us; and reminds us, as we proceed, that no step of our deduction is to turn on any of the specific varieties which that figure may exhibit.

Reid's criticism of Berkeley, that a member of a class cannot be made its representative without an abstract conception of the characteristic properties of the class, is answered simply: a class is specified by a class name with its definition. It is not too much to say that 'we think as well as speak by means of words'. When particulars are at once generalized by general words, and the words in turn given meaning by being given things to stand for, general reasoning with a factual application becomes possible. With the representative particular kept in mind, it proceeds, as far as content though not form is concerned, like an operation in geometry; with the particular dropped from view, like an operation in algebra, the words in their manipulation no more

$$
\text { I Aberdeen MSS. } 213 \text { r.6. }
$$

having to call up immediately the thought of things than algebraical symbols do. The difference between the two procedures is like the difference between hieroglyphic writing and writing in alphabetical characters. ${ }^{1}$ Finally, whenever thought is general, signs are the object of its attention whether there is any thing existing to be thought of or not.

'Imagination, when it is distinguished from conception, seems to me', Reid says, 'to signify one species of conception-to wit, the conception of visible objects.' 'Imagination . . . properly signifies a conception of the appearance an object would make to the eye if actually seen." 2 Universals are conceived of and cannot be imagined. The operations of the mind are conceived of and cannot be imagined. In strict propriety of speech, Reid thinks (remembering prominent features of the word's etymology), nothing but the visual appearances of things can be 'imagined'.

Imagination is a species of conception. And according to Reid, no conception, unless it is of an internal object, has an internal object. No remoteness in space or time is a bar to the direct conception of an external object. The same thing can be perceived, remembered, imagined, and in each case it is the thing itself and not any 'idea' of it that is before the mind. I can remember the rose I saw yesterday and can imagine it now present. The rose I saw and nothing else is the object of each of these subsequent acts. ${ }^{3}$

When I imagine yesterday's rose, I remember it and imagine it in different circumstances. Suppose I imagine, not a rose I can remember seeing, but simply a rose. Suppose I imagine something that has never existed, a centaur for instance. What would Reid say of these objects? What he has said seems to require from him the opinion that here too things that were real are before the mind in the special way in which conception brings things before the mind-the rose is perhaps a rose I once saw but cannot now remember having seen; or the characters of real things are before the mind, but formed into unreal combinations - a centaur pictured is an unreal combination of real components. 'Once real' and 'unreal combination' would

Elements, 1. iv. 2; Ir. ii. 2; Works, ii. 1 74; iii. 85-98.
2 Intellectual Powers, , iv. i; v. vi; Works, i. $365-6,407$.

3 Inquiry, n. iii; Works, i. 106. 
allow Reid to hold both that in imagination there is no belief, and that imagination must have objects and these must be extra-mental. He does not think that when people who are not philosophers say that the things they imagine are in the mind', they want somehow to localize them there, with some sort of analogy to the way in which things are physically in things. He is sure that if they do, they are mistaken: there are no images in the mind; nothing has a copy of itself there.

This treatment of the objects of imagination, for what it is worth, could be extended to give the answer Reid might have given, if asked about the objects of false memories. Having once realized that there is no place for ideas as direct objects in remembering, one is inclined to say that where they are needed is in pseudo-remembering; that indeed the difference between the two is constituted by the fact that the first does not have, and the second does have, ideas for objects. To say this is to create the problem: How can present ideas be mistaken for past events when they have not a single property in common? Finding it insoluble, ideas are reinstated for both true and false memory.

There is no need to have ideas as the objects of false memories. When you remember what actually happened, you are retrospectively aware of persons, things, events, times and places, as they actually were. When you are sure you remember and do not, you are still retrospectively aware of persons, things, events, times and places, but one person is confused with another, things and events are mistaken for other things and events, or the times are wrong, or the places; some features of the past are not recognized for what they were. When you positively remember returning to the library the book afterwards found slipped down behind the shelves, you do recall the book and you do recall returning books to the library and you think you did with this book what you did with other books. You do not, with all the sceptical implications in doing so, mistake the 'idea' (in the theory sense) of returning the book for returning the book. You may 'have an idea' (in the sense that Reid would allow) that you did what you never did, but this is to fail to recognize some feature of the past for what it was, not to mistake anything in the present for something in the past.

\section{I}

\section{THE SCEPTICAL DEDUCTION}

\author{
I. THE LOGICAL DEDUCTION
}

T DEAS seem to have something in their nature unfriendly to other existences.' They begin their career humbly as representatives of things and in this capacity appear to do the very useful work of making the operations of the mind intelligible, and they end by pushing everything out of existence except themselves. ${ }^{1}$ We shall be concerned in this section with Reid's logical deduction of the sceptical consequences of the theory of ideas and in the next with his historical deduction of Hume from Locke.

When I think of Alexander, I am told that there is an image or idea of Alexander in my mind, which is the immediate object of this thought. The necessary consequence of this seems to be, that there are two objects of this thought-the idea, which is in the mind, and the person represented by that idea; the first, the immediate object of the thought, the last, the object of the same thought, but not the immediate object. This is a hard saying; for it makes every thought of things external to have a double object. Every man is conscious of his thoughts, and yet, upon attentive reflection, he perceives no such duplicity in the object he thinks about. Sometimes men see objects double, but they always know when they do so: and I know of no philosopher who has expressly owned this duplicity in the object of thought, though it follows necessarily from maintaining that, in the same thought, there is one object that is immediate and in the mind itself, and another object which is not immediate, and which is not in the mind.

Besides this, it seems very hard, or rather impossible, to understand what is meant by an object of thought that is not an immediate object of thought. ... There is a sense in which a thing may be said to be perceived by a medium. Thus any kind of sign may be said to be the medium by which I perceive or understand the thing signified. The sign by custom, or compact, or perhaps by nature, intro- duces the thought of the thing signified. But here the thing signified, 
when it is introduced to the thought, is an object of thought no less immediate than the sign was before. And there are here two objects of thought, one succeeding another, which we have shewn is not the case with respect to an idea, and the object it represents.

I apprehend, therefore, that, if philosophers will maintain that ideas in the mind are the only immediate objects of thought, they will be forced to grant that they are the sole objects of thought, and that it is impossible for men to think of anything else. ${ }^{\mathrm{I}}$

Are there two objects before the mind when, say, Alexander is thought of; one of them the historical person and the other the idea of him? If there are, this could hardly fail to be noticed. Ideas especially should be obvious since they are immediately known, and are what they appear to be, and anything else that is known is known only through them.

Yet in spite of these characteristics, unanimously accorded to ideas by philosophers, there must be something unstraightforward about them, Reid thinks, to account for the fact that the history of philosophy is almost the history of an argument over the nature of ideas. Ideas have been held to be self-existent, in the Divine Mind, in our minds, in our brains; to be all innate, all adventitious, some innate and some adventitious; to have God, external things, impressions, as their causes; abstract ideas have been held to exist, have been denied as an absurdity. We must be better acquainted with ideas than with anything else, if there are ideas, and yet there has been all this disagreement and more about their nature. ${ }^{2}$

Quite different sorts of things are, of course, called 'ideas' in this chaos of philosophical disputes, and even when any one of them is separated out from the others, our powers of inspection would need to be very formidable to settle, as Reid seems to think they should be able to, all the questions that might arise about its nature. It might well be beyond them to detect even the presence of the ideas that are objects of every kind of cognition, for though in a way these ideas must be more obvious than anything else, they may not be obviously ideas. Certainly the descriptions that we have to go on do not point unmistakably to their application: 'immediate objects', 'lasting no longer than the consciousness of them', 'located in the mind'-least of all

\footnotetext{
I Intellectual Powers, II. ix; Works, i. 278-9.

Ibid., II. xiv; Works, i. 305 .
}

'immediate objects'. When Locke said that he meant by an 'idea' whatsoever was 'the object of the understanding when a man thinks', and that he supposed it would be granted him that there are such ideas, ${ }^{I}$ the supposition was too well foundedthe trouble is that everyone would grant it if this is all that is meant by an 'idea'. And there is no way of supplementing the metaphysical description with a list of typical examples of ideas as objects of thought. A list of typical examples of ideas of sense does not sound straightaway an impossible compilation. We would know what to look for when told to look for patches of colour and so on. But when Locke says that these are ideas, meaning by 'ideas' all that he does mean, the trouble is that many people would not allow that they are ideas.

We are concerned at present with the ideas which the mind has before it as representative objects when we are thinking of something that exists at the time or has existed in the past. And looking for them we do have this to go on: we know that there are to be two objects of thought, respectively immediate and remote, whenever we think of anything not itself in the mind; and the immediate object is the idea and it is in the mind and to be looked for there. So if two objects are not to be found in the relationship the theory prescribes for them, then either ideas are fictitious, or it is false that we can think (except, perhaps, introspectively, where 'the mind is its own archetype') of anything else.

Are there then the two objects? We are thinking of events in Alexander's life, and very likely while we are, there is a flickering succession of images (which might be quite different on another occasion when we thought of the same events). Are these the ideal objects of which the theory is speaking? Does it merely assert their occurrence when we are thinking of things quite different from them, such as events in the life of Alexander? If this is all there is to the theory, it is a psychological banality not worth powder and shot. The ideas were to be direct objects representing remote and directly inaccessible objects, and we are certainly thinking directly, in a perfectly clear sense of the word, of the past events. What argument there is should be over the propriety of calling the images to which no attention is being paid, objects of thought at all, let alone direct objects.

$$
\text { I Essay, r. i. 8; Works, i. 6-7. }
$$


If we are to find two different sorts of objects before the mind at the same time with a significant epistemological relation between them, we have not found them. Should we have looked for successive objects?

There are the familiar experiences in which we come to think of one thing by first thinking of another, as in any chain of reasoning or in any causal inference, as in memory we sometimes grope back from clue to clue towards an accurate recollection, as in the transition from any sign to its signification. The mediation is temporary and has failed unless it is. It ends in our thinking directly of the later thing to which the earlier has led us. There is no analogy here with the structure of cognition in the theory of ideas, where the indirect object never becomes the direct object. This structure, Reid claims, is unintelligible through and through.

For, whatever the object be, the man either thinks of it, or he does not. There is no medium between these. If he thinks of it, it is an immediate object of thought while he thinks of it. If he does not think of it, it is no object of thought at all. Every object of thought, therefore, is an immediate object of thought, and the word immediate, joined to objects of thought, seems to be a mere expletive. ${ }^{\mathrm{I}}$

It is not surprising that Reid finds himself wondering for a moment if the theory of the two objects has been a theory which anyone has ever tried to hold. He cannot remember any philosopher actually saying that there are the two. But add together 'immediate' and 'mediate' and you have two, and either term implies its correlative even if its correlative is not expressly mentioned. And what has Locke, for instance, been trying to say in saying 'the mind knows not things immediately, but only by the intervention of the ideas it has of them', ${ }^{2}$ if not what Reid shows cannot be said? That there are not two objects discoverable on inspection, but only the idea with, however, its representative, symbolical, relative function? Reid is not answered. Either we know what is represented, symbolized, or we do not. If we do, then there are the two objects. If we do not, the idea is absolute and has no representative, symbolical function. Unless we can get beyond ideas to what they are ideas of, we are, as Reid says, in the position of a savage shown a book in a

\footnotetext{
Intellectual Powers, vi, iii; Works, i. 427.

2 Essay, IV. iv. 3; Works, ii. 127.
}

language he cannot read and does not even know to be a language. ${ }^{1}$

The theory that things must be thought of mediately through their ideas implies the necessity, Reid maintains in effect, of what it asserts to be impossible. For if $r$ cannot be thought of immediately, it cannot be thought of mediately through the idea of it. To think of $X$ as the idea of $r$, is to think of $X$ directly, $r$ directly and directly of the relation between $X$ and $r$. (The alternative: an infinity of mediating ideas between $X$ and $r$.) Ideas overcome no barriers. If the barrier is the thing's remoteness, ideas leave it remote; if it is that the conditions of thought impose phenomenal distortion, then ideas either are this distortion, or they are involved in it. Therefore it is either impossible to think of $r$, or it is necessary to think of it immediately. To say that nothing but ideas can be thought of immediately, is already to have given up the theory of mediate cognition, for it is to say that nothing but ideas can be thought of-'immediately' here is a mere expletive. One way or the other, Reid is convinced, the unintelligible duality of cognitive objects has to be given up. With the ideas cut out, we are back at common sense. With the alternative excision, Hume is reached.

A theory of representative sense perception, detached from a general theory of representative cognition, is free from its selfcontradiction. If it is allowed that we can think without ideas, that we can perceive only through ideas becomes a possible assertion. The statement that the senses never show us the thing itself, nor any of its properties in themselves, nothing but its fugitive and ideal appearances, is a statement that can be understood. Of course, as the standard criticism points out, the content of our thought of the object lying behind its ideal manifestations in sense experience is going to be quite arbitrary; we shall not have any reasons for supposing that there is any hidden object there at all, let alone for a claim to know what it is like. The supposition and claim, however, are not self-contradictory, though the fact that we have no reason for them is a good reason for their sceptical rejection, for striking out here also 'immediate' from the proposition that ideas are the mind's only immediate objects.

The opinion that the immediate object in remembering is an I Philosophical Orations, p. 35.

6228 
idea representing something in the past, is open to the same objection.

And, from the present existence of this idea of memory I am left to infer, by reasoning, that, six months or six years ago, there did exist an object similar to this idea.

But what is there in the idea that can lead me to this conclusion? What mark does it bear of the date of its archetype? Or what evidence have I that it had an archetype, and that it is not the first of its kind?

The sceptical deduction from the proposition that ideas are the mind's only immediate objects, is reinforced by the implications of the principle of conceptual empiricism limiting the sources of concepts to sensation and reflection. As we have mentioned, the theory of ideas for Reid included both as components, and he is liable without warning to mean by 'the theory of ideas' either or both of them. They are in fact independent principles. Reid is always disposed to regard the second as derived from the first. One can dimly see why. If there is no perception of things except through their images in the mind, there can be no content to the conception of them except such as is provided by their images in the mind. This seems to have been Reid's argument. ${ }^{2}$ In spite of his distinction between the old and the new form of the theory of ideas, Reid was always disposed to think that whenever philosophers spoke of ideas, they were speaking of images.

... there is a tribunal of inquisition erected by certain modern philosophers, before which everything in nature must answer. The articles of inquisition are few indeed, but very dreadful in their consequences. They are only these: Is the prisoner an Impression or an Idea? If an idea, from what impression copied? Now, if it appears that the prisoner is neither an impression, nor an idea copied from some impression, immediately, without being allowed to offer anything in arrest of judgment, he is sentenced to pass out of existence, and to be, in all time to come, an empty unmeaning sound, or the ghost of a departed entity. ${ }^{3}$

If the only possible objects of thought are possible objects of sense or introspective experience and if the objects of sense experience are ideas (counting 'impressions' as 'ideas'), then

\footnotetext{
3 Intellectual Powers, v. v; Works, i. 445.

2 Inquiry, vi. vi; Works, i. 140 .

${ }^{3}$ Ibid. vi. viii; Works, i. 144 .
}

the world becomes at once exclusively my world, its history part of my autobiography, and I become what is introspectively discoverable in me.

This picture of the consequences of the two principles has exaggerated features. (Reid would insist that in one respect it is not drawn strongly enough: it should have blacked out any sort of history at all, since the intervention of ideas shuts off memory and thought from the past.) It has room for no more than a single experiencer, who is himself reduced to a succession of experiences somehow linked together as his by a pervasively personal quality in all of them. But there could be other private worlds for other minds. It is true that no one's mind can be an object of experience to someone else. The principle of conceptual empiricism, however, allowed significance to statements if their descriptive language had possible application to the same sort of things as one's own sense and introspective data, even though these things could never become part of one's own sense and introspective data. The question 'How do we know that there are other minds?' remains, but the question 'How do we know?' is sooner or later an embarrassment for any philosophy except one which claims to know less than we do know.

And the queerness of as many sensible worlds as there are sentient beings, a world apiece, surrounding each one with a visible and tangible aura, but visible and tangible only to each one, is already there before the deduction, as part of the queerness of a physical world unreachably beyond its different ideal appearances to different individuals. For these appearances constitute as many different sensible worlds as there are individuals; never left by them as long as they live and never entered by anybody else. There are even linguistic palliatives available, now that there are no longer both these multitudes of private worlds and a single physical world neither private nor public. A physical object might be defined as a collection made up out of its sense appearances to different individuals. It would thus be given a sort of independence of any one individual, and we could be encouraged to call the perception of any part of the collection perception of the object. (People who see different parts of a thing rightly say they see the same thing.) How far this verbal gesture of reconciliation would do, would depend on the stubbornness of the common sense that had to be appeased. 
At any rate, in a metaphysics where appearance and reality coincide, as they do after the deduction, the words 'see', 'touch', 'hear', \&c., could be used with less obviously forced meanings. We no longer have to choose between saying, on the one hand, that we see and touch what is invisible and intangible, and, on the other, that we do not see and touch material objects.

Finally, though the self cannot be one individual thing to which its successive experiences belong, there is a serial identity for it instead, and anyone making the change would probably deny that common sense was committed to the first, and so deny that there is anything sceptical in the substitution of the second for it. None of the ordinary expressions for personal identity, it would be said, have to be given up; even the words 'one individual thing to which its successive experiences belong', unless opposed to a serial identity, might describe it.

Reid sees the principle of conceptual empiricism for what it is; he sees the a priori behind the empirical front. ${ }^{I}$ You have the idea of scarlet because you have seen that colour; you have felt angry and so have the idea of anger: you have never seen a centaur, but you have seen men and horses and you have the idea of a centaur; you have never tasted pineapples so you have no idea of the taste of a pineapple. It is a safe proposition that every idea you have has had a similar origin. Too safe; quite invulnerable, for nothing will be allowed to count against it. ${ }^{2}$ The fact that an alleged concept has no empirical derivation is a complete reason for regarding it as a pseudo-concept. 'And when he suspects that any philosophical term has no idea annexed to it (as is too common) he always asks from what impression that idea is derived? And if no impression can be produced, he concludes that the term is altogether insignificant.' 3

Hume does not quite do that, at least not when the terms are in philosophical and ordinary use. To write off such expressions as meaningless is to invite the reply: 'It would be very strange indeed, if mankind had always used these words so familiarly, without perceiving that they had no meaning; and that this

I Active Powers, I. iv; Works, ii. 520.

2 As an empirical generalization, Hume does allow it a minor exception (the shade of blue never seen but imaginable), but none to it as an a priori criterion of meaning.

${ }^{3}$ Hume, Abstract of Treatise of Human Nature, ed. J. M. Keynes and P. Sraffa (Cambridge, 1938), p. 11. discovery should have been first made by a philosopher of the present age.'I (It is the word 'power' that Reid has particularly in mind and the other words logically related to it.) What Hume does maintain, when he is careful, is that if a philosopher borrows a term from common speech and does not annex to it an idea with the prescribed origin, he uses it without its common meaning, without, indeed, any meaning. And since whenever Reid would call something a material object, Hume would also; since both could agree on the criteria for applying the expressions 'personal identity', 'cause and effect', 'free will', 'right and wrong', and other expressions which enter into the statement of common-sense beliefs, Reid cannot prove that Hume means more by them than he admits, and Hume cannot prove that Reid means less by them than he claims, and neither can prove that he has the rest of mankind with him against the other. The philosophy of Common Sense has to appeal twice to self-evidence: to the self-evident meaning of statements which state common-sense beliefs and then to their self-evident truth.

\section{THE HISTORICAL DEDUCTION}

There is a simple and familiar diagram for the illustration of the development of philosophy from Locke to Hume. Three concentric circles would represent Locke's position, the outer one standing for material objects, the middle one for ideas, and the inner one for the self. Berkeley deleted the first of these circles; Hume deleted the first and the third, leaving nothing but ideas. Very crudely, this is Reid's derivation of Hume from Locke. Two successive sceptical revisions of Locke, the first surrendering the independence of the external world with the intention of countering Locke's implicit scepticism, the second revision making what was implicit fully actual; Berkeley and Hume respectively; Berkeley, Locke made more self-consistent; Hume, Locke made quite self-consistent. Reid's influence fixed this as the outline of the standard version of the progress of philosophy from the Essay Concerning Human Understanding to the Treatise of Human Nature. (Reid was not responsible for the modification of it which derives Hume indirectly from Locke through Berkeley, which has Hume pruning Berkeley as Berkeley

$$
\text { I Active Powers, r. i; Works, ii. } 515 .
$$


had pruned Locke.) It has kept its authority in spite of some protests until quite recently.

The historically decisive Locke, for Reid, was Locke saying that 'the mind, in all its thoughts and reasonings, hath no other immediate object but its own ideas', ${ }^{x}$ and at the same time not wanting to deny that we can know any of the things that we all ordinarily claim to know. The contradiction had to be ended in one of two ways. If the theory of ideas is true, 'there can be no knowledge of anything but of ideas And, on the other hand, if we have any knowledge of anything besides ideas, that theory must be false.'2 Berkeley and Hume accepted the theory and went on, Berkeley half-way, Hume with a harder logic, to its consequences.

Reid's Locke, however, is not Locke simply tailored to a premiss for Berkeley and Hume to work from; Locke keeps some of his ambiguities and contradictions. Reid genuinely wonders whether some of his most important statements can have the meaning they seem to have. There are contexts in which 'idea' with Locke is a synonym for 'act of thought' or 'act of perception'; in others it is a deplorable word for the objective qualities of things. And Reid can see why it might be claimed that the word has one or other of these meanings in all its contexts: 'ideas, being supposed to be a shadowy kind of beings, intermediate between the thought and the object of thought, sometimes seem to coalesce with the thought, sometimes with the object of thought, and sometimes to have a distinct existence of their own'.3

'Since the mind, in all its thoughts and reasonings, hath no other immediate object but its own ideas, which it alone does or can contemplate; it is evident, that our knowledge is only conversant about them.'

Does Locke mean anything by the word 'immediate'? Does he intend it 'to limit the generality of the proposition'? This seems improbable to Reid for a number of reasons, and he emphasizes one of them. If the word is significantly restrictive, the consequential clause does not follow from its antecedent. If, on the other hand, the word is a 'mere expletive', 'the two clauses will be perfectly consistent, the second being only a repetition or explication of the first'.4

\footnotetext{
'Essay, Iv. i. I; Works, ii. $5^{8 .}$

3 Ibid., II. ix; Works, i. 279-80.

2 Intellectual Powers, vi. iii; Works, i. 433. + Ibid., v1. iii; Works, i. 427 .
}

Reid's comment is at first sight disconcerting. But he is not going back on all that he has said. He is not denying here that 'The mind has no objects other than its own ideas' follows from 'The mind has no immediate objects other than its own ideas'. His comment on Locke shows that he holds it to follow analytically. Its 'deduction' is a demonstration of its identity with its antecedent, by means of a demonstration that the word 'immediate' has no meaning in its antecedent.

Locke asserts that knowledge consists in perception of the agreement or disagreement of ideas, and is to be found asking how the mind, perceiving nothing immediately but its own ideas, can know their correspondence with things. Locke 'did not believe that he himself was an idea; that his friends and acquaintances were ideas'; that God was an idea; that the 'external objects of sense' were ideas. And he believed that he had 'some certain knowledge' of all of these, and not by any inference from 'the agreements and disagreements of ideas'.

The persistent formula in which knowledge appears as a matter of perceived relationships between ideas puzzled Reid more than anything else in Locke. It perhaps puts forward no theory but only a new terminology. 'I say a sensation exists, and I think I understand clearly what I mean. But you want to make the thing clearer, and for that end tell me, that there is an agreement between the idea of that sensation and the idea of existence. To speak freely, this conveys to me no light, but darkness; I can conceive no otherwise of it, than as an odd and obscure circumlocution.' 2 If Locke had been thinking merely of the abstract knowledge we have in axioms and demonstration, as Reid has no doubt he primarily was, the formula would be intelligible and unobjectionable. Abstract knowledge is a matter of the perceived relations of ideas, provided that by 'ideas' are understood the attributes of things conceived without regard to their actual existence. ${ }^{3}$ But Reid cannot see how 'in any sense' the formula can be applied 'to the evidence of consciousness, to the evidence of memory, or to that of the senses'.4

\footnotetext{
Ibid. vr. iii; Works, i. 432.

2 Inquiry, n. v; Works, i. 107

3 Intellectual Powers, vi. iii; Works, i. $428 \mathrm{ff}$.

4 Ibid., II. xx; Works, i. 330.
} 
It required 'no Samson' to bring down the pillars on which Locke supported the external world. But Berkeley's motive was not a destroyer's; he was countering scepticism by a sceptical manœuvre. He was abandoning the material world in order to secure the immaterial world. It was better to make a clean sweep of what was doomed in any case and might involve more important things in its ruin. Matter could go without loss and with advantage. The grounds of atheism and irreligion went with it. ${ }^{\mathrm{x}}$

Reid misunderstood Berkeley's intentions. Berkeley was not concerned simply with protecting religion and the soul. ${ }^{2}$ Nothing, he would have claimed, has gone except the fiction of material substance; he was not surrendering the material world; he was beating back scepticism from it in the one way possible, by showing that our senses open onto it. Material things are precisely things we see, handle, hear, taste, and smell. Berkeley did, J. F. Ferrier remarks, what Reid talked about doing: Berkeley showed that the material world is directly perceived. ${ }^{3}$

'I am not for changing things into ideas, but rather ideas into things.' Berkeley changes things into ideas both in name and nature, the Common Sense philosophers say. He turns things into thought, Beattie insists, determined not to let huge absurdity escape. Ideas are thoughts, as everyone who knows the language knows, and if we allow Berkeley to persuade us to accept the transformation, we have to give up all claim to being able to distinguish anything from anything else.

All external objects have some qualities in common; but between an external object and an idea, or thought of the mind, there is not, there cannot possibly be, any resemblance. A grain of sand, and the globe of the earth; a burning coal, and a lump of ice; a drop of ink, and a sheet of white paper, resemble each other in being extended, solid, figured, coloured, and divisible; but a thought or idea hath no extension, solidity, figure, colour, nor divisibility: so that no two external objects can be so unlike, as an external object and (what philosophers call) the idea of it. Now we are taught by BERKELEY,

Inquiry, 1. v; Works, i. I01; Intellectual Powers, I1. xii; Works, i. 293.

2 And if Reid had understood why Berkeley held that 'the soul always thinks' (Principles, 98, 139; Philosophical Commentaries, 429, 652) he would not have been at all sure that Berkeley was protecting the soul.

3 Works (2nd ed., Edinburgh and London, I875), iii. 417. that external objects (that is, the things we take for external objects) are nothing but ideas in our minds; in other words, that they are in every respect different from what they appear to be. . . . The candle may be a lump of ice, an Egyptian pyramid, a mad dog, or nothing at all ... for any thing I know, or can ever know to the contrary, except you allow me to judge of its nature from its appearance; which, however, I cannot reasonably do, if its appearance and nature are in every respect so different and unlike as not to have one single quality in common.

Part of the price a philosopher has to pay for saying that stones, trees, and books are collections of ideas is to have a Beattie gyrate round the word, enjoy the absurdities, and be utterly incapable of seeing that it is essential to the theory in which the word occurs to have no implications for experience. So Beattie thought that if Berkeley was right, we ought to be able to stride over precipices with impunity ('my neck, Sir, may be an idea to you, but to me it is a reality'); that to stand on the ground is to perform the astonishing feat of getting the ideas in our heads under our boots. Nothing of this, of course, is a consequence of Berkeley's theory: death comes in the accustomed ways, no psycho-physical acrobatics are involved in standing up, the tissue-paper flimsiness to which the solid earth and everything on it is attenuated by becoming clusters of 'ideas', is an illusion which the word casts on the imagination; nothing in ordinary experience is changed.

For Reid, Berkeley's metaphysics is not the gross affront to common sense that Beattie makes it out to be. Nevertheless common sense rejects it decisively. If things are collections of ideas, nothing that I perceive exists any longer than I perceive it, and nothing that $I$ perceive can be perceived by anyone else. The plain man never doubts that what he perceives exists independently of his perception of it, and that many people can perceive the very same thing. Berkeley, Reid admits, claims to be on the side of common sense here also. Berkeley allows that material things exist independently of the mind of any one of us,

I Essay on Truth, II. ii. 2, pp. 284-5. Beattie wonders if, perhaps, he has misunderstood Berkeley. It is more than possible, he thinks; after all, Berkeley did not really understand himself or he would have seen that 'his system leads directly to atheism and universal scepticism' (pp. 286-7). Everything Oswald saw and touched refuted Berkeley. Berkeley maintained, Oswald says, that the 'system of matter we inhabit is a mere nonentity' (An Appeal to Common Sense, i. 94). 
denying them only 'an absolute existence distinct from their being perceived by God and exterior to all minds'. I

But here an objection occurs, which it required all his ingenuity to answer. It is this: The ideas in my mind cannot be the same with the ideas of any other mind; therefore, if the objects I perceive be only ideas, it is impossible that the objects I perceive can exist anywhere, when I do not perceive them; and it is impossible that two or more minds can perceive the same object. ${ }^{2}$

Reid then gives Berkeley's answer, quoting the passage in which Berkeley shifts the word 'same', when it means 'individually the same', out of ordinary speech into the technical vocabulary of philosophers. The word 'same' in its 'vulgar acceptation' is applied 'where no distinction or variety is perceived'. Different persons may therefore perceive 'the same thing; or the same thing or idea exist in different minds'. But if the word is used 'in the acceptation of philosophers, who pretend to an abstracted notion of identity, then, according to their sundry definitions of this notion ... it may or may not be possible for divers persons to perceive the same thing'. ${ }^{3}$

Reid makes no comment at all on this answer. He goes on to say that Berkeley's theory of ideas would make us entirely sceptical about the existence of other finite minds than our own. Why? Because it disembodies every person, except oneself, and so cuts off mind from mind. 'What I call a father, a brother, or a friend, is only a parcel of ideas in my own mind; and, being ideas in my mind, they cannot possibly have that relation to another mind which they have to mine, any more than the pain felt by me can be the individual pain felt by another.' 4 Do I see other people's minds? 'No. Do I see their ideas? No. Nor do they see me or my ideas.' 5

However Berkeley chose to meet Reid's difficulty about knowledge of other people's minds-perhaps the analogical argument is as unaffected by the privacy of ideas as Berkeley thinks it is-Reid could have argued with some success that Berkeley had two alternatives before him with regard to the status of ideas. One of them will alienate him from common

I Three Dialogues, ni; Works, ii. 235.

2 Intellectual Powers, II. x; Works, i. 284

3 Three Dialogues, IIr; Works, ii. 247.

4 Intellectual Powers, Ir. x; Works, i. 285.

5 Ibid., vi. v; Works, i. 446 sense and the other destroy the foundation of his idealism. Either ideas are related to perception, as pain to feeling, or they are not. If they are, then undoubtedly they must be perceived in order to exist. But then my ideas are as fleeting as my perceptions of them, and (theological difficulties apart) ${ }^{\mathrm{I}} \mathrm{I}$ could have no access to God's ideas, which would be as private as my own. Nothing that $I$ see or touch was there before I saw or touched it, nor will be afterwards. No two people see and touch the same thing, except in the sense of 'same' in which they can both have the same headache. If, on the other hand, individual ownership is made accidental to the nature of ideas (the possessive pronoun wedged off the word), ideas may then be public objects, ${ }^{2}$ but they are loosed from their dependence on perception. To be is to be perceived by someone or other is not a proposition shining with the light of self-evidence.

In a further recession from common sense, Berkeley, Reid says, seems to make the ideas of sense and those of imagination differ in nothing but degree: the ídeas of imagination are 'less regular, vivid, and constant'. On

this doctrine, if we compare the state of a man racked with the gout, with his state when, being at perfect case, he relates what he has suffered, the difference of these two states is only this-that, in the last, the pain is less regular, vivid, and constant, than in the first. We cannot possibly assent to this. Every man knows that he can relate the pain he suffered, not only without pain, but with pleasure; and that to suffer pain, and to think of it, are things which totally differ in kind, and not in degree only. ${ }^{3}$

It is a pity, Reid remarks, that Berkeley who is always opposing common sense to philosophical paradox, should have taken over, without suspicion, the philosophers' supposition upon which his own paradoxes are founded. But there it is at the beginning of the Principles of Human Knowledge: 'It is evident to anyone who takes a survey of the objects of human knowledge,

i Berkeley was, of course, fully aware of the theological difficulties, and he did not think that we perceive ideas existing in the mind of God. (Correspondence between Berkeley and Johnson, Berkeley's Works, vol. ii.) We do not perceive the Divine ideas, and the ideas we do perceive are related to God as effects to their cause. God 'imprints' them 'on the senses' or 'excites' them 'in our minds'.

2 'Berkeley's position is that there is only one corporeal realm, which God and we alike apprehend directly ...' (T. E. Jessop, Berkeley's Works, ii. 268).

${ }^{3}$ Intellectual Powers, II. xi; Works, i. 291. 
that they are either ideas actually imprinted on the senses, or else such as are perceived by attending to the passions and operations of the mind. ...

Reid did not see that this statement for all its Lockian ring is already Berkeleyan, and not a premiss provided by Locke for his own refutation. Berkeley did not reach his idealism by drawing some but not all of the consequences of the theory of ideas. His idealism was axiomatic, could be read off from the meaning of 'existence' as predicated of sensible objects, which again show the inseparability of their being and their being perceived. And he does not move against Locke simply by arguing that the word 'immediate' has to come out of the proposition, that ideas are the only immediate objects of perception, there being no possible justification for an inference from immediate to mediate objects of perception with the senses, reason, and memory all silent. He eliminates Locke by a number of arguments, good and bad, besides this one. A physical world existing independently of the mind is inconceivable. What would it be like, since nothing in it could be like an idea? What is it that is being asserted to have independent existence, when neither ideas nor their archetypes could have independent existence? It is inconceivable. The attempt to conceive it would fail by succeeding. I These arguments, and others which Berkeley uses, do not turn on the implications of the principle of mediate perception.

As a description of the results of the transition from Locke to Berkeley, Reid's account is near enough the truth. Berkeley dropped the hidden, independent physical world; he changed ideas into things by calling them things and denying that there were any other things of which they were ideas; his real world has all the characteristics of Locke's ideal world; it has to be as private and fugitive if there is to be any reason for the dependence of esse on percipi. And Locke's ideal world has all the

1 'Philonous. How say you, Hylas, can you see a thing which is at the same time unseen?

Hylas. No, that were a contradiction.

Philonous. Is it not as great a contradiction to talk of conceiving a thing which is unconceived?'

(Three Dialogues, I; Works, ii. 200.)

Ferrier attacking Reid, paraphrased Berkeley: We want matter per se; we get matter in relation to mind. 'We may ring for No. 1, but No. 2 always answers the bell.' (Works, iii. 441.) characteristics of Berkeley's real world, is as palpable, as full of colour and sounds and scents. Reid's deduction, however, of Berkeley from Locke is not more than fragmentarily historical.

How did Berkeley, beginning with Locke, as Reid supposes, avoid ending with Hume? He inconsistently departed from 'the common opinion about ideas' and allowed that there are some things, notably our minds, other finite minds, and God, of which we have no ideas, but of which we do have notions. By 'notion', Berkeley meant, as far as Reid can see, what the word does mean: 'A notion is an act of the mind conceiving or thinking of some object.' The object may be indifferently in or outside the mind. And if consciousness and reflection furnish us with notions of spirits and of their attributes, without ideas, may not our senses furnish us with notions of bodies and their attributes, without ideas?'I

Hume corrected Berkeley's deviation. Locke taught us that all the immediate objects of human knowledge are ideas in the mind. Bishop Berkeley, proceeding upon this foundation, demonstrated, very easily, that there is no material world. . . . But ... while he gives up the material world in favour of the system of ideas, he gives up one-half of that system in favour of the world of spirits; and maintains that we can, without ideas, think, and speak, and reason, intelligibly about spirits, and what belongs to them.

Mr. Hume shews no such partiality in favour of the world of spirits. He adopts the theory of ideas in its full extent; and, in consequence, shews that there is neither matter nor mind in the universe; nothing but impressions and ideas. What we call a body, is only a bundle of sensations; and what we call the mind is only a bundle of thoughts, passions, and emotions, without any subject. ${ }^{2}$

Reid, popularized by Beattie, imposed a caricature on the history of philosophy, Professor Kemp Smith maintains, in representing Hume's teaching as

sheerly negative, being in effect little more than a reductio ad absurdum of the principles which Hume's predecessors, and Hume himself, have followed in their enquiries. Hume, in other words, is depicted as having done no more than deliver his successors from a bondage to which he himself remained subject. A strangely paradoxical verdict! Hume, whose genius is analytic and critical, and whose criticism is eulogised as being so clear-sighted and thoroughgoing, is

\footnotetext{
Intellectual Powers, II. xi; Works, 288-9. $\quad$ 2 Ibid., II. xii; Works, i. 293.
} 
declared to have been unable to perceive what was already so patent to Reid, and even to Beattie, that the source of the trouble lay in his unconsidered acceptance of the hypothesis commonly entitled the 'theory of ideas'. Hume, who was sceptical-so it was alleged-about almost everything else, has yet been so uncritical as to erect the elaborate body of argument that constitutes the Treatise on a foundation which he has not been concerned to examine, and to the unreliability of which he has himself, though all unconsciously, been a chief witness! ${ }^{1}$

Beattie did not share to any great extent Reid's interest in deriving Hume's conclusions from Locke's principles. 'The Cartesian philosophy is to be considered as the ground-work of modern scepticism.'2 The universal doubt was bound to issue in sophistry and scepticism; bad arguments to prove what, if proof were possible, could not be made more certain, and scepticism when the proofs failed.

Reid was not concerned to maintain that Hume took over the theory of ideas without examination. He remarks casually that Hume offers no proof for the theory, but the one argument for it, not of an analogical kind, which he examines, is Hume's argument from perceptual relativity. ${ }^{3}$ Reid said that Hume took over the theory of ideas, and Hume said that his principles were the common principles.

Hume wrote to Reid after having been shown large parts of the Inquiry before its publication. He begins the letter by telling Reid that he has gone through his work 'with great pleasure and attention'. He had noticed some obscurities, but thought these might have disappeared if he could have had the whole of the book in front of him at once. And there were objections he might have made to the chapter 'Of Sight' had he been sure that he had fully understood it. He would not go into any further difficulties until he had more than fragments of the book to work on.

I shall only say, that if you have been able to clear up these abstruse and important subjects, instead of being mortified, I shall be so vain as to pretend to a share of the praise; and shall think that my errors, by having at least some coherence, had led you to make a

\footnotetext{
The Philosophy of David Hume (London, 1941), pp. 3-4.

2 Essay on Truth, II. ii. I, p. 217.

3 Intellectual Powers, II. xiv; Works, i. 302 ff.
}

more strict review of my principles, which were the common ones, and to perceive their futility.

It is not as 'candid and liberal' a letter as Stewart supposed when he inserted it into his Life of Reid' to give credit where credit was due, but a kinder letter than Kemp Smith supposes, and not as ironical. It is ironical-'my errors', 'their futility'but not so ironical as to mean that Hume's principles did not include 'the common ones'. Reid says that Hume took Locke's theory of ideas to its sceptical conclusion. The essential principle of the theory is to be found in its sceptical potentiality in the Treatise, and with a reference to its sanction by philosophers which Reid could not have improved upon: 'tis universally allow'd by philosophers, and is besides pretty obvious of itself, that nothing is ever really present with the mind but its perceptions . . $\therefore{ }^{2}$ ('Really present', that is, 'immediately present', since Hume could not have supposed agreement among philosophers that the mind has no objects at all other than its 'perceptions'.) The sceptical deduction is not made, however, with the simple logic Reid favoured from the theory of ideas as a theory of mediate cognition. 'Perceptions' occupy existence exclusively only after Hume has added the empiricist principle of conceptual limitation, though this is also one of Locke's principles and is part of what Reid meant by Locke's theory of ideas.

In the second and third books of the Treatise Hume develops his psychological and moral theory on the assumption that there is a permanent physical world which is not to be resolved into 'perceptions'. (Here and there the same assumption emerges in the first book, islands left from a drowned continent.) On the traditional interpretation of Hume this is put down to inconsistency. On Kemp Smith's important reinterpretation it is no inconsistency. To stop at the impressions and ideas is to stop with the sceptical half of Hume. Hume has pushed the sceptical implications of Locke's theory hard in order to show its inadequacy. He was unperturbed by Reid's criticism that it wrecks our common-sense beliefs, because he had himself already shown that by itself it does so, but that supplemented it leaves them intact. It needed to be limited and could not be

$$
\text { I Works, x. 256-7. } \quad \text { 1. ii. 6, p. } 67 \text {. }
$$


abolished. Not the theory of ideas, but the demand for rational justification of every belief we are entitled to hold had to be rejected. In 'the human situation' feeling has a primacy over reason. Hume's scepticism is provisional; it is where reason alone would leave us, but where reason leaves us, Nature takes over imperatively.

There are two questions here, in one of which Reid would be very interested, and in the other only faintly. The first is whether the theory of ideas can be combined with anything else so as to have its sceptical implications cancelled; the second, whether Hume aimed at philosophical scepticism. The answer to the first question depends on how much is put into the theory. If the theory is a general theory of mediate cognition, channelling all thought of what is not in the mind through ideal objects that are in the mind, Reid would claim that the answer is No, and that he had shown that the theory is logically incoherent, and that if the ideal objects are to be retained, they must be retained as the only objects there are. Take the theory more moderately as a theory of representative sense perception. There is no logical impossibility in our having true beliefs without having evidence for them. The belief in a permanent world behind its fugitive and ideal manifestations might be one of these beliefs. We might even be able to know its truth without evidence. But what is this world like? How is it to be described? To say that anything in it is like the impressions which are its effects, is to ask for the reminder that nothing can be like an impression except its fainter copy in the imagination. To refuse to say it, makes an answer very difficult, and impossible if one is also demanding definitions for all descriptive words in terms of impressions, or of the 'manner' in which impressions present themselves to the mind.

With this demand, Hume certainly cannot allow any content to our 'natural belief' in a world independent of our perceptions, unless he rejects any theory of representative perception. And of course he does, when he is expressly dealing with the matter. The world does not contain objects resembling impressions, or objects that do not resemble them; it is the world of impressions themselves. The senses cannot justify a belief in the 'distinct' and 'continu'd' existence of any object of sense,

\footnotetext{
× The Philosophy of David Hume, pp. 8-12, 45-46.
}

and reason shows the belief to be unjustifiable. The way in which 'imagination' works to produce it can be explained. If Hume does not say that the belief is a true belief, he is still where Reid saw him. And he could not, in Reid's opinion, even say that it might be a true belief.

What is an 'impression'?

I ask the philosopher this question; but I find no answer to it. And when I read all that he has written on this subject, I find this word impression sometimes used to signify an operation of the mind, sometimes the object of the operation; but, for the most part, it is a vague and indetermined word that signifies both. ... Mr. Hume's system, with regard to the mind, required a language of a different structure from the common: or, if expressed in plain English, would have been too shocking to the common sense of mankind ... if a man would persuade me that the moon which I see, and my seeing it, are not two things, but one and the same thing, he will answer his purpose less by arguing this point in plain English, than by confounding the two under one name-such as that of an impression. ${ }^{\mathrm{I}}$

Reid's puzzlement is not genuine. Everything that Hume has written of impressions has led him to understand that in an impression the operation of the mind and its object are not two things, but one and the same thing, as a pain and the feeling of it are one thing. Hume has been meaning by 'impression' or 'perception'-Reid is perfectly certain-what Berkeley meant by 'idea'. Ideas cannot exist unperceived; nothing can be separated from itself. The same disability prevents the unperceived existence of the objective component of an impression or of a perception. If the time has now come to sanction our belief that the moon is there whether we see it or not, it will be necessary, one would think, to change the meaning of 'impression'.

Hume does not appear to think so. The 'supposition of the continu'd existence of sensible objects or perceptions involves no contradiction'. ${ }^{2}$ What then is an 'impression' or a 'perception'? We are not helped at this point by being told that 'perception' and 'object' are interchangeable words which Hume will be using to refer simply to anything presented to us by our senses, to the sort of thing that a common man calls 'a hat, or shoe, or stone'. We want the 'more philosophical way of speak-

$$
\begin{aligned}
& \text { Intellectual Powers, 1. i; Works, i. 227-8. } \\
& \text { F }
\end{aligned}
$$


ing and thinking' which Hume has dispensed with for the moment in giving this explanation (p. 202). When this is restored, it is clear that the words 'impression' and 'perception' do not have the metaphysical neutrality of the word 'object', if this word is used with no implications as to the conditions of a thing's existence. The proposition that nothing is ever really present to the mind besides its own perceptions would be the most banal truism, if 'objects', keeping its neutrality, could replace 'perceptions'. How then is the continued existence of our perceptions possible? We say that hats, shoes, and stones exist in our absence. Is Hume merely authorizing us to go on saying so, provided we mean that they would exist, or could be perceived, if we were present? He has too much respect for our natural beliefs. When he denies that there is any contradiction, any absurdity, in the supposition that sensible objects continue to exist after we have ceased to perceive them, he means by 'continue to exist' what we mean.

The continued existence of our perceptions when we do not have them is possible because

what we call a mind, is nothing but a heap or collection of different perceptions, united together by certain relations, and suppos'd, tho' falsely, to be endow'd with a perfect simplicity and identity. Now as every perception is distinguishable from another, and may be consider'd as separately existent; it evidently follows, that there is no absurdity in separating any particular perception from the mind; that is, in breaking off all its relations, with that connected mass of perceptions, which constitute a thinking being (p. 207).

All perceptions have the same metaphysical status. "Tis also evident, that colours, sounds, etc. are originally on the same footing with the pain that arises from steel, and pleasure that proceeds from a fire; and that the difference betwixt them is founded neither on perception nor reason, but on the imagination' (p. 192). All perceptions are separable existents. There could not be unfelt pain, but, Hume seems, however improbably, to be asserting, there might be a pain which no one felt. Colours and sounds are necessarily sensations, but possibly ownerless sensations. Reid said that Hume had discovered that there could be thought without a thinker, love without a lovera 'bundle' cannot be the subject of any action or passion.' One dismisses Reid's remark, perhaps, as a crude misunderstanding invited by a crude word. Unless Hume has changed the meaning of 'perceptions' when he comes to speak of the detachability of perceptions from the bundle, or unless-and this would make Hume unrecognizable-he has never meant more by 'perceptions' than objects of awareness, never meant that they were indissoluble hyphenations of object and awareness, some such possibility, and more radically than Reid supposed, is Hume's discovery.

Whether Hume aimed at philosophical scepticism, is a question to which Reid would have answered Yes and, preoccupied as he is with the implications of the theory of ideas, would not have thought particularly important. He would have thought it important to insist that if Hume intended, as Kemp Smith maintains, to avoid scepticism by bringing commonsense beliefs into line with moral beliefs, he would first have had to reform his account of moral beliefs. 'Mr. Hume will have the Moral Sense to be only a power of feeling without judging.'x If there is no more belief in the convictions of common sense than Hume allows in our moral 'sentiments', they may be imposed upon us by Nature herself and without epistemological mystery, since they make no epistemological claims.

And it is with very dubious epistemological claims that common sense breaks through in the Treatise. Reid and Beattie thought that Hume was speaking with them against himself when they came on the places where he seems to say that nature silences the sceptic. But it is hard to make out the significance which Hume attaches in the Treatise to the fact that when you have finished philosophizing you have to 'live, and talk, and act like other people'. You must yield to the current of nature. And in this 'blind submission' show a final scepticism? Or yielding to the current, are you safely trusting yourself to something that will sweep you out of scepticism into truth beyond the reach of reason? ${ }^{2}$ Hume does not seem to have made up his mind, but the tone is wrong for the second interpretation, and not really so very much better when he says that nature forces belief, like breathing and feeling, on us. ${ }^{3}$ That is how, as

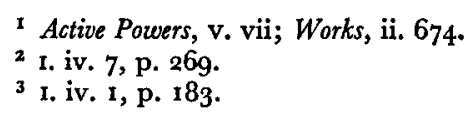


a matter of fact, it is, with no telling as to whether or not that is all there is to it.

The tone changes in the Enquiry Concerning Human Understanding; our natural beliefs have acquired a less ambiguous authority. The extreme sceptic can raise difficulties to which no solutions can be found, but he knows himself, as we all do, that his conclusions are dream-conclusions. 'Common sense and reflection' are correctives (in the Treatise 'carelessness and inattention'). The change is shown again in the section where Hume deals with our belief in the uniformity of nature. 'Sceptical Solutions of Sceptical Doubts'; Beattic runs the titlephrases contemptuously together, but Hume speaks as a subtler Reid. 'My practice, you say, refutes my doubts [about inference from the past to the future]. But you mistake the purport of my question. As an agent, I am quite satisfied in the point; but as a philosopher. . . I want to learn the foundation of this inference.' 2 The foundation is still 'custom', as in the Treatise, but without the sceptical implications which are not removed from 'custom' in the Treatise. The subjective principle is somehow able to be the foundation for an objective inference, as though the correspondence between the succession of our ideas determined by custom and the course of nature had been arranged-as perhaps it has. ${ }^{3}$

If we are to hold the beliefs which are sanctioned in the Enquiry, what are we to believe concerning the world presented to the senses? That when our eyes are shut nothing is changed; everything is like it was when they were open? That there is something there, but something so indeterminate as not to be worth a sceptic's cavil? Nature and reason are in contradiction and no directions for our belief emerge.

Hume made the Enquiries the standard of his 'philosophical sentiments and principles'-'a compleat Answer', he tells his publisher Strahan, 'to Dr. Reid and to that bigotted silly Fellow, Beattie'. 4 They would not have thought so. Apart from anything else, the theory of ideas has not been given up, and its consequences, Reid would have said, cannot be abridged from those that are found in the Treatise of Human Nature.

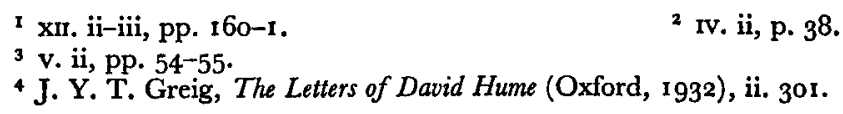

\section{THE SGEPTICAL GONGLUSION}

When philosophers 'split objects into two, where others can find but one', they compensated for their extravagance, Reid says, by economizing on the number of the mind's operations, making one of these do the work of three: perceiving, remembering, imagining all became the perception of an idea. The uniqueness of each is a matter of plain experience and plainly expressed in common language. Common language was not gogd enough for the philosophers who thought they could explain how we perceive, remember, and imagine. They substituted their theorydarkened language, and what is clear becomes opaque and different things are blurred into one another. ${ }^{\mathrm{I}}$

The linguistic accidents behind the extended use which philosophers had given to the term 'perception' quite escaped Reid. He did not see that it was as non-committal, as satisfactory, and as unsatisfactory a word as his own word 'thought', 'which includes all the operations of our minds'. For him it was implicated in the ideal theory from the first. And with Hume, 'love is a perception, hatred a perception; desire is a perception, will is a perception. ... This is an intolerable abuse of language, which no philosopher has authority to introduce.'2 The extent of the abuse ought to have warned Reid that its purpose was not even in Hume to achieve a coalescence of perception, memory, and imagination. Reid had sunk too much polemical capital into the opinion that philosophers had been turning the different kinds of cognitive act into a single kind to match a single kind of object, for him to give it up on being told that historically the extended use of the word 'perception' did not have significant theoretical implications. It seems to have been his view that if there are ideas, we are simply aware of them; we 'perceive' them.

And he would not have been impressed by the protest that the word 'perception' was never used, could never have been used to smudge perception, memory, and imagination into one and the same thing. Reid does not have to be convinced that no philosopher has ever thought of the three words as really synonymous and proposed a simplified vocabulary in which 'perception' takes the place of the others. Everyone, of course,

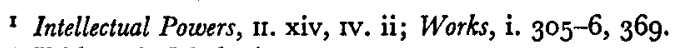


acknowledges some difference between perception, memory, and imagination, but Hume, Reid says, making explicit what was implicit in the theory of ideas, made the difference a matter of degree. Before considering Reid's exposition of Hume, we shall briefly assemble some of the materials Hume provides for it.

Perceptions are either impressions or ideas. 'The difference betwixt these consists in the degrees of force and liveliness with which they strike upon the mind.' $T$ The difference between the ideas of memory and the ideas of imagination is a difference in 'force and vivacity'. ${ }^{2}$ Impressions, therefore, and the ideas of memory and of imagination, are perceptions in an order of diminishing intensity. All impressions, 'external and internal . . . are originally on the same footing' with 'pains and pleasures'. ${ }^{3}$ Pain and felt pain are identical. In all perceptions, therefore, act and object are identical. And nothing but perceptions exist or are conceivable. It is 'impossible for us so much as to conceive or form an idea of any thing specifically different from ideas and impressions. ... Let us chace our imagination to the heavens, or to the utmost limits of the universe; we never really advance a step beyond ourselves, nor can conceive any kind of existence, but those perceptions, which have appear'd in that narrow compass.' 4 Not only then do perceiving, remembering, and imagining differ only in degree, but the real, the remembered, and the imaginary shade off into one another as higher and lower on a single scale of intensity.

Beattie has a jocose refutation of Hume. If Hume is right, it will follow that the

idea of a roaring lion must emit audible sound, almost, if not altogether, as loud, and as terrible, as the royal beast in person could exhibit; - that two ideal bottles of brandy will intoxicate as far at least as two genuine bottles of wine;-and that I must be greatly hurt, if not dashed to pieces, if I am so imprudent, as to form only the idea of a bomb bursting under my feet. ${ }^{\mathrm{T}}$

Reid's refutation of Hume is ironical exposition, covering also Hume's opinion, as Reid states it, that 'belief is nothing but a certain degree of vivacity in the idea of the thing believed':

The belief which we have in perception, is a belief of the present

I Treatise, 1. i. 1, p. 1.

2 Ibid. 1. iii. 5, p. 85 .

3 Ibid. 1. iv. 2, p. 190.

s Essay on Truth, II. ii. 1, p. $24^{8}$. existence of the object; that which we have in memory, is a belief of its past existence; the belief of which we are now speaking [the belief involved in expectation] is a belief of its future existence; and in imagination there is no belief at all. Now, I would gladly know of this author, how one degree of vivacity fixes the existence of the object to the present moment; another carries it back to time past; a third, taking a contrary direction, carries it into futurity; and a fourth carries it out of existence altogether. Suppose, for instance, that I see the sun rising out of the sea: I remember to have seen him rise yesterday; I believe he will rise to-morrow near the same place; I can likewise imagine him rising in that place, without any belief at all. Now, according to this sceptical hypothesis, this perception, this memory, this foreknowledge, and this imagination, are all the same idea, diversified only by different degrees of vivacity. The perception of the sun rising is the most lively idea; the memory of his rising yesterday is the same idea a little more faint; the belief of his rising to-morrow is the same idea yet fainter; and the imagination of his rising is still the same idea, but faintest of all. One is apt to think, that this idea might gradually pass through all possible degrees of vivacity without stirring out of its place. But, if we think so, we deceive ourselves; for no sooner does it begin to grow languid than it moves backward into time past. Supposing this to be granted, we expect, at least, that, as it moves backward by the decay of its vivacity, the more that vivacity decays it will go back the farther, until it remove quite out of sight. But here we are deceived again; for there is a certain period of this declining vivacity, when, as if it had met an elastic obstacle in its motion backward, it suddenly rebounds from the past to the future, without taking the present in its way. And now, having got into the regions of futurity, we are apt to think that it has room enough to spend all its remaining vigour: but still we are decived; for, by another sprightly bound, it mounts up into the airy region of imagination. So that ideas, in the gradual declension of their vivacity, seem to imitate the inflection of verbs in grammar. They begin with the present, and proceed in order to the preterite, the future, and the indefinite. This article of the sceptical creed is indeed so full of mystery, on whatever side we view it, that they who hold this creed are very injuriously charged with incredulity; for, to me, it appears to require as much faith as that of St. Athanasius.

There are two questions: Supposing that this is Hume, does the theory of ideas end in Hume? Is this Hume?

The premiss that the mind's only immediate objects are ideas

Inquiry, vi. xxiv; Works, i. 198-9. 
does not, even conjoined with the principle of conceptual empiricism, entail the conclusion that the real, the remembered, and the imaginary are more or less of the same thing, strong, weaker, and vanishingly faint. There are all the considerations of 'regularity' and 'constancy' to be taken into account. But set them aside. Ideas could occupy existence exclusively and remain uniquely distinct species. Reid was historically wrong and logically wrong: 'perception' was not a reductive term when applied to all the cognitive acts, and the theory of ideas does not call for any such reductive term.

Rosmini calls attention to the curious half-similarity between Reid's view and Hume's. On Reid's view, perceiving, remembering, and imagining all have the same kind of object; they differ as different kinds of awareness of it. ' Rosmini's reference is to a passage from the Inquiry:

I beg leave to think, with the vulgar, that, when I remember the smell of the tuberose, that very sensation which I had yesterday, and which has now no more any existence, is the immediate object of my memory; and when I imagine it present, the sensation itself, and not any idea of it, is the object of my imagination. But, though the object of my sensation, memory, and imagination, be in this case the same, yet these acts or operations of the mind are as different, and as easily distinguishable, as smell, taste, and sound. ${ }^{2}$

The situation which Reid is here describing is not one of pure imagining, but a hybrid of remembering, imagining, and perceiving. Even so, in spite of his determination to say that things imagined may or may not exist, Reid is driven by the pressure of an assumption he shared with the theory of ideas, combined with the denial that there are ideas, towards saying that they must exist, at least their components must. 'When we conceive anything, there is a real act or operation of the mind. Of this we are conscious, and can have no doubt of its existence. But every such act must have an object; for he that conceives must conceive something. ${ }^{3}$ This is common ground to Reid and to the theory of ideas; imagination must have objects. His disagreement with the theory of ideas is over their nature: they are not ideas, not in the mind.

\footnotetext{
The Origin of Ideas (London, 1883 ), i. 68-73.

Inquiry, II. iii; Works, i. 106.
}

3 Intellectual Powers, rv. i; Works, i. 368.
Reid would certainly deny that there is any significant resemblance between his views and Hume's: with the object drawn into the act to form an impression or an idea, with no difference (apart from their context) except relative intensity between an impression and an idea, Hume shades off the real into the imaginary. But though Reid keeps the act and the object separate, he has not explained how he keeps the real and the imaginary separate. And if objects cannot be taken away from imagination-their presence perhaps vouchsafed for by 'consciousness'-it might not be possible to keep the real and the imaginary separate without locating the objects of imagination 'in the mind' as ideas. And should this be so, one proposition in the theory of ideas would have to be true, if we are to avoid the most paradoxical of the conclusions which Reid held to be implied in the theory of ideas.

The conclusions to which the theory of ideas leads are not as paradoxical as Reid supposed. Are Hume's conclusions as paradoxical as Reid supposed ? ${ }^{1}$ Hume does say that perceptions are the only conceivable existents; that they fall into two classes, impressions and ideas; that the difference between impressions and ideas consists in their relative degree of vivacity (without metaphor, that they differ 'only in degree, not in nature').$^{2}$ It is no more than putting together these things that Hume does say to have him holding that the real, the imagined, and the remembered are gradations on a single scale. No more possibly for single impressions and ideas, but the real is only half real without the other impressions and ideas which cluster round a genuine impression when a thing is actually perceived, and are absent in memory and imagination. And the ideas of memory are tied down to the original order of impressions. Imagination is free. This difference seems to disappear on Hume's second thoughts; but it appeared ambiguously and it disappears ambiguously; it came in perhaps as a constitutive feature of memory and it goes out perhaps as an applicable criterion of memory. ${ }^{3}$ Finally, when Hume says that impressions and ideas differ 'only in degree, not in nature', he may not have meant it,

I As we are looking at Hume through Reid's eyes, we are interested only in Hume's radical conclusions, not in the empirical philosophy which he always wanted, except in his destructive moods, to establish.

Treatise, 1. i. 1, p. 3 .

3 Ibid., I. i. 3, I. iii. 5 . 
because he goes on to say things that seem to imply that impressions and ideas, and ideas and ideas, differ not only in degree but in nature.

Comparing memory and imagination in the first section of the Treatise in which he deals with them, Hume speaks of the contrast of force and languor as a 'sensible difference betwixt one species of ideas and another'. In the second of the sections he says that an idea of memory can lose its vivacity until it is mistaken for an idea of the imagination, and that an idea of the imagination can acquire such a vivacity that it becomes a 'counterfeit' memory. As Kemp Smith points out, there could be no question of mistake and counterfeiting, if the difference between ideas of memory and ideas of imagination was nothing but a relative degree of vivacity. Similarly, an exchange of vivacity between an impression and an idea causes one to be mistaken for the other. There must therefore be some other difference between them than merely in degree.

We now need to know what is meant by 'vivacity' and its synonyms and their opposites. They are words we would have to use to express the familiar distinction between clear and vivid, and faint and blurred imagery. Hume does not use them for this purpose; we are not deceived by sharp imagery into taking fancies for realities. The situations in which an impression and an idea coincide in the vivacity Hume means, are those borderline experiences between sense and imagination in which, for example, we are not sure whether we have heard a sound or only imagined it. The situations in which the two sorts of ideas coincide in vivacity are situations in which we are not sure whether we are remembering or just imagining. And there is no feature in these dubious experiences for the faint intensity to mark except the fact that they are dubious, and in experiences of the first kind, the fact that the sound, smell, or whatever it might have been, if there was one, was very faint. If, after keeping clear of the invitation in the scale of relative intensity to compare the sound of a pin drop with an imaginary clap of thunder or the potencies of real wine and unreal brandy, one sets about thinking of what there is to be said in its favour, it is hard to find anything.

In the Appendix to the Treatise memory and imagination are distinguished 'by the different feeling of the ideas they present' (p. 628). The difference in 'feeling' gives a meaning to the difference in 'vivacity' between experiences of remembering and imagining. But Hume goes on to consider the nature of the feeling: 'And here I believe every one will readily agree with me, that the ideas of the memory are more strong and lively than those of the fancy.' In the final remarks in the Treatise on the nature of belief the intensity words, put forward with less conviction as explanatory, are allowed more obviously to take on intelligibility from the thing they are to explain. 'An idea assented to feels different from a fictitious idea.' To explain this different feeling by calling it 'a superior force, or vivacity, or solidity, or firmness, or steadiness' is to use words that 'express something near it'. 'But its true and proper name is belief, which is a term that every one sufficiently understands in common life'; $;$ and belief, Hume says in the Enquiry Concerning Human Understanding, is as indefinable as 'the feeling of cold or passion of anger'. ${ }^{2}$ He has come a long way round to reach Reid ${ }^{3}$ - that is if it is Reid that has been reached.

One would not have been surprised to find Reid claiming that there was nothing in Hume more thoroughly sceptical than the assertion that the 'three acts of the understanding'conception, judgement, and reasoning-'all resolve themselves into the first, and are nothing but particular ways of conceiving our objects'.4 As Reid understood 'conception' when it is contrasted with 'judgement', as the logicians had understood the term, the question whether a conception is true or false cannot arise. And if judgement, and therefore belief, is resolved into conception so understood, the question whether a belief is true or false cannot arise. And Hume may have intended to make it an impossible question, if truth is thought of as the correspondence of judgement or belief with what is independent of all judgement or belief. If this was Hume's intention, 'enlivened ideas' could give way to 'feeling' and 'feeling' to 'belief' in the description of the phenomenology of belief, and Hume would still be as far from Reid as when he first began to speak of the nature of belief.

And perhaps Hume did mean, though not consistently, that the difference between impressions and ideas of memory and

$$
\begin{array}{ll}
\text { Treatise, Appendix, p. } 629 . & 2 \text { v. ii, p. } 48 . \\
3 \text { Inquiry, II. v; Works, i. 107. } & 4 \text { Treatise, i. iii. 7, p. } 97 .
\end{array}
$$


ideas of imagination is constituted by a difference in 'vivacity'; that there is no more to being real (and really remembering) and being imaginary, as far as individual impressions and ideas are concerned, than feeling real and feeling imaginary. Real and imaginary, in any further sense, is a matter of what comes (or could have come) before and after the individual impression or idea. Did I hear or merely imagine the footfall on the path? Well, did I hear the door-handle being tried a moment later? Would I have seen someone there if I had pulled aside the curtains and looked out? Reid has perhaps not altogether misunderstood Hume in the ironical exposition of the scale of intensity. Where he quite lost Hume's meaning was in thinking that a single impression or idea could be considered by itself. ${ }^{\mathrm{I}}$

The theory of ideas is to have Hume as its conclusion. If Hume is to be pinned down to shading off the real, the remembered, and the imaginary into one another, the sceptical implications of the theory, as we have seen, do not go so far. At least they go so far that nothing but 'perceptions', as Hume called them, are left, nothing but 'ideas' in Reid's word. Or has Reid made a mistake here also?

The question is whether the theory of ideas is a universal solvent, of 'the mind' as well as of 'matter'. The answer depends on whether, according to the theory, all direct objects without exception are ideas. If they are, then it is. But why should they be, if Reid is right in thinking that the theory depends upon the principle of cognitive contact? Nothing could be closer to the mind than the mind itself. When Reid is deducing Hume's conclusions with regard to the mind from the theory of ideas, he states the theory in a form that is already Humian:

The received doctrine of ideas is the principle from which it [the opinion that there may be thought 'without a thinking being'] is deduced, and of which indeed it seems to be a just and natural consequence. . . . It is a fundamental principle of the ideal system, that every object of thought must be an impression or an idea-that is, a faint copy of some preceding impression. This is a principle so commonly received, that the author above mentioned, although his whole system is built upon it, never offers the least proof of it. It is 1 . . . we may observe, that all sensations are felt by the mind, such as they really are, and that when we doubt, whether they present themselves as distinct objects, or as mere impressions, the difficulty is not concerning their nature, but concerning their relations and situation'. (Treatise, x. iv. 2, p. 189.)

upon this principle, as a fixed point, that he erects his metaphysical engines to overturn heaven and earth, body and spirit. And, indeed, in my apprehension, it is altogether sufficent for the purpose. ${ }^{I}$

The theory of ideas, even if it is taken as including the proposition that all 'ideas' are derived from corresponding 'impressions', does not provide quite adequate premisses for Hume's dissolution of the mind into its 'perceptions'. We need to know also that there is no impression of their subject, and the absence of this impression is not simply an empirical discovery. The introduction to the introspective experiment which reports nothing but a 'bundle of perceptions' ends axiomatically. 'All these ["our particular perceptions"] are different, and distinguishable, and separable from each other, and may be separately consider'd, and may exist separately, and have no need of anything to support their existence.'2

With this axiom securing the appeal to introspection from any inconclusiveness, Hume defeats the 'metaphysician's' claim that the mind is something simple at any time and numerically identical through time, and his own patient and subtle attempt to find an alternative unity for it. He has to leave its fragments heaped together and 'plead the privilege of a sceptic'. 'Three laws of association', Reid says, 'joined to a few original feelings' constitute the mind when Hume is its creator. 'Is this the man that Nature made? . . . A puppet. . . . It shows tolerably by candle light; but, brought into clear day, and taken to pieces, it will appear to be a man made with mortar and a trowel.'4

Many of Hume's 'peculiar tenets', Reid remarks casually, are built upon the 'maxim' that whatever we can conceive is possible. The maxim seems to Reid 'a necessary consequence of the received doctrine of ideas'-since every idea copies an impression, there can be no idea of something impossible-and to have the general sanction of philosophers. Some philosophers hold also that whatever we cannot conceive is impossible. If they are not mistaken, we have 'a short road to the determination of every question about the possibility or impossibility of things. We need only look into our breast, and that, like the Urim and Thummim, will give an infallible answer. If we can conceive the thing, it is possible; if not, it is impossible. And,

Inquiry, n. vi; Works, i. 108-9.

Ibid., Appendix, p. 636 .
2 Treatise, r. iv. 6, p. 252.

4 Inquiry, I. vi; Works, i. so3. 
surely, every man may know whether he can conceive what is affirmed or not.'

Reid can think of no plausible meaning for the maxim, even in its narrower extent, in which it is not false. 'Whatever is said to be possible or impossible, is expressed by a proposition.' What is it to conceive a proposition? Is it something more than understanding it? By the 'simple apprehension' or 'conception' of a proposition there does not seem to be anything more that could be meant. Take, then, a true proposition and one stating an impossibility, a demonstrated conclusion in geometry, for example, and its contradictory. The second is as easily understood as the first. Every necessarily true proposition has a contradictory which is impossible, and the that conceives one conceives both'. Every reductio ad absurdum requires us 'to conceive things that are impossible, in order to prove them to be so'.

The maxim perhaps affirms that nothing we conceive, that is judge, to be possible is impossible. Have people never thought something to be possible and been mistaken? Men have 'contradictory judgments about what is possible or impossible, as well as about other things'. ${ }^{1}$

Reid does not trace a connexion between the maxim of possibility and any of Hume's conclusions, nor its operation in one of Hume's most fundamental principles, that whatever is distinguishable is separable in thought, and whatever is separable in thought could be separate in existence. The proposition comes briefly under Reid's scrutiny during his discussion of abstract ideas. Things

inseparable in their nature may be distinguished in our conception. And we need go no farther to be convinced of this, than the instance here brought to prove the contrary. ${ }^{2}$ The precise length of a line, [Hume asserts] is not distinguishable from the line. When I say, This is a line, I say and mean one thing. When I say, It is a line of three inches, I say and mean another thing. If this be not to distinguish the precise length of the line from the line, I know not what it is to distinguish. ${ }^{3}$

Too intent on deducing Hume's conclusions from the theory of ideas as a theory of cognitive mediation and conceptual

Intellectual Powers, rv. iii; Works, i. 377-9.

Treatise, I. i. 7, pp. I8-19.

3 Intellectual Powers, v. vi; Works, i. 4 Io. limitation, Reid failed to notice where they largely came from. He was looking at a proposition which, by turning 'connexions' into 'conjunctions', required, for example, the negative side of Hume's doctrines of the mind and of causation.

Reid would have spoken with some care of the damage done to the notion of causation. In one way, of course, the proposition is deadly: nothing can owe its existence to anything else, if everything is entirely loose and separate from everything else. And it is part of common-sense belief that everything that happens has a cause which brings it into existence, makes it happen. On the other hand, Reid agrees with Hume that we know nothing of the causal transactions between bodies beyond the regular antecedence and consequence of events. But he will not allow that it follows that the future is locked up against us, that we must say to ourselves: mere regularity cannot be depended upon to continue. We are not ignorant of the manner in which nature will behave, though we are unable to give any reasons to justify our knowledge. The inductive principle, as Reid proposes to call it, never getting it to more precision than the 'anticipation', the 'prescience', 'that there is a fixed and steady course of nature' is an 'original principle of human nature'. ${ }^{1}$

Hume's atomism supplies him with a premiss for the denial of substantival being to the mind. Reid treats Hume's atomism as a consequence of this denial. ${ }^{2}$ And though he criticizes features of Locke's atomism, he draws no Humian consequences from it which do not follow from the existence of ideas as mediate objects of perception. He makes no comment on the connexion between the primitive simplicity of ideas and the fragmentation of everything in which he saw the theory of ideas ending.

I Inquiry, vi. xxiv; Works, i. 199. Reid, in Priestley's opinion, is always multiplying principles when as a philosopher he ought to be engaged in reducing their number. There is no necessity for this mysterious prescience which he is appealing to under the name of the 'inductive principle'. Our knowledge of the uniformity of nature is a matter of straightforward experience: 'What is now time past, was once future'; and though 'no man has had experience of what is future, every man has had experience of what was future' (Examination, p. 85). George Campbell's answer to Priestley may be taken as the answer of Reid's school to empirical justifications of our belief that we can know the future from the past: The question is not about 'what was future', but about 'what is future'; and to infer from anything in the past that the future will be like the past, needs the conclusion for a premiss. (The Philosophy of Rhetoric, Ist ed., London and Edinburgh, 1776, i. 184.)

2 Inquiry, I. vi; Intellectual Powers, Ir. xii. 
As Reid understood him, Locke held that the first act of the mind is the 'simple apprehension' of simple ideas. Locke was doubly mistaken. Simple apprehension is less complex than judgement and comes after it in the order of nature. The

ideal system ... teaches us that the first operation of the mind about its ideas, is simple apprehension - that is, the bare conception of a thing without any belief about it: and that, after we have got simple apprehensions, by comparing them together, we preceive agnzements or disagreements between them; and that this perception of the agreement or disagreement of ideas, is all that we call belief, judgment or knowledge. Now, this appears to me to be all fiction, without any foundation in nature; for it is acknowledged by all, that sensation must go before memory and imagination; and hence it necessarily follows, that apprehension, accompanied with belief and knowledge, must go before simple apprehension, ${ }^{\mathrm{I}}$ at least in the matters we are now speaking of. So that here, instead of saying that the belief or knowledge is got by putting together and comparing the simple apprehensions, we ought rather to say that the simple apprehension is performed by resolving and analysing a natural and original judgment. ${ }^{2}$

Nor do we begin with simple qualities and build up complex objects out of them. As we realize when we reflect on experience, we begin with what is complex and reach what is simple by analytic abstraction. 'Nature presents no object to the senses, or to consciousness, that is not complex.' And if we had only our senses and not the 'superior powers of understanding, by which we can analyse the complex object, abstract every particular attribute from the rest, and form a distinct conception of it', every object in our experience would be the 'confused' totality it probably is to the lower animals. 'So that it is not by the senses immediately, but rather by the powers of analysing and abstraction, that we get the most simple and the most distinct notions even of the objects of sense.' ${ }^{3}$ It is 'so far from the truth, that all our simple ideas are got immediately, either from sensation or from consciousness, that no simple idea is got by either, without the co-operation of other powers. The objects of sense, of memory, and of consciousness, are not ideas but individuals;

We shall be considering in Chapter V Reid's account of the 'original' belief or judgement which results from the operation of sensations as 'natural signs'.

${ }^{2}$ Inquiry, II. iv; Works, i. 106-7.

${ }^{3}$ Intellectual Powers, Iv. iii; Works, i. 376 . they must be analysed by the understanding into their simple ingredients, before we can have simple ideas.' 1 And when we have them, we do not have the ideas of which Locke spoke; no objects have entered the mind. To have an idea of anything is merely to think of it.

Intellectual Powers, v. v; Works, i. 404. 


\section{I}

\section{GOMMON SENSE (I)}

I. PLAIN TRUTH AND STRANGE DOUBT

$\mathrm{T}$ $O$ ask whether the convictions of common sense are true is to ask a disreputable question. A philosopher who had any appreciation of what would make him look foolish, would carefully avoid it in the company of plain men if there was any risk that he might be taken seriously. And the question is hardly to be asked any longer in the company of philosophers. James Oswald's prophetic eye foresaw the day when even among them common sense would overwhelm scepticism and incredulity. However, let us bring ourselves to ask it and ask it concretely.

Do I know, for example, that I am sitting on a chair with a table in front of me? Do I know that I am the same person as I was yesterday; that what I am doing now I am doing of my own free will? Do I know that there are other people besides myself with their own thoughts and feelings? Do I know that this day will end and that another day will come? Of course I know all this and much more of the same sort, and I know that other people have the same sort of knowledge about things, about themselves, and about other people. I know, therefore, that there are material objects, that there is personal identity and free will, that there are other minds and valid inductions. And the man who denies or doubts such plain truths of common sense must be 'disordered in his intellectuals', Oswald says; must be 'out of his senses', Beattie says; needs for a cure not logic and metaphysics, Reid says, but 'physic and good regimen'. The contradictory of a common-sense belief, they all agree is 'absurd' and is properly met not with argument but with laughter.

It is a matter of philosophical importance to Reid that there is a place for ridicule in defending common sense and only a

' After Moore, 'A Defence of Common Sense', Contemporary British Philosophy (2nd series), ed. J. H. Muirhead (London, 1925), pp. 193-6. limited place for argument. Opinions which 'contradict first principles, are distinguished from other errors, by this:-That they are not only false but absurd.'I To have absurd opposites is one of the criteria which distinguish common-sense beliefs from inveterate prejudices. And apart from the fact that the absurd is the absurd and any argument against it too late once it has been reached, argument aimed at establishing the truths of common sense and not merely at breaking up objections to them would require, Reid 'maintains, premisses more obviously true than the truths of common sense, and there are none.

They are too obviously true-how could anyone deny or even doubt them? What philosopher in fact ever has? Who was it, for instance, that Moore refuted when, with a more sophisticated simplicity even than Reid's, he proved the existence of material things by holding up his hands?2

To question whether any philosophers have ever really set themselves up against common sense would, in the eyes of the Common Sense philosophers, be nearly as perverse as to set oneself up against common sense. There have surely been men professing an absolute scepticism, claiming to know nothing at all-Pyrrho who lived to be ninety led around by a keeper. ${ }^{3}$ And, Beattie and Oswald would ask without the slightest hesitation, is not the denial that there are material things just what constitutes any phenomenalism, the denial of other minds a feature of a sufficiently radical positivism, the denial of personal identity the negative side of every serialist view of the self, the denial of free will the meaning of determinism, and the denial of inductive validity Hume's special discovery? The questions are not too naïve to have come from Reid and Stewart also.

The total sceptic's scepticism was surely a pretence-Pyrrho 'forgot his principles on some occasions'. If it was not a pretence he was mad. And if there was a man who really believed that

Intellectual Powers, vi. iv; Works, i. 438.

2 We might have thought that the refutation was meant for phenomenalists of one sort or another. But Moore explains that it was directed against the philosophers who have "used "material thing" in such a sense that from "There are no material things" there does follow "There are no human hands"'. ('A Reply to my Critics', The Philosophy of G. E. Moore, ed. P. A. Schilpp, Evanston and Chicago, 1942, p. 670.) ${ }^{3}$ Inquiry, 1. v; Works, i. I02. 
there were no tables and chairs, or who was absolutely convinced that he was another person every other minute, or who never spoke to anyone else because he was certain that there was no one else to speak to ... he would be mad. The Common Sense philosophers cannot bring themselves to say simply that is what the paradoxical philosophers are. They do not adopt that reassuring explanation of philosophers' extraordinary doubts and denials of the plain truths of common sense; in spite of the therapeutic recommendation, in spite of the comparison of the man who doubts his own existence until a Cartesian demonstration of it is provided with the man who is afraid that he might be made of glass, and in spite of the most deliberate of Reid's explanations of what he means by 'common sense'.

This inward light or sense is given by heaven to different persons in different degrees. There is a certain degree of it which is necessary to our being subjects of law and government, capable of managing our own affairs, and answerable for our conduct towards others: this is called common sense, because it is common to all men with whom we can transact business, or call to account for their conduct.

The laws of all civilised nations distinguish those who have this gift of heaven, from those who have it not.... It is easily discerned by its effects in men's actions, in their speeches, and even in their looks; and when it is made a question whether a man has this natural gift or not, a judge or a jury, upon a short conversation with him, can, for the most part, determine the question with great assurance. ${ }^{I}$ "

Beattie and Oswald, although they attributed to philosophers many opinions which no sane man could hold, at least did not muddle the senses of 'common sense' as disastrously as Reid when they came to say what they meant by it. ${ }^{2}$ Reid's definition would leave him with no work at all to do. He would have no philosophical opponents in his defence of common-sense truthexcept those who would tell him that he had none-if the only attacks on common-sense truth were from people without common sense as he has defined it.

The most extravagant philosophical paradox, however, does not prevent its advocates from behaving like other men. All the

I Intellectual Powers, vi. ii; Works, i. 422.

2. Stewart's opinions on the meaning of 'common sense' will be given in the next chapter.
Common Sense philosophers see this and they would all like to give the same explanation. Beattie and Oswald sometimes say that the philosophers did not believe their doctrines sincerely enough to act on them.' The paradoxical opinions are not believed in practice, Stewart thinks. ${ }^{2}$ And Reid agrees; they have to be given up in practice. If Hume's friends had suspected that even in solitude he tried to put into practice the principles which he confessed he could hold in society, they would have had the charity never to have left him alone. ${ }^{3}$

The explanation would take all urgency out of the defence of common sense, and the Common Sense philosophers thought its defence a matter of great urgency. They were arguing with men who were quite sane and whose opinions were not held in makebelief. They found this situation inexplicable, and a fundamental criticism of the philosophy of Common Sense would begin with the fact that they did so. An examination of this criticism will occupy us in one way or another throughout the present chapter.

Philosophers, the Common Sense philosophers would be told, have never disbelieved or even doubted the plain truths of common sense, whatever they might have said. The phenomenalist is not doubting the existence of tables and chairs. The positivist does not think that other people are untenanted bodies. No one who holds a serialist view of the self believes that he is continually going out of existence and being replaced by someone with the same name and a similar body. Determinism does not take away the difference between having to do something and doing it of your own free will. Hume had no need to be relieved every time he woke up and found that daylight had come again. If philosophers have said that there were no material objects, \&c. (or that perhaps there were none), they did not mean what they seem to have meant. When they have said things that seem to have implied these denials or doubts nothing that they have said really implied them, at least they never intended the implication. So there is no need to suppose that they only half believed their paradoxes (in theory but not

\footnotetext{
Beattie, Essay on Truth, 1. ii. 8, p. 134; Oswald, An Appeal to Common Sense, i. 96 .

Elements, ir. i. 2; Works, iii. 49.

3 Inquiry, 1. v; Works, i. I02.
} 
in practice), or believed them only while philosophizing and the rest of the time with the rest of the world (Hume in solitude and in society). They were not engaged in an impossible conflict with common sense. To think that they were is to misunderstand either them or it. And this criticism of Reid and his school would continue: in fact the Common Sense philosophers misunderstood both. Beattie and Oswald steadily misunderstood the nature of the theories they attacked; Reid and Stewart intermittently. They all misunderstood the nature of common sense. And misunderstanding it, they could not see why they were right in claiming final authority for it. The argument from the paradigm case would show why.

Crudely: if there is any word the meaning of which can be taught by reference to paradigm cases, then no argument whatever could ever prove that there are no cases whatever of whatever it is. Thus, since the meaning of 'of his own freewill' can be taught by reference to such paradigm cases as that in which a man, under no social pressure, marries the girl he wants to marry (how else could it be taught?): it cannot be right, on any grounds whatsoever, to say that no one ever acts of his own freewill. For cases such as the paradigm, which must occur if the word is ever to be thus explained (and which certainly do in fact occur), are not in that case specimens which might have been wrongly identified: to the extent that the meaning of the expression is given in terms of them they are, by definition, what 'acting of one's own freewill is'....

To see the power, and the limitations, of the Argument of the Paradigm Case is to realize how much of common sense can, and how much cannot, be defended against philosophical paradoxes by simple appeal to the ordinary use of words; and why. ${ }^{\mathrm{I}}$

If this argument shows why the Common Sense philosophers were right about the absurdity of denying the truths of common sense, it also shows why they were wrong in reading this denial into the language of philosophical paradox. (Or possibly that they were in a stronger position than they realized; what they thought was factual absurdity was a kind of logical nonsense.) And if the truth of the propositions of common sense is to be established in the way the argument prescribes, its further consequence is that in loading them until their truth is no

I A. Flew, 'Philosophy and Language', Essays in Conceptual Analysis, ed. Flew (London, 1956), pp. 19-20. The limitation of the argument is that by itself it cannot be used 'to establish any matter of value, moral or otherwise'. longer given with their meaning, the Common Sense philosophers loaded them with an alien content. And with this content their denial is no longer absurd.

Supposing, for the time being, that philosophical propositions can never really collide with the propositions of common sense, they can seem to do so in two ways. They can seem to state or imply that the truth of the propositions of common sense cannot be known for certain. They can seem to state or imply that some or all of the propositions of common sense are false, or meaningless, or radically confused and are to be rejected altogether. We shall now look at the first of these apparent conflicts. Gommon sense takes common-sense beliefs as certain, will not allow the possibility that they are mistaken, repudiates, for example, the statement that there may be no material things as decisively as the statement that there are no material things. The philosophical positions with which we are here concerned appear to represent no matter of fact belief as certain, or more extremely no belief as certain, or more extremely no belief as more probable than any other. We are not at present concerned with the certainty or otherwise of common-sense beliefs outside this general context of doubt.

Reid and Stewart can see why one might want to hold that some philosophical assertions, which seem to conflict with the claim to certainty which common sense makes for its beliefs, only seem to. The statement that there is no knowledge of matters of fact takes common-sense truth into its orbit. Reid does not like restrictions on the use of the word 'knowledge' which would allow it only a fraction of its usual application, ${ }^{\mathrm{I}}$ but he does not find anything disturbing in the statement or in its familiar equivalent that matters of fact are matters of probable opinion. In either variant it is a logician's classificatory marking, not a matter of fact proposition: 'knowledge' is kept for knowledge with demonstration behind it and for its axiomatic premisses; the word 'probable' is given a technical sense different from its ordinary sense.

In common language, probable evidence is considered as an inferior degree of evidence, and is opposed to certainty: so that what is certain is more than probable, and what is only probable is not certain. Philosophers consider probable evidence, not as a degree,

$$
\text { I Intellectual Powers, vi. iii; Works, i. } 426 .
$$


but as a species of evidence, which is opposed, not to certainty, but to another species of evidence, called demonstration. . . . That there is such a city as Rome, I am as certain as of any proposition in Euclid; but the evidence is not demonstrative, but of that kind which philosophers call probable. Yet, in common language, it would sound oddly to say, it is probable there is such a city as Rome, because it would imply some degree of doubt or uncertainty. ${ }^{1}$

Stewart agrees with Reid that the statement that no matters of fact are more than probable is a logician's statement and does not have the meaning it would have in ordinary speech.

As certain as death-as certain as the rising of the sun-are proverbial modes of expression in all countries; and they are, both of them, borrowed from events which, in philosophical language, are only probable or contingent. In like manner, the existence of the city of Pekin, and the reality of Caesar's assassination, which the philosopher classes with probabilities, because they rest solely upon the evidence of testimony, are universally classed with certainties by the rest of mankind; and in any case but the statement of a logical theory, the application to such truths of the word probable would be justly regarded as an impropriety of speech. ${ }^{2}$

Stewart, however, is more concerned than Reid over the ambiguity of the word 'probable'. It has caused some philosophers to mistake certainties for mere probabilities, and to look for demonstrations to convert them into what they already are.

This difference between the technical meaning of the word probability, as employed by logicians, and the notion usually attached to it in the business of life, together with ... erroneous theories concerning the nature of demonstration ${ }^{3} \ldots$ have led many authors of the highest name, in some of the most important arguments which can employ human reason, to overlook that irresistible evidence which was placed before their eyes, in search of another mode of proof altogether unattainable in moral inquiries, and which, if it could be attained, would not be less liable to the cavils of sceptics. ${ }^{4}$

Reid would have accepted the self-evident truth that it is

I Intellectual Powers, vir. iii; Works, i. 482.

2 Elements, iI. ii. 4 ; Works, iii. 180 .

3 Stewart's view is that strict demonstration, as in mathematics, has 'hypothetical' or suppositional premisses, and the 'truth' of its conclusions is no more than the fact that they necessarily follow from their premisses. (Elements, Ir. ii. 3.)

4 Ibid., II. ii. 4; Works, iii. 180-1. always logically possible that we are mistaken in a matter of fact judgement. He would not have allowed that it is always possible that we are mistaken. There are matters of fact as certain as any truth in Euclid.' (There are some matters of fact, Beattie remarks, with regard to which we know that if we knew everything, we would not have to change our opinions about them..$^{2}$ ) We know that the thing we have sat on, bumped into, moved up to the table, will not surprisingly turn out to have been an hallucinatory chair. We would refuse to believe anybody who said he thought he might be dreaming that he was awake. To use one of Reid's examples: it is more than probable, quite certain, that Charles I died on the scaffold. There is a stage in the verification of a proposition after which we have, so to speak, a clairvoyant anticipation of the results of further verifications, after which, Reid says, 'to desire more evidence would be absurd'. ${ }^{3}$

Hume argued that no judgement we ever make can be more than probable, and that only temporarily. Its evidence has always two determinants, one 'deriv'd from the nature of the object' and the other 'from the nature of the understanding', and the second always subtracts from the first. No matter what the grounds for a judgement appear to be, we must always allow something for the possibility that we are making a mistake. Beginning with less than certainty, we end without even probability, for the subtractions must go on. The reliability of the 'faculty which judges' has to be assessed, and we might be making a mistake. The assessment has to be assessed, and we might be making a mistake. By 'all the rules of logic' the confidence to which we were originally entitled is whittled down and whittled down, and as it had only a finite value to begin with and the reassessments never end, it ends in nothing. 4

In any case demonstration could not monopolize certainty, because it is never formally demonstrable that the demonstrative operations have been carried out correctly, however absolutely certain it may be that they have been. And the rules of demonstration have themselves been discovered by 'our fallible and uncertain faculties, and have no authority but that of human judgment'. (Intellectual Powers, vir. iv; Works, i. 486.) Reid will not allow any proposition an immunity from human error in virtue of its category. Every proposition has to be put together and understood by someone.

2 Essay on Truth, Ir. i. 3, p. 207,

3 Intellectual Powers, vir. iii; Works, i. 482.

4 Treatise, 1. iv. 1, pp. 182-3. 
We make mistakes and this proves, Reid says, that we can make mistakes. It does nothing to prove that we never know that we are not making a mistake. Our general capacity for error is irrelevant to our being right or wrong in particular cases, except in so far as keeping it in mind makes us rather less likely to go wrong. I am reminded, Reid continues, of the fallibility of human judgement when I claim to have reached a conclusion demonstratively. I go over my reasoning several times and can find no flaw, have it checked by someone else, who can find no flaw, am willing to hear from the sceptic 'what step in it he thinks fallacious, and why. He makes no objection to any part of the demonstration, but pleads my fallibility in judging. I have made the proper allowance for this already, by being open to conviction.'

It is not quite clear from Hume whether the competence of the understanding is to be examined and re-examined with regard to the matter in hand or with regard to other matters; whether we are to watch its performance on the same argument over and over again or try it out on other arguments. Reid takes it for granted that if you want to find out whether you have made a mistake in $A$, you work at $A$ again; you do not turn to $B$ and then to the rest of the alphabet. And to come to the same conclusion a second and third time is a good reason for thinking that you came to the right conclusion the first time, and consequently for thinking that the understanding is capable of truth. What more does anyone want who wants assurances of what Hume calls the 'truth and fidelity' of our faculties?

I might, of course, Reid says, have grounds for being suspicious of my former proceeding. I might have been in a hurry or excited or too interested in getting a particular result. I have to go back over the argument again, coolly, slowly, and with the opposite interest. It is

evident that this review of the subject may confirm my first judgment, notwithstanding the suspicious circumstances that attended it. Though the judge was biassed or corrupted, it does not follow that the sentence was unjust. The rectitude of the decision does not depend upon the character of the judge, but upon the nature of the case. From that only, it must be determined whether the decision be just.

\footnotetext{
Intellectual Powers, vir. iv; Works, i. 487.
}

The circumstances that rendered it suspicious are mere presumptions, which have no force against direct evidence. ${ }^{1}$

Our faculties show their capacity for truth by presenting us with it in particular cases. The sceptic is perhaps still dissatisfied: how do we know that anything which we regard as truth is more than the illusion of truth? We know it, but if proof is required there is none available, Reid says. No demonstration of the truth and fidelity of our faculties is possible if their presenting us with truth in particular cases is not to count. The attempt at demonstration would be like taking a suspected liar's word that he is honest. For the same reason no reason can be given for suspecting them. No argument can be advanced for or against them until we have new faculties to sit in judgement on the old. In the meantime we are not left with a choice as to whether or not we shall rely on the ones we have. As a brief intellectual feat we can hold ourselves in sceptical suspense towards them, and a man can stand on his hands for a minute or so but he cannot go a journey on them-it is against nature. Stop admiring him and he will soon be found walking on his feet like other men. ' $W$ ho ever has taken the pains to refute the cavils of this total scepticism, has really disputed without an antagonist.'3

Hume and Reid disagree about the validity of an argument for total scepticism, but they both agree that nobody could really believe what the argument would prove even if it were valid. How nearly the difference between common sense and scepticism over these issues of doubt and certainty is a matter of what one chooses to say about the same empirical facts. What Hume chooses to say-scepticism imposes too great a strain on the imagination-leaves the feeling that scepticism has the last word. ('If we believe, that fire warms, or water refreshes, 'tis . only because it costs us too much pains to think otherwise.') The difference between common sense and scepticism is a difference in the way of looking at the same empirical facts. For scepticism there is no right way, or, if there is, nobody knows what it is. For common sense there is a right way and we know what it is, and therefore right and wrong words to express

\footnotetext{
Ibid., vir. iv; Works, i. $4^{87}$.
}

2 Ibid., vi. v; Works, i. $44^{8}$. 
it, or at least a right and wrong intonation when the words of the sceptical philosopher and a philosopher defending common sense are the same, when both say, for example, that nature leaves us no choice.

Reid saw that the sceptical language of philosophers is not always to be taken at its face value. Words such as 'merely probable', even the word 'doubtful', are perhaps being used with meanings different from the meanings they have in common language. If the philosopher, unwilling to have his scepticism peaceably withdrawn from him, replies that by 'doubtful' he does mean what everybody means by it, that he is willing to use any of its ordinary synonyms, then for Reid the sceptical assertions are false and need some refutation: they show their falsity in particular instances, the sceptic does not believe them himself, cannot act on them. Reid, however, could hardly have objected to hearing from modern critics of the sceptical language of philosophers that there was nothing to be refuted, that no meaning had been given to the word 'doubtful'. What would the sceptic count as certain? He does not know. What sort of evidence would remove the doubt? No evidence would remove the doubt. A 'doubt' which is not contrasted with any certainty, and which no imaginable evidence would remove, is not a doubt. The empty shell of the word is in the sceptic's speech. His behaviour shows that he does not believe his assertions; as they say nothing, there is nothing in them to believe. The illusion of a conflict here between a philosophical assertion and common sense is cast by the illusion of an assertion, in which the key words seem to have a meaning because they had a meaning in the familiar contexts from which they were borrowed.

We have now to consider whether philosophical propositions can be taken at their face value when they seem to be stating or implying that any of the propositions of common sense are false or meaningless or radically confused. If common-sense truths can be established by paradigmatic cases, it is a fairly clear consequence that, however these paradoxical propositions are to be understood, they are not to be understood as repudiating common sense. When, for example, philosophers have said, or have said things which seem to imply, that there are no material objects but only ideas, sensations, perceptions, no permanent self but only the flux of experience, we have missed their point if we think they are denying what everybody knows to be true. They are rejecting a metaphysics in which common sense has no interest, or perhaps putting forward a metaphysics in which common sense has no interest. Or they are giving 'analyses' of the notions of material object and self-identity. (How readily a philosopher who might have said that there are no material objects, only clusters of sensations, would change his statement into 'There are material objects and they are clusters of sensations'.) Or again, the language of common sense is perhaps being criticized; no one is proposing alternative beliefs to the beliefs of common sense.

Were the Common Sense philosophers then defending the beliefs of common sense against imaginary menaces? On some of these interpretations of the nature of philosophical paradox, the collision between common sense and philosophical paradox appears to be purely linguistic. Is it purely linguistic on these interpretations, and purely linguistic on the other interpretations also? Phenomenalists, positivists, and determinists have often expressed their views in language intolerable to common sense. Is it only the language that is intolerable to common sense, while it is neutral towards the views themselves, since it has no metaphysical commitments? Provided the paradoxical philosopher does not say such things as that there are no material objects (and does not use words such as 'idea' in a way that makes it sound as if he were saying them), can he mean what he meant when he did say them and face no protest from cornmon sense?

Philosophers nowadays have learnt so thoroughly to 'speak with the vulgar while they think with the learned' that none of them of any sophistication, whatever their views, would deny, for example, that material objects exist, that there are other minds besides their own, that we have free will, or allow anyone to put these constructions on their words, any more than they would say that they were taking away the distinction between right and wrong, whatever their account of 'right' and 'wrong'. That mode of speech belongs to a bygone innocence. Hume's views have not changed, but his language, whenever there is the risk of an affront to common sense, is now the same as Reid's. 


\section{THE METAPHYSIGAL GOMMITMENT OF}

COMMON SENSE

The Common Sense philosophers would have thought that their occupation had gone if it could have been shown to them that the truth of common-sense beliefs does not come into philosophical dispute. Moore attempts to show this by shifting the place of dispute over common-sense beliefs from their truth to their analysis.

'The earth has existed for many years past.' This is certainly true, Moore says, and its analysis quite uncertain. And true in the ordinary meaning its words have, as it would be naturally understood. One hesitates to ask for the meaning of the statement when its words have their ordinary meaning. 'Such an expression as "The earth has existed for many years past" is the very type of an unambiguous expression, the meaning of which we all understand.'I If we do ask, we can be answered simply. We can be told the same thing over again in the same words or the same thing over again in different words. But once talk has begun about unanalysed and analysed meanings here, and the uncertainty of the second has been reflected back on the first, the time for that answer seems to have passed. Once we have reflected that the statement has to be true whichever of its analyses is true, and once we have turned over in our minds some of its possible analyses, the doubt as to the meaning the statement must have in order to satisfy this condition is not one which we can be sent to the dictionary to resolve. What could its ordinary meaning be if its analysed meaning may be what Mill can be taken as saying it is, or what the most naive realist says it is, or if it may be anything between these two extremes? For all these proposals must be reckoned as analytic possibilities if the proposers are not to be represented as doubting or denying a fact which common sense unhesitatingly accepts.

Construed in one way the statement is true beyond dispute, and that is if it is taken as asserting what has been observed, and what could have been observed (if there had been observers where no one was). In so far as it is verifiable, this is as far as it is verifiable. And one might have supposed that this was its preanalytic meaning, the sense Moore was referring to in which

$$
1 \text { 'A Defence of Common Sense', p. } 198 .
$$

everyone would naturally understand it (and in which its truth could be empirically established for anyone who happened to doubt it). And why should anyone not understand it to be asserting simply this? Nothing, it might be said, is left out; for what has been observed is the earth-parts of it-and what could have been observed is the earth-the whole of it. With this meaning, however, as all it means, with nothing but a conditional filling for the blanks in the earth's observed existence, all analyses except those of one type are initially proscribed, and Moore wants to keep the range of possible analyses wide open.

So again, what is the statement asserting, when it is asserting something so obviously true that all philosophical dispute is shifted from its truth to its analysis, and yet something which is open to such radically opposed types of analysis? Let us for simplicity concentrate on the verb without paying any special attention to the particularity of the subject, and since the earth has not been always all of it continuously observed, let us treat the problem as one of providing for different types of analysis of a statement asserting the existence of a material thing at times when it has not been perceived. We want a sense of 'existed'-its ordinary sense-which will allow the statement the possibility of either a phenomenalistic or of a non-phenomenalistic type of analysis, the correct analysis to be synonymous in meaning with the unanalysed statement. ${ }^{1}$ And the sense one naturally thinks of as the ordinary sense of the word does not have the necessary plasticity. In the ordinary sense of the word, something which does not exist except as a set of possibilities of sensation, does not exist. Understanding 'existed' in this ordinary sense, one would not naturally understand 'The earth has existed for many years past' to be an assertion as to what has been observed, and what could have been observed if observers who were absent had been present. It is a statement with some sort of implication to this effect, but not this sort of statement.

Even supposing, however, that the required sense is to be found and that one has somehow missed it because of its very

I '. . any expression which expresses the analysandum must be synonymous with any expression which expresses the analysans'. This, Moore explains, is a condition of 'analysis', as he has understood it. ('A Reply to My Critics', p. 663.) 
ordinariness, all philosophical dispute would not be shifted from the truth of the statement to the correctness of its analysis. Because if the unanalysed statement might be synonymous in meaning with a statement giving some analysis of the second type, that is enough. For the phenomenalist ex officio, it might be false.

Many of the philosophers who came to share Moore's conviction that there was no doubt about the truth of the beliefs of common sense have construed them in such a way that there is no doubt about their truth.

The short method for establishing it has been mentioned earlier in this chapter. We learn the common-sense language of knowledge and doubt, of reality and illusion, body and mind, cause and effect, of choice, of morality, by being introduced to situations in which it applies and shown how to apply it. The general truths of common sense are guaranteed by the fact that there is an applicable language of common sense.

'We are apt to imagine that those who formed languages were no metaphysicians', Reid remarks, ${ }^{1}$ and he thinks the supposition greatly mistaken. But how correct it is for the language of common sense if the beliefs of common sense can be established in this way. They would need, however, to lack more than metaphysics for a linguistic demonstration of their truth to be possible. The thinness of their truth with this certification is in proportion to their incorrigibility, their incorrigibility in proportion to the approximation of the descriptive expressions in them to names; since the more descriptive these expressions are, the more they say something about what they refer to, the more they risk being misdescriptions. I cannot ask someone whose name I know to be $\mathcal{N}$, 'Are you really $\mathcal{N}$ or only called " $\mathcal{N}$ " '; his being called ' $\mathcal{N}$ ' is his being $\mathcal{N}$. If it is impossible to doubt, for instance, that there are independently existing material objects, because in order to know the meaning of the expression 'independently existing material object' one has had to be shown its application, then what it is impossible to doubt is that there are things called 'independently existing material objects'.2

If the beliefs of common sense cannot be given a logical

I Intellectual Powers, vi. iv; Works, i. 44I.

2 A. D. Woozley, 'Ordinary Language and Common Sense', Mind, July 1953. justification and retain any real content, they can be empirically established as certain-with the implication that their content is purely empirical. If you are not convinced that it is, you can be given a priori assurances, and perhaps deprived of speech to express your dissatisfaction. 'Presumably what people mean must be confined to what they can mean.'I And what they can mean can be limited by general principles; by Hume's principle of conceptual empiricism, for example, or by the verification principle.

The philosopher who has drawn boundaries for significant speech by allowing it to express only empirical concepts, seems to have his opponent at a severe disadvantage. When you talk, for example, about the existence of unperceived objects, about self-identity, about free will, you have to mean what he means when he talks about them, or mean nothing. But this is now an embarrassment to him, for if your words have a meaning, his words and yours have the same meaning. And as he is afraid of being taken to mean what you do mean, he naturally finds himself saying what cannot be said, explaining what 'unperceived existence' does not mean, opposing a serial to a numerical self-identity and the 'liberty of spontaneity' to the 'liberty of indifference'. 'Positivistic' types of opinion in general are understood by contrast with opposed views.

With his theory of how descriptive words come to have a meaning, Hume ought, as much as Berkeley, to have appeared in the role of a philosopher of common sense, scraping off the incrustations of metaphysical nonsense from the purity of its beliefs. He would have done so if he had not been Hume; the Treatise was intended to shock. And besides, there was too much of Reid in Hume for him to fit comfortably into that role. The result is that when Berkeley and Hume consider their philosophies in relation to common sense, Hume seems oldfashioned compared with Berkeley.

No great changes are necessary in order to bring Hume up to date. All that has to be done is to make him consistent by making a few excisions. What people mean must be confined to what they can mean; what they can mean has been prescribed; the tension between the natural and universal beliefs of man-

I A. E. Duncan-Jones, 'Does Philosophy Analyse Common Sense?', Proc. Arist. Soc., Supp. vol. xvi, p. I 45 . 
kind and 'philosophy' disappears - it depended on Hume's forgetfully allowing men to mean more than they could. Some commonplaces would then be required on the language of impressions and ideas as being the language of analysis, as therefore not in competition with the language of common sense, but a technical vocabulary to be used in its philosophical elucidation. The absurdities which arise from the confusion of the two levels of language would be referred back to their authors. ${ }^{x}$ Hume is no longer a paradoxical opponent of common sense but engaged in its analysis, not denying or questioning the existence of material objects, self-identity, free will, or any of the things that common sense is unshakeably convinced of; on the contrary, taking them for granted in order to say what they are.

The opposition between common-sense statements and philosophical paradoxes is altogether illusory on this interpretation of the nature of philosophical paradox. There seemed to be an opposition of matter of fact statements to matter of fact statements. There is only one set of matter of fact statements, but these are stated in alternative languages; in ordinary language and in a technical language for its elucidation. The illusion of paradox arises when the technical language borrows ordinary words and uses them with new meanings, and they are understood by the reader or hearer in their ordinary meanings. And the illusion will be strengthened if in the course of philosophical elucidation a philosopher happens to reject some metaphysical misinterpretation of a common-sense statement with a verbal denial of a common-sense statement. Free will, for instance, might be denied when what is meant is that indeterminism is false and no part of common-sense belief.

There is another interpretation of the nature of philosophical paradox which should be considered here. On this other interpretation the paradoxes are again really linguistic and apparently factual, but this time really paradoxical. The Common Sense philosophers would have found either interpretation equally disconcerting.

Lord Russell said in effect that whenever anyone sees any-

1 We learn from 'Mr. Hume's philosophy' that 'a succession of ideas and impressions may eat, and drink, and be merry'. (Intellectual Powers, vi. v; Works, $\mathrm{i}$. 444.) thing, what he strictly sees is part of his own brain. ${ }^{\mathrm{I}}$ When Reid encountered an earlier version of this opinion, he rejected it as against common sense and false. It is against common sense and false, Professor Malcolm agrees, but not empirically false.

No, Russell was not making an empirical statement. In the normal sort of circumstances in which a person would ordinarily say that he sees the postman, Russell would agree with him as to what the particular circumstances of the situation were. Russell would not disagree with him about any question of empirical fact; yet Russell would still say that what he really saw was not the postman, but part of his own brain. It appears then that they disagree, not about any empirical facts, but about what language shall be used to describe those facts. Russell was saying that it is really a more correct way of speaking to say that you see a part of your brain, than to say that you see the postman.

And when a philosopher defending common sense replies to Russell that it is the postman we see and not part of our brain, he is to be interpreted, in Malcolm's opinion, as meaning that it is 'correct language' to say it is the postman we see, and quite incorrect to say it is part of our brain. ${ }^{2}$ What makes the one way of speaking correct and the other incorrect is not, for Malcolm, the fact that it is the postman we see and not part of the brain, except in so far as this fact is identical with the fact that the thing in question is always called a 'postman' and never a 'part of the brain'.

Reid did not have to deal with a treatment of philosophical paradox as sophisticated as this, and his only direct contribution to its discussion is his reminder, that it is on the face of it unplausible, that a statement which purports to be about one thing should actually be about something quite different. Unplausible, for instance, that statements which have every appearance of being about the right and wrong of conduct should really be about someone's feelings about conduct. ${ }^{3}$ And that statements which are intended to be factual should instead be linguistic, has a similar initial unplausibility. For it

\footnotetext{
I Outline of Philosophy (London, 1927), ch. xiii.

2 'Moore and Ordinary Language', The Philosophy of G. E. Moore, p. 350.

${ }^{3}$ Active Powers, v. vii; Works, ii. 673.
} 
is presumably not Malcolm's view that a philosopher, in making some paradoxical assertion or other, intends his assertion to be a linguistic one; he does not himself see through its factual disguise. And this can remain impenetrable to him no matter how much he is talked to. If a man says $X$ and someone says to him, 'What you really mean is $Y$ ', and he agrees, then $r$ no doubt is what he really means. But if he keeps insisting that he does not mean $Y$, then $Y$ is not his assertion but one put into his mouth.

Supposing, however, that these apparently factual statements have been rightly construed as linguistic statements, they are more paradoxical than ever. In the sense in which correct language is the standard language we are taught to speak, and in which we correct deviations from it, ${ }^{I}$ no one who had learnt the language could deny that it is correct language to call the thing we always do call a 'postman' a 'postman'.

Why then would the paradoxical philosopher be saying that the ordinary language for describing the objects of perception is incorrect? His reason for saying so is that it incorrectly describes the facts. But since his factual comment has been cancelled, this reason is taken away from him. He is allowed to say that there is something wrong with ordinary language but not allowed to say what is wrong with it.

In the statement that we never see anything but some part of our own brain, ordinary words are run into such an extraordinary combination that no meaning comes through. There are, however, philosophical paradoxes which are worded intelligibly, and which are not linguistic assertions or recommendations, because they are either reasons for these, or because the philosopher is quite satisfied with ordinary language as it is and does not want to change it at all. A man with a phenomenalist doctrine might want to cut the word 'permanent' out of our vocabulary, because he thinks there is nothing for it to apply to. On the other hand, he may claim that there is nothing in the established usage of the word inconsistent with his doctrine. In neither case does the doctrine disappear into a linguistic proposal or assertion.

The question which has to be decided before it can be de-

I '. . we should smile, and correct his language'-the child's, who remarks to people sitting on chairs around the room, that it is 'hichly probable' there are chairs in the room (Malcolm, p. 355). cided whether there are philosophers who reject any of the beliefs of common sense as false, meaningless, or radically confused, is a general question about the content of these beliefs. Have they merely an 'empirical' content or level, or do they also have what, for want of a better word, might be called a 'metaphysical' content or level? (Almost any word would be a better word in Beattie's judgement; a 'metaphysical' opinion is the kind of opinion to be found in Hume.) Is the significance of the language of common sense exhausted when it has been used with reference to what can fall under the senses and (the speaker's) introspection, or does it go beyond this to what these cannot reach?

The common-sense belief in the existence of material things includes a belief in their existence at times when we are not perceiving them. Let us take any statement involving this belief, the statement, for instance, that there is an old seachest in the attic. It specifies what could be seen and handled by anyone going into the attic. Does it say what is there whether anyone goes there or not? It does. Is being in the attic when no one is in the attic, as far as common sense is concerned, being able to be seen and handled by anyone going in to the attic (anyone not blind, sleep-walking ....)? There is some sort of implication between them. If for common sense the implication is one of identity, then the common-sense belief in the existence of material things when they are not perceived is a belief which has merely what we are calling an 'empirical' content. But if for common sense, being there when no one is there is being there, the word stubborn against any hypothetical paraphrase, then the common-sense belief in the existence of material things when they are not perceived includes what we are calling a 'metaphysical' component.

When I speak of other people's joys and griefs, am I alto-

3 Sooner or later speaking indiscriminately of common-sense beliefs is bound to lead to difficulties, and it does so here. For with regard to at least one of these beliefs, the belief that the future can be anticipated from the past, the issue of a single or of a double content does not arise. It does not arise, because of the high level of generality in the belief about the future. Whatever the account we give of, say, the material things of past experience, we shall give the same account of the material things of future experience. But the belief would be a 'metaphysical' belief, in the sense in which 'metaphysical' is here being used, if we are driven back onto having to claim self-evidence for it. 
gether speaking (as I partly am) of their smiles and laughter, their hunched shoulders and wan faces, or also of something quite different and 'metaphysical' which these express? Is all that the ordinary language of personal identity can be used to say said in reference to the continuity of my experience, to my feelings of being the 'same person', to something of this sort when I use it inwardly of myself, and when you use it of me, is its reference merely to my public uniqueness in appearance and character; or does it refer (also) to a 'metaphysical' subject of which there is no 'impression'? It is against common sense to deny that we have free will. Is it against common sense to deny that we have free will in any sense in which it is not verifiably true that we have it?

If there is nothing in the beliefs of common sense which is not verifiably true, if the language of common sense does not go beyond an empirical reference, the paradoxical philosophers of the past were not taking anything away from common sense. Their paradoxes were merely verbal and were designed to protest against their metaphysical opponents' (perhaps meaningless) additions to it, or were occasioned by the misleading language in which the analysis of its statements was conducted. These philosophers only seemed to be against common sense because they did not speak its language; either saying, or sounding as if they were saying, that there are no material things, \&c., but not meaning that there are not, in any sense in which common sense believes that there are. If, however, there is a metaphysical as well as an empirical level to the beliefs of common sense, and if consequently its language has a double reference, philosophers who hold the phenomenalistic or positivistic types of opinion which philosophers once expressed in paradoxical language are really against common sense though they speak its language.

What more is there to common-sense beliefs than their empirically verifiable content? For this question to be answered in any detail, the beliefs would have to be taken one by one. This, however, can be said in general: Just what more may be a matter for philosophical elucidation. ${ }^{x}$ But philosophical eluci-

I Stewart mentions the wordlessness with which ordinary men hold the general beliefs of common sense. They are beliefs taken too much for granted to be explicit. No one but a philosopher would think of stating them to himself or to anyone else. (Elements, II. i. 1; Works, iii. 37.) dation is not needed equally for all these beliefs, and perhaps not at all for some of them. The man who was asked what he meant 'by other people's feelings' would be puzzled to know what was meant by the question. He could be quickly puzzled as to how much was implied in assertions implying his belief in the unperceived existence of material things. When he said, when everyone was downstairs, that there was an old sea-chest in the attic, did he mean that it was there with exactly the same characteristics as it shows to the senses? If so, he is soon hesitating. Or perhaps he is already acquainted with the philosophers or the popular physicists, and is sure that he did not mean anything so simple. What did he mean? Will he settle for the primary qualities without the secondary, or for atoms and electrons? Where does common sense say a final No to the whittling down of unperceived material things from their condition when they are perceived-if not from the start? And if from the start, at least one of its beliefs is more fragile than the Common Sense philosophers will allow any of its beliefs to be.

But this indeterminateness is not present in all commonsense beliefs, and when it is present it may not be in their metaphysical aspect. The metaphysical notion of the self as a single, individual thing (no one of its experiences and a different one at different times, no construction out of its experiences, nor the series of them, but in the traditional language of metaphysicians, their 'subject') is a notion definite enough, however unsatisfactory it might be in other ways. The difficulty is to explain the notion of personal identity without reference to it.

'Who can doubt whether men have universally believed the existence of a material world ... that every change that happens in nature must have a cause . . . that there is a right and a wrong in human conduct?'I Nobody. And because all philosophers would give Reid's answer to his question, his question as it stands is too naive to have any philosophical point. Reid asked, however, though only half-realizing it, a question about beliefs with a metaphysical content, and got an answer about beliefs with a merely empirical content. Because the Common Sense philosophers only half-realized that there were the two I Intellectual Powers, vi. iv; Works, i. 440. 
levels in common-sense beliefs, they mistook the doubts and denials of their truth at the metaphysical level for doubts and denials of their truth at the empirical level. But because they half-realized it, they could not quite bring themselves to dismiss these questionings and rejections as intellectual makebelief or insane delusion. ${ }^{1}$

A philosopher denies that there are unperceived tables and chairs, defines the mental life of other people in terms of their actual and hypothetical behaviour, thinks with Hume that he himself is a 'collection of different perceptions, which succeed each other with an inconceivable rapidity'... Y You may call his position 'metaphysical lunacy', as Reid does, ${ }^{2}$ but it would be polemically much more satisfactory if it could have been shown to be ordinary lunacy. And this it would have been if he had denied truths of common sense at their empirical level; if, for example, every time he was shown a chair he was convinced that there was nothing there at all or anything but a chair, if he was inconsolable because all his possessions ceased to exist as soon as his back was turned; if, again, he was convinced that it did not matter what happened to other people because other people have no feelings; if he was sure that he was no more the same person in the morning and in the evening than (as Beattie thinks Hume might as well have said) 'Nero is the Man of Ross'. Accepting the beliefs of common sense at their empirical level, the philosopher will behave like other men, and without any inconsistency between theory and practice.

The Common Sense philosophers are always saying that one of the features which stamps a belief as a belief of common sense and stamps it with the mark of inescapable truth, is the fact that 'even those who reject it in speculation, find themselves under a necessity of being governed by it in their practice' ${ }^{3}$ An un-

1 Reid's and Stewart's misunderstanding was intermittent-Beattie's and Oswald's rarely falters. The following is typically Beattie and Oswald: 'That we cannot do some things, but have it in our power to do others, is what no man in his senses will hesitate to affirm. I can take up my staff from the ground, but I cannot lift a stone of a thousand weight. ... When a man asks me question, I have it in my power to answer or be silent, to answer softly or roughly, in terms of respect or in terms of contempt. Frequent temptations to vice fall in my way; I may yield or I may resist. ... But this idea [of power] has had the misfortune to come under the examination of Mr. Hume.' (Beattie, II. ii: 3, pp. 294-5.)

2 Inquiry, v. vii; Works, i. 127.

3 Intellectual Powers, vi. v; Works, i. 447. fortunate criterion. Reid and his school are in fact opposing a metaphysically loaded common sense to phenomenalistic and positivistic types of opinion, and to a version of common sense that would fit in with them. Half in the dark as to what they are doing, they adopt something which it is hard to distinguish from the positivistic criterion of meaning and truth as their criterion of the meaning and truth of the propositions of common sense. It is (by definition) empirical beliefs which 'practice' can verify. We shall, indeed, never open the door quickly enough to catch tables and chairs snapping back into existence, or alternatively waiting for us with a continuous duration-a phenomenalistic metaphysics is no more empirical than its contraries. And positivistic opinions are not often metaphysically agnostic; they go beyond the empirical into metaphysical denials. The Common Sense philosophers have to reckon with what is more formidable than either. They have to reckon with an interpretation of the beliefs of common sense which makes them consistent with either, an interpretation of them as altogether metaphysically neutral, not going beyond the empirical in any direction.

The beliefs of common sense, Reid, says, are reflected in the structure of language, in its universal grammar. It is usually taken for granted that any opinion, whether true or false, can be expressed equally well in any language which has sufficient words for the purpose. There is a most important exception to this general rule. 'There are certain common opinions of mankind, upon which the structure and grammar of all languages are founded.' All languages are recalcitrant to the expression of opinions which are at variance with these common opinions. ${ }^{1}$

Language is the express image and picture of human thoughts; and from the picture we may draw some certain conclusions concerning the original.

We find in all languages the same parts of speech; we find nouns, substantive and adjective; verbs, active and passive, in their various tenses, numbers, and moods. Some rules of syntax are the same in all languages.

Now, what is common in the structure of languages, indicates an
I Ibid., I. i; Works, i. 228-9 
uniformity of opinion in those things upon which that structure is grounded.

The distinction between substances, and the qualities belonging to them; between thought and the being that thinks; between thought and the objects of thought; is to be found in the structure of all languages. And, therefore, systems of philosophy, which abolish those distinctions, wage war with the common sense of mankind."

It is not to the ordinary use of ordinary words that Reid is going for philosophical illumination here, and elsewhere when he speaks in the same way; it is to supposedly common features of the grammar of all languages. 'The philosophy of grammar, and that of the human understanding, are more nearly allied than is commonly imagined.'2 The metaphysical doctrines of causation ('verbs, active and passive'), of substance and its modifications, and of the independence of the objects of cognition from cognition are in front of anyone who knows how to parse. Reid is not always so naïve. 'We can only expect, in the structure of languages, those distinctions which all mankind in the common business of life have occasion to make.' 3

Beattie also wrote on universal grammar, but without looking for the confirmation of the metaphysical beliefs of common sense. We might compare, for instance, his opinion of the import of substantives with Reid's. There must be substantives. 'Men could not speak of one another, or of anything else, without Substantives.' A substantive is

a word denoting a substance; or more properly, is a word denoting the thing spoken of. Now the things we speak of either have a real existence, as man, tree, house, hatchet; or have had a real existence, as Babylon, Eden, Gesar; or are spoken of as if they had existed, or did exist, as Jupiter, Fairy, Lilliput; or are conceived by the mind as having at least the capacity of being characterized by qualities, as virtue, beauty, motion, swiftness.

Thus the structure of language allows us to speak of a quality as a 'thing' and, since abstract nouns can take adjectives, as a thing that may be characterized by other qualities. And this, Beattie remarks, is very nearly the 'description of a substance'. Beattie does, however, doubt whether abstract nouns are essential parts of speech. Though they are found in every known

\footnotetext{
Intellectual Powers, vi. iv; Works, i. 440-1.

2 Brief Account of Aristotle's Logic, ir. v; Works, ii. 692.

3 Intellectual Powers, $\mathrm{x} . \mathrm{v}$; Works, i. 238.
}

language, they could perhaps always be dispensed with by circumlocutions. ${ }^{\mathrm{I}}$

Beattie's treatment of substantives is typical of his treatment of other features of universal grammar. Why is there a universal grammar? 'Certain modes of human thought' are common to all men in the circumstances of human life. Universal grammar is the system of linguistic necessities for their expression. ${ }^{2}$

We have already met instances and shall meet others of Reid's appeal to common language in philosophical discussion. The appeal is often destructive and made in order to oppose a theory, not to oppose a theory to a theory, not, at least not immediately, to put anything in place of a theory. ('Let us next consider the proper meaning of the word impression in English, that we may see how far it is fit to express either the operations of the mind or their objects. ...') In this way it is a detail in Reid's argument against the theory of ideas. The appeal is sometimes made in order to oppose a conviction of common sense to a theory. ${ }^{3}$ In the most extended instance, the objectivity implicit in the language of morality is set against subjectivist theories of the nature of morality. But this form of the appeal to common language on behalf of common sense is incidental with Reid; he looks for the metaphysics of common sense in the structure of what is said rather than in what is said.

If Reid is mistaken in thinking that there is a metaphysics of common sense, why do most men resist the analyses of common-sense beliefs put forward by the phenomenalist or positivist? (One is, of course, speaking impressionistically in saying that they do, but safely enough.) When told, 'This is the sort of thing you really mean', why do they not say 'Yes, that is

I Dissertations (London, 1783), pp. 323-4.

2 Ibid., p. 322.

3 There are anticipations of Reid which are left undeveloped in the following passage from Turnbull: 'Such ways of speaking are of universal use and extent: none are more such: but to say that such phrases, received in all languages, and universally understood, have no meaning at all, is to assert an absurdity no less gross than this; that men may discourse, hold correspondence, and be influenced and determined in their correspondence with one another, without any ideas at all. Common language is built upon fact, or universal feeling. ... It is only such philosophers, who seeking the knowledge of human nature, not from experience, but from I know not what subtle theories of their own invention, depart from common language, and therefore are not understood by others, and sadly perplex and involve themselves.' (Principles of Moral Philosophy, London, 1740, i. 16.) 
the sort of thing I really mean'? They have it patiently explained to them, for example, that the philosopher is not telling them that there are no tables; that on the contrary, he is telling them what tables are. They are unimpressed. They do not think that 'There are tables and they are clusters of sensations' is any better than 'There are no tables, only clusters of sensations.' The phenomenalistic analyses are rejected by most men as soon as they are proposed and understood, and if suspected of being phenomenalistic, before they are understood.

The positivistic analyses of common sense beliefs, allowing them no more than what we have called an 'empirical' content, are turned down more or less emphatically, and with a more or less definite feeling of what has been left out-not all of them, perhaps, with equal decision if enough talk has been gone through. It depends on the clarity of the belief and the proportion between its two kinds of content. The exteriorization of other people's minds into their behaviour is rejected with complete scepticism, the individual subject (like the unperceived material object when the phenomenalist has finished his argument) survives perhaps as a nescio quid, clung to with puzzled stubbornness. If the Common Sense philosophers are right in finding in the beliefs of common sense self-evident metaphysical beliefs, and rightly claim that they can count on the agreement of most men, they must be prepared to find disturbingly that, as far as the agreement goes, some of these beliefs might be more self-evident than others, certainly that it is clearer in some than in others what it is that is self-evident.

Let the beliefs of common sense be refused the possibility of a metaphysical content, and their truth can be withdrawn from philosophical dispute. Reid and his school will not accept this eirenicon. These beliefs cannot be freed from their metaphysical commitments and remain the beliefs of common sense. And their truth, they maintain, is not jeopardized by the weight they carry; no unloading is needed to make them safe. They are true as they are, and arc known to bc so, if not by all men, then by most men, and those who deny them act on them. Reid has no answer to the question 'How do we know that they are true?' except that it is a question that cannot always be asked if it is ever to be answered; all evidence must terminate in selfevidence, and these beliefs are self-evident.
Alternatively, they are forced upon us by 'the constitution of our nature'. And no belief can have a more unanswerable authority. Sir James Mackintosh remarks that he observed to Dr. Brown in 1812 that Reid and Hume 'differed more in words than in opinion'. Brown answered: 'Yes, Reid bawled out, We must believe an outward world; but added in a whisper, We can give no reason for our belief. Hume cries out, We can give no reason for such a notion; and whispers, I own we cannot get rid of it.'

I Dissertation on the Progress of Ethical Philosophy (2nd ed., Edinburgh, 1837), p. 346 . 
 \\ COMMON SENSE (2) \\ I. REASON AND COMMON SENSE}

$\mathrm{T}$ HERE is this difference between the antient and these modern sceptics, that the antients professed neither to understand nor believe any thing, whereas these moderns, believe every thing, though they profess to understand nothing.' These are Priestley's words, and the 'modern sceptics' are Reid and his school. Their 'new and strange' appeal to 'common sense', Priestley considers, not only carries with it a denial that reasons can be given for our natural and universal beliefs, but, more dangerously sceptical, it drowns these beliefs in subjectivity. The doctrine of Locke, that truth is a matter of the agreements and disagreements between ideas, made 'truth to depend upon the necessary nature of things, to be absolute, unchangeable, and everlasting'. The doctrine of 'common sense' makes it depend upon 'the arbitrary constitution of our nature', and so to be 'a thing that is relative to ourselves only'. With Beattie the scepticism in 'common sense' comes out into the open. The title of his book mentions the immutability of truth. In his book Beattie says that all we know of truth and falsehood is that 'our constitution determines us in some cases to believe, in others to disbelieve ... that to us is truth which we feel that we must believe; and that to us is falsehood which we feel that we must disbelieve'.' Truth has entirely gone, Priestley comments. We are left by Beattie with how things appear to us, and are never to know how they are in themselves-'which alone is, strictly speaking, the truth'. Beattie pushes that quite out of our reach. According to Beattie, "we can only see with our own eyes, and judge by our own faculties, or rather feelings'.

And Beattie does not break with his school in this matter. Reid and Oswald also significantly call their final authority for truth 'sense', a term which philosophers have kept for 'those faculties in consequence of which we are liable to feelings relative

\footnotetext{
I Essay on Truth, II. i. 2, p. Ig6.
}

to ourselves only, and from which they have not pretended to draw any conclusions concerning the nature of things'. The 'system of common sense' puts feeling in the place of reason, therefore relative, in the place of absolute, truth. And a further conscquence of this exaltation of feeling and depression of reason is that any topic which an adherent of the system chooses to refer to 'common sense' is removed from discussion. He does not have to argue with his opponents; they are to be treated as persons with some defect in their constitution, as 'ideots or madmen'.

Priestley's criticism will form a convenient text for the further exposition in this section of the views of the Common Sense philosophers on the nature of common sense. We shall begin with the fundamental disagreement between Reid and Priestley over the nature of sense.

Priestley's mistake, in Reid's opinion, is the very general mistake of philosophers, and to correct it was one of the main concerns of the Inquiry. Feelings relative to ourselves, and from which no conclusions can be drawn as to the nature of thingssense perception, construed according to the theory of ideas, gives us these. According to the theory of ideas, from sense we have sensations and nothing else, nothing that takes us further than ourselves. And the philosophers who have recognized other senses besides the external ones, a moral sense, for instance, have, as a rule, assigned them the same function: they are there to give us feelings and nothing else. Reid does not think of sense in this philosophical way. He uses the word 'sense', he claims, as it is used in common speech where it always implies judgement, where 'good sense' is good judgement, 'nonsense' absurd judgement, where beauty and deformity are 'judged of' by taste. From which 'it is natural to think that common sense should mean common judgment; and so it really does'. ${ }^{2}$ And equally natural, it seems to Reid, for anyone holding that the sole province of sense is to provide us with sensations or ideas, to draw the consequence that the sole province of judgement is to perceive their relations. The antecedent is false. The senses (unless disordered) and common sense, through the judgement involved in them, do not leave us locked up within ourselves; they efface us so

\footnotetext{
I Examination, pp. xxi, 121-7.

2 Intellectual Powers, vi. ii; Works, i. 42I-3.
} 
thoroughly that they present us with things as they would be even if we personally did not exist.

Beattic defines common sense as

that power of the mind which perceives truth, or commands belief, not by progressive argumentation, but by an instantaneous, instinctive, and irresistible impulse; derived neither from education nor from habit, but from nature; acting independently on our will, whenever its object is presented, according to an established law, and therefore properly called Sense; and acting in a similar manner upon all, or at least upon a great majority of mankind, and therefore properly called Common Sense. ${ }^{\mathrm{I}}$

Would this definition be acceptable to the other Common Sense philosophers? Oswald would object to nothing in it, ${ }^{2}$ and Reid to very little. He would not care to authorize without qualification the instantaneity and irresistibility of the operation of common sense, even though he himself says that the propositions of common sense are believed as soon as understood. There are obstructions to common sense, other than congenital defect, which are not paralleled in the external senses which Beattie is taking as his model. Understanding the propositions of common sense is more than understanding the words of the sentences in which they are stated; they are propositions which have to be looked at from 'a proper point of view'. Reid does not explain this remark, but he has said just previously that a vulgar prejudice may disguise itself as a truth of common sense, and a truth of common sense may 'by the enchantment of words, have such a mist thrown about it, as to hide its evidence'. ${ }^{3}$ He was perhaps thinking in summary of things he says in other places: a sufficient schooling in sceptical philosophy can reduce the otherwise irresistible pressure of common-sense belief to a fitful insistence. And apart from the wilful delight in paradox, there are power-

I Essay on Truth, r. i. p. 45. Cf. Buffier: "What is here meant by common sense, is that disposition or quality which Nature has placed in all men, or evidently in the far greater number of them, in order to enable them all, when they have arrived at the age and use of reason, to form a common and uniform judgement with respect to objects different from the internal sentiment of their own perception, and which judgement is not the consequence of any anterior principle.' (First Truths, $\mathrm{I} . \mathrm{v}$, London, 1780, p. 22.) There is nothing 'new and strange' in the appeal to common sense, Beattie remarks in his 'Hints for an Answer to Dr. Priestley' (Aberdeen MS., B45); it is 'as old as literature, as old as human nature itself'.

2 An Appeal to Common Sense, i. I 70.

3 Intellectual Powers, I. ii; Works, i. 23 I. ful intellectual motives behind the philosophical invention of scepticism, notably the double determination to force simplicity on complexity, and to leave nothing unexplained. It was the determination to leave nothing unexplained which led to the adoption of the theory of ideas with its unexpectedly destructive consequences. Reid speaks more cautiously than Beattie, but obviously Beattie would have agreed that the light of common sense can be philosophically darkened, or he would not have written his book.

Beattie's definition of common sense is 'liable to censure in almost every line', Stewart asserts. For one thing, its affected precision is quite out of place. 'The very idea, indeed, of appealing to common sense, virtually implies that these words are to be understood in their ordinary acceptation, unrestricted and unmodified by any technical refinements and comments.' Stewart's main criticism is that Beattie not only supposes that 'common sense' means 'something quite distinct from reason, but something which bears so close an analogy to the powers of external sense, as to be not improperly called the same name'. How much more unexceptionably Reid speaks of common sense, when he speaks of it as that degree of sense in virtue of which we are 'capable of managing our own affairs' and of being 'answerable for our conduct towards others'; when he explains that it is 'called common sense, because it is common to all men with whom we can transact business'; when he adds that the 'same degree of understanding' which equips a man for the business of life, makes him 'capable of discovering what is true and what is false in matters that are self-evident, and which he distinctly apprehends'. Stewart does not notice that the philosophical opponents of the truths of common sense have been defined into madness or imbecility. And wishing to stress Reid's view of common sense as a power of the understanding, he passes over Reid's agreement with Beattie that it is also rightly thought of as a sense when sense is rightly thought of.

However comparatively unexceptionable Reid's language, the whole appeal to 'common sense', in Stewart's opinion, is most unfortunately worded. The appeal is in fact to the 'fundamental laws of belief', and it is not part of the function of what is ordinarily called 'common sense' to authorize these. 'Common I Elements, II. i. 3; Works, iii. 63-69. (Reid, Intellectual Powers, vi, ii; Works, i. 422). 6228 
Sense', as generally understood, 'is nearly synonymous with Mother-wit . . . and refers, not to the speculative convictions of the understanding, but to that prudence and discretion which are the foundation of successful conduct'. A regrettable feature, Stewart remarks, of Reid's technical appropriation of the word is that it was the appropriation of a word which too easily became a school label, under which wide differences of opinion disappeared, and independent thinkers were made responsible for each other's doctrines. And even more regrettably, all of them (at least to 'title-page readers') seemed, from its associations, to be lining themselves up on the side of the vulgar whenever the vulgar were against the learned.2

Reid uses the expression 'common sense' in reference to a mental power or faculty and in reference to a set of beliefs or principles. Stewart was not more than half right in thinking that Reid was using it in a new way. 'Common Sense' was a philosopher's word, at any rate a scholarly word, before it became everybody's word. After first translating the Latin translation of Aristotle's koine aesthesis, and so beginning with a meaning that had no connection with its later meaning, 'common sense', in its faculty reference, came to signify average intelligence (allowing the depreciatory 'mere common sense'), and also practical sagacity, settling down to this as its most familiar meaning when it refers to mental endowment. An Oxford English Dictionary citation of an early eighteenth-century writer shows how little it has changed since then: 'By a man of common sense we mean one who knows, as we say, chalk from cheese.' There does not seem to be much sanction for Reid's opinion that 'common sense' is the proper name for the faculty which has first principles as its province.

The principles 'which the constitution of our nature leads us to believe, and which we are under a necessity to take for granted in the common concerns of life, without being able to give a reason for them' are, according to Reid, 'what we call the principles of common sense; and what is manifestly contrary to them, is what we call absurd'. ${ }^{3}$ We are now more accustomed in everyday speech to the usage by which, if something is a 'matter of

1 Life of Reid, $\mathrm{n} ;$ Works, x. 306.

2 Elements, u.. i. 3; Works, iii. 67-69; Life of Reid, $\mathrm{n} ;$ Works, x. 306.

Inquiry, in. vi; Works, i. 108. common sense', it is the obviously sensible thing to do. Alternatively, a 'matter of common sense' is an obvious inductive inference, and what is against common sense is an inductive absurdity. But 'common sense' has more than one meaning when it means a set of beliefs. And in Reid's time there was not, any more than there is now, anything unusual in speaking of philosophical paradoxes as 'against common sense', and of the beliefs opposed to them as 'beliefs of common sense'. Berkeley, and Hume (occasionally), anticipating Reid here, were speaking in the vernacular, and the philosophy of Common Sense was popular because it was or seemed to be defending common sense.

Stewart wants the intellectual power which Reid calls 'common sense' called 'reason' - as a matter of linguistic propriety. $\mathrm{He}$ is not preparing a quick destruction for the philosophical opponents of common sense. But if there was a man whose behaviour revealed a disbelief in his own existence, in his selfidentity, in the reality of the things round about him, it would not be good English to say that he had no common sense. We would say that he had lost his reason. And the appeal to common sense has an older and more venerable wording as the 'appeal to the light of human reason from the reasonings of the schools'.'

In the Inquiry Reid had spoken as if there could be an opposition between reason and common sense in which one would have to submit to the other: Common sense 'declines the tribunal of reason', reason must be the servant of common sense or its slave. ${ }^{2}$ In the Intellectual Powers Reid has come to realize that this is not the way to speak. (It never was more than a way of speaking. God gave us reason and common sense; the opposition, Reid would have explained, was of course between common sense and misused reason.) Reason and common sense go together in nature as they do in the phrase. Reason has two functions, an intuitive function and a deductive function. 'Common Sense' is an alternative name for reason in its intuitive function. ${ }^{3}$ Indeed all the Common Sense philosophers except Beattie, who follows the earlier Reid in keeping the word 'reason' for 'reasoning', are sooner or later willing or anxious to use on occasions 'common sense' and 'reason' interchangeably. Oswald is at

$$
\text { I Elements, Ir. ii. r; Works, iii. } 50 . \quad 2 \text { v. vii; Works, i. I27. }
$$$$
3 \text { vI. ii; Works, i. } 425 .
$$ 
some pains to make it clear that 'feeling' will not do as a substitute for 'common sense', because feelings ought to be disciplined by reason, and because to exalt feeling in this way would be to give a licence to bigotry. ${ }^{\mathrm{I}}$

Stewart objects to the indiscriminate reference of axioms of 'abstract science', particular truths derived from perception, memory, and 'consciousness', along with 'fundamental laws of belief', to a single intellectual faculty. It carries the implication that all intuitive evidence is of one single type. ${ }^{2}$

Where Reid writes 'common sense', Stewart writes 'reason'. Neither Stewart with the word 'reason', nor Reid with the word 'common sense' obliterates differences between different kinds of intuitive evidence any further than 'intuitive evidence' obliterates them. In one way Reid does diminish the significance of different kinds of evidence, and that is by insisting that they are too different to have any logical unity, and then providing them with another kind of unity. Philosophers, Reid remarks, have tried by analysing the different kinds of evidence to find out some common feature in virtue of which they are all evidence. The Schoolmen sought it under the name of the "criterion of truth'. There have been many suggestions. Descartes's is the most celebrated. Reid does not understand what Descartes meant by 'clarity' and 'distinctness', and the more he considers the different kinds of evidence, the less he can see that they have anything in common, except this that 'they are all fitted by Nature to produce belief in the human mind, some of them in the highest degree, which we call certainty, others in various degrees according to circumstances'. ${ }^{3}$

The evidence of perception, memory, and consciousness, and of the other modes of cognition, is then in each case unique. How, if this is so, does common sense enter into their evidence, as Reid implies that it does? Its function seems to be the authorization of all the transitions from empirical to metaphysical fact which we find inevitable, know to be justified and cannot justify. There are no such transitions when we are merely conscious of what is within our own minds, but what assurance do we have that consciousness does not deceive us? We have the

\footnotetext{
I An Appeal to Common Sense, i. I31-42.

2 Life of Reid, II; Works, x. 305.
}

${ }^{3}$ Intellectual Powers, 11. xx; Works, i. 328. assurance of common sense. This is Reid's answer, though not in so many words. The integrity of consciousness, he says, is one of the 'first principles' of human knowledge, principles selfevidently true or, alternatively, guaranteed to us by 'the constitution of our nature'.

The principles in Reid's list of 'first principles of contingent truths'I look more heterogeneous than they are. One of themthe inductive principle-is in a class by itself, but the others can be sorted, at least roughly, into two groups: (a) principles which generalize, in its metaphysical aspects, the evidence of the various modes of cognition concerned with matters of fact-such principles as that there is an external world, that there are other minds besides one's own; $(b)$ principles which affirm the truthfulness of our faculties. The 'first principles of contingent truths', together with some of the 'first principles of necessary truths', are the principles of common sense.

Reid and Stewart do not make it unmistakably clear anywhere in their books whether they recognized that some of the principles they regarded as necessarily true have self-contradictory contradictories and some do not. Without explicitly marking the logical difference between them they keep them unconfused. ${ }^{3}$ It is quite clear that they would not have thought the logical difference epistemologically disturbing. Their view would have been that we can say why the contradictories of one sort of necessary proposition are impossible; we cannot say why the contradictories of the other sort are impossible; but we can see-unless our intelligence is in some way impaired-that the contradictories of both are equally impossible.

Hamilton remarks that the distinction between analytically and synthetically necessary propositions is to be found in George Campbell's Philosophy of Rhetoric, and that it attracted Stewart's attention. ${ }^{4}$ Campbell regards mathematical propositions as

Ibid., vi. v.

2 Ibid., v. vi. The distinction between necessary and contingent truths, Reid explains (vI. v; Works, i. 442), coincides nearly, but not quite, with the distinction between 'abstract' and 'matter of fact' truths. The principles of contradiction and causation are abstract and necessary truths; that one exists oneself and that other people exist, are contingent and matter of fact truths; but that God exists is a necessary truth.

3 As nearly as one can tell from Reid's vagueness, the necessary truths which he reckoned as principles of common sense were those not analytically necessary.

4 Reid's Works, note A, ii. 787-8. 
'identical' propositions, but not as tautologies. ' 4 and 1 are 5 ' is not like ' 5 is 5 '. In the arithmetical proposition the number 5 appears in the subject and predicate in different aspects ('divided' in the subject, 'single' in the predicate), whereas in the tautology the subject is sterilely repeated in the predicate. Mathematical propositions differ in kind, though not in superior evidence, from the intuitive principles of common sense. The difference is that no 'conclusions concerning actual existence' can be drawn from a mathematical proposition. ${ }^{\mathrm{I}}$ The principle of causation is unique among the principles of common sense in that its denial is 'not only false, but contradictory'. ${ }^{2}$ Reid and Stewart had nothing to learn in this matter from Campbell. Stewart was interested in his account of the nature of mathematical propositions, not in his comparison between them and the propositions of common sense. ${ }^{3}$

At some time or other (and with no knowledge of Kant) Reid came to recognize clearly the formal distinction between the two kinds of truths which he regarded as equally necessary. McCosh printed in an appendix to his Scottish Philosophy fragments of several papers of Reid's.4 One of them (it was undated but looked 'very old', McCosh says) ends with a question and answer:

$Q$. Is there not a difference between the evidence of some first principles and others? A. There are various differences perhaps. This seems to be one, that, in some first principles, the predicate of the proposition is evidently contained in the subject: it is in this, two and three are equal to five; a man has flesh and blood. In these and the like self-evident principles, the subject includes the predicate in the very notion of it. There are other first principles in which the predicate is not contained in the notion of the subject; as, where we affirm that a thing which begins to exist must have a cause. Here the beginning of existence and causation are really different notions, nor does the first include the last. ... The truth of principles of the first kind is only perceiving some part of the definition of a thing to belong to it (pp. 475-6).

Cf. Reid : ' . from no mathematical truth can we deduce the existence of anything; not even of the objects of the science'. (Intellectual Powers, vi. v; Works, i. 442.) 2 The Philosophy of Rhetoric, i. $105^{-15}$.

3 Elements, II. i. I; Works, iii. 26-30.

4 When the Scottish Philosophy was published (1875) these papers were part of a collection of Reid MSS. in the possession of Francis Edmond of Aberdeen. I have not been able to find out what happened to it.
When Reid and Stewart referred common-sense belicfs to reason, they did not delude themselves into thinking that they were giving a reason for them, let alone the best of all reasons. So far from thinking this, they regard it as one of the marks of a common-sense belief that nobody asks a reason for it. Ordinary men who want reasons where they can be given, do not ask for them when they cannot be given and are not needed. They do not want to have it proved to them that they exist and are the same persons from hour to hour, or that other people besides themselves exist. They do not want any of these matters, about which there is no doubt, put beyond doubt by arguments. It has been the vice of philosophers, in Reid's opinion, to want this. And once proof is insisted on and never found, it is hardly possible not to begin questioning the most obvious things. Reid is sure that the only way to resolve a Cartesian doubt with regard to them is to draw back out of it. To hope to go through with it and emerge by reasoning is sophisticated credulity. It is trying to make more evident what is already as evident as it can be, and from premisses that are arbitrarily privileged. But philosophers have not been willing to take the only way out with its rebuke to philosophical pride, Reid says, and so to them the history of failed demonstrations tells against the truth of common-sense beliefs when it ought to tell against the attempt to demonstrate it. Reid and Beattie are never tired of proving that demonstrations must proceed from indemonstrable premisses, premisses which shine with the light of an unborrowed truth. As we shall see later, it is Stewart's criticism that Reid and Beattie speak of the principles of common sense in a way that would lead one to suppose that they are not only indemonstrable but premisses.

If the truths of common sense are self-evident, how can there be any dissent from them? To answer this question is the first of two most difficult problems for the philosophy of Common Sense. Part of the explanation has just been given. The unsatisfied demand for demonstration casts a shadow of doubt over the truths of common sense. Much more importantly, the logic of the theory of ideas, adopted unsuspectingly as an explanatory hypothesis, has driven philosophers into a rejection of common sense. And the sheer dislike of a multiplicity of inexplicable principles is important. To recognize the principles of common sense 
as self-evident is to acquiesce in this multiplicity. The whole tendency of modern philosophy is against such an acquiescence, Reid remarks, ${ }^{1}$ a 'revolution' against the extravagance with which ancient philosophy dealt in first principles. In the new economy-impossibly down to one principle in Descartes, grudgingly supplemented by his successors-we are to have no beliefs which cannot be deductively or inductively established. And there is no deduction or induction of the truths of common sense.

In Beattie's opinion, the philosophers who reject the selfevident truths of common sense impose on themselves and others with 'meaningless' and 'ambiguous' words. In Beattie 'meaningless' is an expletive, and the snaring ambiguities he mentions are so grossly obvious-for example 'sight' is a word with a subjective sense and an objective sense, and idealism reads the subjective sense in to the objective sense--that it is hard to imagine how anyone could hope to trap others in them, let alone be trapped himself. ${ }^{2}$ It remains a fact that Beattie had the idea of a connexion between some philosophical paradoxes and ambiguities in common speech, even if it was an idea with which he could do nothing.

All that the Common Sense philosophers have to offer in further explanation of the mystery of dissent from self-evident truth is that those who cannot see it, when the difficulties have been cleared out of the way, lack the capacity to see it. And in calling this a lack of 'common sense' or of 'reason' they obscured from themselves how disturbingly particular the privation is. It is obviously not the absence of the same degree of understanding as equips a man for the ordinary business of life, in which Hume and Reid get on equally well. If it is a defect in reason or intelligence, it is one with no other manifestation than this inability to see the truth of the metaphysical beliefs of common sense.

The first of the two problems for the philosophy of Common Sense is to explain how dissent from the self-evident truths of common sense is possible. The second is to provide some reason for thinking that in spite of this dissent they are self-evidentevident in themselves, truths which do not need any outside justification, and which therefore ought to be assented to as soon as understood-some reason for thinking that their self-evidence is not merely evidence to oneself and to numbers of other people.

\footnotetext{
I Inquiry, vir; Intellectual Powers, vi. vii; Works, i. 206; 462 ff.
}

2 Essay on Truth, n. ii. 1, pp. $251 \mathrm{f}$
The Common Sense philosophers cannot be asked to show with demonstrative rigour that the propositions of common sense are self-evident. That is a contradictory demand. A proposition, not known to be self-evident, might be demonstrated to be self-evident, if it is, and does not appear to be, a proposition which cannot be denied without self-contradiction. But the propositions of common sense are not logically necessary truths. There is no logical incoherence of any kind in their denial when they are taken as having a metaphysical content. The only proof there could be that they are evident in themselves is their evidence to people. The Common Sense philosophers can be asked to explain why these propositions are not self-evident to everyone. They try to do this. They can be asked to dispose of explanations of the origin of common-sense beliefs which explain away the appearance of self-evidence. They do not try to do this. They can be asked to show such a massive suffrage in favour of the intrinsic self-evidence of the propositions of common sense, that it will be more likely that those who cannot see it, cannot see what is there, than that those who claim to see it, 'see' what is not there. They try to do this.

If the propositions of common sense are not assented to by everybody who understands them, they are assented to, Reid claims, by nearly everybody. And this he regards as a very good reason for thinking that they really are self-evidently true, for why should almost everyone think that they are unless they are?

In a matter of common sense, every man is no less a competent judge than a mathematician is in a mathematical demonstration; and there must be a great presumption that the judgment of mankind, in such a matter, is the natural issue of those faculties which God hath given them. Such a judgment can be erroneous only when there is some cause of the error, as general as the error is. When this can be shewn to be the case, I acknowledge it ought to have its due weight. But, to suppose a general deviation from truth among mankind in things self-evident, of which no cause can be assigned, is highly unreasonable. ${ }^{1}$

There is, Reid maintains, a proper and an improper place for the appeal to the many against the few, and this is a proper place. This is where the consensus gentium is to be invoked against idiosyncrasy. If the decision on the truth of the propositions of

\footnotetext{
Intellectual Powers, vi. iv; Works, i. 440.
} 
common sense was a matter 'beyond the reach of common understanding', or a matter of being in a position to make recondite observations, the voice of mankind would have no authority against the learned. Where the philosopher and the ordinary man are on a level, as they are here, this authority is final. ${ }^{1}$ We are not dealing here, Stewart adds, with what may turn out to be a nearly universal prejudice due to a misreading of the facts. The denial of one of the fundamental beliefs of the human mind is not something that we may find in time to be like the denial that the sun moves round the earth. It is like the denial that there is motion at all.2

And the authority of the consent of ages and nations is all the more final, since the philosopher who questions or denies the truths of common sense is a man divided against himself, saying one thing - often having to break with common language in order to say it-and acting out another, with conflicting professional and unprofessional opinions, and almost certainly also inconsistent in his professional opinions. For it is the fate of the philosophers who reject some of the beliefs of common sense to find themselves, in spite of themselves, accepting others on its bare authority. Thus they will perhaps allow that memory can be veracious, though when asked for their reasons they have none, every attempt to prove the veracity of memory presupposing it. Or they will confidently expect the course of nature to remain the same, with no better justification. At least they can be depended upon not to call in question the deliverances of 'consciousness'. We are conscious of all the 'actions' and 'passions' of our own minds as they occur. If we are asked to prove that consciousness makes no mistakes about its objects, we do not know where to look for the premisses. The principle has the characteristic marks of a principle of common sense, certainty, and indemonstrability.

It is, as it stands, very obviously a philosopher's principlë, and to make it true, the objects of consciousness would have to be narrowed down until there is no logical room in them for a distinction between appearance and reality. Leaving this aside,

I Cf. Buffier: Philosophers are more to be credited than other men where philosophical competence is relevant, that is where conclusions have to be reached by reasoning, or by inference from experiment. But where common sense is concerned, all men are philosophers. (First Truths, I. viii, p. 47.)

2 Elements, II. i. 3 ; Works, iii. 6r-62. the whole appeal to the world against the philosopher and to the philosopher against himself in the argument we have put together from Reid ${ }^{\mathrm{I}}$ is too easy. If it was a question of commonsense beliefs in their empirical content, the appeal would be entirely successful and unnecessary. But very few of the philosophers who disown common-sense beliefs in their metaphysical content would admit so obligingly as Hume does on occasions, that they are rejecting natural and universal beliefs of mankind, and that they keep their scepticism for the study.

Reid does not want the beliefs of common sense sheltered from examination; everything that can be said against them ought to be heard. To put forward any belief as a belief of common sense is in fact to invite its thorough discussion. Is it a belief of common sense, or of prejudice aping common sense? Is it a belief which all or nearly all men regard as self-evident and whose denial they regard as absurd, a belief which governs the practice of anyone professing to deny it, a belief for which no universal cause of error can be discovered to match its universality? These criteria sift the beliefs of common sense from their counterfeits. ${ }^{2}$

The appeal to common sense, critics of the philosophy of Common Sense have traditionally said, is an appeal from the learned to the vulgar. It is, Reid and Stewart say, an appeal from some of the learned to the rest of mankind on matters and only on matters in which superior understanding gives no additional competence, and an appeal from the theory to the practice of the dissidents, from their extraordinary to their ordinary beliefs. The discussion it ends is a discussion of the truth of common-sense beliefs, no other discussion, and not a discussion as to whether or not a belief is a belief of common sense. Hamilton, therefore, though with a different emphasis, was speaking according to the mind of Reid and Stewart and not reffining upon their crudity when he stated that

Common Sense is like Common Law. Each may be laid down as the general rule of decision; but in the one case it must be left to the jurist, in the other to the philosopher, to ascertain what are the contents of the rule; and though in both instances the common man

\footnotetext{
Intellectual Powers, vi. iv-v.

2 Ibid., I. ii, vI. iv; Works, i. 234, 439 ff.
} 
may be cited as a witness, for the custom or the fact, in neither can he be allowed to officiate as advocate or as judge. ${ }^{\text {I }}$

Beattie would be reluctant to allow a philosopher any competence in a dispute as to what is and what is not a matter of common sense, but he is in substantial agreement with Reid and Stewart on the limits of common sense. Oswald stands aside from the other Common Sense philosophers when these limits are in question. In theology alone common sense can establish the principles of natural religion, guarantee that there is a revealed religion, and dissolve the pretensions of the Catholic Ghurch. Oswald, Priestley says in recognizable caricature, thinks that nothing is too hard for common sense. ${ }^{2}$

'You ask, why I believe what is self-evident? I may as well ask, why you believe what is proved? Neither question admits of an answer; or rather, to both questions the answer is the same, namely, Because I must believe it.' The nature of the necessity? 'We are convinced by a proof, because our constitution is such, that we must be convinced by it: and we believe a self-evident axiom, because our constitution is such that we must believe it.' These are Beattie's words, ${ }^{3}$ and Reid often asserts that belief in the truths of common sense is imposed upon us by the 'constitution of our nature'. When Reid and Beattie speak in this manner, what they are doing is exchanging the half-logical, half-psychological language of self-evidence for the wholly psychological language of compulsory belief, in order to speak with an unanswerable finality. They are not putting forward a relativism according to which the principles of common sense are categories of the mind imposed upon a wholly secret reality, ways in which we have to think of things (because we are made that way), but perhaps no more than that, perhaps with no correspondence to the nature of things.

If from the constitution of my nature I must believe that the

Reid's Works, note A, ii. 752.

2 Examination, p. 299. 'Common consent, sensus communis, is for us the seal of truth; there is no other.' (Lamennais, Essai sur l'indifférence, In. i, nouvelle édition, Paris, nd ii 85) Lamennais's appeal to common sense, though on behalf of a its extent. It has almost as few resemblances to Reid's and Stewart's as 'an appeal to common sense' could have. For Lamennais, common sense simply is common consent, sensus communis the consensus gentium.

${ }^{3}$ Essay on Truth, 1. ii. 1, pp. 61-62. principles of common sense are true, I cannot believe that this belief may be the arbitrary effect of the constitution of my nature, cannot maintain an agnostic reserve towards the objectivity of its dictates. The belief that it dictates to me the truths of common sense is the belief that it dictates their truth. As Priestley says, the truth of things is the way they are, not how they appear to us. And as Beattie says, to believe that we have the truth is to believe that our opinion would not alter if we were 'perfectly acquainted with every thing in the universe'.'

There is, however, a standing invitation to both relativism and tautology in assertions that the constitution of our nature determines our beliefs and disbeliefs. It is too much to expect that Beattie, at any rate, would altogether decline it, and he can move from relativism to tautology within a sentence. We know nothing of 'the eternal relations and fitnesses of things'-in the only relevant meaning here, nothing of how they are in themselves as distinct from how they seem to us to be-'that to us is truth which we feel that we must believe'-we must believe what we must believe; for Beattie is not defining truth as 'what we must believe', since he goes on to admit that we can be wrong when we are sure we are right. ${ }^{2}$

In a rough paper Reid has discussed the reference of the beliefs of common sense to the constitution of our nature. He shows that he intends no subjectivity, but in claiming that the reference is simply a faculty-reference, he ignores the finality with which it ends an argument.

It is one thing to say such a truth depends upon my constitution; it is another thing to say that my perception of that truth depends on my constitution. . . . Why do I believe first principles? One philosopher says, Because I am so constituted that I must believe them. This, say some, is the only possible reason that can be given for the belief of first principles. But, say others, this is a very bad reason; it makes truth a vague thing which depends on constitution. Is not this the ancient sceptical system of Heraclitus [sic], that man is the measure of truth, that what is true to one man may be false to another? How shall we judge of this controversy? Answer, This question admits of two meanings. I. For what reason do you believe first principles? 2. To what cause is your belief of first principles to be ascribed?

$$
\text { I Ibid., 1. i, p. 34. }
$$

2 Ibid., II. i. 2, p. 196 
Reid's answer to the first of these questions is that evidence is the 'sole and ultimate ground of belief, and self-evidence is the strongest possible ground of belief'. To the second he can 'give no other answer but that God has given us the faculty of judgment or common sense.' $x$

The relativism of which Priestley accused Reid and Beattie would be in Reid's eyes a peculiarly absolute form of the theory of ideas. It is in his ambiguity, at least, with regard to this matter that Hamilton breaks with Reid's school. We know 'nothing absolute-nothing existing absolutely, that is, in and for itself, and without relation to us and our faculties'.2 The question is whether this 'great axiom' of Hamilton's, the Relativity of Human Knowledge, is not the triviality that Beattie's 'relativism' becomes at the end of Priestley's exposition of it'we can only see with our own eyes, and judge by our own faculties'.

Part of what Hamilton means by the relativity of knowledge is not trivial in this sense. He holds with Reid and Stewart that behind the observable characteristics of matter and mind lie the impenetrably mysterious 'substances' 3 of matter and mind. We know that these substances exist because we know that without them their observable characteristics could not exist. Extension, figure, and magnitude ... and again thought, feeling, and desire ... show themselves to be qualities, characteristics, properties, attributes, and therefore show that there is something to which they belong as qualities, properties, attributes. We know also, from the mutual incompatibility of the two sorts of characteristics, that matter and mind do not coincide in substance. Reid, Stewart, and Hamilton speak of this wholly oblique knowledge of substance as a 'relative' knowledge of it.

What does Hamilton want us to understand by the general axiom of relativity? He makes the answer more difficult by pointing to concealed substance and revealed qualities, as

McCosh, Scottish Philosophy, Appendix, pp. 474-5.

2 Lectures on Metaphysics (6th ed., London and Edinburgh, 1877), i. 137.

${ }^{3}$ Reid nearly always avoids using the word 'substance' of the mind, and Stewart hates its barbarity. It makes, he says, true statements sound like nonsense, and conjures up the physical imagery that is always a threat to the philosophy of the mind. 'Being' is a better word. It would be better still 'to avoid, by the use of the pronoun that, any substantive whatever, "Mind is that which thinks, wills", etc.'. (Dissertation on the Progress of Philosophy, 1. ii. 2, note I; Works, i. 542.) though its whole application was to be found here. Having laid down the axiom in its complete generality, he proceeds to its illustration and vindication. 'Our knowledge is either of matter or of mind.' What do we know of matter? We know its qualities or 'phaenomena', its extension, solidity, divisibility, \&c., and we know that these qualities inhere in a substance of which we know nothing beyond the bare fact of its existence. We know then nothing of matter as it exists 'absolutely and in itself'; knowing its qualities, we know it in its relative or phaenomenal existence'. Our knowledge of mind is similarly a relative knowledge, the thing in itself 'unknown and unknowable'.

The relativity in the axiom seemed from the wording of the axiom to be a relativity to our faculties of cognition, with some implications of subjectivity. And if it is a relativity of this kind, there is no connexion at all between the axiom and its standard application. The relativity in our knowledge of substance is the fact that substance is not known otherwise than relatively to its attributes; there are no implications of subjectivity.

When the axiom is clearly asserting the relativity of everything known to the knower, its clearly untautological formulations are extremely rare. Still they do occur. 'We can know, we can conceive, only what is relative. Our knowledge of qualities or phaenomena is necessarily relative; for these exist only as they exist in relation to our faculties.'2 The 'modes' of being 'can be known only if they stand in a certain relation to our faculties ... are presented to, and known by, the mind only under modifications determined by these faculties themselves' ${ }^{3}$ The context of this second passage complicates the doctrine of relativity still further. It is, Hamilton says, part of the work of philosophy to distinguish in 'an act of knowledge ... what is contributed by the mind itself'. And this suggests that Hamilton might have regarded the subjective relativity in our knowledge as always provisional, as always capable of detection and theoretical cancellation.

The unambiguous formulations of the axiom of relativity would be sufficient to determine the interpretation of the ambiguous formulations as significantly relativistic (since we can hardly

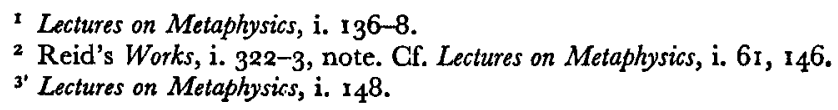


suppose that a philosopher could be seized with the urgency of insisting and insisting that everything that is known by us is known by us), if it was not that with the axiom significantly relativistic, Hamilton's philosophy would be split into two contradictory halves. For no doctrine is more reiterated by Hamilton than the doctrine that in perception the mind is face to face with things outside it, nothing whatever coming between it and them. In its typical statement: the 'external reality itself constitutes the immediate and only object of perception'. ${ }^{\text {I This is the }}$ common-sense doctrine of perception and therefore Hamilton's own, and he is always watching for Reid's deviations from it.

Yet commenting on Reid's opinion that the senses disclose the nature of the primary qualities as they are 'in themselves', but give us merely a 'relative' notion of the secondary qualities, informing us only that 'they are qualities that affect us in a certain manner - that is, produce in us a certain sensation', ${ }^{2}$ Hamilton remarks: 'Reid cannot mean that the former are known to us absolutely and in themselves - that is, out of relation to our cognitive faculties; for he elsewhere admits that all our knowledge is relative.' It is not possible to guess what passage Hamilton thought contained Reid's admission. Reid uses the notion of 'relativity' in three connexions : in connexion with the secondary qualities of bodies in the way just mentioned, in connexion with substance in the way explained above, and in connexion with 'power'-power is known only relatively to its effects. ${ }^{3}$

The critics and expositors of Hamilton have dealt in different fashions with the problem of interpreting him. Mill's inclination is to reduce the axiom of relativity to a truism. 4 J. H. Stirling brings the relativism and the 'natural realism' into head-on collision. ${ }^{5}$ The Hamiltonians Mansel ${ }^{6}$ and Veitch 7 relativize the objects of perception. They say that the objects of perception are 'phenomena', joint products of the mind and of another reality which they screen off from the mind, but 'objective' phenomena and 'material', not subjective representations of

\footnotetext{
I Discussions, p. 59.

2 Intellectual Powers, II. xvii; Works, i. 313.

3 Active Powers, r. i; Works, ii. 514 .

4 Examination of Sir William Hamilton's Philosophy (London, 1865), ch. iii.

3 Sir William Hamilton (London, 1865), pp. 2-10.

6 The Philosophy of the Conditioned (London and New York, 1866), pp. 78-87.

7 Hamilton (Edinburgh and London, 1882), pp. 142-6.
}

material things. Reid would have had some difficulty in understanding this, but he could have made out enough to recognize 'ideas' in yet another of their chameleon variations.

Hamilton, who was deeply influenced by Kant, gave the philosophy of Common Sense (at least in words) a Kantian transformation with the axiom of relativity, which divides off things as they are 'absolutely or in themselves' from things as they appear, so that everything we know is 'phaenomenalphaenomenal of the unknown'.

Kant's distinction between appearance and reality is a consequence of the 'Copernican revolution'. Hamilton's axiom has a wholly gratuitous look. There are, however, some surface indications ${ }^{2}$ of the subterranean argument by which he probably reached it. Knowledge brings an object into relation with a subject, is a relation with these two determinants. There can never, therefore, be complete identity between a thing known and unknown; there is always the relational difference. So that when anything is known, there is the knower and the known, and beyond the known the unknowable-the object as it is apart from its relation to a subject. Knowledge is necessarily hyphenated with invincible ignorance.

This argument, supposing it to be implicitly Hamilton's, does not help to solve the problem as to whether or not the proposition it supports is trivial. The relativity of all our knowledge may amount to no more than a tautological agnosticism. Or Hamilton may have held that knowing modifies its object, or that possibly it does so, and that the fact or the possibility is consequent upon the fact that knowledge is a relation with subject and object as its determinants.

Ferrier (1808-64), with whom the impulse given by Reid to the development of Scottish philosophy exhausted itself, Hegelianized Hamilton with a version of absolute idealism which he claimed was native to Scotland, and towards which Reid's mistakes and Hamilton's had been fundamental enough to point instructively. And correcting Hamilton directly and Reid through him, Ferrier maintained that there is no ignorance where there can be no knowledge; that there can be no knowledge of material things apart from their relation to mind, or of

$$
\begin{aligned}
& \text { I Discussions, p. } 644 \text {. } \\
& 2 \text { Ibid. p. 604; Reid's Works, note N, ii. } 965 \text {. }
\end{aligned}
$$


the mind except as objectified in 'some particular state, or in union with some non-ego'. 'Matter' and 'perception' are the syllables of a single ontological word and are meaningless apart from their place in its structure. ${ }^{\mathrm{I}}$

\section{PHILOSOPHY AND THE PHILOSOPHY OF COMMON SENSE}

This universal and primary opinion of all men is soon destroyed by the slightest philosophy (Hume).

'Philosophy has no other root but the principles of Common Sense (REID).

Reid does not speak at great length of the functions of a philosophy of common sense, but it is clearly his opinion that there are two things it has to do. The first is to refute any assertion such as Hume's. The gestures against reason at the beginning of the Inquiry were gestures. Reid never had any doubt that nothing could be more serious than that reason could be found to be against common sense, and he never thought that this schism in nature, if it was there, could be plastered over by calling 'common sense' 'reason'. It is a characteristic mark of common-sense beliefs that we cannot give them up even if we cannot refute objections to them. Nevertheless, to refute objections to them is what the common-sense philosopher exists for. His other work is to show how philosophy has its roots in common sense, and how it is to be cultivated.

The philosophy of common sense is to make itself unnecessary. Its present necessity is a misfortune. It is not valuable as a search after truth; it has made no positive discoveries and will make none. It is not even a school of instruction in other people's discoveries, for its claim is that the truths in which it is interested have always been known and are indeed momentous platitudes. Some of them might need a little clarification and precision of statement, but that is not a task which could absorb all the powers of a philosopher. And without any metaphysical impulse towards the discovery of new truths, it is without any epistemological concern to discover reasons justifying our acceptance of truths as old as human nature. They need no such justification

\footnotetext{
Works, i. 241, 412-27; iii. 450-2.
}

and none is possible. The philosophy of common sense is called for only because these platitudes have been attacked and the attack against them should be broken up. Its philosophical value is polemical. Its best hope is to become, with the attack on common sense, an episode in man's intellectual history. Something like this would be Reid's estimate of his philosophy from one point of view, and from that point of view something like it must be a correct estimate, if Reid's views on the nature of common-sense truths are correct.

In defending common sense, however, Reid believes that he is defending philosophy also. In attempting to destroy common sense it was also destroying itself. In that enterprise it is contemptible and to be cried out against. 'I despise Philosophy, and renounce its guidance-let my soul dwell with Common Sense'I -a declamation which hung in the air over all Reid had written, to damage his reputation and embarrass Stewart.

Reid thinks that he knows what is behind the attack on common sense. And he thinks that in turning the light on to it he has revealed important origins of philosophical error and, by contrast, necessary conditions for the attainment of philosophical truth. The error is fundamentally an error of method: hypothesis where there should be severe induction, analogies where the facts should be left to their uniqueness, and a vacuum in the place of first principles. Once the proper method is adopted, the philosophy of common sense could disappear into philosophy, and philosophy become what it has not yet been, except in name, a science.

We have seen Reid in the refutation of error. We have now to see how he maps out the path of philosophical progress.

The objects of human knowledge, Reid states in the preface to the Intellectual Powers, fall into two great divisions: the material world and the world of minds (finite minds and God). The corresponding division of the sciences is into natural philosophy and the philosophy of the mind.2 Until the time of Galileo

Inquiry, 1. iii; Works, i. ro1.

2 Are 'grammar, logic, rhetoric ... morals, jurisprudence, law, politics and the fine arts' sub-divisions of the philosophy of the mind? Not, Jouffroy points out, if the philosophy of the mind is described as the science which has mind for its object. 'Aucune de ces sciences, aucun de ces arts n'a pour objet la connaissance des esprits; seulement tous présupposent la connaissance d'un certain esprit qui est l'esprit humain' (GEuvres de Thomas Reid (Paris, 1828-36), Preface du Traducteur, 
and Bacon, natural philosophy was the chaos of conflicting opinion that the philosophy of the mind still is. Its reformation was a reformation in method. The reformation of the philosophy of the mind will be a reformation in method.

In what the philosophy of common sense has to teach philosophy Reid does not think that there is really very much of his own; he has done little more than put together what he has learnt from Aristotle, Descartes, and Bacon (especially from Bacon). From Aristotle the necessity for first principles; from Descartes the uniqueness of the facts with which the philosophy of the mind is concerned; from Bacon that the method of their investigation is to be strictly inductive.

A science of real existence, Reid says, must be based upon observation. There is a unique kind of observation matching the mind's uniqueness. It is, however, difficult, so difficult that Reid can persuade himself that its difficulty is one of the principal reasons why a science of the mind has hardly begun. It needs a completely disinterested determination to find nothing that is not there, all anticipations and prejudices laid aside. (In actual fact, Beattie remarks, it is usually undertaken with a 'metaphysical' book in one's hand.) Its objects are most fugitive. It is painfully against all our normal habits of concentration on what is outside of us, habits formed by the very nature of the operations of the mind. Finally, introspective attention is almost certain to modify what is being observed. $x$

There are these difficulties in the way of the careful observation of the mind's actions and passions, which is the first stage in an inductive science of the mind. And how can anyone tell by attending to his own mind whether what he finds there are its peculiarities, or features common to the minds of all men? There are ancillary sources of information in the inquiry into the mind which can take us beyond singularity to these universal features. 'The various operations of the understanding, will, and passions, which are common to mankind, have various forms of speech

p. xxxviii). Reid becomes aware of this before the end of his preface and ends it by making a group of these sciences and arts, because they have a common dependence on the knowledge of the mind as the root from which they grow and are all nourished. In Stewart's classification of the sciences and arts these sciences and arts go together, because they are related to the philosophy of the mind 'somewhat' as the whole of medical science to anatomy. (Life of Reid, $\mathrm{n}$; Works, x. 274.)

Intellectual Powers, I. vi. corresponding to them in all languages.' Our 'intellectual powers' show something of their nature in our opinions, and our conduct shows the 'active principles' which govern our lives. The errors even, and prejudices of men, when they are general, are instructive, since they must have as general a cause, the discovery of which will throw some light on the structure of the human understanding. And here, in Reid's opinion, is the main use of the history of philosophy. It is a history of fanciful theorizing, of contradiction, and of absurdity clinging to truth. We may be able to find the point of view from which things appeared to the author of a system, and from it see improbabilities take on plausibility. We shall have learnt obliquely something of the operations of the mind which we might not have been able to learn in any other way. ${ }^{\mathrm{I}}$

The temptation to philosophers-this can never be said too frequently, Reid thinks-has always been to describe and to explain the operations of the mind by analogy with the operations of bodies. For the reasons just mentioned, we are more familiar with the world outside us than with the inner world of ourselves, and naturally think of the unfamiliar in terms of the relatively familiar. And philosophers are hurried into these descriptions and explanations by the almost completely analogical vocabulary which everyday language has for the mind.2 Ordinary people are not led astray, Reid appears to think, by this analogical language. ${ }^{3}$ They are not led astray because they do not try to turn it into theory. This is what philosophers have done, and, wanting to make the operations of the mind intelligible, they have looked to the operations of bodies to make them intelligible. The theory of ideas is the great consequence.

I Ibid, r. v.

2 Stewart regretfully turns down proposals for the invention of a new and direct vocabulary for the statement of mental facts. The metaphors in the old words would insinuate themselves into the new symbols, if not when they were invented, then when they were taught. Two things can be done protectively in philosophical discourse upon the mind. One is to keep varying the metaphors so that the theories which could be read into them cancel each other out. The other is to attend as far as possible to what the words signify and as little as possible to the images that go along with them. (Elements, III. i. 3 ; Works, iv. 55-59.)

3 Intellectual Powers, Iv. ii; Works, i. 373-4. If this is Reid's opinion, it is not his consistent opinion. The once universal belief that the mind was made of some subtle matter arose because men's earliest notions of being were all of material being. These notions moulded language, and when the mind was described they were transferred analogically to it. (Inquiry, vir; Works, i. 202.) 
There are others. Thus the standard arguments for determinism get their plausibility from the picture of the self as the subject of impressed forces. I The philosophy of the mind that has come down to us from antiquity 'is almost entirely drawn, not from accurate reflection, but from some conceived analogy between body and mind'. Philosophers have begun to turn to the mind itself for its description, and 'by that means have made important discoveries'. These, however, have been located in a conceptual system determined by the old analogical notions. The combination was bound to have the sceptical consequences it has had.2 (Reid is presumably thinking of the 'discovery', from a careful attention to their nature, that sensations could have no archetypes in the physical world, and of the consequences of the incorporation of this discovery in a representative theory of perception.)

Nothing, in the opinion of Reid and Stewart, has led to so many errors in the philosophy of the mind as the imaginary analogies between matter and mind. Matter and mind are totally different. There is the same absurdity in trying to explain a mental action, such as perception, upon physical and physiological principles as in trying to explain, for instance, chemical affinity by desire. ${ }^{3}$ Nothing but mistakes can come from the attempt to get anything of philosophical importance out of the analogical language in which we ordinarily speak of the mind. How, with this total difference between matter and mind, is the analogical language possible at all? Reid and Stewart do not say anything that would help towards an answer. The 'slightest similitude or analogy is thought sufficient to justify the extension of a form of speech beyond its proper meaning, whenever the language does not afford a more proper form'.4 But there is not, in their opinion, the slightest similitude or analogy between matter and mind. Somehow the analogical language is there, and the philosophical way to treat it is to treat it as if it was not there.

Since the dualism of Reid and Stewart is phenomenologically absolute-Stewart at times seems to be agnostic as to the nature

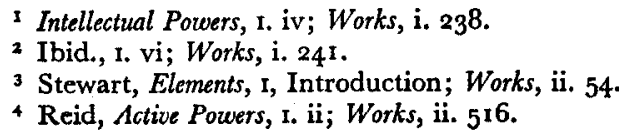

of what lies behind the phenomena-their negative attitude to ordinary language here is no surprise. And it is hard to see that they missed anything because of it which they could have wanted to find. They did not expect that evidence would ever be needed that there are bodies and minds, that minds are things and agents, though quite different from material things and agents, or they might have found a use for the analogical language which seems to provide it.

To prescribe to nature, as he held philosophers had traditionally done, Bacon spoke of as a 'second Fall'.' Eritis sicut Dii was the whisper heard in the Garden, and it is still in the ears of every philosopher who approaches nature with his mind made up as to how things are going to be. This is the approach of nature's Author, not of its interpreter. Philosophers have always been very ready, in Reid's opinion, to take over the work of creation, always very ready with 'conjectures', 'theories', 'hypotheses'. If they continually reminded themselves and others that these are all conjectures, there would be nothing to complain of. The reminders are commonly absent, and truth is put out of reach behind supposition, and we have its illusion instead. Descartes's correspondent was right when he remarked that the man who discourses on nature from the study may tell us what the world would have been like if God had given him the commission to make it, but he does not tell us what the world is like. Would a conjectural anatomist have come anywhere near the truth? The rest of nature is as impenetrable as the structure of the body to any method of investigation except that of observation and its extension in experiment and inductive inference drawn from their results. ${ }^{2}$

Reid's conjectural anatomist is not an easily recognizable type of philosopher or scientist, and his being mentioned might lead one to suppose that Reid's condemnation of hypotheses is less inclusive than it is.

When the claim is made that some 'phaenomenon in nature' is accounted for, there are two things we need to know. Can the cause assigned be shown to exist? Would it explain the phenomenon if it did exist? Unless both these conditions are satisfied, the explanation is a mere 'hypothesis' and its place is

\footnotetext{
I M. E. Prior, 'Bacon's Man of Science', Joumal of the History of Ideas, June 1954, 
on the rubbish heap. ${ }^{x}$ The theory of ideas Reid regards as a perfect 'hypothesis'; there is no evidence for it beyond its explanatory powers, and these are illusory. The theory of ideas is not a causal theory, and Reid's discussion of hypotheses is of causal hypotheses, but its results are meant to be applicable to other types of explanation. Thus Reid thinks that he has shown that there are no ideas, and that if there were, they could not do what he thinks they were intended to do, that is, make the cognitive operations of the mind intelligible.

Reid is emphatic on the authority of the two conditions which causal explanation must satisfy. Their statement is intended to be a paraphrase of the first of Newton's regulae philosophandi, ${ }^{2}$ and Newton's rules are 'maxims of common sense'.

The causal explanations which we can give consist in assigning to an event the antecedents upon which it always occurs and without which it does not occur-nothing more than that. We know of course, Reid maintains, that there must be something more than that, something that makes it happen, something more to the occurrence of an event than the bare occurrence of other events previously. But we never know how anything is made to happen. We do not know whether there are any real efficient causes, any agents in the strict sense of the word, besides ourselves and God. For all we know, every effect that we do not produce ourselves may be produced immediately by God, according to the rules of antecedence and consequence which we regard as causal laws. 'Philosophical' (scientific) discovery is the discovery of these causal uniformities and their subordination to more and more general uniformities. When we say

that one thing produces another by a law of nature, this signifies no more, but that one thing, which we call in popular language the cause, is constantly and invariably followed by another, which we call the effect; and that we know not how they are connected. Thus, we see it is a fact, that bodies gravitate towards bodies; and that this gravitation is regulated by certain mathematical proportions, according to the distances of the bodies from each other, and their quantities of

I Intellectual Powers, I. iii; Works, i. 236. In a later chapter (r. iii; Works, i. 251) Reid allows that hypotheses are useful in suggesting experiments and directing inquiries.

${ }_{2}$ 'We are to admit no more causes of natural things than such as are both true and sufficient to explain their appearances.' (Mathematical Princibles of Natural Philosophy, Motte's trans. revised by F. Cajori (Berkeley, 1947), p. 398.) matter. Being unable to discover the cause of this gravitation, and presuming that it is the immediate operation, either of the Author of nature, or of some subordinate cause, which we have not hitherto been able to reach, we call it a law of nature. If any philosopher should hereafter be so happy as to discover the cause of gravitation, this can only be done by discovering some more general law of nature, of which the gravitation of bodies is a necessary consequence. In every chain of natural causes, the highest link is a primary law of nature, and the highest link which we can trace, by just induction, is either this primary law of nature, or a necessary consequence of it. To trace out the laws of nature, by induction from the phaenomena of nature, is all that true philosophy aims at, and all that it can ever reach. ${ }^{\mathrm{I}}$

The relation of laws to events is different from the relation of events to events. Why did a thing happen? We may be asking what happened before it, asking for its cause. We may know what happened before it, but be unable to see the connexion between what went before and what came after, and be asking for the law connecting the two. Reid persistently speaks of causal laws as causes, slurring over the difference between them in his emphasis on the fact that causal transactions present themselves to our experience, when we are not involved ourselves as agents, as matters simply of antecedence and consequence.

Since to be a cause, in the sense in which we assign causes to phenomena in nature, is no more than to be the constant antecedent of an invariable consequent, how are we to know what could cause a thing-except in so far as anything could be the cause of anything - without knowing what actually does? Reid always speaks of the independence of the two conditions which explanations must satisfy. The 'syllogism' of discovery has a hypothetical first premiss and a categorical second premiss. 'If such a cause exists, it will produce such a phenomenon : but that cause does exist: Therefore, etc.'2 How could one be in a position to assert the first premiss except as a truism from the second? Presumably it is by some analogy with what we have experienced-Descartes's vortices could take the planets round the sun; we have watched eddies in water take things round things.

How do we find out that a possible cause is a cause? Whether the possible cause of something is its cause is 'a question of fact', and to be settled by 'positive evidence'. How was the paradigm

Inquiry, vi. xii; Works, i. 157.

2 'Letter to Lord Kames', Reid's Works, i. 57. 
of scientific explanation, the principle of the universal gravitation of matter, established? It was established

by induction, partly from our daily experience . . . and partly from the observations and experiments of philosophers, which shew that even air and smoke, and every body upon which experiments have been made, gravitate precisely in proportion to the quantity of matter; that the sea and earth gravitate towards the moon, and the moon towards them; that the planets and comets gravitate towards the sun, and towards one another, and the sun towards them. This is the sum of evidence. ... It is the same kind of evidence which we have, that fire will burn and water drown, that bread will nourish and arsenic poison. ${ }^{1}$

So late in the day one ought, Reid thinks, to have been able to take the proscription of hypotheses for granted and press for action on it in the philosophy of the mind. It could not be taken for granted. Hartley ${ }^{2}$ had given his recommendation to methods of hypothesis as properly scientific (with perhaps the implication even that they were nearer to the methods of science than the methodological reflections of scientists, more Newtonian than the Newtonian hypotheses non fingo) and he had used them in a physiological approach to the mind. According to Hartley, though there may be no direct evidence at all for an hypothesis,

still, if it serves to explain and account for a great Variety of Phaenomena, it will have an indirect Evidence in its favour by this means. Thus we admit the Key of a Cypher to be a true one, when it explains the Cypher completely; and the Decypherer judges himself to approach to the true Key, in proportion as he advances in the Explanation of the Cypher; and this without any direct Evidence at all. And as the false and imperfect Keys, which turn up to the Decypherer in his Researches, prepare the Way for the Discovery of the true and complete one, so any Hypothesis that has so much Plausibility, as to explain a considerable Number of Facts, helps us to digest these Facts in proper Order, to bring new ones to Light, and to make Experimenta Crucis for the sake of future Inquirers. ${ }^{3}$

I 'Letter to Lord Kames', Reid's Works, i. 57.

2 David Hartley (1705-57) had an impressive contemporary reputation which lasted, with some assistance from Priestley, until the end of the eighteenth century. His attempt at writing the natural history of the mind in terms of an associationist psychology was more widely influential than the speculative theory which he constructed on the model of Newtonian mechanics as a step towards the deduction of mental phenomena from physiological.

3 Observations on Man, I. i. (Ist ed., London, I 749), i. 15-16.
Reid makes no comment on Hartley's distinction between what is true in a 'useful practical Sense' and what is true in an 'ultimate and precise one', nor is he disarmed by the end of the passage just quoted, with its hints at the deductive and indirect verification of hypotheses by the predictions they authorize. ${ }^{\mathrm{I}}$ Let hypotheses 'suggest experiments, or direct our inquiries; but let just induction alone govern our belief'. Hartley appeared to be saying that an hypothesis did not absolutely need independent confirmation of its truth, if it could explain a wide range of phenomena. And Reid's answer is to repeat that 'could explain' does not take us any way towards 'does explain'-Descartes's vortices and Pope's gnomes and sylphs could explain a wide range of phenomena. Reid fumbles for the mistake in the cypheranalogy. To find hypothetically the key to the cypher of nature 'requires an understanding equal or superior to that which made the cypher'.2 The mistake in the cypher-analogy, Stewart says, is that 'there are few if any physical hypotheses, which afford the only way of explaining the phenomena to which they are applied; and therefore, admitting them to be perfectly consistent with all the known facts, they leave us in the same state of uncertainty, in which the decypherer would find himself, if he should discover a variety of keys to the same cypher.'3

The common defect, Stewart remarks elsewhere, in all theories claiming to have physiological explanations for mental phenomena is that they are "entirely unsupported by proof; and what is worse, are of such a kind, that it is neither possible to confirm nor to refute them, by an appeal to experiment or observation'.4 Yet Stewart's attitude to the place of hypotheses is very different from Reid's. The Copernican astronomy was justified even before it was confirmed by empirical evidence. It was justified by its simplicity. The justification of simplicity in an explanation is that it is analogous to all that we know inductively of the economy of nature. Analogies, Stewart continues, within the system of the material world may support hypotheses within the system of the material world, and this is true also of analogies and hypotheses within the system of the

These hints are made plainer in m. ii. Reid knew this section; he quotes from it.

2 Intellectual Powers, II. iii; Works, i. 250-1.

3 Elements, II. iv. 4; Works, iii. 313-14.

+ Philosophical Essays, Preliminary Dissertation; Works, v. 8. 
'intellectual' world. No analogies from one system will support hypotheses in the other. ${ }^{\mathrm{I}}$

It is now time to ask what Reid and Stewart think is to come from this concern over uniqueness of the mind and the proper methods of studying it. Reid says, I may not have got very far, but this does not matter if $I$ have been on the right road as far as I have gone; others may be able to go farther. ${ }^{2}$ But where to? Stewart says that it is less by his particular conclusions than by the originality of his method, 'so systematically pursued in all his researches', that Reid 'stands so conspicuously distinguished among those who have hitherto prosecuted analytically the study of Man'.3 You see Reid at his philosophical work, and you hear him talking about how the work of philosophy is to be done, and it is hard to find any connexion between the two. What has inductive inference to do with the argument between Reid and Hume? Supposing it is true that Reid has been able to give especially careful attention to the operations of his mind,4 how does this contribute to a philosophy of common sense? The philosophical method which Reid and Stewart advocate so urgently is a method of discovery, and the philosophers in Stewart's Dissertation on the history of philosophy are always adding or failing to add to the 'stock of human knowledge', but Reid does not seem to be trying to add to the stock of knowledge. If you had put in front of you, in extracts, Reid's and Stewart's remarks on method, coupled with their remarks on the special subject matter to which it is to be applied, you would think they came from books of psychology. Reid's books are not books of psychology. Stewart often writes as a psychologist, but he takes it for granted that his remarks on method and subject matter have a general application to his work as a philosopher. 'Philosophy', of course, had a wider sense in the eighteenth and early nineteenth centuries than it has now, and no one then would have found it surprising that a 'philosopher' should use inductive methods, but we need more than this reminder to understand Reid and Stewart.

Nor is it only when they themselves speak about what they are doing in philosophy that the puzzling contrast appears between the word and the action. According to McCosh, Reid

\footnotetext{
Elements, Ir. iv. 4; Works, iii. $3^{11-15}$.

3 Life of Reid, $\mathrm{n} ;$ Works, $\mathrm{x} .278$.

2 Inquiry, i. ii; Works, i. 99.

4 Inquiry, Dedication; Works, i. 96.
}

and Stewart showed how an inductive philosophy of the mind is to proceed. This he considers to be one of their greatest merits. As the whole of Scottish philosophy from Hutcheson through to Hamilton is marked off, in McCosh's judgement, from other philosophical traditions by a more or less steady adherence to an inductive method of inquiry (fitful in Hume, undeviating in Reid and Stewart), too much precision is not to be sought for in this characterization of Reid and Stewart. The difficulty is to understand it at all.

The great lesson, in Jouffroy's opinion, taught philosophy by the Scottish philosophy, is the possibility of an inductive philosophy of the mind. Jouffroy provides some materials for an elucidation of this opinion, and we might by looking at Reid and Stewart through Jouffroy's eyes, be helped to see them as they saw themselves when they saw themselves as inductive philosophers.

The name of Locke and the work of Condillac established a sensationistic scholasticism in France. The Baconian revolution which was needed had begun effectively in Scotland. Reid and Stewart, though with exaggerated ideas as to the complete novelty of their enterprise, made inquiry into the mind an inductive inquiry, and freed in principle a whole order of reality from the distortions of theory and system.

These acknowledgements, Jouffroy insists, have to be tempered with criticism. If Reid and Stewart are to be believed, the science of the mind is in its present state as a result of the perverse method applied by antiquity in all the sciences, expelled under the influence of Bacon from the physical sciences, but still with an unrelaxed grip on the science of the mind. And they are believed; their opinion 'has acquired among us [the Eclectic school] something of the status of an historical axiom'.

They were not, Jouffroy thinks, simply mistaken. The physical sciences were transformed by a transformation of method; there has been no similar transformation of the science of the mind; and its transformation will be a transformation of method. Reid and Stewart saw the truth, but they did not see into the truth. Why did all the sciences begin with analogical conjecture, and why has the science of the mind not emerged from it? Reid and Stewart have no satisfactory explanation, and consequently their I Scottish Philosophy, pp. 4-5, p. 305 and passim. 
opinions on the history of the sciences are unplausible and unilluminating even when they are factually accurate. Newton's regulae philosophandi are, as Reid states, maxims of common sense. How could anyone prefer analogy and conjecture to observation in the investigation of any part of nature that is open to observation? And in fact when the description of a thing and of the laws of its behaviour has been straightforwardly wanted, men have always examined the thing, whether it is something in the physical world or the mind itself. The suggestion that it is a modern and Scottish proposal in the study of the mind to study the mind directly is painfully naive if it is made without its proper qualifications. The questions which can be settled by observation have always been settled by observation, when there has been any immediate interest in the answers to them. The sciences began with no interest in the answers to them, with an interest in vast metaphysical problems. What is the nature of the soul? Has it always existed? Will it always exist? The world outside us presented problems of similar ultimacy. And to the solution of such problems nothing could come immediately from observation except hints for analogy and conjecture. The speculative systems which resulted worked downwards and deductively towards conclusions which were matters for empirical investigation only. The reformation of inquiry, achieved in the physical sciences, was brought about, and in the science of the mind remains to be brought about, by taking first questions which come last in human interest, questions which can be settled by observation and experiment. In their answers (when these are brought into combination with the principles of common sense) and nowhere else lie deeply implicit the solution of any of the ultimate problems which have solutions. Reid and Stewart saw where the science of the mind had to begin; they failed to see why it had not begun there. ${ }^{\mathrm{I}}$

The approach of Reid and Stewart to the philosophy of the mind is important for a number of reasons, Jouffroy thinks. The first is that it sweeps away false approaches. This is Reid's and Stewart's own view. Jouffroy's special interest here was in the damage which the inductive philosophy of the mind does to the deductive pretensions of sensationistic and materialistic philo-

1 Euvres de Reid, vol. i, Préf., pp. vi ff.; Esquisses de philosophie morale (a translation of Stewart's Outlines of Moral Philosophy), Préf. V, 3rd ed., Paris, I841. sophies. It was also Reid's interest, and, for philosophies with a materialistic tendency, even more Stewart's-Hartley looms over his world with something of the size of Hume over Reid's. We have already noticed the further polemical use which Reid makes of the uniqueness of the mind. It silences questions as to how the mind can do what bodies cannot do, that is enter into direct relationships with things remote in space and time. It disallows the analogies out of which the great sceptical hypothesis grows. And the inductive method also has its destructive side; it teaches us what to think of mere hypotheses. The truths of common sense are not inductive discoveries, but their rediscovery, if they have been lost, will owe more to education in the inductive method than to anything else, for if they have been lost, it will have been under the rubbish of hypothesis.

In their philosophy of the mind Reid and Stewart laid the proper foundations for a science of the mind, an empirical psychology. This is Jouffroy's opinion. It was also Reid's and Stewart's opinion, though they made no clear distinction between a philosophy and a science. What Reid saw himself as cautiously beginning was an empirical science of the mind. He saw himself therefore as positively an inductive philosopher. 'The rubbish being now removed, and the foundations laid, it is time to begin the superstructure', Stewart remarks. ${ }^{1}$ The superstructure, with which Stewart admits he has not got very far, is more a descriptive psychology than anything else.

When Reid and Stewart looked into the future of their philosophy of the mind, they thought that there was distantly visible a science with the two features of a developed science, 'analysis' and 'synthesis'. The work of analysis is to reduce the phenomena in any field of investigation to laws of the highest generality and simplicity. The work of synthesis is to deduce the consequences of such general laws taken severally or in combination. ${ }^{2}$ The works of Reid contain no synthetic deduction of phenomena, and the works of Stewart very little. How could it be otherwise, their critics have asked, when they contain so little and such perfunctory analysis? Reid requires as many original principles to explain the nature of man 'as have by others been thought

Elements, 1, Introduction; Works, ii. $5^{6}$.

${ }^{2}$ Reid, Inquiry, 1. ii; Works, i. 99; Stewart, Outlines of Moral Philosophy, Introduction; Works, ii. 7 . 
necessary for the system of the universe', Priestley says. I To philosophize is to simplify, in Brown's view; Reid refuses to simplify and refuses to allow other philosophers to simplify. ${ }^{2}$ And whether these critics were right or wrong in criticizing Reid for resisting analytic simplification in the philosophy of the mind, they were of course right in thinking that the philosophy of Common Sense had to resist it over large areas.

Priestley's charge that Reid was suffocating investigation under a multitude of principles is easily answered, Stewart thinks. Reid, remembering the infancy of the philosophy of the mind, had himself implied that his conclusions were provisional. 'And if, in any case, we should give the name of a law of nature to a general phaenomenon, which human industry shall afterwards trace to one more general, there is no great harm done. The most general assumes the name of a law of nature when it is discovered, and the less general is contained and comprehended in it.' 3

Priestley had noticed the passage. It seemed to him that Reid was preparing for the day when some of his 'ultimate', 'original', and 'inexplicable' principles would have their origin psychologically explained, and trying to postpone its arrival with the paralysing words 'ultimate', 'original', 'inexplicable'.4

Reid was not allowing for the revision of the principles of common sense, and some of the principles which Priestley was criticizing were principles which Reid regarded as principles of common sense. Two different kinds of principle are ambiguously accorded by Reid and Stewart the titles of 'original principles of the mind', 'general laws of our constitution': principles presupposed by all investigation (the principles of common sense, the 'fundamental laws of belief') and principles reached after investigation and 'analysis'.5 The first are unalterable; the second are open to revision at any stage in the progress of the philosophy of the mind.

Reid and Stewart, Francis Jeffrey remarks, were not moving as they thought towards a science of the mind which would parallel the physical sciences, giving us like them information

Examination, p. r ro.

2 Lectures, xil, p. 79

3 Inquiry, vi, xiii; Works, i. 163. 4 Examination, pp. $21-2$

5 Examples of these are, in Reid, the 'laws of vision' (Inquiry, vi. $x$-xiii), in Stewart, the 'law of sympathetic imitation' (Elements, wr, ii). that we did not previously have, and no continuation of their work will bring that science any nearer. They were doing something important, but quite different. What they were doing is more like the work of a grammarian who 'arranges in technical order the words of a language which is spoken familiarly', or the work of a cartographer when he maps out a man's native parish for him, than it is like the activity of a 'chemist or experimental philosopher'. In the philosophy of the mind knowledge we already have is arranged and systematized for us, and as the philosopher has no sources of information that are not available to all of us, this is all that can be done in the philosophy of the mind. Where, for instance, has the most careful reasoning on our perception of the external world brought us than 'back to the creed and ignorance of the vulgar'?

'Logic, whose end is the discovery of truth, is founded', George Campbell had said, 'in the doctrine of the understanding; and ethics, (under which may be comprehended economics, politics, and jurisprudence) are founded in that of the will.'2 A 'distinct knowledge of the powers of the mind', Reid says, 'would undoubtedly give great light to many other branches of science'. In his alternative metaphor, the tree of knowledge has its roots in the knowledge of the human mind. The philosophy of the mind deserved to be studied not only because of its intrinsic dignity, but also for the sake of many sciences, logic and ethics among them, which have an 'immediate connection' with it. And Reid quotes with approval the passage in which Hume proposes the capture of the citadel of the sciences in human nature. ${ }^{3}$ Stewart shares Reid's unsuspicious admiration for Hume's project. It was, Stewart remarks, Reid's 'great object' to promote the accomplishment of that design 'by exemplifying, in an analysis of our most important intellectual and active principles, the only method of carrying it successfully into execution'.4 One of the main objects with which Stewart himself began his inquiries into the human mind was to establish and exemplify the 'fundamental principle' that, in order to prepare the way for a 'just and comprehensive system of Logic, a previous

' Review of Stewart's Life of Reid, Edinburgh Review (Jan. 1804), iii. 276-7.

2 The Philosophy of Rhetoric, i. 12.

${ }^{3}$ Reid, Intellectual Powers, Preface; Hume, Treatise, Introduction.

4 Life of Reid, in; Works, x. 275. 
survey of our nature, considered as one great whole, is indispensably requisite'. ${ }^{\mathrm{I}}$

With these intentions Reid and Stewart would naturally think of themselves as inductive philosophers. In spite of these intentions, and of the connexions and relations they mention, they were able to leave the discontinuities between psychology and logic and ethics intact. To make the system of logic more comprehensive, Stewart wrote on the logic of induction. He gave it no foundations in human nature, apart from finding there a guarantee of the truth of the inductive principle. And the 'logic of morals' (in Stewart's phrase) was for both Reid and Stewart a logic of unique fact not reducible to or deducible from any matters of fact.

The virtues of the philosophy of Reid and Stewart were not exhausted in Jouffroy's eyes by its usefulness in controversy with error, and by the directions it gave for the construction of a science of the mind which would have significant implications for all philosophical disciplines. He saw in it also the potentialities of metaphysical development. This is not an opinion which Reid and Stewart share. They were not looking themselves for answers to great questions of philosophy unanswered by common sense, and did not think that anyone who was looking for them would ever find them. (The question of God's existence they held to be almost answered by common sense.) Reid allows himself a brief speculation on time and eternity and on the infinity of space in extent and divisibility; enough to see that when we discuss such problems we have gone beyond the limits of human understanding. In spite of these limits, however, Reid could see that space and time are necessarily infinite, and that space is also eternal. Pure space is so nearly nothing that 'it seems incapable of annihilation or of creation'. And the nunc stans of which the Schoolmen spoke has as much meaning for Reid as 'square circle'. 2 To Stewart, traditional metaphysical inquiry is a 'frivolous and absurd' intrusion into mysteries 'placed beyond the reach of the human faculties'. 3 Stewart holds

1 Philosophical Essays, Preliminary Dissertation; Works, v. 49.

2 Intellectual Powers, Ir. xix, m. iii. A number of 'determinations concerning matter' - such propositions as that two bodies cannot be in the same place at the same time-appear to Reid to be 'necessary truths' and therefore not 'conclusions of our senses' alone, which can never show necessity. (II. xix; Works, i. 324.)

3 Elements, i, Introduction; Works, ii. 45 strongly, nevertheless, to the axiomatic eternity of space and time. The conviction of their 'necessary existence' is 'inseparable from the very conception' of them. ${ }^{x}$

It is within our competence to find out that there is a God. Common sense, as the faculty of first principles, supplies the argument for God's existence from 'final causes' with its first premiss: 'from certain signs or indications in the effect, we may infer that there must have been intelligence, wisdom, or other intellectual or moral qualities in the cause'. Its second premiss is the proposition that the world displays these signs and indications. Reid will not allow that we need experience to teach us the signs and indications of intelligence and purpose. Experience cannot show that there is a connexion between two things when only one of them is a matter of experience. Our minds are objects of experience only to ourselves. And the man who can see no evidence for God's existence from final causes ought in consistency, Reid thinks, to see no evidence for any intelligence other than his own. ${ }^{2}$

The principles of common sense are not truths which have to be reached at some later stage of philosophical development, reappearing there with a deductive justification behind them. Still less are they mere approximations to truth which are to disappear at some later stage of philosophical development, replaced by the truth at which they hinted and which a philosopher has discovered. They are, according to Reid, truths without which other truths could not be reached. They are first principles in philosophy. Their place is not in the superstructure; they are its foundations.

Why, Reid asks, has the history of mathematics been a history of unbroken progress with hardly any disputes and these soon settled? Mathematics was founded upon first principles, upon 'a few axioms and definitions', and is the rigorous deduction of their consequences. Why was the history of natural philosophy a battlefield until Bacon and Newton? It was not only because

Philosophical Essays, 1. ii. 2; Works, v. 116.

antellectual Powers, vi. vi; Works, i. $460-1$. Stewart and Beattie agree with Reid that the existence of God is inferred. Oswald maintains that the world shows itself to common sense to have had an intelligent cause. We may say instead, if we wish, that we infer the existence of God, but we are saying very little; the premisses (the two which Reid requires) are supplied by common sense. (An Appeal to Common Sense, ii. 57-59.) 
hypothesis was pitted against hypothesis; it was also because natural philosophy was without first principles.

Lord Bacon first delineated the only solid foundation on which natural philosophy can be built; and Sir Isaac Newton reduced the principles laid down by Bacon into three or four axioms, which he calls regulae philosophandi. From these, together with the phenomena observed by the senses, which he likewise lays down as first principles, he deduces, by strict reasoning, the propositions contained in the third book of his 'Principia', and in his 'Optics'; and by this means has raised a fabric in those two branches of natural philosophy, which is not liable to be shaken by doubtful disputation, but stands immovable upon the basis of self-evident principles. ${ }^{x}$

When first principles are listed and agreed upon for 'the other branches of philosophy' - the 'great desideratum in logic'-they can expect a similar stability and progress.

Reid is mistaken, in Stewart's opinion, (i) about the nature of geometrical demonstration-it is clearly geometrical demonstration that Reid is thinking of; (ii) about the nature of Newtonian principles; (iii) about the function of the principles of common sense in philosophy. (Stewart is dealing with the principles of common sense which Reid calls 'first principles of contingent truths', and with the purely logical principles among the 'first principles of necessary truths'. He would not regard his remarks as applying, for instance, to the principles of causation and 'design' which function as premisses in proofs for the existence of God.)

The premisses for geometrical demonstration are not selfevident truths. They are not truths at all. The premisses are the definitions; not the axioms and definitions, as Reid sometimes says, still less the axioms alone, as he sometimes says. The axioms are deductively quite sterile. Nothing is implicit in such selfevident truths as that if equals are taken from equals, the remainders are equal.2 But although the axioms are not 'the principles of our reasoning, either in arithmetic or in geometry, their truth is supposed or implied in all our reasonings in both; and, if it were called in question, our further progress would be impossible'. ${ }^{3}$

Intellectual Powers, vi. iv; Works, i. 436.

2 The 'mathematical axioms' he has in view, Stewart explains, are the 'truisms' not the 'theorems' among the Euclidean axioms.

3 Elements, Ir. i. I; Works, iii. 32-34.
The Newtonian principles are not like mathematical axioms, because they are principles of deduction, and because they are reached by induction. The principles in the philosophy of the mind which will correspond to the Newtonian principles in natural philosophy are the 'general laws of our constitution' which, once reached by 'analytic' examination of the facts of consciousness, will allow, like the Newtonian principles, deductive explanation of phenomena. ${ }^{\text {I }}$ (And of course Newton's procedural rules are no part at all of his premisses.)

The principles of common sense are matter of fact propositions, and so are the Newtonian principles. The likeness between them ends there. The principles of common sense, though matter of fact propositions, are like the mathematical axioms in several respects. They are intuitively self-evident, and deductively sterile.

From such propositions as these-I exist; I am the same person to-day that I was yesterday; the material world has an existence independent of my mind; the general laws of nature will continue, in future, to operate uniformly as in time past-no inference can be deduced, any more than from the intuitive truths prefixed to the Elements of Euclid. ${ }^{2}$

The principles of common sense are, however, like mathematical axioms in another respect. As the mathematical axioms are presupposed in all mathematical reasoning, so the principles of common sense are general presuppositions of our thinking. They are not 'data' from which conclusions can be drawn; they are 'vincula which give coherence to all the particular links of the chain'.3 Thus all our reasoning concerning nature takes for granted its uniformity, and the existence of a material world independent of our perceptions of it; all our reasoning takes for granted our own self-identity and the reliability of memory.

If the account now given of these laws of belief be just, the great argument which has been commonly urged in support of their authority, and which manifestly confounds them with what are properly called principles of reasoning, is not at all applicable to the subject; or at least does not rest the point in dispute upon its right foundation. If there were no first principles, (it has been said,) or in other words, if a reason could be given for everything, no process of

\footnotetext{
Ibid., 1, Introduction; Works, ii. 51-52

2 Ibid., Ir. i. 2 ; Works, iii. 45-46

3 Ibid., Ir. i. I; Works, iii. 39 .
} 
deduction could possibly be brought to a conclusion. The remark is indisputably true; but it only proves (what no logician of the present times will venture to deny) that the mathematician could not demonstrate a single theorem, unless he were first allowed to lay down his definitions; nor the natural philosopher explain or account for a single phenomenon, unless he were allowed to assume, as acknowledged facts, certain general laws of nature. What inference does this afford in favour of that particular class of truths to which the preceding observations relate, and against which the ingenuity of modern sceptics has been more particularly directed? If I be not deceived, these truths are still more intimately connected with the operations of the reasoning faculty than has been generally imagined; not as the principles from which our reasonings set out, and on which they ultimately depend, but as the necessary conditions on which every step of the deduction tacitly proceeds; or rather (if I may use the expression) as essential elements which enter into the composition of reason itself. ${ }^{\mathrm{I}}$

In treating the beliefs of common sense as presuppositions of experience, vincula of its coherence, Stewart is no more able than Reid to avoid self-evidence. The philosophy of Common Sense, as was mentioned earlier, is doubly burdened with it: once in having to claim for the statements of common-sense beliefs a content self-evidently metaphysical, and again in having to claim for them self-evident truth.

\footnotetext{
I Elements, Ir. i. 2; Works, iii. 46-47.
}

\section{THE LANGUAGE OF SENSATION}

\section{NATURAL SIGNS}

A self-evident and incapable of proof, the truths of common sense have no logical antecedents. How do we know, for example, that there is an external world? Understood in one way, this is a question, Reid thinks, to which there is no answer. It cannot be answered if it is asking for a proof that there is an external world. All the efforts of philosophers to supply such a proof have failed to produce an argument fit to convince anybody. The question can be taken in another way and answered. The principles upon which we do in fact come to a knowledge of the external world can be discovered, and with them the foundation in nature and in human nature of our knowledge of many of the truths of common sense.

Reid's account of this foundation is given in his doctrine of natural signs. And here he is heavily in Berkeley's debt. He owes to Berkeley the notion of a natural sign and the theistic context in which this notion is set, a large part of the analogy between natural signs and human language and much of his description of the operation of the natural signs whose meaning has to be learnt. What is entirely Reid's own is his theory of the two classes of self-explanatory natural signs and his theory, therefore, of 'the foundation of common sense'.

Language, Reid says, is commonly supposed to be something that men have entirely invented. By nature they are as dumb as brutes, but they are more intelligent, and have taught themselves to speak by contriving artificial signs to express their thoughts and purposes and having these signs established by compact. This account of the origin of language is too marvellous for Reid. There is one very obvious explanation of the origin of language, and it is philosophically interesting because it 'tends to lay open some of the first principles of human nature'. The word 'language' may be extended to include

all those signs which mankind use in order to communicate to others their thoughts and intentions, their purposes and desires. And such 
signs may be conceived to be of two kinds: First, such as have no meaning but what is affixed to them by compact or agreement among those who use them-these are artificial signs; Secondly, such as, previous to all compact or agreement, have a meaning which every man understands by the principles of his nature

-these are 'natural signs'. And Reid thinks it

demonstrable, that, if mankind had not a natural language, they could never have invented an artificial one by their reason and ingenuity. For all artificial language supposes some compact or agreement to affix a certain meaning to certain signs; therefore, there must be compacts or agreements before the use of artificial signs; but there can be no compact or agreement without signs, nor without language; and, therefore, there must be a natural language before any artificial language can be invented. ${ }^{\mathrm{I}}$

The primordial language is not a dead language.' Its vocabulary is still what it was: gesture, modulation of the voice, and varying facial expression. These are natural signs, significant apart from convention. They do not have to be given a meaning; nature has already given them a meaning. We do not have to learn it; nature has already taught us. Babies are frightened by grim and menacing faces. Everyone who has watched children will have noticed that they can very easily distinguish between what is said to them playfully and what in earnest. They go by the natural signs, the tone of voice, the half-smile, when these contradict the 'artificial' signs. If we want any further evidence that there is a wordless language and an intuitive understanding of it, there is the fact that men who have no conventional language in common can communicate with one another.

Everybody will admit, Reid remarks, that there is a wordless language of gesture, intonation and facial expression; the question is whether its interpretation has to be learnt. How could it be learnt?

When we see the sign, and see the thing signified always conjoined with it, experience may be the instructor, and teach us how that sign is to be interpreted. But how shall experience instruct us when we see the sign only, when the thing signified is invisible? Now, this is the case here: the thoughts and passions of the mind, as well as

\footnotetext{
Inquiry, iv. ii; Works, i. 11 7-18.
}

the mind itself, are invisible, and therefore their connection with any sensible sign cannot be first discovered by experience; there must be some earlier source of this knowledge. ${ }^{\mathrm{I}}$

The natural language, which was prior to all conventional languages, is still contemporaneous with them; its vocabulary was and is everywhere the same, and everywhere intelligible without having to be learnt. The assertions about the past in Reid's theory are secure against any empirical criticism. Reid is not committed to the view that the connexions which nature has established between the 'thoughts and passions of the mind' and their manifestations are too rigid to be capable of modification by custom, natural signs being replaced by conventional signs whose meaning has to be learnt. And if it should be discovered that these thoughts and passions express themselves in ways which are hardly more universal than the universal grammar, on which Reid leans so heavily, in conventional languages, they might nevertheless once have had signs which were universal and immediately intelligible. This is not enough for Reid. The 'principles of human nature' which made possible men's understanding of one another without speech, so that they could proceed to the invention of speech, are permanent, and are the foundation of the knowledge every man has of the minds of other men.

Apart from any empirical criticism, Reid has to reckon with a behaviouristic account of the signs of what is in the mind, an account of them as means by which we go from the overt to the overt, and never from the overt to the covert. And here common sense, rejecting the exteriorization of the mind, would have to secure its own foundations.

The natural signs in the native language of mankind belong to the second of three classes of natural signs distinguished by Reid. In all three classes the connexion between the sign and what it signifies is established by nature-it is this that distinguishes a natural sign from a conventional sign. The signs of the first class are not understood intuitively; they might mean anything, as far as we are concerned, until we find out what they do mean. They are in themselves like words in an unfamiliar language. High streaky clouds are a sign of wind and the blueness of hills a sign of their distance. We have discovered this by

\footnotetext{
I Intellectual Powers, v. v; Works, i. 449-50.
} 
experience and would never have known it otherwise. This class of natural signs is the 'foundation of true philosophy', which is the discovery by observation and experiment of the matter of fact connexions established by nature, their reduction to general laws and the deduction of the consequences of these laws. The inquiry in which a natural philosopher is engaged has traditionally been described as a search for causes.

What we commonly call natural causes [Reid remarks in a passage which echoes both Berkeley and Hume] might, with more propriety, be called natural signs, and what we call effects, the things signified. The causes have no proper efficiency or causality, as far as we know; and all we can certainly affirm is, that nature hath established a constant conjunction between them and the things called their effects; and hath given to mankind a disposition to observe those connections, to confide in their continuance. ${ }^{\mathrm{I}}$

In the second class of natural signs, the sign itself explains itself. The signs of this class, constituting the natural language of mankind, are also, and for this reason, the foundation of the fine arts. In the expressiveness of the arts we hear again the primordial language which we can all understand and to which we respond at a level deeper than the level of the understanding. (Abolish conventional languages, and Reid's prophecy is that in a century every man would be a painter or a musician or an actor.) Reid does not think that art is simply the disciplined communication of emotion, but he does think that it must be the expression of some aspect of the mind. There is no beauty or sublimity in material things apart from the 'signature' of mind somehow upon them. The beauty and sublimity of nature is God's mind, so to speak, sensibly present. And in another way, Reid perhaps suggests, it is the expression of our own minds. Even our everyday descriptions of nature are full of worn-out poetry; the sea rages and the skies lower (things external to man made signs of what is within him). ${ }^{2}$

The problem of our knowledge of other minds is thus easily solved as far as it has a solution. We know them through their self-disclosure in natural signs, for these are 'so many openings into the souls of our fellow-men, by which their sentiments be-

I Inquiry, v. iii; Works, i. 122.

2 Ibid. Intellectual Powers, vrr. iii; Works, i. 497. come visible to the eye' 1 The epistemological problem has not, of course, been solved. No reason has been given to justify our claim to a knowledge of other minds; no premisses have been provided for a deductive conclusion. The inference from the sign to its signification has its own unique logic. No one can 'perceive any necessary connection between the signs of such operations, and the things signified by them'.2 Nevertheless the connexions are there, the signs do signify, and it is through them that a man's private consciousness becomes publicly accessible - to other men before they can speak to one another and while they speak to one andther. And since the belief that everyone lives an inner life of thought, feeling, and desire does not come to us through reasoning, it would not be surprising if we were unable to give a reason for it, and that the ordinary man should find the demand for such a reason astonishing. Tell him that he must have a reason, that he cannot be so credulous as to hold the conviction with such strength and be unable to say anything at all in support of it, and you might get from him an argument that would equally prove a watch or a puppet to be alive and conscious. Show him that his argument is a very bad argument. You 'cannot make him in the least doubtful'; you have not touched the foundations of his belief.

One could indeed give a reason for concluding that other men are intelligent beings: what they do bears the marks of intelligence. And in the same way the world shows itself to be the work of intelligence. But our knowledge of other men's minds is not reached by an argument similar to the argument from design. And in any case, the principle upon which the argument from design depends is itself a principle for which no reason can be given. ${ }^{3}$

Reid speaks of 'thoughts', 'purposes', 'desires', and 'passions' as all signified to us by natural signs. There is no great mystery, Stewart thinks, in our interpretation of the natural signs of the 'passions'. It is not the result of analogical reasoning. We did not as children first notice the visible manifestations of our emotions and then from what we saw in other people, infer their emotions. It would have been necessary for us to have watched ourselves in mirrors, or else to have learnt inexplicably

\footnotetext{
Active Powers, III. ii. 6; Works, ii. 574. $\quad 2$ Ibid., v. vi; Works, ii. 665.

3 Intellectual Powers, vi. v-vi; Works, i. 448-9, 46o.
} 
to identify what we felt on our own faces with what we saw on someone else's. It is, however, equally unbelievable that the natural signs of an emotion are interpretable without the prior experience in oneself of what they signify in others. (We cannot be sure, Stewart admits, that Reid thought that they were, but his words are certainly open to this construction.) Stewart accounts for the interpretation of the natural signs of the emotions by the 'law of sympathetic imitation' ${ }^{x}$ The connexion of emotions with their expression is reversible. The emotions produce their appropriate expression, and similar conditions of the body to those constituting their expression produce something of the correspondent emotions. We imitate, without noticing it, the bodily manifestations of other people's emotions and in consequence similar emotions are aroused in us. Sympathetic imitation, Stewart points out, is strongest in children, and his theory could allow that as we grow older the natural signs come to operate for us with acquired meanings (shifting from the second to the first of Reid's classes). It is thus not by sympathetic imitation that an adult discerns another person's feelings. But in thinking that he has explained something Reid left unexplained - the mechanics of the interpretation of a subclass of a class of natural signs--Stewart has not noticed the gap between states of mind sympathetically induced in us and our knowledge that someone else shares them.

Natural signs qualify for membership in the third of Reid's classes when they are signs which, 'though we never before had any notion or any conception of the thing signified, do suggest it, or conjure it up, as it were, by a natural kind of magic, and at once give us a conception and create a belief of it'. ${ }^{2}$ And as the first class of natural signs is the foundation of 'true philosophy' and the second of the fine arts, so the third is 'the foundation of common sense-a part of human nature which hath never been explained'. ${ }^{3}$ Thus, for example, the commonsense belief in an external world is grounded upon the fact that our sensations, themselves nothing but modifications of ourselves, are yet signs of the presence of physical objects existing in entire independence of us.

In all three classes of natural signs nature has established the

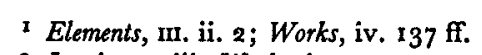

I Elements, II. ii. 2; Works, iv. $137 \mathrm{ff}$.

2 Inquiry, v. iii; Works, i. 122. connexion between the signs and what they signify. In none of them is the connexion, as far as we know, a necessary connexion. In the second and third classes the signs are understood intuitively, but not in the first. How does the third class differ from the second? Reid does not elaborate the difference, but it seems to turn on the origin of the conceptions involved in understanding the signs.

To understand a natural sign is to have a conception of the thing signified, and a belief in its existence. ${ }^{1}$ The conceptions involved in understanding a natural sign of the third class are obtainable in one way only, and that is by understanding the sign. Thus there is a single source of the conception of a physical object, as well as of the belief in physical pbjects. It is the significatory power of the sensations which we have from them. There is a single source of the conception of a substantival self, and of the belief in it. All our experiences signify, as part of their reference, the subject to which they belong. The conceptions involved in understanding signs of the second class are obtainable without the mediation of natural signs; they are obtainable introspectively. And perhaps they are obtainable in no other way. In that case the signs of the second class would be unintelligible until we had experienced in ourselves what they signify in others. The conceptions involved in understanding them would have to be brought to the understanding of them. Or it may have been Reid's view that the meaning of these signs could be read off independently of any experiences we might have had ourselves. The conceptions involved in understanding the signs of his second class would then have alternative origins.

$\therefore$. the foundation of common sense - a part of human nature which hath never been explained'. Hamilton in a footnote directs our attention to Stewart's comment. Stewart's comment is that Reid is using 'common sense' here with a 'technical meaning of his own, and has even spoken of this meaning as a thing not generally understood'. ${ }^{2}$ It is an odd comment for Stewart to have made, when the purpose of the chapter on natural signs is so plain. Reid is not engaged in elucidating the meaning of

The signs of the first class presumably create anything between a firm belief and a mere tendency to belief, according to our experience of the constancy of the connexion between the sign and what it is a sign of. We put, for instance, different degrees of reliance on different weather signs.

Elements, ณ. i. 3; Works, iii. 68. 
'common sense', but in providing the only kind of answer he thinks possible to anyone asking how we come to know that the beliefs of common sense are true: Nature is so constituted that certain empirical facts are signs of certain metaphysical facts, and human nature is so constituted as to be able to interpret these signs intuitively.

It is untidiness in a point of detail that our common-sense belief in other minds depends on natural signs belonging to the second class. There are more important anomalies. The inductive principle stands aside from other common-sense beliefs as a condition of the operation of signs of the first class. (Something analogous to it is a condition of the operation of the signs belonging to the other classes as well.) Reid has made the immediacy of memory so thorough that nothing seems to be left which could function as a sign connecting the present with the past. Morality presupposes a number of beliefs, such as the belief that we have free will. These have the authority of common sense, and are not reached by any interpretation of natural signs.

Reid would not be impressed by this criticism. If some of the beliefs of common sense dispense with a foundation which others of them require, an inductive philosophy of the mind has to recognize that this is so, and to resist the temptation towards theoretical completeness.

Scattered through the Inquiry are the fragments of an elaborate though unsystematic analogy between the systems of natural signs and a language. We shall put the more interesting material in the fragments into some sort of order.

To begin with, Reid wants us to see that natural signs are in one respect really much more like words than would occur to us when we think of the signs as established by 'nature'. Words are sounds or marks which have no meaning in themselves, but are given a meaning by being arbitrarily chosen, he says, to signify things. Nature has not chosen to establish relations of signification, but the true author of these is not nature but nature's Author. Reid is always emphasizing the arbitrariness of the connexions in nature; apart from God's appointment, anything might have gone with anything, for all we know to the contrary. But just as the connexions between words and the things they are made to stand for, once established, retain by custom some permanence, so by the custom of Divine provi- dence the connexions between one thing and another once established, remàin established.

When the ways in which we come to understand the language of nature and the way in which we come to understand human languages are compared, a partial break appears in the analogy. A human language has to be learnt. Only part of the language of nature has to be learnt. (The Novum Organum is its grammarbook, Reid remarks. The borrowed materials for Reid's analogy are from Bacon when they are not from Berkeley.) One system of natural signs resumes the likeness to a language in being a means of communication between men, and as learning a foreign language involves the use of our mother tongue, learning our mother tongue involves the use of this still more native 'language'.

Though, however, only one of the, systems of natural signs is a means of communication between men, all of them function in something which has some resemblance to communication. They are all parts of the language in which the 'testimony' of nature is communicated to men. The strain is taken off the analogy a little when we again remind ourselves that Reid is not merely personifying nature. Nature's speech is God's at second hand. It is God in fact, in Reid's philosophy, who lays the foundation of common sense. (The mottoes of Reid's first two books are: "The inspiration of the Almighty giveth them understanding.' 'Who hath put wisdom in the inward parts?') It is not indeed the case that without a belief in God we shall sooner or later find ourselves without the beliefs of common sense. They force themselves on us whatever our other beliefs. But if it is a question of how we could be in a position to know their truth, and in the way Reid supposed, of how things must be for this to be possible, what other answer is there, it might well be asked, than a reference to the way God has made us and the world? It would be too improbable that there should merely happen to be systems of empirical signs with metaphysical significations, signs which it merely happens we can understand intuitively. One would more readily believe that they do exist, if one also belieyed that they were intended to exist, and so had this further resemblance to a language.

Human language would be impossible without a disposition in speakers to speak the truth and in hearers to believe what 
they are told. God has matched in us the two principles of 'veracity' and 'credulity'. Reid sees an analogy to the first of these principles in the fact of the regularity of nature. 'If there were not a principle of veracity in the human mind, men's words would not be signs of their thoughts: and if there were no regularity in the course of nature, no one thing could be a natural sign of another.' $\mathrm{He}$ sees an analogy to the second of them in the fact that we are intuitively certain of this regularity. Though part of the testimony of nature is given in a language whose meaning is learnt by 'custom', it is not by custom, it is by an 'original principle implanted in human minds', that we know that there is the dependable connexion, without which the language of nature could not exist, between the signs and the things they signify.

Why is Reid so deeply interested in the analogy between systems of natural signs and a language? There is no likeness between words and what they stand for, nor any necessary connexion between them. There is no likeness between natural signs and what they signify, nor (so far as we know) any necessary connexion between them. When we have learnt the meaning of a word, the word calls to mind the object it stands for and 'creates the belief of it'. When we have learnt the meaning of a natural sign, or know its meaning without having to learn it, the sign operates in a similar way to produce a conception of what it signifies and a belief in its existence. ${ }^{2}$ The purpose of the analogy is to illuminate the operation of natural signs. Natural signs and words do the same thing in a similar way.

We need, in fact, to have understood Reid's account of the operation of natural signs, in order to understand the double function he is ascribing to words; otherwise we should not know what he means when he says that words 'create a belief' in the objects they stand for. Natural signs do this; words merely as words do not. Reid no doubt on reflection would entirely agree. The analogy between natural signs and language at this point will have to be between natural signs and a special use of language, its use with the intention of producing belief. It will have to be, as Reid usually implies, analogy between the testimony of nature expressed through natural signs and human testimony expressed through words and accepted without hesi-

I Inquiry, vi. xxiv; Works, i. 198.

2 Ibid., vi. xxiv; Works, i. 195. tation. In both, to understand the sign, whether it is a verbal sign or a natural sign, is to pass immediately from the sign to 'a conception and a belief of the thing signified'.

\section{SENSATION AND PERGEPTION}

There is a language of sensation. Sensations are the natural signs of physical objects and their properties and as such constitute this language, and it is, Reid maintains, by understanding the signification of these signs that we are enabled to know all that we do know of physical objects and their properties. For without perception we could know nothing of them at all, and to perceive a physical object is to have the "conception and belief of it' 'suggested' to us by the sensations that we have from it. Reid says that he has no theory of perception, and Stewart says that Reid has no theory of perception. They mean that Reid's account of perception is nothing more than a straightforward description of the central facts involved by the constitution of our nature in perception, and that the inexplicability of the connexions between these facts is recognized by Reid and left untampered with by conjecture. The wording of the description has the sound of theory, and in any case it will be convenient to speak of Reid's theory of perception.

Reid introduces his theory in its application to the simpler senses, beginning with the sense of smell. There are advantages in taking the more complicated sense of touch first-for one thing, what Reid calls 'sensations' are here less doubtfully sensations.

I pick up a billiard ball. I immediately perceive it to be round, smooth, and hard. If I attend carefully to all that I am aware of, or can become aware of as I hold the ball, I notice the feelings in my fingers and the palm of my hand. These feelings have no names of their own in any language. When they are referred to at all, they are referred to significantly as feelings of roundness, of hardness, of smoothness. We have to bring ourselves to attend to them, just as we have to bring ourselves to attend to the look of the words on a page we are reading, for like words their function is to point away from themselves. These feelings Reid calls 'sensations'. The sensations are not in the thing I am holding in my hand. Where are they? Reid says 
they are 'in the mind'. One might have thought that an untheoretical description of the facts of perception would have said with ordinary men that the feelings are in the fingers and the palm of the hand. Reid's reply to this criticism would have been that if his purpose in speaking of the location of sensations had been the ordinary man's, the ordinary words would have been the right words. When 'a man says he has pain in his toe, he is perfectly understood, both by himself and those who hear him. This is all that he intends. He really feels what he and all men call a pain in the toe.'I As an ordinary man, he locates his sensations where their causes are. He has no occasion to reflect on the esse of sensations, and therefore none to ask and answer a philosopher's question.

Now let us compare the feelings of roundness, hardness, and smoothness with roundness, hardness, and smoothness. They are as different as things can be, without one property in common. And when we compare their modes of existence, we find that we are comparing things that can exist no longer than we are aware of them with things that exist whether we are aware of them or not. Yet all I have to go on (supposing my eyes are shut) in perceiving that I am holding something round, smooth, and hard are the sensations in my fingers and the palm of my hand. If I had been born blind, these are all that I would ever have had to go on. I cannot have learnt the signification of these sensations. I can learn that one thing is the sign of another thing, and so learn to infer one from the other, when I can experience the two things independently and discover their connexion. But this is not how it is here. There is no resemblance between sensations and physical qualities, and when we look for any 'tie or connection' between them, anything that would begin to explain why this sensation 'suggests' or 'introduces' that quality, we can find nothing at all. Take hardness, for instance, and the feeling of hardness. The feeling is not a copy of the quality; 'nor will the logician ever be able to shew a reason why we should conclude hardness from this feeling, rather than softness, or any other quality whatsoever'. ${ }^{2}$

What answer would Reid give to the logician who said that the reason why the feeling of hardness suggests hardness and

Intellectual Powers, II. xviii; Works, i. 320.

2 Inquiry, v. v; Works, i. 125. nothing else, is that a hard object, as far as common sense is concerned, is nothing but an object which gives us the feeling of hardness when we press against it? By 'hardness', Reid says, we mean in common speech something 'whose parts stick so firmly together, that they cannot be displaced without considerable force'.' Reid might have been persuaded easily enough that this is a natural philosopher's account of hardness. He himself maintains that the sensations which we have from the secondary qualities of physical objects signify no more than that there is something or other in the objects in virtue of which we have these sensations from them. It would not damage his theory of perception if he had to speak in the same way of hardness which he ranks among the primary qualities. It would destroy it if he had to speak in the same way of one physcial quality after another. What notion do we have of smoothness? Is a smooth surface simply one which gives silky feelings to the hand that is run over it? Not even to a blind man, Reid is certain. A blind man can feel the absence of irregularities in it, and therefore he knows what a smooth surface is, not merely what it is relatively to his touch. (The notion of smoothness though relative, is objectively relative.) And Reid is as certain that our notion of figure is of figure as it is in itself, and our notion of the extension which is presupposed by all other physical qualities.

How do we come to have the notion of extension? Where are we to look in order to find the origin of that idea? We are told by philosophers, Reid says, that the idea of extension is an idea of sensation, as if that put an end to any difficulty in the matter. We are told something that conceals a mystery under a show of obviousness. How does a sensation or a combination of sensations give us the idea of extension? If we reflect on the origin of this idea and of our belief that we live in a world of extended objects, we shall have to recognize once again the inexplicable operation of sensations as natural signs.

The notion of extension is so familiar to us from infancy, and so constantly obtruded by everything we see and feel, that we are apt to think it obvious how it comes into the mind; but upon a narrower examination we shall find it utterly inexplicable. It is true we have feelings of touch, which every moment present extension to the mind;

$$
1 \text { Inquiry, v. v; Works, i. } 125 .
$$


but how they come to do so, is the question; for those feelings do no more resemble extension, than they resemble justice or courage-nor can the existence of extended things be inferred from those feelings by any rules of reasoning; so that the feelings we have by touch, can neither explain how we get the notion, nor how we come by the belief of extended things.'

The simple truth is that we know by 'a natural and original principle of our constitution' how to interpret the sensations of touch.2

What has Reid explained that the philosophers left unexplained when they said that the idea of extension is an idea of sensation? Nothing. It is the answer required by Reid's doctrine. The connexion between every natural sign and the thing it signifies is altogether inexplicable. Our knowledge of the connexion is altogether inexplicable, when the sign is a sign belonging to either the second or third class of natural signs. If the doctrine explains nothing, does it even assert anything that anyone would deny? It asserts that we know intuitively the signification of the sensations which we have from physical objects, and that if we did not, experience could not inform us. And these assertions would be denied by philosophers denying that we have any knowledge of physical objects existing independently of us, and by philosophers with a claim to be able to derive all our knowledge from 'experience'.

We now turn to the other senses. Reid examines two of these in detail. The examination of the sense of smell gives results he thinks transferable, with trivial modifications, to taste and hearing. The sense of sight requires separate attention.

There are, according to Reid, sensations of smell. We had no difficulty in understanding the phrase 'sensation of touch'; we have to be helped to understand the meaning of 'sensation of smell'. One would like to say that Reid speaks of a 'sensation of smell' where we would ordinarily speak of a 'smell'. Reid would disown this attempt at elucidation. The words 'smell',

\footnotetext{
I Inquiry, v. v; Works, i. 124
}

2 We may not always have known. A child 'for some short period of its existence' is perhaps 'merely a sentient being; the faculties by which it perceives an external world, by which it reflects on its own thoughts, and existence, and relation to other things, as well as its reasoning and moral faculties, unfold themselves by degrees; so that it is inspired with the various principles of common sense ... when it has occasion for them.' (Ibid., v. vii; Works, i. 130.) 'taste', 'sound', as also 'heat' and 'cold' and even 'colour', he considers, all have a kind of ambiguity. As words in common use, they stand for certain 'sensations' and also for the qualities of physical objects in virtue of which we have these 'sensations' -and primarily for the qualities. These words have only a kind of ambiguity. They cannot be said to stand sometimes for the qualities and sometimes for the 'sensations'. They cover both in a single application, there being no occasion in the common affairs of life to distinguish between them. It is essential for philosophers to make the distinction. Reid uses the expression we are trying to understand in order to make it. And if he has not misdescribed the ordinary use of the word 'smell' (and of other words which resemble it) we know what he is referring to.

We shall not perhaps have understood why Reid is calling it a 'sensation'. Examine its nature. It is simply such as it appears to be. We know practically nothing by the sense of smell of smell as a physical quality; what it is is a matter for physical inquiry. For the other thing named by the word 'smell', there is no other source of information than the sense of smell. And this thing is plainly something to which it would be absurd to ascribe any physical characteristics, even spatial location. It is plainly something which cannot exist except in a sentient being, and its duration is the duration of the consciousness of it. These are characteristics of a sensation. ${ }^{\text {I }}$

If, when they are pointed out to us, we are unable to discern these characteristics in the 'sensation' of smell or in the 'sensations' of taste, sound, and colour, if we think that these things are not sensations, that some or all of them might exist in the absence of any sentient being, Reid is unable to say anything that will make their nature more evident. He has explanations showing why these characteristics are unnoticed before they are pointed out. We do not attend to the sound of words, but to their sense; not to natural signs, but to the things they signify. And sensations, in their normal self-effacement before the things they signify, seem to merge into them, to take on alien characteristics, to have their own obliterated.

Sensations are essentially identical with the awareness of them, and signify objects which are essentially distinct from the awareness of them-external objects, the objects of perception.

$$
\text { I Ibid., In. ii; Works, i. 105. }
$$


The same mode of expression is used to denote sensation and perception; and, therefore, we are apt to look upon them as things of the same nature. Thus, I feel a pain; I see a tree: the first denoteth a sensation, the last a perception. The grammatical analysis of both expressions is the same: for both consist of an active verb and an object. But, if we attend to the things signified by these expressions, we shall find that, in the first, the distinction between the act and the object is not real but grammatical; in the second, the distinction is not only grammatical but real.

The form of expression, I feel pain, might seem to imply that the feeling is something distinct from the pain felt; yet, in reality, there is no distinction. As thinking a thought is an expression which could signify no more than thinking, so feeling a pain signifies no more than being pained. What we have said of pain is applicable to every other mere sensation. . . . Perception ... hath always an object distinct from the act by which it is perceived; an object which may exist whether it be perceived or not. ${ }^{\mathbf{X}}$

Sensations thus appear in Reid's theory with double objects: the object identical with the act and the object signified, distinct from the act and therefore external. Reid's constant assertion is that sensation and perception are entirely different things, but the difference between them in his theory of perception is not the difference between sensation and something else; it is the difference between a sensation and a sensation functioning as a natural sign (the difference between a word looked at blankly and a word understood).

We have considered the sensation of smell as a mere sensation and have now to consider it as a natural sign. Imagine a man suddenly and for the first time in his life given the power of smell, and there is a rose in front of him. He has a sensation of smell. What does he perceive by means of this sensation? Not the rose-not to begin with. He is aware of a new sensation in himself. It signifies the existence of its external cause, but nothing further as to the nature of its cause. ${ }^{2}$ What is signified

I Inquiry, vi. xx; Works, i. 182-3.

2 The passage reporting the results of this theoretical experiment reports vaguer results. ' $\ldots$ he is conscious that he is not the cause of [the sensation] himself; but cannot, from the nature of the thing, determine whether it is caused by body or spirit, by something near, or by something at a distance. It has no similitude to anything else, so as to admit of a comparison; and, therefore, he can conclude nothing from it, unless, perhaps, that there must be some unknown cause of it.' (Ibid., II. ii Works, i. 105.) Reid elsewhere takes it for granted, as his theory requires, that such by a sensation is what is perceived by means of the sensation.

When the rose is taken away the sensation of smell disappears and returns when the rose is brought back. The cause of the sensation then is the rose or something in the rose. When this has been learnt, the sensation becomes a sign of the presence of a rose, shifting for all practical purposes from the third to the first class of natural signs. The rose becomes an object of perception through smell.

We are now in a position to understand the 'real foundation' for the distinction between the primary and secondary qualities of bodies. Our senses

give us a direct and a distinct notion of the primary qualities, and inform us what they are in themselves. But of the secondary qualities, our senses give us only a relative and obscure notion. They inform us only, that they are qualities that affect us in a certain manner-that is, produce in us a certain sensation; but as to what they are in themselves, our senses leave us in the dark. ${ }^{\mathrm{I}}$

The too unqualified assertion that sensations efface themselves before the things they signify has to be corrected.

We may see why the sensations belonging to secondary qualities are an object of our attention, while those which belong to the primary are not.

The first are not only signs of the object perceived, but they bear a capital part in the notion we form of it. We conceive it only as that which occasions such a sensation, and therefore cannot reflect upon it without thinking of the sensation which it occasions: we have no other mark whereby to distinguish it. The thought of a secondary quality, therefore, always carries us back to the sensation which it produces. We give the same name to both, and are apt to confound them together.

But, having a clear and distinct conception of primary qualities, we have no need, when we think of them, to recall their sensations. When a primary quality is perceived, the sensation immediately leads our thought to the quality signified by it, and is itself forgot. We have no occasion afterwards to reflect upon it; and so we come to be as little acquainted with it as if we had never felt it. This is the

sensations by themselves (since it must be by themselves or not at all) firmly signify their external causes.

Intellectual Powers, Ir. xvii; Works, i. $3^{\text {I } 3}$ 
case with the sensations of all primary qualities, when they are not so painful or pleasant as to draw our attention. ${ }^{I}$

Nobody asks to be told what extension, figure, smoothness and roughness, solidity, divisibility, and motion are. His senses have already told him. And the information supplied concerning the nature and existence of these qualities is entirely objective information. When we perceive that something is round, smooth, and hard we know implicitly that it is perceived as it would be if we did not exist. We know implicitly from the testimony of the senses that even the secondary qualities of bodies are whatever they are in complete independence of ourselves. (Sense experience has essentially this objectivity in Reid's opinion, and we have misunderstood him unless we have seen him maintaining a similar objectivity in common sense as part of the implication of the analogy between sense and common sense.)

Nobody knows by the sense of smell what smell in the rose is, by the sense of taste what taste in the pineapple is, by the glow of warmth what heat in the fire is. These are matters for investigation, in which, Reid mentions, there has been a good deal of progress. Interested in the progress of such inquiries, a 'plain man' asks a 'modern philosopher' what, for instance, smell in plants is. 'The philosopher tells him, that there is no smell in plants, nor in anything but in the mind; that it is impossible there can be smell but in a mind; and that all this hath been demonstrated by modern philosophy.'2 Who is to blame for the plain man's opinion of the philosopher? The philosopher is to blame. For either he means by the word 'smell' what other men mean by it-primarily the external quality - and then his opinion is really absurd, or else, abusing language, he expresses a true opinion absurdly.

The plain man's encounter with the philosopher is repeated in the Intellectual Powers. This time the philosopher is assuring him that fire is not hot. Reid now thinks that there is some confusion in the plain man's mind to begin with. It is not to be expected that he will have made distinctions which the everyday affairs of life do not require. He does not therefore distinguish between primary and secondary qualities. His notions of

Intellectual Powers, II. xvii; Works, i. 3 I5.

2 Inquiry, II. viii; Works, i. 112. the primary qualities are clear and accurate; of the secondary qualities, not so much erroneous as clouded. A secondary quality is 'the unknown cause or occasion of a well-known effect'. As plain men we have not had to distinguish between the objective and the subjective components in our notions of the secondary qualities. The philosopher has been asked a question which cannot be answered until the distinctions are made. He has made the distinctions, but without any respect for ordinary language. When he has explained himself and the plain man has thought about heat, they no longer charge each other with opposite absurdities. ${ }^{\mathrm{I}}$

We have now to deal with the sense of sight and to consider first colour and then 'visible figure'.

By colour, all men, who have not been tutored by modern philosophy, understand, not a sensation of the mind, which can have no existence when it is not perceived, but a quality or modification of bodies, which continues to be the same whether it is seen or not. The scarlet-rose which is before me, is still a scarlet-rose when I shut my eyes, and was so at midnight when no eye saw it. The colour remains when the appearance ceases; it remains the same when the appearance changes. For when $I$ view this scarlet-rose through a pair of green spectacles, the appearance is changed; but I do not conceive the colour of the rose changed. To a person in the jaundice, it has still another appearance; but he is easily convinced that the change is in his eye, and not in the colour of the object. Every different degree of light makes it have a different appearance, and total darkness takes away all appearance, but makes not the least change in the colour of the body. ${ }^{2}$

The appearance of colour is a sensation. 'Mr. Locke calls it an idea' and, Reid adds astonishingly, 'it may be called so with the greatest propriety. ... It is a kind of thought, and can only be the act of a percipient or thinking being. ${ }^{2}$. The sensation of colour is never called 'colour', Reid says (though he says, as Stewart noticed, that sensation and quality are run together so closely in the imagination as to be mistaken for the same thing). He then denounces with especial severity the philosophical paradox that visible objects have no colour and that colour is in something invisible, the mind.

Stewart has a brief conjectural history of the externalization Intellectual Powers, II. xvii; Works, i. 315-16.

2 Inquity, vr. iv; Works, i. I37. 
of the sensation of colour. The connexion of the sensation of colour with 'visible extension and figure' is a matter of association, but since the association began as soon as our eyes opened, it is now indissoluble. It is not improbable that visible extension and figure would appear to us at first merely as 'modifications of the mind'. Distance is not perceived by sight until sight has learnt from touch. Visible figure comes to be visually located where tangible figure is, the sensation of colour moving with its associate to an illusory distance. ${ }^{\mathrm{I}}$

To locate 'visible objects' in the mind is to affirm 'a top and a bottom, a right and a left in the mind', Reid says in criticism of Berkeley, and he adds that he is not well enough acquainted with the 'topography of the mind' to be able to give any sense to this top and bottom and right and left. ${ }^{2}$ When Reid located visible objects in the mind, he 'shaved off' their extension first, one of his nineteenth-century critics remarked. ${ }^{3}$ Reid seems to think that with certain deformations of the eye colour can be seen unextended, and it looks then as things do when seen through a 'glass of broken gelly', their colour visible but not their shape. ${ }^{4}$ Stewart does not offer any experimental assistance to make it easier for us to imagine how visible extension and figure would look if they ever appeared to us as modifications of the mind.

Visible figure is the one exception allowed by Reid to the rule that there is no similitude and no necessary connexion between a natural sign and what it signifies. Visible figure is a natural sign of real ('tangible') figure, resembles it, and is necessarily connected with it. The visible figure of a thing is its perspectival figure. A thing has one real shape which does not change with the different points of view and distances from which it is seen, and as many different apparent shapes as there are points of view and distances from which it is seen.

Visible figure is not a sensation. It is a real figure-a 'real and external object to the eye'-though not the real figure of the thing of which it is the appearance. The structure of the eye partly determines its nature. The relation between real figure and visible figure, as determined by the structure of the

Dissertation, 1. ii. 2; Works, i. 131.

2 Inquiry, vi, xi; Works, i. 155 .

3 John Fearn, The Physiology of Mind (London, 1829), p. 35 .

4 Inquiry, vi. viii; Works, i. 145. eye, is the relation between a three-dimensional figure and its projection onto the surface of a sphere. It is altogether irrelevant to the existence of visible figure that it is seen (assuming that Reid means by 'external' in this context what he means by it elsewhere)

A peculiarity in the awareness of visible figure is that it is an awareness of an external object which is not conveyed by any sensation. There is no sensation present whenever we see except the 'sensation' of colour. This is not a sign of visible figure, and we might, Reid thinks, have been so constituted as to be able to see without being able to see colour. ${ }^{2}$

There is a necessary connexion between visible figure and its dimensions, and real figure and its dimensions. Visible figure with its magnitude is mathematically deducible, given the real figure of a thing, its magnitude, distance, and 'position'. ${ }^{3}$ It would not be impossible for a blind man, Reid says, to calculate a thing's visible figure from these data. All he needs to be able to do is to 'project the outline of a given body, upon the surface of a hollow sphere, whose centre is in the eye. This projection is the visible figure he wants: for it is the same figure with that which is projected upon the tunica retina in vision.'4

'On the retina' cannot be Reid's answer to the question 'Where is visible figure?' He often remarks with obvious truth that we never see the retinas of our eyes or anything on them. One would have supposed from the other things that Reid says, that he located visible figure at the surface of the eye. The boy who was 'couched' by Cheselden, and whose reports of what he saw as soon as he was able to see were seized on by everybody, including Reid, with questions concerning perception which they wanted empirically settled, reported, as commonly understood, that he first saw colours and shapes up against his eyes.

1 'External' is doubly contrasted with 'in the mind' in Reid's use of the expressions: (a) 'All things except the mind itself may be distinguished into things in the mind and things external.' 'Things in the mind signify things whereof the mind is the subject and which are of such a nature that they cannot possibly cxist by themselves or in any other subject. ... Things external are all other subjects or things existing in those subjects.' (Aberdeen MSS. 2131.5; cf. Intellectual Powers, 1. i; Works, i. 22 I.) (b) Whatever exists but not in the mind as its subject, exists independently of our perceiving or thinking of it, and is in this sense also 'external to the mind. $\quad 2$ Inquiry, vi. viii; Works, i. 146

3 'Objects that lie in the same right line drawn from the centre of the eye, have the same position.' $\quad$ Ibid., vi. vii; Works, i. 142-3. 
Visible figure would not be a sign of anything to the blind man who had calculated it. To other men it is a sign of the real figure of the thing they are looking at. They do not look at it, never notice it. We do not see the book on the table across the room as a two-dimensional patch of colour about the size of a hand; we see it in its three dimensions and the size it is. The appearance of things constitutes a visual language, which once learnt and familiar takes us straight to the things its signs signify, as though we perceived these things 'without the intervention of any sign'.'

The signs by which objects are presented to us in perception, are the language of Nature to man; and as, in many respects, it hath great affinity with the language of man to man, so particularly in this, that both are partly natural and original, partly acquired by custom. Our original or natural perceptions are analogous to the natural language of man to man ... and our acquired perceptions are analogous to artificial language, which, in our mother-tongue, is got very much in the same manner with our acquired perceptions. ${ }^{2}$

The perception of real figure through visible figure as its sign is an 'acquired perception'. The perception of visible figure (if we attend to it so far as to perceive it) is an 'original' perception. The perception of real figure by touch is an 'original' perception. In acquired perceptions original perceptions become signs; or sensations acquire new signification. Reid has nothing unfamiliar to say on the manner in which acquired perceptions are acquired. The principle is that the 'proper objects' of one sense are found by experience to be connected with the 'proper objects' of another sense, ${ }^{3}$ and so become their customary signs. Reid substantially repeats from Berkeley and the optical writers of the time their account of the education of vision to a perception of distance and of the real shape and size of objects at a distance. He is especially anxious to insist on the psychological immediacy of acquired visual perception. Gustom 'by a kind of legerdemain' has withdrawn the 'original and proper objects of sight' and has put in their place 'objects of touch, which have length, breadth, and thickness, and a

1 Inquiry, vi. xix; Works, i. 182.

2 Ibid., v1. xx; Works, i. 185.

3 Or with those of all the other senses. Thus the perception that this is the sound of a passing coach is an acquired perception. determinate distance from the eye'. ${ }^{1}$ The senses of smell and hearing perceive distance and locality after a similar though simpler schooling.

Perception has its anatomical and physiological conditions. Reid's general attitude to these is that they create no problems and solve no problems of what would now be called 'philosophical' interest-perception is an 'act of the mind'. In particular there are two things, Reid thinks, needing to be said. The first is that while it is a fact of our constitution that perception does not take place without the appropriate sense organ and unless certain physiological events have taken place, we have no reason at all to suppose that these events are in any way 'efficient' causes of perception, that they transmit anything, do anything, to the mind as a result of which the act of perception takes place. (This is Reid's deliberate view, though he sometimes speaks casually of the body as 'acting on' the mind.) Reid, however, has no scheme of occasionalism or pre-established harmony. The impression one gathers from his published writings is that it is part of his metaphysical abstinence not to have any theory on the relation of body and mind. In his manuscript 'Lectures on the Fine Arts' he has opinions that are definite enough. There is much to be said for occasionalism, but 'it has been carried greatly too far'. There is a plain inconsistency in asserting that God does, and that the human mind cannot, act on matter. Both are spirits. If we think that the mind acts on the body we are probably not mistaken. We are almost certainly mistaken if we think that the body acts on the mind. It does not seem possible that the mind could be plastic to any of the modes of material action of which we have any knowledge. ${ }^{2}$

The second consideration for emphasis with regard to the anatomical and physiological conditions of perception is their complete arbitrariness as far as we can tell. For all we know, we might have been made so as to 'taste with our fingers, to smell with our ears, and to hear by the nose'. ${ }^{3}$ We might have been so made as to have all the sensations and perceptions we do have with no sense organs at all, or without any of the

\footnotetext{
Ibid., vi. xix; Works, i. 182.

2 Edinburgh University Library, Laing MSS. 176, pp. $21-23$.

3 Inquiry, vi. xxi; Works, i. 187
} 
occurrences in nerves and brain which begin with changes in them. Sensation follows unaccountably upon the transmission of impressions from the sense organs to the brain; perception upon sensation, unaccountably. There is no reason at all for supposing that any link is a necessary link in the chain of events which leads from impressions on a sense organ to an act of perception.

We might, perhaps, have been made of such a constitution as to have our present perceptions connected with other sensations. We might, perhaps, have had the perception of external objects, with out either impressions upon the organs of sense, or sensations. Or, last ly, the perceptions we have, might have been immediately connect ed with the impressions upon our organs, without any intervention of sensations. ${ }^{\text {I }}$

One thing is certain: if we had the sensations alone, or the impressions and sensations alone, we would have been merely sentient and not percipient beings, unable to form even the conception of external objects.

The perception of an object 'implies' both a conception of it and 'a belief of its present existence'.2 According to Reid, Hamilton comments, 'perception is only the conception (imagination) of an object, accompanied with a belief of its present existence'. This could hardly be Reid's view. It would commit him to holding that any belief in the present existence of anything is a perception of it, since he holds that every belief implies a conception of its object. Hamilton takes the statement he is commenting on out of the whole context of sensations as natural signs in which Reid's doctrine of perception is really set. He has a good deal of excuse: the section in the Inquiry and the chapter in the Intellectual Powers, each with the heading 'Of Perception', are misleadingly written out of context. Reid does

I Inquiry, vi. xxi; Works, i. I87. A speculative agnosticism as to the significance of the anatomical and physiological conditions of perception is a characteristic of the philosophy of Common Sense. Stewart gives a muted version of Reid. (Elements, x. i. 3.) The following is from a note-book of Beattie's (Aberdeen MSS. B22): 'Our souls may, perhaps, be not really assisted in external perception by the resp organs of sense, but only hindered from it by the other parts of our body: the ears, for example, may possibly be, not parts of our body enabling the mind to hear, but only the sole parts of our body which do not obstruct hearing; and which can admit those impressions of sound, that a disembodied spirit might receive immediately.'

Inquiry, vI. xx; Works, i. I83. not say in either that perception is merely a matter of conception and belief, but (except for adding 'true' to 'belief') he could not say what more there is to it if what he calls 'sensations' are to be left out of it. And therefore he cannot say that we might have all the perceptions we do have "without any intervention of sensations'. They are essential to his account of perception; the conception of an external object, and the belief in its present existence which are 'implied' in perception, are aspects of the operation of sensations as natural signs.

There is, however, a puzzling remark in this section from the Inquiry. It suggests-and there are hints elsewhere to the same effect-that Reid might have had two views on the nature of perception. 'I am conscious of this act of my mind [the act of perception], and I can reflect upon it; but it is too simple to admit of an analysis, and I cannot find proper words to describe it' (p. 183). The theory of natural signs with acquired or original meanings is an analysis of perception. If there is a different view of the nature of perception here and hinted at elsewhere, it is the view that all that can be said of perception itself (beyond noting that it implies conception and belief) is that it is perception. It is a type of view which Reid always found philosophically attractive. There are in fact a number of features in this section of the Inquiry which are less characteristic of the Inquiry than of the Intellectual Powers where natural signs are much more rarely spoken of.

In one part of the Intellectual Powers where Reid does deal at length with sensations as signs, he speaks inconsistently of what it is that they signify. The chapter 'Of Sensation' begins with the familiar doctrine that sensations signify external objects. The words 'smell', 'taste', 'sound' are words for 'a sensation, and a quality perceived by means of that sensation. The first is the sign, the last the thing signified. As both are conjoined by nature, and as the purposes of common life do not require them to be disjoined in our thoughts, they are both expressed by the same name' (p. 3ro). The qualities perceived by touch are perceived 'by means of a sensation which indicates them' (p. 3 I I). On the next page, after references to the real complexity of some operations of the mind underneath their apparent simplicity, Reid says that sensation signifies perception, and seems plainly to mean the act and not the object. 'Every 
different perception is conjoined with a sensation that is proper to it. The one is the sign, the other the thing signified. They coalesce in our imagination. They are signified by one name, and are considered as one simple operation. The purposes of life do not require them to be distinguished' (p. $3^{\text {I } 2)}$. There is nothing elsewhere in Reid to elucidate the statement that sensations are the signs of perceptions, or to show its relation to the doctrine that sensations are the signs of external objects. ${ }^{1}$

In what appears to have been a draft of the first volume of the Elements which he sent to Reid, Stewart has one criticism to make of Reid's doctrine of perception. Reid understood the criticism to be that, by failing to mark the difference between an 'independent' (external) existence and a 'permanent' existence, he had implied that by the senses we are equally and immediately aware of both. ("I think you will have a just notion of the defect you mention', Reid says in his answer to Stewart, 'if you distinguish between an independent existence and a permanent existence.') This is his answer:

My senses do not testify that the sun and moon continue to exist when I do not perceive them. For anything my senses testify, they might have been created the moment I perceived them and annihilated the moment after. If I have anywhere made their existence when I perceived them not, to be the testimony of my senses as distinguished from all my other powers, I think it an error. But I do not remember that $I$ have done this.

He has never, he explains, tried to give a reason for our belief in the 'permanent' existence of the things we perceive, because he did not know of anyone who 'ever acknowledged a real external existence of the objects of sense when perceived and at the same time denied their existence when they are not perceived'. Why do we believe that the objects of perception have a real external existence? 'As it is not by experience but by consciousness that we learn that the operations of our minds are internal objects, so $I$ think it is not by experience but by per-

' The difficulty would be removed if Reid was using the word 'perception' to mean 'percept', what one perceives of an object on a given occasion. This is unlikely. Not merely in the passage quoted, but several times in its immediate context, Reid speaks of the coalescence of sensation and perception into an the word 'perception' for the operation and away from the object: he is avoiding anything that suggests their coalescence. ception that we learn that the objects of sense are external objects.' 1

Reid presumably sent his comments to Stewart. In the Elements as it now stands (in the first edition as well as in subsequent editions), Reid's account of perception is given the emendation Stewart considers it needs in order to be "completely satisfactory'. Reid

has shewn that certain sensations are, by a law of our nature, accompanied with an irresistible belief of the existence of certain qualities of external objects. But this law extends no farther than to the present existence of the quality; that is, to its existence while we feel the corresponding sensation. Whence is it, then, that we ascribe to the quality an existence independent of our perception? I apprehend we learn to do this by experience alone. We find that we cannot, as in the case of imagination, dismiss or recall the perception of an external object. If I open my eyes, I cannot prevent myself from seeing the prospect which is before me. I learn, therefore, to ascribe to the objects of my senses, not only an existence at the time I perceive them, but an independent and a permanent existence. ${ }^{2}$

Stewart might have meant by 'independent and permanent existence' merely 'permanent existence', but this seems hardly possible. If then we learn by experience to ascribe to the objects of perception both an 'independent' and a 'permanent' existence, perception by itself does nothing to show its irrelevance to the existence of its objects. Stewart does not think he is rejecting Reid's theory of perception; he thinks he is improving it.

We have now before us the materials on which to decide whether Reid's theory is a theory of direct perception. Reid's theory of 'original' perception is a theory of sensations as natural signs (with the anomaly of visible figure as an object of perception without a sensation to signify it). His theory of 'acquired' perception is a theory of original perceptions as natural signs, and of sensations with acquired signification. Is the perception of things through their natural signs direct perception of them? How do natural signs present the mind with the things they

I 'Criticism and Remarks on Stewart's Elements', Aberdeen MSS. 2131.4.

2 I. iii; Works, ii, 153. Cf. Philosophical Essays, r. ii. 2; Works, v.105-6. Our belief that the objects of our perceptions "have an existence independent of our perceptions .... is plainly the result of experience; inasmuch as a repetition of the perceptive act must have been prior to any judgment on our part, with respect to the separate and permanent reality of its object'. 
signify? They 'suggest' them. Reid has other words. He does say that natural signs 'introduce' the things they signify, that they 'present' them; ${ }^{\mathrm{I}}$ oftener than they 'indicate' them. But 'suggest' is much his most usual word. And it might seem hard to imagine how perception could be made out to be more devious, subjective, and uncertain than by being made out to be the result of 'suggestion'.

I beg leave to make use of the word suggestion, because I know not one more proper, to express a power of the mind, which seems entirely to have escaped the notice of philosophers, and to which we owe many of our simple notions which are neither impressions nor ideas, as well as many original principles of belief. I shall endeavour to illustrate, by an example, what I understand by this word. We all know, that a certain kind of sound suggests immediately to the mind, a coach passing in the street; and not only produces the imagination, but the belief, that a coach is passing. ${ }^{2}$

The word is a common word, and in its most common use entirely improper in an elucidation of the nature of perception. Reid could not have seen Mr. Winch's thorough demonstration of this ${ }^{3}$ without wishing that he had chosen some other term to mean what he meant by 'suggestion'. As Winch points out (pp. $329 \mathrm{ff}$.), the circumstances in which we would say 'I hear a sound that suggests a passing coach' are circumstances in which we would not say 'I hear a coach.' We say the former when we know that what we hear is not a coach but something which suggests a passing coach-pine cones blown over a frozen ground in winter is Winch's example; or when the sound might be the sound of a coach but we are quite unsure whether it is. Again, to adapt one of Winch's examples, if you are looking at a camel and are asked 'What does that suggest to you?' you might say 'All the romance of the desert'-something of this sort-anything but 'A camel'. That is something you would perhaps only say if the sight of the camel suggested nothing to you at all. If a thing suggests another thing to us, it makes us imagine it, as the sound of the pine cones makes us imagine a coach or the sight of a camel makes us imagine something

Inquiry, v. ii, iv; Works, i. 120, 123.

2 Ibid., II. vii; Works, i. I 11 .

3 'The Notion of "Suggestion" in Thomas Reid's Theory of Perception', Philosophical Quarterly, Oct. 1953. which is not a camel. There is normally no place for belief. If we are listening for the coach and hear a sound which suggests it, a sound which might be the sound of the coach, there is perhaps a flicker of belief, but no more than that. The notions then of 'perception' and of 'suggestion' 'fall quite apart'.

Winch anticipates an objection. His argument against Reid is based on twentieth-century usage of the word 'suggestion'; whereas Reid, he says, was 'discussing' eighteenth-century usage; and the two might have diverged widely enough to invalidate the argument. The possibility can be ruled out. If Reid's use of the word had been in accordance with standard eighteenth-century usage 'the difference from our current usage would be so marked as to make us want to say that the whole concept of "perception" had radically altered in the last two hundred years'. An alteration of such magnitude could not have gone unnoticed (pp. 335-6).

It is not Winch's contention that Reid's theory of perception is 'nonsense'; his contention is that Reid's theory is false (p. 336). False, because it implies that all perception is doubtful perception, that expressions of the form 'I hear, see, taste . . . something which suggests $X^{\prime}$ are always more appropriate than the simple statement that ' $I$ hear, see . . . X'.

Philosophical theories of the type of Reid's have an attractive appearance because of their air of caution and 'taking nothing for granted'; but this obsessive over-caution, far from being a merit, results in an obscuration of the linguistic distinctions which enable us to discriminate between conditions where caution is necessary, and those where it is not (p. 33r).

To establish his contention Winch should have been building up evidence that Reid uses the word 'suggestion' in its ordinary meaning in an extraordinary context. Had the word been in Reid's theory with all its familiar implications of subjectivity and uncertainty, this would have been enough to show that the theory is the thorough misinterpretation of the facts of perception Winch thinks it is. In Reid's theory 'suggestion' carries none of these implications. To take an essential point. We have by perceptual 'suggestion' beliefs which are irresistible - this is after all Reid's final answer to philosophical doubts about an external world. We have also, of course, weaker beliefs by perceptual suggestion, but these lie on the periphery of Reid's 
attention. His theory of perception seems at first sight to be constructed as if there was no such thing as doubtful perception. His general theory of natural signs does not expressly mark out any place for degrees of belief. Having introduced the term 'suggestion' with the explanation already quoted, Reid goes on to mention the range of its application

... sensation suggests the notion of present existence, and the belief that what we perceive or feel does now exist ... memory suggests the notion of past existence, and the belief that what we remember did exist in time past ... our sensations and thoughts do also suggest the notion of a mind, and the belief of its existence, and of its relation to our thoughts .... any change in nature, suggests to us the notion of a cause, and compels our belief of its existence.

By the 'natural principle' of suggestion we have all these beliefs; all of them beliefs of common sense; all of them therefore irresistible.

If there is a single standard use for 'suggestion', and it is the use described by Winch, then the word is in Reid's theory of perception with hardly a trace of its proper meaning. It has, however, a less common but not uncommon use in which it does not carry any implications of doubt or hesitation. Reid's employment of the word seems to have at least some affinities with this use. I may be quite sure of something, and then ask what suggested that to me? (I knew she was a school-teacher. What made me think so? What suggested to me that she was?) Granted that $X$ suggests $Y$, there are two questions we might ask: What does $X$ suggest? What suggested $Y$ ? The second seems to be more Reid's question. And in confirmation, the first question could not be asked unless $X$ is noticed. The sound of a passing coach could not easily go unnoticed, but many natural signs suggest the things they signify in self-effacement. They most perfectly conform to Reid's conception of a natural sign when they do.

Reid unfortunately did not discuss the way in which the word 'suggestion' is used. He borrowed it unconsciously from Berkeley, employing it, Stewart remarks, as a technical term. And, as has just been indicated, not in the interests of philosophical caution. Reid's theory, at least of original perception, is too incautious. How can you misunderstand a completely familiar word? Natural signs in original perception are like completely familiar words. How can they be misunderstood if there are such things as these natural signs at all? The possibility of mistakes in acquired perception is not perplexing. Words well understood in familiar contexts may be misunderstood in unfamiliar contexts. We learn the perceptual meaning of signs of the first class in a comparatively narrow range of contexts, and consequently are always liable to mistakes in acquired perception.

With the misinterpretation which the word 'suggestion' invites for Reid's theory out of the way, we can ask again whether it is a theory of direct perception. To begin with perception by touch. We feel the shape, the solidity, the smoothness or roughness of whatever it is we are holding; feel them, Reid says, by means of sensations of touch. What would it be for perception by touch to be more direct than it is on Reid's account of it? But will the theory of natural signs fit Reid's descriptive account of perception by touch? The theory itself explains why it must appear inappropriate, for it is a theory of the psychological directness and the logical indirectness of perceptual experience, and because the first is a feature of the experience, the second does not appear as a feature of it. Consequently, the 'transition' of the mind from the sign to what it signifies, the 'conception' and 'belief' 'suggested' by the sign, are bound to seem misdescriptions of the familiar simplicity of the experience. Natural signs operate here as if they did not exist.

Hamilton contrasts passages in Reid asserting the directness of perception with others which seem to assert its indirectness, and underlines their inconsistency. He thinks that Reid changed his mind about perception. There is no reason to think so. The indirect passages all belong to the exposition of Reid's theory of perception. The contrasted passages assert that it is things themselves that we perceive, and not their representatives in the mind. Reid would not have acknowledged any inconsistency between them, would not have been willing to change either the theory or the assertions. The theory authorizes them. We see and handle material things, Reid says. The indirectness in perception which the theory recognizes does not rule out this plain speech, and the psychological immediacy which it also recognizes demands it.

Visible figure does not fit Reid's theory. He has no explanations. 
It is just a fact that there is no sensation by which it is signified, and therefore no analysis of what it is to see it. There is an analysis of what it is to see the real figure of a thing. It is similar to the analysis of the perception of real figure by touch, with this difference, that the perceptual sign is not a sensation and its signification has to be learnt. To ask for real figure to be more directly perceived by sight than it is would be, in Reid's opinion, to ask for the abolition of the laws of perspective.

The objects of perception are external objects. It may not be easy or even possible to show how the perception of tangible or visible figure could be more direct than Reid makes them out to be. If a theory of the direct perception of the 'secondary qualities' is wanted, it would be provided by any theory which held that what Reid calls the 'sensations' of colour, sound, smell, and taste are external objects, that is objects which exist independently of our experience of them. In calling them sensations Reid claims that he is giving them the name their nature requires. The external objects corresponding to them, signified by them, and therefore perceived through them, are their occult 'causes' or 'occasions' in material things. When Reid is attacking the theory of ideas, Thomas Brown remarks, he will not allow that a thing can be said to be perceived if only its effects are perceived. When the polemic is over and Reid is expounding his own theory, he is expounding the theory of ideas. ${ }^{\mathrm{I}}$

The theory of ideas in its simplest form, multiplying no entities, construes the perception of an external object as the reference of a sensation to its external cause, Brown says. And this, he says, is all that perception is when it is more than sensation, the perception of the primary qualities of matter equally with perception of its secondary qualities. There is a distinction between the primary and the secondary qualities of matter: we define matter in terms of incompressibility and extension. These are therefore to us its primary qualities, but all we know of them is that from them we have sensations of certain kinds, as all we know of its secondary qualities is that from them we have sensations of other kinds. Nevertheless we have an irresistible belief that matter exists independently of us, a belief which primitively depends on the feeling of resistance. Our experience of extension by itself would leave us without the notion of external existence, being in origin nothing but the experience of succession in muscular feelings. It is the feeling of resistance interrupting a familiar series of muscular feelings (when, for example, something impedes the free movement of a limb) which first makes us aware of an external object-as a feeling of resistance it compels our belief that it has a cause which is independent of ourselves. Then by association with this feeling, our feelings of extension and our other sensations are brought to have external reference. ${ }^{\text {I }}$

\section{PERCEPTUAL RELATIVITY}

It is, Hume acknowledges, the natural belief of all men that we perceive external objects immediately.

But this universal and primary opinion of all men is soon destroyed by the slightest philosophy, which teaches us, that nothing can ever be present to the mind but an image or perception, and that the senses are only the inlets, through which these images are conveyed, without being able to produce any immediate intercourse between the mind and the object. The table, which we see, seems to diminish, as we remove farther from it: but the real table, which exists independent of us, suffers no alteration: it was, therefore, nothing but its image, which was present to the mind. These are the obvious dictates of reason; and no man, who reflects, ever doubted, that the existences, which we consider, when we say, this house and that tree, are nothing but perceptions in the mind, and fleeting copies or representations of other existences, which remain uniform and independent. $^{2}$

We have to distinguish, Reid says, between 'real' and 'apparent' magnitude, between the size a thing is and the size it looks. The concept of real magnitude is primarily a concept of touch. Apparent magnitude is magnitude as it appears to sight. Except in astronomy, whose objects of study are beyond the reach of touch, apparent magnitude-so far as Reid knows-was without a name until Berkeley gave it one. $\mathrm{He}$ called it 'visible magnitude'. It has no name because it was unnoticed, serving

I Ibid., xxIv-Xxvir. There are some statements in these lectures, and elsewhere in Brown, which are not easily reconciled with his general doctrine that our knowledge of matter in all its properties is essentially 'relative' (in Reid's sense of the term, Brown explains) to its effects on us in sensation.

${ }^{2}$ Enquiry Concerning Human Understanding, xur. i, p. 152. 
only as a sign of real magnitude and distance. In the sense in which visible magnitude is seen, real magnitude is never seen. Similarly we do not hear coaches or bells in the sense in which we hear sounds. It would be absurd, however, to say simply that we never hear a coach or a bell. We hear them, and at a distance or close at hand. Custom is the arbiter of speech, and custom has prescribed the same word for original and acquired perception. ${ }^{\mathrm{I}}$

'The table we see seems to diminish as we remove farther from it ... but the real table suffers no alteration ... therefore, it is not the real table we see.' Let us suppose that it is the real table we see. 'Must not this real table seem to diminish as we remove farther from it? It is demonstrable that it must. How then can this apparent diminution be an argument that it is not the real table? When that which must happen to the real table, as we remove farther from it, does actually happen to the table we see, it is absurd to conclude from this, that it is not the real table we see.' 2

Is it the real table we see or its 'visible figure' (whose magnitude is the table's apparent magnitude)? Both, since to see the visible figure of the table as a sign of its real figure is to see the table. This would have to be Reid's answer to the question he has invited. And Hume might have said, if he had chosen to, that in seeing the 'image' of the table we see the table.

The disagreement between Reid and Hume is not altogether verbal. Their implied disagreement over the status of visible figure is not a disagreement over words. To Reid visible figure is an external object, an object which can exist unseen. In Hume's opinion it is nothing when it is not seen. His argument has no tendency to show that Reid is mistaken. Of course, as Reid continually reminds us, we do not pay any attention to visible figure in itself; it is of no importance to us except as a sign. Whether or not, then, it exists independently of us would hardly seem to be a matter which concerns common sense.

Reid is not in a position to allow it to be a matter of no consequence to common sense. It is a conviction of common sense that we see external objects, and do not merely infer them from something else that we do see. Reid has a theory which has to

\footnotetext{
I Intellectual Powers, Ir. xiv, xxii; Works, i. 303-4, $33^{6}$.

2 Ibid., II. xiv; Works, i. 304 .
}

be squared with this conviction. His theory is that we do not see 'real figure' in the sense in which we see 'visible figure'. (Hume's argument is an argument for this theory.) If we do not, then unless visible figure exists when it is not seen, no external object is seen in the primary sense of the word. We can properly say that we see the real shape and size of a thing, and as properly and more illuminatingly, Reid maintains, we can say that we judge of its real shape and size, infer them, from its visual appearances. Seeing a thing's real shape and size is not something different from judging or inferring its real shape and size from its visual appearances. This is what seeing the real shape and size is.

Plain men surely think that they see the table in the primary sense of 'see', in the sense in which, Reid says, they see visible figure. They are not likely to be satisfied by being told that in this sense they see an external object, but not the external object they think they see. And is not this what they are being told by Reid in defence of their common sense? Not necessarily, provided that Reid is prepared to say a thing has as many different shapes as there are different points of view from which it might be seen.

Reid would say it with great reluctance-if at all: the 'tangible' figure of a thing is its 'real' figure. There is, however, nothing to stop us from saying it if we wish. We run no risk of being contradicted by the testimony of Nature. We would not be saying anything true or false. Nature's speech in the matter ends with the fiat that a thing cannot have different shapes in the one place which it occupies. The generality of the statement that a thing has as many shapes as there are positions from which it might be seen is objectionable, because we want to speak of the 'real' shape (by which we mean either the shape in virtue of which the thing has its 'apparent' shapes or the most familiar of these). But 'the tower seems from here to have the shape of a pepper-pot', 'has the shape of a pepper-pot from here' are idiomatic alternatives. If we are making a philosophical choice between them, we can choose whichever makes us more comfortable.

The distinction between tangible and visible figure and magnitude is as important to Beattie as to Reid: without it, the senses cannot be cleared of the charge that they are fallacious. 
And it is a principle of common sense that things are as they appear to the senses to be. ${ }^{\mathrm{T}}$ The tower you are looking at seems to be no bigger than your thumb. How is this 'sensation' to be reconciled with your belief that the tower is fifty feet high? There is no difficulty: tangible magnitude is the object of your belief, visible magnitude of your sensation.

When we see a lump of salt at a little distance, we may perhaps take it for sugar. Is this a false sensation? is this a proof, either that our taste, or that our sight is fallacious? No: this is only an erroneous opinion formed upon a true sensation. A false sensation we cannot suppose it to be, without supposing that tastes are perceived by the eyes. And you cannot believe your opinion of the magnitude of these towers to be a false sensation, except you believe that tangible qualities are perceived by sight. When we speak of the magnitude of objects, we generally mean the tangible magnitude, which is no more an object of sight than of hearing. ${ }^{2}$

'Fallacies of the senses' - one hears of these from philosophers, Reid reflects, rather than from ordinary men. Still anyone who has had a counterfeit coin passed off on him might complain naturally enough that his senses had deceived him. We can find ordinary uses for the phrase 'a fallacy of the senses'. Yet would we mean that the senses have deceived us? Thoughtlessly we might mean this. Reid remembers talking to a man who was not satisfied with the refutation of the doctrine of Transubstantiation by an appeal to the testimony of the senses: seeing that any of the senses can deceive us, how do we know that there are not times when they are all deceiving us? Reid asked for an instance of the concurrence of several senses in deception. Clay, he was told, could be moulded into the shape of an apple, painted and dabbed with essence of apple-there is a thing which to sight, touch, and smell is an apple. The senses testify, Reid answered, that the thing has the shape, colour, and smell of an apple, and it has. If it is taken to be an apple, the mistake is one of unjustified inference. ${ }^{3}$

In Reid's alternative language the mistake is a misinterpretation of natural signs whose signification has been learnt by experience, but which are not exclusively connected with the thing they have found to signify. Almost every experiment in

Essay on Truth, 1. ii. 2, p. 66.

2 Ibid., II. i. 2, p. 173.

3 Intellectual Powers, II. xxii; Works, i. 335. optics, Reid remarks, to a man who knows nothing of optics must make him think that he cannot trust his eyes. We are no longer surprised to see our reflection in a mirror; but how could a man be more grossly imposed on by his sight than to see himself in front of himself? Yet to anyone acquainted with the principles of optics, this surprising appearance constitutes part of the 'visual language' of nature. He understands this language and knows that there is no deception in it, nothing at all misleading. We need to have discovered the context of Nature's speech not to misunderstand it or find it ambiguous. Thus in vision,

the same appearance to the eye, may, in different circumstances, indicate different things. Therefore, when the circumstances are unknown upon which the interpretation of the signs depends, their meaning must be ambiguous; and when the circumstances are mistaken, the meaning of the signs must also be mistaken.

This is the case in all the phaenomena which we call fallacies of the senses; and particularly in those which are called fallacies in vision. The appearance of things to the eye always corresponds to the fixed laws of Nature; therefore, if we speak properly, there is no fallacy in the senses. Nature always speaketh the same language, and useth the same signs in the same circumstances; but we sometimes mistake the meaning of the signs, either through ignorance of the laws of Nature, or through ignorance of the circumstances which attend the signs. ${ }^{\text {. }}$

The deceptions of sense which most nearly deserve the name are those which are due to disordered sense: the sour taste of sweet wine to the sick, the pain felt in the foot after a leg has been cut off, everything yellowed in jaundice. But what does one expect from a disordered instrument?2 Nature has constituted our sensations perceptual signs under certain conditions. Impressions are made by the object signified upon sense organs and through them upon nerves and brain. The sensation follows its immediate antecedent, the impression on the brain, whatever the antecedents of the impression on the brain. When the remoter antecedents of the sensation are not those which Nature

I Inquiry, vi. xxiii; Works, i. 194.

2 Have we any criteria for deciding when a sense is not disordered? Beattie has a list: Are the perceptions which a sense communicates 'clear and definite', 'uniformly similar in similar circumstances', compatible with the 'perceptions of my other faculties', with other men's perceptions, able to be acted on with security? (Essay on Truth, II. i. 2, pp. 198-9.) 
has established for the true perception of an object, the sensation will be a false perceptual sign. I (The meaning then of the signs even in original perception is a contexual meaning-though the context is a hidden one-so that for all their familiarity, they can be misinterpreted.)

The sensation itself, apart from its signification, can have no falsity in it, and the philosophers who hold the theory of ideas, should, in Reid's opinion, withdraw their complaints about the unreliability of the senses. "If the senses testify nothing, they cannot give false testimony.' They testify nothing, if their office is 'only to give us the ideas of external objects'.2 It is hard to understand how Reid could have failed to see, when he borrowed so much from Berkeley for his doctrine of natural signs, that even if things were perceived only through the ideas of them, or were themselves only collections of ideas, all the fallacies of the senses with which he has been dealing would be possible, ideas signifying ideas.

The relativity of our sensations to varying states of our bodies does not disturb our belief in the absolute existence of physical objects, does not hint at a metaphysical fallacy of the senses by which these objects are presented to us with a false externality. On the contrary, when a man

feels the same water hot to one hand and cold to the other, this gives him occasion to distinguish between the feeling and the heat of the body; and, although he knows that the sensations are contrary, he does not imagine that the body can have contrary qualities at the same time. And when he finds a different taste in the same body in sickness and in health, he is easily convinced, that the quality in the body called taste is the same as before, although the sensations he has from it are perhaps opposite. ${ }^{3}$

It is part of the human condition that all our faculties are liable to damage or disturbance which unfits them for their natural functions, but as this vulnerability is common to them all, it is no justification for singling out the senses as unreliable. Philosophers have traditionally singled them out, and to this mistake they have usually added another: they have usually, Reid says, held that one of the functions of reason is to detect the fallacies of sense. (The senses are levellers; reason puts a

I Intellectual Powers, In. xviii; Works, i. 320-1.

2 Ibid., Ir. xxii; Works, i. 339

Inquiry, n. ix; Works, i. 113-14. proper distance between philosophers and the rest of mankind.) We are in fact as much exposed to error in the use of our reason as in the use of our senses, and the errors we do fall into 'with regard to objects of sense are not corrected by reason, but by more accurate attention to the informations we may receive by our senses themselves'.

Intellectual Powers, II. xxii; Works, i. 339. 
 \\ PERSONAL IDENTITY AND FREE WILL}

\section{PERSONAL IDENTITY}

$A^{x}$ ONG the Reid manuscripts there is a fragment containing reflections, not yet fully Common Sense, on the nature of the self. Reid is asking what he is.

I mean not now to inquire whether I am body or spirit, whether substance or accident, but what is the I concerning which these inquiries may be made? [The succession of ideas] I can divide and separate. But I cannot so much as suppose myself divided or separated. Yet when this train of ideas is taken away what remains? I confess I know not. ... I seem to have no idea of it and yet am under an invincible necessity of believing there is some such thing. ${ }^{\mathrm{I}}$

The fragment ends there, and if Reid returned to the problem of a metaphysically neutral meaning for 'the self', no trace of his inquiry has survived. The philosophy of Common Sense will not allow the ignorance necessary in order to be able to ask the question Reid wished to ask. It will not allow even a provisional doubt as to whether the self is 'substance or accident', that any meaning can be found for ' $I$ ', such that we can fix what it is we are speaking of, and then proceed to inquire into its category. It also answers the question, Body or spirit? With these subtractions, the ignorance confessed in the fragment is the ignorance taught by the philosophy of Common Sense, and the argument against the self as a succession of ideas is its argument.

Sensations are doubly natural signs: they signify their objects and they signify their subject. Different sensations signify different external things; all sensations signify the same internal thing, the self to which they all belong. Our sensations

suggest to us a sentient being or mind to which they belong-a being which hath a permanent existence, although the sensations are transient and of short duration - a being which is still the same, while its

I Aberdeen MSS. $213^{1} .4$. The paper is dated 22 Oct. 1748. sensations and other operations are varied ten thousand ways-a being which hath the same relation to all that infinite variety of thoughts, purposes, actions, affections, enjoyments, and sufferings, which we are conscious of, or can remember. The conception of a mind is neither an idea of sensation nor of reflection; for it is neither like any of our sensations, nor like anything we are conscious of. The first conception of it, as well as the belief of it, and of the common relation it bears to all that we are conscious of, or remember, is suggested to every thinking being, we do not know how.'

If we have an idea of a substantival self, we must have derived it from some 'impression', Hume says. No, Reid says, not from any impression, not in the way that Hume meant, but when Hume said that there was no impression of the self, he was not mistaken. If all the objects of consciousness were to file past consciousness, the self would not be among them. Hume gave reasons why the self must be absent from this procession, and claimed that experiment confirmed its absence. Reid and Stewart, who completely agree with one another on this matter, do not report negative results from an introspective experiment, nor do they give a priori reasons for ruling out the self as a possible object of consciousness.

The objects of consciousness are 'our present pains, our pleasures, our hopes, our fears, our desires, our doubts, our thoughts of every kind; in a word, all the passions, and all the actions and operations of our own minds, while they are present'. ${ }^{2}$ Is there no consciousness of the self because the self is not a transitory object? This cannot be the reason which Reid and Stewart might have given. Like perception and unlike memory, consciousness must have objects that are contemporary with its act. Perception has permanent objects, though perception as such knows nothing of their past and future. For the same reason, and if nothing else prevented it, there could be a consciousness of the self, though no consciousness of its permanence, any more than we are conscious that its operations are fugitive.

Inquiry, vi iii; Works, i. 122.

2 Intellectual Powers, vI. v; Works, i. 442. In Reid's view, we are (effortlessly) conscious of everything that goes on in our minds; we can 'reflect' upon the objects of consciousness as well as upon those of perception, that is consider them attentively, and without this reflection our notions of them must be more or less vague. (Ibid., I. v, vi. v; Works, i. 239, 443.) 
In restricting the range of 'consciousness' to 'the present', Reid claims to be using both these terms with philosophical precision, without the least criticism of their laxer use in everyday speech. We say in everyday speech that we saw a thing move. And correctly. It would be ridiculous to find fault with a way of speaking which is the ordinary way, and has a perfectly clear meaning. By 'the present' philosophers mean the point of time dividing the future from the past. By 'the present' we mean in everyday life a variable period of time going back into the past and on into the future. There is a before and after in motion. Therefore speaking philosophically, we do not see a thing move; speaking with the vulgar, we do. Neither of these forms of speech is more correct than the other-to use a term 'laxly' is to use it correctly where precision would be out of place-and both are needed for different purposes. Similarly there is no occasion 'in common discourse, to fix accurately the limits between consciousness and memory'. If this is not done in philosophy, 'we confound the different powers of the mind, and ascribe to one what really belongs to another'.

We are not conscious of the self, Reid and Stewart say. They do not say why, nor indicate how they would set about arguing a man out of the mistaken belief that the self was one of the things of which he was conscious (provided he was not claiming to be conscious of its identity through time). Is it perhaps a mistake which is bound to arise with the actions and passions of the self as its natural signs? Natural signs are unnoticed, are so unobtrusive that we seem to be as directly aware of the objects they signify to us as if the signs were altogether absent.

If the actions and passions of the self are its natural signs, they are natural signs without this transparency. They do not concentrate all the attention on the inward thing they signify, but on external things or on themselves; they are not effaced before the featureless substance of the self. Their analogies with the natural signs which operate in perception would be with those which signify the secondary qualities of bodies. And in a further respect: these natural signs signify something occult, and the actions and passions of the self signify something occult. They signify merely the substantival being of the self. Reid and

Intellectual Powers, mr. vi; Works, i. 35 I.
Stewart may have held it to be an obvious inference that the self is not an object of consciousness: we could not know of a thing's existence by consciousness and be ignorant of its nature, - as we are ignorant of the nature of the self.

The sensations from the secondary qualities of bodies are signs signifying their unknown causes. Is the understanding of these signs any more than a particular application of the general principle of causation? It is a little more; it is to infer as a cause something which exists when it is not perceived. That all our sensations, all the 'thoughts, purposes, actions ... which we are conscious of, or can remember' signify the self to us as its natural signs, is covered by the principle that everything not a substance must belong to a substance, with the addition that all these experiences show their relation to one substance. In the Intellectual Powers this principle, no longer disguised by the language of sign and signification, is straightforwardly the principle upon which we refer our experiences to their subject. Motion must be the motion of something, shape the shape of something 1 all the 'proper' objects of the senses are qualities of some material substance, bound to it by the essential incompleteness of their being. And similarly a substance of another kind is presupposed by the existence of everything of which we are conscious. Anyone who denies that extension, figure, size, ... require a subject to which they belong; that thought, feeling, desire, ... require a subject to which they belong is beyond argument as a man who 'denies first principles'. He is a man, however, who will find, if he reflects, that the structure of his speech contradicts him. ${ }^{2}$

Stewart is always sparing with the language of sign and signification, and does not use it in the present connexion. Upon the occurrence of any sensation, he thinks, we

learn two facts at once; the existence of the sensation, and our own existence as sentient beings-in other words, the very first exercise of consciousness necessarily implies a belief, not only of the present

' 'Visible figure'? Reid says in the Inquiry that if he is asked about the 'category' of visible figure, the best he can do by way of an answer is to list its characteristics, so that those who are familiar with the categories can decide for themselves where to place it. He gives the list and adds the remark that wherever 'a projection of the sphere' or a perspectival drawing have 'their lodgings in the categories', visible figure 'will be found to dwell next door'. (vi. viii; Works, i. 144.)

2 Intellectual Powers, I. ii; Works, i. 232.

6228 
existence of what is felt, but of the present existence of that which feels and thinks; or (to employ plainer language) the present existence of that being which I denote by the words $I$ and myself. Of these facts, however, it is the former alone of which we can properly be said to be conscious, agreeably to the rigorous interpretation of the expression.

But as in every sensation, in every experience, there is immediately implicit a reference to the self, it is not surprising that we should read this habitual inference from the facts of consciousness into the facts of consciousness. ${ }^{\text {I }}$

The Cogito, ergo sum, Stewart adds, does not 'deserve all the ridicule' that has been poured upon it-by Beattie, for instance, who could not think of anything more absurd than a man trying to prove his own existence. When Milton's Adam woke from the sleep which followed his creation, one of his first thoughts, Beattie remarks, was to inquire into his origin. In Dryden's improvement upon Milton, Adam is obliged to 'prove his existence by argument' before being allowed to engage in any further inquiry. 'Dryden, it seems, had read Des Cartes;2 but Milton had studied nature.' 3

Stewart is inclined to think that Descartes was not so much concerned to prove his existence, as if there was some doubt about it, as to state the truth which Stewart has been stating, that the self is not an object of consciousness, but is plainly declared by all the objects of consciousness.

Every man whose mind is not unhinged is convinced of his . identity as far back as he can remember. What is he convinced of when he is convinced of his identity through this time? He is convinced, Reid answers, that the self to which all his present experiences belong is the self to which all his past experiences have belonged. They have come and gone; it has remained through them all with an unbroken existence as one single, individual thing. ${ }^{4}$ We cannot define the notion of identity and do not need to. We may say, if we wish, that identity is a relation between a thing at one time and a thing at another time, but

I Philosophical Essays, 1. i. 1; Works, v. $5^{8 .}$

2 'What am I? or from whence? For that I am/I know, because I think.' (The State of Innocence, Act II, Scene i.)

3 Essay on Truth, I. ii. 3, p. 77.

4 Reid mentions his thorough agreement with Butler's account of our personal identity. (Intellectual Powers, nI. vi; Works, i. 350. Butler, Analogy, Dissertation I.) we do not have the words to express the difference between this relation and its contraries, although we are in no danger of confusing it with any of its contraries. Diversity is a contrary relation, and similitude and dissimilitude are two more contrary relations which everyone easily distinguishes from identity and diversity. Identity implies an 'uninterrupted continuance of existence. That which hath ceased to exist, cannot be the same with that which afterwards begins to exist; for this would be to suppose a being to exist after it ceased to exist, and to have had existence before it was produced.'

The self is obviously indivisible: 'a part of a person is a manifest absurdity.' People do, of course, (or did) speak of parts of their person, and there are contexts in which 'a part of oneself' would find a natural place. Reid leaves these familiar expressions quite unnoticed, a neglect which he would no doubt have justified on the grounds that the words 'person' and 'self' in such expressions are used with a figurative extension of their proper meaning. It would not have occurred to Reid to wonder whether the meaning with which he used the words is at all their common meaning. And perhaps it is not to be expected that something so much taken for granted as the self, always there and always the same, should have thrust itself into linguistic prominence.

My personal identity, then, is

- the continued existence of that indivisible thing which I call myself. Whatever this self may be, it is something which thinks, and deliberates, and resolves, and acts, and suffers. I am not thought, I am not action, I am not feeling; I am something that thinks, and acts, and suffers. My thoughts, and actions, and feelings, change every moment-they have no continued, but a successive existence; but that self or $I$, to which they belong, is permanent, and has the same relation to all the succeeding thoughts, actions, and feelings, which I call mine. ${ }^{2}$

- What evidence do I have for the fact of my personal identity through time? I have the unimpeachable evidence of memory. I shall not be asked, by anyone who knows what he is asking, to prove the memory is not always fallacious. It would have to

I Intellectual Powers, III. iv; Works, i. 344 .

${ }^{2}$ Ibid., III. iv; Works, i. 345 . 
be always fallacious for its testimony to our personal identity to be mistaken; everything that a man remembers 'convinces him that he existed at the time remembered'. The testimony of a man's memory cannot be split into halves, into a reliable half that things happened and into an always unreliable half that he was in some way concerned. When I remember what happened, I usually remember with the same assurance my part in it. I am always aware, at least implicitly, of the identity of myself remembering and myself remembered. ${ }^{1}$

It is especially Stewart's opinion that the beliefs of common sense are conditions of thought and intelligent action, their presuppositions, the vincula of their coherence. Stewart leaves his opinion almost unargued. Reid has an argument to show that our belief in our personal identity has the status which Stewart later claimed collectively for the beliefs of common sense.

We may observe, first of all, that this conviction is indispensably necessary to all exercise of reason. The operations of reason, whether in action or in speculation, are made up of successive parts. The antecedent are the foundation of the consequent, and, without the conviction that the antecedent have been seen or done by me, I could have no reason to proceed to the consequent, in any speculation, or in any active project whatever. ${ }^{2}$

The evidence which people have of other people's selfidentity, and therefore of their own farther back than they can remember, in Reid's opinion, is of a completely different kind from the evidence they have of their own identity as far back as they can remember. The evidence for other people's identity is the evidence of similarity. The man I met today looks like the man I met a year ago, behaves as he did; I have no doubt that he is the man I met a year ago. Whenever we find great similarity we presume identity unless there is some reason not to. Since the indirect evidence for identity is a matter of similarity, and similarity is a matter of degree, it is evidence which varies from what will justify certainty, to a justification for no more than the barest presumption. ${ }^{3}$

One supposes that Reid knew that he had left the transition from empirical similarities to metaphysical identity undescribed.

$$
\begin{aligned}
& \text { Intellectual Powers, Ir. iv; Works, i. } 345 . \\
& 2 \text { Ibid. } 344 . \\
& 3 \text { Ibid. } 345^{-6 .}
\end{aligned}
$$

He does not give any indication. Nor any indication whether he would allow that the everyday expressions for personal identity change their primary meaning to something less occult, when we use them not of ourselves but of others. No metaphysical thoughts cross our minds when we recognize someone as someone we have met before. It is perhaps that we stop at the signs whose signification we could always go on to realize, but have no occasion to in the ordinary business of life. Reid does not say.

Personal identity is a 'perfect identity'; that is, there are no degrees of it. The identity of material things is imperfect; they are made up of parts which they are always losing and replacing with other parts, or simply losing. If the change is gradual enough it might even become total, and the thing still be considered the same thing as long as it keeps the same name. 'Identity', therefore, Reid says, is a word with this ambiguity, that it is vague when applied to things and precise when applied to persons. The changes which, for 'common language', are consistent with the identity of things differ in number and degree, not in kind, from those which destroy it. Questions as to whether a thing is the same thing at different times are consequently more often than not verbal questions. 'They have either no right answers, or the usual answers are the right answers.

To make personal identity consist in 'consciousness alone', as Locke does, is to confuse with his identity, the evidence a man has for his identity. This is very paradoxical and the confusion of identity with consciousness of identity has very paradoxical consequences. It follows, for example, that 'a man may be, and at the same time not be, the person that did a particular action.

Suppose a brave officer to have been flogged when a boy at school, for robbing an orchard, to have taken a standard from the enemy in his first campaign, and to have been made a general in advanced life: Suppose also, which must be admitted to be possible, that, when he took the standard, he was conscious of his having been flogged at school, and that when made a general he was conscious of his taking the standard, but had absolutely lost the consciousness of his flogging.

These things being supposed, it follows, from Mr. Locke's doctrine, that he who was flogged at school is the same person who took the standard, and that he who took the standard is the same person who was made a general. Whence it follows, if there be any truth in logic,

$$
\text { I Ibid., i. } 346 \text {. }
$$


that the general is the same person with him who was flogged at school. But the general's consciousness does not reach so far back as his flogging - therefore, according to Mr. Locke's doctrine, he is not the person who was flogged. Therefore, the general is, and at the same time is not the same person with him who was flogged at school.'I

The self is 'something which thinks, and deliberates, and resolves, and acts, and suffers'. These are operations of the mind. The self is indivisible and has a 'perfect identity' through time.t It is therefore not the body, and not the composite of body and mind; it is the mind. These are the reasons Reid would give for an identification which he takes for granted. We know what the mind does; we are conscious of its operations. But when we ask not what it does, but what it is, there is, he says, no answer. And if we are not satisfied with the knowledge that matter has the properties of extension, solidity, divisibility, \&c., and want to know the nature of the 'thing itself', there is again, he says, no answer.

We do know what some things are 'in themselves'. Our notions of these may be called 'direct'. 'Of other things, we know not what they are in themselves, but only that they have certain properties or attributes, or certain relations to other things: of these our conception is only relative.' If a thing is distinguished from other things by any extraneous circumstances, by its place, for example, as a book might be by its place on a bookshelf, we have a merely relative conception of it. The secondary qualities of bodies are unknown causes of known effects; we have relative notions of the secondary qualities of bodies. Our notions of their primary qualities are direct, and it is part of the work of natural philosophy to convert our relative notions of secondary qualities into direct notions. We have direct notions of everything of which we are conscious.

There are among our relative notions some which are not derived from a thing's relations to other things or from its effects upon ourselves, but from 'attributes essential to the thing', and these cannot be made direct. One term only of the relation is presented, and its correlative and the relation read off intuitively from it. Our notions of the substantival natures of matter and mind are of this sort. ${ }^{2}$

\footnotetext{
I Intellectual Powers, nIr. vi; Works, i. 350-I.
}

2 Active Powers, 1. i; Works, ii. 513-14.
What is it that Reid supposes is left in obscurity if the 'attributes essential' to matter and mind are disclosed? Presumably attributes which are still more essential, the ground of those which make the essential difference between matter and mind in our experience of them. For if the substances were featureless in themselves, or if their features were simply their observable features, there would be nothing absent in the relative concept which would be present in the direct concept we might have had, if God had given us different intellectual powers.

A relative knowledge of matter and mind is an absolute ignorance of their essential nature, and any words which do not sharply remind us of our ignorance have to be avoided. The words 'spiritual being' applied to the mind are not agnostic enough for Stewart. It is, he remarks, unfortunate that the two very important negative truths, whose recognition we owe especially to Descartes, should have been disguised-one of them by Descartes's commentators, the other by Descartes himself - under misleadingly positive language. How much futile controversy might have been stifled if the simple facts had been simply stated: that the mind is immaterial, and that some of our concepts are not derived from sensation. Instead we have the mysteries of the mind's 'spirituality' and of 'innate ideas'.I

If we know nothing at all of the essential nature of matter and of mind, how do we know that they are essentially different in nature? The question is too obvious to have "escaped Reid's notice, and since he has not answered it and speaks with untroubled conviction of their total difference, he must have thought the traditional answer satisfactory: the opposite properties of matter and mind could not be properties of a single substance. The activity of the mind and the inertia of matter, the indivisibility of the mind, the divisibility of matter-Reid heavily emphasizes these contrasted features of matter and mind, and he may have considered that there was no longer any meaning in the words 'characterizing a subject' if these opposites are supposed capable of characterizing the same subject.

Stewart is less consistently sure ${ }^{2}$ than Reid that the difference between matter and mind goes beyond their phenomenal

Dissertation, 1. ii. 2; Works, i. $117,147-8$.

${ }^{2}$ Cf. Elements, 1, Introduction; Works, ii. 47 with Dissertation, I. ii. I; Works, i. 
difference, and not very interested in whether it does so or not. No important human concerns are affected either way, and certainly not the question of our immortality. We have better assurances of our immortality than from the soul's simplicity; we have 'the moral judgments and moral feelings of the human heart'. 'The proper use of the argument concerning the immateriality of mind, is not to establish any positive conclusion as to its destiny hereafter; but to repel the reasonings alleged by materialists, as proofs that its annihilation must be the obvious and necessary effect of the dissolution of the body.'

But the science of the mind, Stewart insists, depends upon the recognition that the phenomenal difference between matter and mind is absolute, that they are two entirely separate worlds for investigation, that nothing found in one of them can be applied to the solution of any problems in the other. The science of the mind is the examination of the facts of consciousness, their reduction to general laws, and the deduction of the consequences of these laws. The metaphysical materialists are comparatively harmless, because metaphysical; the physiological materialists have a programme which will end the science of the mind. Stewart is usually a mild critic, but he is always fierce against Hartley and any philosopher with similar opinions. 'Many absurd theories have, indeed, at different times been produced by our countrymen; but I know of no part of Europe where such systems as those of Hartley and Bonnet have been so uniformly treated with the contempt they deserve as in Scotland.'2

Reid of course agrees with Stewart that the science of the mind is to be built upon a pure phenomenology of the mind, but the metaphysical interests of common sense have also to be watched, and common sense is implicitly dualist, root and branch. Bodies and minds are altogether different kinds of things, not things that might merge into identity below their manifested properties, though common sense has had to wait on philosophy (on Descartes especially, Reid thinks) to know how to put the difference properly. There was a time when both philosophers and the vulgar alike had no better concepts for the purpose than a distinction between 'gross' and 'subtle'

\footnotetext{
Dissertation, I. ii. 2; Works, i. $115^{-16}$.
}

2 Ibid. ,II. viii; Works, i. 435 . matter. It is not surprising that the tendency 'to materialize the mind and its faculties' should have had so long a history. The language for the description of the mind has been borrowed from the language for the description of material things, the earliest objects of everyone's attention and the strongest for most men all their lives.

Every man knows, however inarticulately, that his being is indivisible and that he is capable of originating action. He has, therefore, Reid thinks, sufficient premisses for the deduction of the soul's immateriality, since material being is essentially divisible and essentially passive. The essential passivity of matter, the fact that it acts only as it is acted upon, is not an intuitive deliverance of common sense. It is a fact established by experience (and so thoroughly that it has become 'a fundamental principle of natural philosophy'). ${ }^{2}$ In the infancy of the race, men not knowing what caused the behaviour of material things but knowing that something must, read into them an activity like the activity they found in themselves. The relics of this notion are to be found in all languages. Thus the analogies between matter and mind have not always been drawn in one direction. Their expulsion was a necessity for natural philosophy, and is for the philosophy of the mind.

According to Beattie, it is the universal conviction of mankind, that we have souls which are completely different things from our bodies. No arguments are needed in support of this conviction; no arguments can shift it. It has intuitive evidence, 'the evidence of internal sense'. Whatever any man may say, he shows in his conversation and behaviour 'by the plainest signs' that he makes an absolute distinction between his body and his soul. Beattie has heard of only one person whose professed belief that he had no soul was uncontradicted by his behaviour, a clergyman of a generation back, who became certain that God had for some reason taken away his soul and left him a mere animal. Everyone will agree that his melancholy delusion was due to madness, to a 'depravation of intellect, as real, and as extraordinary' as if he had come to believe that he did not have a body. ${ }^{3}$

Without personal identity, no moral responsibility. And no

$$
\text { I Inquiry, vir; Works, i. } 202 . \quad 3 \text { Aberdeen MSS. } 2 \text { 1 } 3 \text { ז.6. }
$$$$
2 \text { Essay on Truth, 1. ii. 3, pp, } 79-8 \mathrm{I}
$$ 
philosopher is to be found disputing it. This is frustrating be- cause Reid did not intend the statement eirenically. $\mathrm{He}$ is quite sure that ordinary men, and the philosophers who have resolved personal identity into a serial identity, do not mean the same thing by the 'same person'. The personal identity implied by moral responsibility is the identity of the same individual being through time. There could still be the deceptive agreement. If one is to be driven into technicalities which will have to be laboriously explained to the plain man whose convictions are being defended, if his convictions cannot be stated in his own language because philosophers have made it ambiguous, then the identity presupposed is the identity of 'substance'.

When Hume explains in turn in his vocabulary what personal identity is, he says it is 'that succession of related ideas and impressions, of which we have an intimate memory and consciousness' ${ }^{x}$ Reid and Hume are now able to disagree on one of the presuppositions of moral responsibility. The personal identity which consists in the unity of a series is inadequate for moral responsibility, Reid maintains. A series is not the sort of thing that can do things and be held responsible for them; none of the capacities of a person are capacities of a series. Only the individual members of a series are ever actual. Therefore if our personal identity is to be resolved into a serial identity, and something real is to be responsible for what something real has done, future members of the series will be made responsible for the actions of past members; that is for what they themselves have not done and could not have prevented. 'If one set of ideas makes a covenant, another breaks it, and a third is punished for it, there is reason to think that justice is no natural virtue in this system.'2

Our moral responsibility for our actions is not more evident than the personal identity which it implies, nor more evident than the freedom of the will which it also implies. While the Common Sense philosophers do not regard the truths of common sense as forming a system of truths connected by mutual implications, they would maintain that there are necessary connexions between some of them. Moral responsibility presupposes personal identity and free will; the personal identity and free will presupposed presuppose a self irresolvable into its

$$
\text { I Treatise, ir. i. 2, p. 277. } \quad 2 \text { Inquiry, xi. vi; Works, i. 1og. }
$$

actions and passions, a self which is an immaterial and substantival being.

$$
\text { 2. FREE WILL }
$$

Hume and Reid agree, of course, that moral responsibility implies a freedom of the will; their difference is over its nature.

We shall find, unless Hume is greatly mistaken, that 'all men have ever agreed in the doctrine both of necessity and of liberty, according to any reasonable sense, which can be put on these terms; and that the whole controversy has hitherto turned merely upon words'. It is taken for granted by everyone that 'the conjunction between motives and voluntary actions is as regular and uniform as that between the cause and effect in any part of nature'. Do we need reminders? A prisoner on the way to the scaffold knows he will die from the inflexibility of his guards as inevitably as from the edge of the axe. A man who has left a purse full of gold on a pavement at Charing Cross would as little expect to find it untouched on his return as to have seen it fly off like a feather. Human life depends as much upon the uniformity of human behaviour as upon the uniformity of nature. Nothing of what is ordinarily said of the inconsistency and unreliability of men contradicts, or is thought to contradict, the uniform dependence of their actions upon their motives. We allow for our ignorance of character or circumstances.

Everyone who acknowledges this uniformity in men's behaviour, and everyone does 'in common life', Hume says, acknowledges a necessity in human actions. Anyone who denies a necessity in human actions is stumbling over the word 'necessity'. He is thinking of necessity, Hume implies, as constraint or compulsion, and he knows that many of his actions are free from constraint or compulsion. ${ }^{I}$ In the Treatise Hume had mentioned that 'liberty' in the 'most common sense of the word' means no constraint or compulsion, without mentioning that in the most common sense of the words 'liberty' and 'necessity' are opposites. He had even spoken of the 'bonds of necessity' from which we can never free ourselves. ${ }^{2}$ In the

I Enquiry Concerning Human Understanding, vir. i.

2 ni. iii. 2, pp. $47^{\circ-8}$. 
Enquiry the bonds of necessity are not heard of, and the word'necessity' itself might have disappeared with advantage. Its disappearance would manœuvre the indeterminist nearer to unintelligible speech, and its presence brings with it the clanking of chains. Necessity is no more than 'the constant conjunction of like objects'; or from a different point of view, it is 'the inference of the understanding' from one to the other, founded upon their constant conjunction. ${ }^{\mathrm{I}}$

The belief in liberty is as universal as the belief in necessity. No one denies that we have ' $a$ power of acting or not acting, according to the determinations of the will' $;^{2}$ that there are many things which we can do, if we choose. And obviously there is no contradiction between necessity, as Hume has defined it, and liberty, as Hume has defined it.

It is a verbal embarrassment to Hume to be at once reconciling 'liberty' and 'necessity' and attacking the 'doctrine of liberty'. To avoid it we shall, where it is likely to arise, use the words 'determinism' and 'indeterminism' for the opposed doctrines and keep the word 'free will' as far as possible neutral between them.

In the Treatise more strongly than in the Enquiry, but there also, Hume gives the impression that he thought that the belief in the indeterminacy of the will was a very general belief, a widespread illusion. There is not simply a universal belief in determinism and a universal belief in the free will which is consistent with it. 'Few are capable of distinguishing betwixt the liberty of spontaneity, as it is call'd in the schools, and the liberty of indifference; betwixt that which is oppos'd to violence, and that which means a negation of necessity and causes.' 3 Necessity may be denied in words by people who have misunderstood the word 'necessity', and indeterminism is asserted ${ }^{-4}$. against necessity by people who have not thought out the meaning of indeterminism. And people have imagined that they could actually experience the indeterminacy of choice; there is a 'false sensation' of liberty. The controversy over free will has not been merely a controversy over words; some argument dealing with the psychological mistake is needed, besides 'a few intelligible definitions', in order to put an end to it.

\footnotetext{
I Enquiry, virx. ii, p. 97.

3 Treatise, u. iii. 2, p. 407

2 Ibid. virr. i, p. 95.
}

There is, then, a universal belief in determinism and in a freedom of the will compatible with it, and a very general belief in a freedom of the will incompatible with it.

The doctrine of indeterminism, in Hume's opinion, either means nothing, or something absurd. As the negation of necessity and causes, the doctrine is intelligible and absurd. For what is this negation but the assertion that all human actions are random and chance occurrences? It is unintelligible, has no meaning at all, when it is construed as an attempt to combine the negation of necessity with the assertion of causes, since 'necessity' is an essential part of what we mean by 'cause'. Some philosophers try to make a distinction between causes which are necessary and others which are not. Hume will allow the distinction when he sees 'cause' defined with the idea of necessary connexion left out, and the origin of the idea expressed by the definition clearly indicated. He is sure that he will never see it. We would have no notion of cause and effect if we had had no experience of the constant conjunction of objects; we have no other notion of cause and effect than the notion of this conjunction with the inference founded upon it. 'And this constancy forms the very essence of necessity, nor have we any other idea of it.' A definition of 'cause' omitting these circumstances will either be unintelligible, or the terms in it will be synonymous with the term to be defined. ${ }^{\mathrm{I}}$

Moral responsibility presupposes free will. It presupposes, in Hume's opinion, a free will which is compatible with determinism and it is incompatible with a free will incompatible with determinism.

Actions are, by their very nature, temporary and perishing; and where they proceed not from some cause in the character and disposition of the person who performed them, they can neither redound to his honour, if good; nor infamy, if evil. The actions themselves may be blameable; they may be contrary to all the rules of morality and religion: But the person is not answerable for them; and as they proceeded from nothing in him that is durable and constant, and leave nothing of that nature behind them, it is impossible he can, upon their account, become the object of punishment or vengeance. According to the principle, therefore, which denies necessity, and consequently causes, a man is as pure and untainted, after having

I Enquiry, vnr. i, pp. 95-96. 
committed the most horrid crime, as at the first moment of his birth, nor is his character anywise concerned in his actions, since they are not derived from it.

The belief in liberty and the belief in necessity, Hume might have said, are beliefs of common sense, if anything is. Both are universal (though as a universal belief the belief in necessity does not go under that name); and if either is denied in theory, it is affirmed in practice. And both are implied by the commonsense belief in moral responsibility. The work that the commonsense philosopher has to do on these beliefs is the work that Hume has been doing: clarifying them, showing their mutual consistency, prising off a third and false belief which has fastened on to the first. Hume might have said this also.

One would have expected that when Reid came to deal with the questions of liberty and necessity, he would have dealt carefully with Hume, and either have accepted his work in principle, or have set about exposing it as more dangerous to common sense than an open attack. Reid scarcely mentions Hume. As Reid grew old, Priestley seems to have displaced Hume to some extent in his attention-not the Priestley of the Examination with whom Reid hardly bothered, but Priestley the materialist and necessitarian. It is Priestley who figures in the discussion, Priestley and with him Leibniz. Reid's argument has to be deflected from them and unnamed necessitarians to Hume, if we want his answer to Hume.

'If it cannot be proved that we always act from necessity, there is no need of arguments on the other side to convince us that we are free agents.' 2 The philosopher defending common sense is concerned with arguments against our free agency, and first with its apparent assertion and real denial.

A power of acting 'according to the determinations of the will'-what more does anyone want in the way of free will than to be able to do a thing if he chooses? To be able to choose to do it or not to do it. We require, Reid says, besides the power to act as we will, a power 'over the determinations of the will'. $^{3}$ We have, in Reid's opinion, half the free will we think we have, if we have no more of it than is allowed to us by a theory of the type held by Hume.

I Enquiry, vin. ii, p. $98 . \quad 2$ Active Powers, rv. vi; Works, ii. 620.
Hume does say that the liberty of the will is a 'hypothetical' liberty; and this seems to imply that 'We could sometimes have done something we did not do' needs the expansion of 'if we had chosen', in order to bring out the meaning in which it is a true statement (and verifiably true). And this leaves unanswered, might even seem to rule out, the question 'Could we ever have chosen to do anything which we did not do?'. But in maintaining the liberty which is opposed to 'violence' and 'constraint', Hume would certainly maintain that he had provided for our being able to choose, and had not left us with merely executive powers. There are obvious things that he might have said. Whenever we declare that we could not have chosen to do otherwise, we are prepared to state what it was that prevented us. Threats or physical compulsion; we acted in the grip of an ungovernable passion; before we had time to think. Circumstances such as these take away our power of choice, and Hume of course denies with plain common sense that we always find ourselves in circumstances such as these.

A 'doctrine of necessity', Reid is convinced, must deny us power over the determinations of the will, power of choiceif the choice is to be one between genuinely open alternatives. And necessitarian philosophers, he says, have frequently argued that there is a logical absurdity in speaking of a power over the determinations of the will.

Liberty, they say, consists only in a power to act as we will; and it is impossible to conceive in any being a greater liberty than this. Hence it follows, that liberty does not extend to the determinations of the will, but only to the actions consequent to its determination, and depending upon the will. To say that we have power to will such an action, is to say, that we may will it, if we will. This supposes the will to be determined by a prior will; and, for the same reason, that will must be determined by a will prior to it, and so on in an infinite series of wills, which is absurd. To act freely, therefore, can mean nothing more than to act voluntarily; and this is all the liberty that can be conceived in man, or in any being.

Reid's answer is that this argument 'does not apply to moral liberty' as he has defined it, since it is an argument based on a definition which is 'totally different'. He has defined 'the 
Liberty of a Moral Agent' as 'a power over the determinations of his own a will'.

There must be more to Reid's answer than shows on the surface. It is perhaps this, that the argument is improperly assimilating 'to be able to do a thing' and 'to be able to choose to do it'. To be able to do a thing is to be able to do it, if one chooses. The necessitarian philosopher is demanding a similar expansion for the other phrase, and then pointing to the absurdity in speaking of a power over the determinations of the will. Reid's answer is a denial that 'a power over the determinations of the will' conceals any hypothetical.

The necessitarian philosopher has not yet finished with Reid's definition. When we say in common speech that we have power over something, we mean that it is under the control of our will, so that it is meaningless to say that we have power over the determinations of our will.

Reid's reply is that the implications of ordinary language here have been misunderstood. In

common life, when men speak of what is, or is not, in a man's power, they attend only to the external and visible effects, which only can be perceived, and which only can affect them. Of these, it is true that nothing is in a man's power but what depends upon his will, and this is all that is meant by this common saying.

But this is so far from excluding his will from being in his power, that it necessarily implies it. For to say that what depends upon the will is in a man's power, but the will is not in his power, is to say that the end is in his power, but the means necessary to that end are not in his power, which is a contradiction. ${ }^{2}$

To have free will, to be a free agent, is to have power over the determinations of the will and (though this is not in dispute) to have power to act as we will. The 'doctrine of necessity' is the doctrine that the determination of the will is 'the necessary consequence of the constitution of the person, and the circumstances in which he is placed'. ${ }^{3}$ It is a consequence of the possession of free will, understood indeterministically as Reid understands it, that a man's actions might have been different, the constitution of his person being what it was, and his circumstances what they were. Might have been different and yet, Reid maintains,

I Active Powers, rv. i; Works, ii. 6ox.

${ }^{2}$ Ibid.; Works, ii. 602.

3 Ibid.

were not random occurrences, were the actions of an agent, actions which have had a cause as every event must. We have now to see Reid with the problem on his hands of combining the denial of necessity with the assertion of causes.

Reid will allow no exceptions to the principle of causation. 'Neither existence, nor any mode of existence, can begin without an efficient cause.' This is a necessary truth and a principle of common sense, and, Reid says in a bad moment, 'if it were possible for any man to root out this principle from his mind, he must give up everything that is called common prudence, and be fit only to be confined as insane'.' An efficient or 'metaphysical' cause is a cause which produces its effect, /makes it happen, brings it into existence. These synonyms cannot be elucidated in terms merely of antecedence and consequence. They cannot, Reid would say, be elucidated at all: nevertheless we understand them, and because we do we can see that they cannot be elucidated in terms merely of antecedence and consequence. They do not exhaust the meaning Reid has for 'efficient cause', but they mark the distinction he is initially making between an efficient cause and a cause which is no more than the set of antecedents upon the occurrence of which an event of a certain kind invariably occurs. Natural philosophy is concerned with causes in the second of these senses, and we are concerned with causes in this sense, Reid would have admitted on reflection, when we regulate our lives with common prudence.

How did we come to have the notion of an efficient cause? We are ourselves the efficient causes of our voluntary actions. Without the knowledge of our own agency we should, in all probability, Reid thinks, have been without the notion of an efficient cause, and consequently ignorant of the necessary truth in which this notion figures. $\mathrm{He}$ is certain that we have no notion of an 'active power' which is not analogous to the power we find in ourselves; that is a power which is exerted by 'will and understanding'. The Divine agency is something we can understand up to a point; material agency defeats our comprehension.

Why does Reid find the notion of material agency so peculiarly baffling? He has very nearly defined agency in such a way that only persons can be agents. Active power is the power to originate change, the power to act without being acted upon,

$$
\text { I Ibid., rv. ii; Works, ii. } 603 \text {. }
$$


a power therefore which belongs to will, and, as far as we can see, to nothing else. Matter acts only as it is acted upon; its nature excludes spontaneity.

... everything which undergoes any change, must either be the efficient cause of that change in itself, or it must be changed by some other being.

In the first case, it is said to have active power, and to act in producing that change. In the second case, it is merely passive, or is acted upon, and the active power is in that being only which produces the change. ${ }^{\mathrm{I}}$

Power to produce any effect, implies power not to produce it. We can conceive no way in which power may be determined to one of these rather than the other, in a being that has no will. ${ }^{2}$

The power in virtue of which an efficient cause produces its effect is active power. How then could any material thing possibly be an efficient cause? Reid listens uncomprehendingly to the assertion of this possibility. If there is any meaning in the words he hears, it is 'essentially different' from the meaning he has for the words 'power' and 'efficiency'.3

Does Reid think that matter can do anything at all, act even with a derivative agency? Standard commentary 4 on Reid represents him as considering it highly doubtful, as holding that causal transactions between material things are the occasions for the actions of real agents, that there are no occult depths in a physical cause in virtue of which it is ever more than an antecedent in a constant pattern of antecedence and consequence. Nature displays numberless effects, Reid says, but the agent is always behind the scenes, and might be God Himself, or some intelligent being to which God has delegated agency, or some unintelligent being-we can never know. 5 The evidence that Reid held physical causes to be no more than 'occasional' causes is constituted by his assertions that matter is without 'active power', is incapable of real 'agency' or 'efficiency'. But the meaning which Reid puts upon these words is essentially different from the meaning they have for anyone else.

To say that we derive our notion of an efficient cause from

I Active Powers, rv. ii; Works, ii. 6o3.

2 Ibid., r. v; Works, ii. 523

3 Ibid.; Works, ii. 525. At the beginning of this chapter Reid was more hesitant. We ought to be cautious; we know so little.

4 Cousin, Cours de l'histoire de la philosophie moderne, iv. 550 ff.; McCosh, Scottish Philosophy, pp. 225-6; A. C. Fraser, Thenas Reid (Edinburgh, 1898), ch. viii.

5 Active Powers, I. v; Works, ii. 522. our activity as efficient causes is, Reid recognizes, to say very little. Agency is not introspectible. If all our ideas are ideas of sensation or of reflection, we do not have the idea of an efficient cause. We have the idea. Everyone familiar with the language knows that the word 'cause' has a meaning, and a primary meaning, which is not given by the addition together of the ideas of priority, contiguity, and constant conjunction. The power, in virtue of which an agent can be an agent, is no more an object of consciousness than it is of touch or sight. But we have the idea of power, though the idea is matched by no impression'. If we had 'no idea of power, if the word 'power' was a word without meaning, we could not distinguish between sense and nonsense in a discussion of the nature of power. ${ }^{\mathrm{I}}$

The freedom of the will is a necessary consequence of the fact that we are the causes of our own actions, Reid says. To be an agent is to be free to choose how one shall act and to be able to act as one chooses. ${ }^{2}$ Let us keep our attention fixed on the meaning of 'cause' and the meaning of 'agent', and we shall 'immediately perceive a contradiction' in the terms necessary cause and necessary agent'. To say that man is 'a free agent, is no more than to say that, in some instances, he is truly an agent and a cause, and is not merely acted upon as a passive instrument'. ${ }^{3}$ Neither existence nor any mode of existence can begin without an efficient cause, and an efficient cause is a being, actualizing the power of self-determining choice.

Can anything be salvaged from this? 'Self-determining agent' would have to come out of the meaning of 'efficient cause'. A free action is an occurrence, and like every other occurrence must have a cause. What is its cause? Reid can still give the answer he wanted to give: 'a free action is an effect produced by a being who had power and will to produce it'. ${ }^{4}$ If it is not part of the meaning of 'cause' that a cause is a self-determining

I Ibid., r. i; Works, ii. $5^{\text {I } 4}$.

2 Philosophers may 'dispute innocently, whether we be the proper efficient causes of the voluntary motions of our own body; or whether we be only, as Malebranche thinks, the occasional causes'. The man who knows that an event 'depends upon his will, and who deliberately wills to produce it, is, in the strictest moral sense, the cause of the event; and it is justly imputed to him, whatever physical causes may have concurred in its production'. (Ibid., 1. vii; Works, ii. 528.)

Ibid., rv. iii; Works, ii. 607

4 Ibid., Iv. ix; Works, ii. 626 . 
agent, it is equally not part of its meaning that a cause is a necessary agent. A cause is a cause.

Reid acknowledges that if our only notion of a cause is that of 'something prior to the effect, which has been found by experience to be constantly followed by the effect', then a free act, being an event without determining circumstances, would be an event without a cause. But this is not what is meant by 'cause' in the principle that everything that happens must have a cause. If it were, the principle would have an exception: "whatever was singular in its nature, or the first thing of its kind, could have no cause'. I And, in Reid's opinion, whatever is antecedent to the origin of a thing is as nothing to its origin, if its connexion with this is merely antecedence. If a thing cannot begin to exist without a cause, the cause on which its existence depends is an efficient cause, one which brings it into existence.

Reid also acknowledges, he says, that nothing more is needed to establish the doctrine of necessity than that 'throughout all nature, the same consequences should invariably result from the same circumstances'.2

Supposing that, as a matter of fact, the same consequences invariably follow upon the same antecedents, how is our free will in any way affected? I do not in any way have to do the thing I do because I always would do that thing in those circumstances. And a philosopher who held a deterministic theory of the kind which Hume held might continue: with causal necessity dissolved into this mere matter of fact-constancy forms the very essence of necessity, nor have we any other idea of it' - all the fatality has gone out of it. "Twas utterly impossible for us to have acted otherwise' 3 softens into 'Our actions would be the same in the same circumstances'. The libertarian contradiction of the necessitarian statement becomes 'Our actions might not be the same in the same circumstances'. And this randomness is no foundation for moral responsibility. It is its dissolution. If indeterminism is true, a man's actions are events which merely happen to happen regardless of his character; he is not the author of them; they proceed from nothing in him that is 'durable and constant'; however bad they are, he is always innocent.

\footnotetext{
Active Powers, iv. ix; Works, ii. 627-8.

3 Treatise, ir. iii. 2, p. 407
}

Reid gives no reasons for his opinion that the doctrine of necessity is admitted, when it is admitted that the same antecedents have invariably, as a matter of fact, the same consequents. And we shall come later on to his argument that the uniformity which we do find in human behaviour is consistent with our having a power over the determinations of our wills, and is indeed what is to be expected from our having this power. We shall defer consideration of the question whether any form of determinism can allow us the possibility of having acted otherwise which moral responsibility for what we have done requires. Does indeterminism leave our actions without agents? We have seen Reid's answer; it bends this criticism back on to Hume. No man is ever really the author of his actions, on Hume's view of causation. One thing happens and then another thing happens; nothing is ever made to happen, brought into existence. There are invariable patterns of antecedent and consequent, but between antecedent and consequent there is no other connexion than sequence. They are entirely loose and separate in themselves. But a man's actions are not his actions unless he really brings them into existence and not his actions unless he brings them into existence without necessity. And the actions which a man brings into existence without any necessity proceed from the most constant and durable thing in him, from his personal being which is responsible for all that he does because it is the self-determining agent in all that he does. If, of course, his personal being is resolved into a series of associated 'perceptions', it would be absurd to suppose it capable of free agency, absurd to suppose it capable of any sort of agency.

There is a similar impossibility in the opinion that our motives force our actions upon us. Motives are turned into causes or agents acting upon the person whose motives they are, when in fact they are 'neither causes nor agents'. They require

an efficient cause, and can do nothing without it. We cannot, without absurdity, suppose a motive either to act, or to be acted upon; it is equally incapable of action and of passion; because it is not a thing that exists, but a thing that is conceived; it is what the schoolmen called an ens rationis. Motives, therefore, may influence to action, but they do not act. They may be compared to advice, or exhortation, which leaves a man still at liberty. For in vain is advice given when there is not a power either to do or to forbear what it recommends. 
In like manner, motives suppose liberty in the agent, otherwise they have no influence at all.

We do ask 'What caused him to act in that way?', and we might possibly be asking for a man's motives, and Reid is not saying that there would be any impropriety in the wording of the question. The word 'cause' is very ambiguous;' many secondary meanings have grown out of its primary meaning. There is a definition which seems to Reid to cover all its meanings: 'Causa est id, quo posito ponitur Effectus, quo sublato tollitur. This ... includes many relations, and, I believe, includes all that in any language are expressed by cause, though in some languages some of the relations included under the definition may not be called causes, on account, perhaps, of their having some other word appropriated to signify such relations.' 3 Since a motive is called a cause in this highly general sense, we are encouraged to think that it is a cause in the sense in which it is not and could not be.

Once motives are regarded as efficient causes, as forces, analogy suggests the law of their operation. 'Every action, or change of action, in an intelligent being, is proportional to the force of motives impressed, and in the direction of that force.'4

Even supposing it true that we never act without a motive, necessitarian theory has misconstrued what it is to act with a motive: the theory represents it as being acted upon by a motive. It is, however, in Reid's opinion, not even true that we never act without a motive. We often do, he thinks, and act moreover with 'forethought and will'. Cases frequently occur in which an end of some importance may be reached equally well by any one of a number of different means. A man has no difficulty in taking one of these rather than another, though the one he selects has no title to preference over the others. 5 And if

Active Powers, rv. iv; Works, ii. 6o8-9.

2 Aristotle's 'distinction of causes into four kinds is not a division of a genus into its species, but of an ambiguous word into its different meanings'. ('Letter to James Gregory', Reid's Works, i. 75.)

3 'Letter to James Gregory', Reid's Works, i. 77

4 Active Powers, rv. iv; Works, ii. 6 og.

3 Ibid. Reid's example is Buffier's: one guinea is as good as another, but one guinea is chosen rather than another. Commenting on the proposition that a man 'necessarily inclines his will to what he judges the best', Buffier says: 'The mind will ... be puzzled to distinguish a better that is present and less durable, from a better that is to come and more lasting; a better according to the senses, from a better according men cannot act without a motive, what, Reid asks, are such words as 'wilfulness' and 'caprice' doing in the language? There is, he admits, no moral value in a motiveless action, but the fact that we can act without a motive shows that the will can reinforce a weak motive against a strong motive, and this is a fact of great moral consequence.

The characteristic assertion of necessitarian theory is the assertion that where there are contrary motives the strongest prevails. It is put forward as self-evident truth. How does one set about testing the relative strength of different motives? Reid can see that where two motives are of the same kind, it may be easy enough to say which is the stronger. Thus a bribe of a thousand pounds provides a stronger motive than a bribe of a hundred pounds. But when the motives are of different kinds, when, for example, duty and interest are opposed, how do we discover which is the stronger? When the answer to this question is examined, it is clear that the proposition that the strongest motive always prevails is either tautologically true or empirically false. Is prevalence to be the test of strength? Then the proposition is an 'identical' proposition. There is some other test of strength? There is only one other: motives differ in felt strength. This can mean nothing but that the stronger of two contrary motives is the one to which it is easier to yield, against which a severer effort of self-government has to be made if it is to be resisted. And it is not true that people always do the easiest thing. ${ }^{\mathrm{I}}$

Do we ever have to summon up reserves of self-control in order to resist advice or exhortation? Motives may be reasons for an action, as Reid seems to imply, and therefore not psychological forces; may be final causes, as Hamilton remarks in elucidation of Reid, and therefore not efficient causes. But related to a final cause for an action, to a reason for an action, there is what philosophers have often called some 'impulse' to an action, whatever its proper name should be; and as the word 'impulse' indicates, and as the words which describe it indicate ('weak', 'strong', irresistible'), it is something analogous to a force. Reid referred to it when he spoke of the felt strength of

to reason the will is always found to follow what is best as to itself; because the will itself makes the best by its own choice.' (First Truths, I. vii, pp. 39-40.)

I Active Powers, rv, iv; Works, ii. 6ro-1 1 . 
motives. If these 'impulses' are not to be called 'motives', the necessitarian will give them any generic name that Reid pleases, 'desires' and 'aversions' perhaps, maintaining that they are the determinants of human behaviour.

Reid does not dispute their presence; 'impulse' is a word he uses himself with its qualifying adjectives. His dispute with the necessitarian opinion is over the relation of the 'impulses' of desire and aversion to the will. Some philosophers use the notion of desire to elide the will by representing desire 'as a modification of will'. ('Will as a modification of Desire', Hamilton corrects Reid.) ${ }^{\mathrm{I}}$ These philosophers are mistaken. To will is one thing, to desire is another, and this distinction is clearly marked in common language. 'A man may desire riches, he may desire pleasure, but to will riches or to will pleasure is not English, nor is it sense.'2 What we will 'must be an action, and our own action; what we desire may not be our own action; it may be no action at all ... we may desire what we do not will, and will what we do not desire'. ${ }^{3}$ (We may have contrary desires, Stewart adds, but not contrary wills.) It does happen, Reid agrees, that desire rising to ungovernable passion over-rides the will and determines a man's actions, and when this happens, he is no longer responsible for them unless, of course, he has weakened his will by past indulgence.

If men 'are not necessarily determined by motives, all their actions must be capricious'-Reid is speaking for the necessitarian philosopher. Reid's main concern is to dispose of the objection that men are ungovernable unless their actions are governed by their motives: rewards and punishments will have no effect upon them. In this context Reid touches incidentally on the matter of the predictability of our behaviour if our wills are free. We shall briefly summarize the argument against indeterminism from the predictability of human behaviour and (after a comment upon it) see how Reid handles it.

I Active Powers, n. i Note; Works, ii. 531.

2 From a fragmentary draft of Intellectual Powers, Aberdeen MSS. 2131.3. 3 Active Powers, II. i; Works, ii. 532 . Reid is mistaken, Brown says. We do not find
when we examine our consciousness, desire and will. 'Will' is no more than desire immediately terminating in action; 'desire' as distinguished from will, is desire without immediate effect. (Observations on Cause and Effect, and ed ill, is desire I 806, pp. 62-63. The following pages introduce some complication into this
simplicity.)
$X$ If men's actions are not determined by their motives, their actions are random occurrences even though they might have 'efficient' causes. But in fact we can nearly always say why we did what we did (and when we are puzzled, other people can often enlighten us), and the more we know of anyone's character the more predictable his behaviour is. These facts are inconsistent with an indeterministic theory and consequences of the theory that our motives determine our actions.

Any action done with a motive allows an answer to a question asking why it was done. The answer is the same on a deterministic and on an indeterministic theory. It states the motive. But on an indeterministic theory, although there is always a reason for a choice I make freely, there is never a 'sufficient reason'. What is finally unanswerable on an indeterministic theory is a question asking why preference was given to one rather than another of two conflicting motives. ${ }^{I}$ The indeterminist might ask whether the answer which determinism finally requires-'I acted the way I did because I am the person I am' -is much more illuminating than the silence which indeterminism imposes, and be told that it was: unless a man acts in the way he does because he is the person he is, his actions in known circumstances give no indication of how he will act in similar circumstances

In Reid's opinion the facts with regard to the calculability of human behaviour are as we would expect them to be, if men were free agents in the sense in which determinism denies that they are. The facts are that people usually act in character and occasionally out of character. Suppose that men have 'moral liberty'. What use

may they be expected to make of this liberty? It may surely be expected, that, of the various actions within the sphere of their power, they will choose what pleases them most for the present, or what appears to be most for their real, though distant good. When there is a competition between these motives, the foolish will prefer present gratification; the wise the greater and more distant good.

'Now, is not this the very way in which we see men act? ... Is it not weak reasoning, therefore, to argue, that men have not

Cf. W. G. Maclagan, 'Freedom of the Will', Proc. Arist. Soc, Supp. vol. xxv, pp. 194-5. 
liberty, because they act in that very way in which they would $X$ act if they had liberty?'I

Reid's problem is to explain how the choices we make can be free in the indeterministic sense, and yet substantially predictable. In answer to it he seems to be saying that we choose according to our character, and is not this what the determinist says? There is no reason why the indeterminist should not say it. It is a statement which is neutral as between determinism and indeterminism: 'in accordance with' is not 'following necessarily from'. The sort of choices a man does make could show the choices which he is likely to go on making, though he makes them all freely, because they show how he is setting his will, how he is exerting the power which he has over its determinations. Something to this effect Reid must have meant, if he is attempting an answer to the deterministic objection and not, in spite of himself, simply speaking as a determinist.

There is implicit in some of the things Reid says a further reason why our behaviour should be largely calculable though our wills are free. Every choice in one direction makes another choice in the same direction easier and therefore more likely. To have free will as we have it does not imply that any choice we might make is as probable as any other. To have free will is to have a power over the determinations of the will, and we have this power, Reid says, in varying degrees according to the circumstances in which we find ourselves. 'In different men the power of self-government is different, and in the same man at different times.' It is diminished in proportion to the violence of desire and passion, and diminished in proportion to the strength of habit. (Our power of self-determination in another sense-which Reid does not notice is another sense-is increased, Reid mentions, by good habits. Reid does not notice the shift in sense, because he does not notice the difference between his technical expression 'power over the determinations of the will' and the expression 'power of self-government'.) 2

Stewart's account of free will follows Reid's with one apparent and one real deviation. The apparent deviation occurs where Stewart asserts that the principle of causation has no exceptions, and that our free actions are uncaused. The argument

1 Active Powers, rv. iv; Works, ii. 612.

2 Ibid., ni. ii, rv, vi; Works, ii. 534, 6rg-20. 'for Necessity', he says, 'derives all its force from the maxim, "that every change requires a cause". But this maxim, although true with respect to inanimate matter, does not apply to intelligent wents, which cannot be conceived without the power of selfdetermination.' 'Every change in inanimate matter' requires a cause. The 'determinations of a voluntary agent' need no cause. The agent is himself 'the author of them; nor could anything have led philosophers to look out for any other causes of them, but an apprehended analogy between volition in a mind and motion in a body'. As Stewart is simply concerned to make room for free agency, he is not exempting from causation the changes undergone involuntarily by intelligent beings; he was not thinking of these when he limited the principle of causation to changes in material things.

To ground the defence of free will in any way upon the proposition that we can act without motives is a mistake, Stewart thinks. We certainly cannot act as rational beings without motives.

The question is not concerning the influence of motives, but concerning the nature of that influence. The advocates for Necessity represent it as the influence of a cause in producing its effect. The represent it as the influencerty acknowledge that the motive is the occasion of advocates for Liberty acknowledge that the motive is is so far from being the efficient cause of it, that it supposes the efficiency to exist being the efficient cause of it, that it supposes the effiente two opinions there is an essential distinction. The one represents man merely as a passive instrument. According to the other, he is really an agent, and the sole author of his own actions. He acts, indeed, from motives, but he has the power of choice among different ones. When he acts from a particular motive, it is not because this motive is stronger than others, but because he willed to act in this way. Indeed, it may be others, but because he willed to act in when applied to motives. It is obviously an analogical or metaphorical expression, borrowed from a class of phenomena essentially different. ${ }^{2}$

It is 'a dictate of common sense', Reid says, 'that we can be under no obligation to do what it is impossible for us to do'. ${ }^{3}$ We do not blame madmen and idiots for what they do. They do not know right from wrong, nor would they be responsible

- Active and Moral Powers, Appendix; Works, vi. 352.

2 Ibid.; Works, vi. 370.

3 Active Powers, rv. vi; Works, ii. 6 I 7 . 
for their actions if they did, since it is not in their power to make them different. There is the same darkness in the understanding of infants and the same incapacity for self-government. It would be unthinkable to blame them for anything. Children have very little power of self-government and therefore we hardly hold them morally responsible. There are ungovernable passions and these cancel moral responsibility as completely as madness. They are madness while they last. If we never in practice allow that even the fiercest passion exculpates a man completely, it is because we are never quite sure that it was irresistible. Passion is always allowed to be some excuse. It excuses because it invades the power of self-determination. There is, then, 'a perfect correspondence between power, on the one hand, and moral obligation and accountableness, on the other .... every limitation of the first produces a corresponding limitation of the two last'. I

Does Reid think that a doctrine of necessity abolishes the distinctions between actions which could not have been avoided (for which there is no responsibility), actions that it would have been very hard to avoid (for which there is diminished responsibility), and actions which could have easily been avoided (for which there is full responsibility)? It seems that he does. 'Upon the system of Liberty', he says, these distinctions are 'perfectly intelligible; but, I think, irreconcileable to that of Necessity; for, How can there be an easy and a difficult in actions equally subject to necessity? -or, How can power be greater or less, increased or diminished, in those who have no power? $?_{2}$

Reid could no doubt have been easily persuaded that a deterministic theory does not abolish the empirical distinctions between the three classes of actions. He would still have insisted that the moral distinctions could not be grounded upon the empirical distinctions, if these are set in the context of a deterministic theory.

We have hitherto been using the word 'necessitarian' in exposition of Reid so as to keep the tone of his argument, and the word 'deterministic' in comment so as to avoid it. We might now usefully divide deterministic theories into two types: those which make 'necessitarian' assertions, at least implicitly, and those which do not. The 'necessitarian', in the limited sense in

\footnotetext{
I Active Powers, Iv. vi, vii; Works, ii. 619, 622.
2 Ibid., Iv. vi; Works, ii. 620.
}

which we are now using the word, asserts (with proper safeguards against being misunderstood) that we had to do anything we have ever done, or that we never could have done anything we did not do. His assertions and the indeterminist's are in contradiction. The determinist of the other type holds that the indeterminist's assertions are meaningless. A deterministic theory of either type will provide for the distinction between actions which 'could have been avoided' and those which 'could not', using these expressions to mark the difference between actions done under no physical or psychological compulsion and others where there was compulsion. It is not yet a deterministic theory in making this provision; it has not yet defined itself against indeterminism. The necessitarian has given these explanations in order that he will not be misunderstood when he asserts that we could not have done anything we did not do. Further explanations may be needed, further senses of 'could have' recognized, in which, consistently with deterministic inevitability, we could have done something we did not do. They will be given, the further senses recognized, and with the risk of misunderstanding removed, the assertion is repeated. Whatever else Reid may have thought that the necessitarian philosopher was committed to, he knew that he was saying that we could not have done anything we did not do, and he knew what was meant.

In what sense of 'could have' is the indeterminist asserting that we could have done things we did not do? In the sense in which the necessitarian is asserting that we could not have done them. This easy answer is not open to the indeterminist when the determinist is carefully not making this assertion; when he is saying that the meaning of 'could have' is exhausted once its empirical senses have been exhausted; and that it is meaningless to say in any further sense (except a purely logical one) that we could ever have acted otherwise.

Reid would deny that this further meaning has to be looked for: it is the meaning our words have when we admit that we could have acted otherwise, because we did not act under compulsion; no one forced the action on us, no ungovernable passion had us powerless.

If we have to do whatever we do (or if there is no meaning except meanings of a kind consistent with determinism in saying 
that we do not have to), nothing is ever our fault-a necessary consequence, in Reid's opinion, and, he remarks, with a glance in Priestley's direction, one that is being openly avowed. Priestley had been reluctant to give up his liberty until he saw that necessity really sets men free. ${ }^{I}$ It restores them, Reid says, taking up this theme, 'to the state of innocence ... delivers them from all the pangs of guilt and remorse, and from all fear about their future conduct. . . . They may be as secure that they shall do nothing wrong as those who have finished their course.'2

It will be objected that feelings of guilt and remorse and resolutions of amendment do not imply a belief in the liberty of the will, since those who subscribe to the doctrine of necessity are to be found blaming themselves and others for their actions, repenting and resolving to do better. They are and not surprisingly, Reid agrees; when a common-sense belief is given up in speculation, it keeps its hold on a man in practice.

The belief in our free agency has a double grip upon us; its own and our realization that without it the presupposition of morality has gone. No obligation without the possibility of complying with it; no possibility of complying with it unless we can do what we do not do; no merit or demerit for doing what must be done; no rewards or punishments-no just rewards or punishments-where there is no merit or demerit. If we

adopt the system of necessity, the terms moral obligation and accountableness, praise and blame, merit and demerit, justice and injustice, reward and punishment, wisdom and folly, virtue and vice, ought to be disused, or to have new meanings given to them when they are used in religion, in morals, or in civil government; for, upon that system, there can beno such things as they have been always used to signify. ${ }^{3}$

That 'ought' implies 'can', is not a proposition which divides philosophers. Their unanimity breaks up when it comes to the elucidation of 'can'. We need not concern ourselves here with any analytical refinements: 'can' in an indeterministic sense, or in one or several of the senses compatible with determinism? This is not a question which is answerable without a decision on the nature of moral obligation. If, for example, the significance of the moral 'ought' is confined to its imperative and

\footnotetext{
1. The Doctrine of Philosophical Necessity (London, 1777), p. xxxi.

2 Active Powers, Iv. vi; Works, ii. 618.
}

3 Ibid., IV. vii; Works, ii. 622.

\section{PERSQNAL IDENTITY AND FREE WILL}

ve functions in utterances in which we urge conduct of certain kind upon ourselves or others, then what these utterances presuppose is the belief that the relevant physical and psychological capacities are present and duress of any kind sufficiently absent. There would be no point in construing 'can' indeterministically. The 'scheme of necessity', unless it was incompetently constructed, would not require any reformation of cour moral vocabulary. But if moral imperatives do not originate with us, if they are, as Reid believed, imperatives of an immutable moral law, then-and here one has to appeal to selfevidence-their presupposition does seem to be a free will incompatible with any kind of determinism. 
VII

\section{MORAL DISTINCTIONS}

I. MATTER OF FACT AND MORAL FACT

$\mathrm{M}$

RAL approbation and disapprobation are as familiar to us as anything can be and yet, Reid says, their nature has become a question in serious dispute among philosophers. It is not that they have begun to pay closer attention to the operations of their minds in approving and disapproving and have found an illusory clarity darken into obscurity. The dispute has had another origin. It is the 'modern system of Ideas and Impressions' which has obliged philosophers to ask with manufactured ignorance what approbation and disapprobation are; whether they include ' $a$ real judgment' which 'like all other judgments, must be true or false', or whether they are no more than 'some agreeable or uneasy feeling, in the person who approves or disapproves'.

Before the advent of this system nothing 'would have appeared more absurd than to say, that when I condemn a man for what he has done, I pass no judgment at all about the man, but only express some uneasy feeling in myself'. It is, in Reid's opinion, a consequence of the system, that this apparent absurdity of speech is an appropriate description of the facts. Not a consequence which was immediately obvious; time was needed to enter into the spirit of the modern way of looking at things. Descartes and Locke went so far as to transform the secondary qualities of bodies into ideas, and to deprive the senses of the office of judgement, making them merely channels through which ideas were conveyed into the mind. Judgement is subsequently possible, and immediately on the relation of ideas to ideas. Judgement on the relation of ideas to the external world must be mediated by reasoning, and the premisses available will support no conclusions. Locke's principles in Berkeley's hands transformed the primary qualities into ideas and left no external world to be even the indirect object of judgement. The same principles applied to matters of taste showed that 'beauty and deformity are not anything in the objects ... but certain feelings in the mind of the spectator'. The same principles take the judgement out of moral approbation and disapprobation and leave them as the expression of feelings of another kind; or if there is a judgement left to them, it is the judgement that one has feelings of this other kind. ${ }^{\mathrm{I}}$

Many operations of the mind which go under a single name are complex, and have feeling or sensation as one constituent and judgement or belief as another, and these constituents inseparably related. In some of them the belief is a 'consequence of the sensation' and 'regulated' by it, as in sense perception. More often the relation of dependence between the constituents is reversed. Thus nobody feels grateful unless he believes that some kindness has been done to him, or frightened unless he thinks there is something to be frightened of. Moral approbation is complex. There is feeling in it-a complex feeling-and judgement, and the feeling is dependent on the judgement, would change to its contrary if the judgement changed to its contrary. This judgement, according to Reid, is the judgement that the conduct approved of 'merits esteem'. It is a judgement which cannot be resolved into a judgement that one has feelings of any kind, or into the expression of feelings of any kind. ${ }^{2}$

I might say of someone that he did 'well and worthily, his conduct is highly approvable'. Suppose I say instead that his conduct ' gave me a very. agreeable feeling'. If 'approbation be nothing but an agreeable feeling', the first of these statements must have 'the very same meaning' as the second. There is 'no rule in grammar or rhetoric, nor any usage in language, by which these two speeches can be construed so as to have the same meaning. The first expresses plainly an opinion or judgment of the conduct of the man, but says nothing of the speaker. The second only testifies a fact concerning the speaker-to wit, that he had such a feeling'. And again the first can be contradicted without giving affront, but not the second; 'for, as every man must know his own feelings, to deny that a man had a feeling which he affirms he had, is to charge him with falsehood'.

The moral judgement is not a judgement about the speaker's feelings. Is it possible that it is not a judgement at all but an expression of the speaker's feelings? It is not possible, Reid says.

$$
\text { I Active Powers, v. vii; Works, ii. 670-1. } \quad 2 \text { Ibid.; Works, ii. 672-3. }
$$


It is not possible that 'every form of speech which language affords to express our judgment, should . . . be used to express what is no judgment; and that feelings which are easily expressed in proper language, should as universally be expressed by language altogether improper'.

Reid's place in the history of moral philosophy is as a critic of subjectivist views of the nature of morality. The subjectivist views had been his own. He announces his conversion from them in a 'discourse'2 with this question as its title: 'Whether our moral determinations are real judgments which must be true or false and whose truth depends not upon the constitution of the person who judges but upon the nature of the things which he judges?'

I confess [Reid says] I have not always been of the same mind in this question, having been long pretty much determined on one side, afterwards dubious and uncertain and for some time past more inclined to the contrary side. I wish, however, to guard against the zeal of a convert. And as I expect to hear in this meeting the objections against the opinion which I am to propose set in the strongest light, I shall not be ashamed upon conviction to return to my first faith.

What is surprising is how late Reid's conversion seems to have been. He mentions at the end of chapter iii of essay $v$ of the Active Powers that the four final chapters were written in substance 'Iong ago, and read in a literary society'. The Aberdeen Philosophical Society, one supposed with Hamilton; so that these chapters would have been written in substance before the Inquiry was published. And accordingly one treated the chapter, part of which has just been summarized, a chapter belonging to this group, as a commentary on the statement in the Dedication to the Inquiry, that 'virtue' was among the things 'overturned' when the consequences of the theory of ideas became explicit in Hume. One assumed as a matter of course that when Reid wrote the Inquiry he held moral perception to be as objective as sense perception, and the theory of ideas to have forced subjectivity equally on both; that the philosophy of Common Sense had seen from the beginning the 'metaphysical' commitment in the common-sense belief in

I Active Powers, v. vii; Works, ii. 673-4.

${ }^{2}$ Aberdeen MSS. 2131.3. the reality of moral distinctions, had seen that for common sense these distinctions are unique, factual, and immutable.

The minute book of the Aberdeen Philosophical Society records'nearly all Reid's papers as dealing with topics belonging to the Inquiry. The one relevant exception is a paper with the title of one of the four chapters (v. iv) of the Active Powers. The 'literary society' then to which Reid was referring would be the Literary Society of Glasgow. But though its minute book ${ }^{2}$ records Reid's question (30 March 1770 ), it records it with a Dr. Wight as its 'proposer', and if Reid's paper was a contribution to the discussion, this is not mentioned. Reid is down (7 May I 779) as having proposed a question on the nature of contract. This is the topic of one of the four chapters (v. vi). He might have dealt with the topics of the remaining two in papers to the society some time between 25 January 177 I and I November 1776 . There is an almost complete blank in the minute book between these dates. Elsewhere there are occasional anomalies in consecutive entries: Reid, for example, is mentioned at one meeting as proposing a question for the next, and there is no mention of his question in the minutes of the next meeting.

Assuming that Reid's conversion in moral theory belongs to his early Glasgow period, what did he have in mind in the Inquiry when he spoke of the theory of ideas as carrying implications fatal to morality? The self resolved into a bundle of perceptions-no moral subject, no moral agent; it seems to have been this, and not anything concerned with the subjectivity of moral distinctions.

The paper whose approximate date we have been trying to fix concentrates, with one or two additional details, observations on the nature of the moral judgement which are scattered in the Active Powers. The moral judgement is a real judgement; a judgement in which the speaker is not the 'subject'; a judgement involving unique concepts. It is not enough to maintain that the moral judgement is a real judgement, which like other judgements must be true or false, which therefore cannot be resolved into the expression of some feeling. "To have the toothache

I Now in the Library of King's College, Aberdeen.

2 Now in the Library of the Royal Faculty of Procurators, Glasgow. I am indebted for the information concerning it to Mr. A. T. W. Liddell. 
is not to judge but to feel, but to affirm that one has the toothache, is not to feel but to judge. The feeling cannot be true or false, but the affirmation must be true or false.' To affirm that one has feelings of a certain kind from the contemplation of an action is to make a real judgement, but a judgement in which one is oneself the 'subject'. It must be true or false, but it will change from truth to falsity with a change in one's feelings. Are our moral determinations judgements of this kind? This question, along with the question whether they are real judgements at all, is to be answered by examining the manner in which they are expressed in language. And the manner in which they are expressed in language is a plain declaration of 'the common sense of mankind' that they are real judgements and are quite unlike judgements of this kind; that they are true or false according to the constitution of the things judged and independently of the constitution of the person judging. They are objective judgements then, and the notions involved in them appear to the most careful reflection to be notions 'of a peculiar nature and unlike to anything else'.

Moral distinctions are derived from a moral sense, Hume says. Reid agrees that moral distinctions can be said to be derived from a moral sense. He differs from Hume on the nature of a sense, and therefore on the nature of the moral sense-'Mr. Hume will have the Moral Sense to be only a power of feeling without judging.' 1 There is this analogy between the senses and the moral sense:

as by them we have not only the original conceptions of the various qualities of bodies, but the original judgment that this body has such a quality, that such another; so by our moral faculty, we have both the original conceptions of right and wrong in conduct, of merit and demerit, and the original judgments that this conduct is right, that is wrong; that this character has worth, that demerit. ${ }^{2}$

'Original conceptions' of morality; Reid speaks of them in the plural, but he seems to find one unanalysable concept sufficient. The concept expressed by the word 'ought' has for him an obvious primacy. The right and the good are what ought to be done, the wrong and the bad what ought not to be done. ${ }^{3}$ And

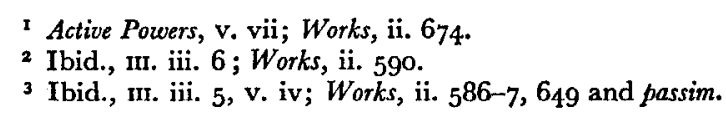

where Reid does not himself actually identify moral concepts, it is clear that he would not oppose their unification by means of analyses in which the word 'ought' would be the moral term.

The concept of moral obligation is unanalysable, but is unmistakably a relational concept. (And 'to determine relations is the province of judgment, not of mere feeling' ${ }^{\prime}$ )

If we examine the abstract notion of Duty, or Moral Obligation, it appears to be neither any real quality of the action considered by itself nor of the agent considered without respect to the action, but itself, nor celain relan between the one and the other.

When we say a man ought to do such a thing, the ought, which expresses the moral obligation, has a respect, on the one hand, to the person who ought; and, on the other, to the action which he ought to do. Those two correlates are essential to every moral obligation; to do. Those two correiates are existence. So that, if we seek the place take away either, and it has no existence. So that, if we seek the pategory of moral oblig

of relation. ${ }^{2}$

If moral judgements are real judgements which like all other judgements must be true or false, what are the facts which make them true or false? 'Take any action allow'd to be vicious; Wilful murder for instance.' Point out 'that matter of fact, or real existence, which you call vice'. There is nothing there besides the strangling hands and the intention to kill and the motive behind it.

The vice entirely escapes you, as long as you consider the object. You never can find it, till you turn your reflexion into your own breast, and find a sentiment of disapprobation, which arises in you, towards this action. Here is a matter of fact.... It lies in yourself, not in the object. So that when you pronounce any action or character to be vicious, you mean nothing, but that from the constitution of your nature you have a feeling or sentiment of blame from the contemplation of it. Vice and virtue, therefore, may be compar'd to sounds, colours, heat and cold, which, according to modern philosophy, are not qualities in objects, but perceptions in the mind. ${ }^{3}$

I Ibid., v. vii; Works, ii. 677. The 'Sentimental philosophers', Reid says, dem demand a definition of this relaty. Other words might be used instead of 'obligaequality, similitude, or contrariety. Other words 'better understood'. (Aberdeen MSS. tion', but 2131.3.)

2 Active Powers, mr. iii. 5; Works, ii. 588-9.

3 Hume, Treatise, III. i. I, pp. 468-9. 
In one way, Reid would agree, the moral description of the action adds nothing to its physical and psychological descriptions; its 'vice' is not some additional property which these omit. What Reid maintains is there is a fact of another kind altogether, besides the fact that the action was done and with such and such motives, and that contemplating it, we feel a sentiment of disapprobation. It is the fact that what was done ought not to have been done (and ought to be condemned by everybody). And the moral judgement which states this fact is a judgement in the same sense as a judgement which states any matter of fact.

It is difficult to avoid speaking of moral 'qualities', 'properties', 'attributes', using these words quite non-committally. They occur so rarely in Reid as to suggest that their avoidance is deliberate. I Yet Reid does say emphatically that beauty is a quality, is a property of things, and says so in discussing the conclusions which Hume draws from the analogy between beauty and virtue. Reid has no doubt that there is the analogy: Hume is as mistaken about the nature of beauty as he is about the nature of virtue, has the same paradoxical opinions with regard to both, and with regard to both is opposed by 'the common language and common sense of mankind'.2

Reid's discussion of the nature of beauty needs fairly careful attention. If one took account only of its very prominent features and neglected others less obtrusive, one could come to the mistaken conclusion that Reid's disagreement with Hume is merely verbal, and since Reid and Hume agree that there is a close analogy between beauty and virtue, possibly to the further conclusion that their disagreement over the nature of morality is verbal, or that Reid has two inconsistent opinions on the nature of morality.

There is, in Reid's view, a close analogy not only between moral approbation and aesthetic taste, but also between aesthetic taste and physical taste. Aesthetic taste, like the taste of the palate, enjoys some things, dislikes others, finds others indifferent and is sometimes undecided. Things are bitter or sweet whether they are tasted or not; when they are tasted, sensations of bitterness or sweetness are produced. Things are beautiful or

1 Cf. D. D. Raphael, The Moral Sense (London, 1947), p. 184 .

2 Active Powers, v. vii; Works, ii. 677. ugly whether they are seen or not; being seen, they produce in the spectator a correspondent emotion. Taste in bodies is a secondary quality; we know no more about it by tasting than that it is something or other which gives us a certain sensation. We may be as ignorant of what it is that makes an object beautiful, knowing that it is beautiful, but unable to say why. On the other hand, we may be able to see how in a work of art, for example, "every part is fitted with exact judgment to its end'. Its beauty is then no longer mysterious, but 'perfectly comprehended'; we know 'wherein it consists', as well as 'how it affects' us.'

The different kinds of tastes are innumerable and nearly all of them, having no names of their own, are named from the things to which they belong. This is true of the different kinds of beauty also, which are still more radically heterogeneous. As the nature of the secondary qualities of bodies is a matter for inquiry, so philosophers properly concern themselves with the attempt to discover what it is that makes beauty beauty whereever it is found. Since it is found in things as different as a mathematical demonstration, the human face, and a stroke of wit, the investigation might seem to be futile. There appears to be 'no identity, nor even similarity' in the beauty of things so diversely beautiful. Then why are they all called 'beautiful'? If they do not have some property or set of properties in common, they must have some common relation to us or to something else. And not to anything else; there is nothing that could be the centre of this circumference except ourselves.

All the objects we call beautiful agree in two things, which seem to concur in our sense of beauty. First, When they are perceived or even imagined, they produce a certain agrecable emotion or feeling in the mind; and, secondly, This agreeable emotion is accompanied with an opinion or belief of their having some perfection or excellence belonging to them. ${ }^{2}$

I Intellectual Powers, virl. i; Works, i. 490-1.

2 Ibid., vur. iv; Works, i. 498. Stewart is in general agreement with Reid over the nature of beauty, but without mentioning him, he introduces his own discussion of its nature with a protest against the naivety of the assumption that things must have something in common in order to have the same name. The assumption overlooks the 'transitivity' of names. Suppose that ' $A, B, C, D, E$, denoss some one quality in common with $B ; B$ a qute a serith $D ; D$ a quality in common with $E$; - while, at the same time, no quality can be found which belongs in 
There is the greatest variety in aesthetic emotion, but broadly it is of two kinds: the emotion aroused by grandeur or sublimity, and the emotion aroused by beauty-if we now use the word 'beauty' more narrowly and properly than we have hitherto been doing. The emotion aroused by beautiful things is 'gay and pleasant. It sweetens and humanises the temper, is friendly to every benevolent affection, and tends to allay sullen and angry passions. It enlivens the mind, and disposes it to other agreeable emotions, such as those of love, hope, and joy.'I The emotion to which we are moved by grandeur is 'awful, solemn, and serious'. It is akin to devotion, and 'inspires magnanimity, and a contempt of what is mean'.2

There is indeed a very real sense in which beauty and sublimity are in the mind-in the mind of the creator, not in the mind of the spectator. (In so far as we project our feelings on to nature we create, before we contemplate, what moves us to aesthetic emotion.) To look for beauty and sublimity in anything physical, thought of as merely physical, is to look for the living among the dead. If we imaginatively adopt the Epicurean philosophy while contemplating the sublimities of the world, we find that the earth, the sea, and the stars no longer have any aesthetic significance; 'the clashing of atoms by blind chance' has nothing in it fit to elevate the soul with the emotion of grandeur. A 'great work' is a work of 'great power, great wisdom, and great goodness, well contrived for some important end. But power, wisdom, and goodness are properly the attributes of mind only'. ${ }^{3}$ They are expressed in the work, given a 'body' there, clothed with sensible qualities there, and the work has grandeur by derivation. In the same way there is an original beauty and a reflected beauty, and original beauty is an attribute of the mind. The original beauty is an intellectual

common to any three objects in the series. Is it not conceivable, that the affinity between $A$ and $B$ may produce a transference of the name of the first to the second; and that, in consequence of the other affinities which connect the remaining objects together, the same name may pass in succession from $B$ to $C$; from $C$ to $D$; and from $D$ to $E$ ?' In this way a 'common appellation' will arise between $A$ and $E$, and $A$ and $E$ have nothing in common. (Cf. Wittgenstein, Philosophical Investigations, 8\& 65-67). Every metaphor, Stewart adds, is 'necessarily a transitue expresion, although there are many transitive expressions which can, with no propriety, be said to be metaphorical'. (Philosophical Essays, II. i. I; Works, v. 195-7.)

Intellectual Powers, virr. iv; Works, i. 498.

2 Ibid., virr. iii; Works, i. 494.

Ibid.; Works, i. 496. or moral beauty-the emphasis in the Inquiry on the communication of emotion has diminished in the Intellectual Powers-and its lustre is reflected on to the objects which manifest it. This is the main drift of Reid's opinion: sensible beauty is borrowed beauty. Reid is not quite consistent. At least as we are constituted, he also says, beauty results from the commerce between the world of sense and the world of the mind. Thus the language of poetry is pleasing because it is a language in which properties are figuratively exchanged between the two worlds. ${ }^{1}$

But this doctrine of Reid's, that beauty is in the mind, is not of course the paradoxical doctrine of 'modern' philosophers that beauty is in the mind contemplating, not in the object contemplated. According to Reid's doctrine, beauty is in the object, though originally in a remoter object than the objects of sense, and there independently of anyone's contemplation of it; it is derivatively in objects of sense, and there independently of anyone's contemplation of it. The paradoxical doctrine, in the words of Hutcheson which Reid uses to state it, is that beauty is not 'any Quality suppos'd to be in the Object, That should of itself be beautiful, without relation to any Mind which perceives it: For Beauty, like other Names of sensible Ideas, properly denotes the Perception of some Mind; so Cold, Heat, Sweet, Bitter, denote the Sensations in our Minds.'2 In looking at this paradox we can ignore, as Reid does, the difference between original and derived beauty, and for convenience we shall also ignore the difference between beauty and sublimity.

The teaching of Locke on the nature of the secondary qualities is behind this paradoxical account of the nature of beauty, Reid says. Locke 'distinguished very properly between the sensations we have of heat and cold', for example, and

that quality or structure in the body which is adapted by Nature to produce those sensations in us. ... What remained to be determined was, whether the words heat and cold, in common language, signify the sensations we feel, or the qualities of the object which are the cause of these sensations. Mr. Locke made heat and cold to signify only the sensations we feel, and not the qualities which are the cause of them. And in this, I apprehend, lay his mistake. For it is evident, from the use of language, that hot and cold, sweet and bitter, are

Ibid.; Works, i. 497

2 Inquiry into Beauty and Virtue, r. i (Ist ed., London, 1725), p. 13. 
attributes of external objects, and not of the person who perceives them. Hence, it appears a monstrous paradox to say, there is no heat in the fire, no sweetness in sugar; but, when explained according to Mr. Locke's meaning, it is only, like most other paradoxes, an abuse of words. ${ }^{\mathrm{I}}$

Is this all there is, in Reid's opinion, to the paradox which turns beauty into feeling - the misapplication of a word? That this is all there is to it, one would naturally take to be the implication of the general analogy between aesthetic taste and the taste of the palate, between beauty and the secondary qualities of bodies. It is the implication suggested also by a number of details in the analogy, and especially by the contrast between beauty as an 'occult' quality, when all we know of it is how we are affected by it, and beauty as a quality 'distinctly conceived and ... specified'. Our 'judgment of beauty' is 'instinctive' in the first case and 'rational' in the second.2 These judgements seem to be simply matter of fact judgements. And in one place Reid inadvertently makes the 'real' judgement in moral approbation simply a matter of fact judgement. He is illustrating the dependence of moral feeling on moral judgement: I see a man exerting himself energetically in a good cause; ' $I$ judge that this conduct merits esteem' and therefore contemplate it with approving pleasure; persuade me that he was bribed and my feelings are altogether different. ${ }^{3}$

Reid has here obscured the thing he is contending for. It is that moral approbation includes a judgement of moral fact. The analogy between beauty and the secondary qualities consistently obscures his parallel contention. It is that aesthetic approval includes a judgement of value which is similarly factual.

There are two things common to all things which we call beautiful, Reid says. They produce in us 'a certain agreeable emotion', and this agreeable emotion 'is accompanied with an opinion or belief of their having some perfection or excellence belonging to them'. Grandeur 'in objects', he says, 'seems to be nothing else but such a degree of excellence, in one kind or another, as merits our admiration'.4

Intellectual Powers, vir. iv; Works, i. 499.

3 Active Powers, v. vii; Works, ii. 672-3

Ibid.; Works, i. 500-1.

4 Intellectual Powers, virr. iii, iv; Works, i. 494, 498.
An 'excellence' or 'perfection' is not for Reid a special quality which a thing has over and above its other qualities. It is identical with some one, or several, or all of the thing's constitutive qualities. But there is for Reid more to an excellence than this identity. There is the fact that a thing with these qualities merits admiration, that it ought to arouse certain emotions. And this is a fact quite different from the fact that it has these qualities, that it is admired, that it does or could arouse these emotions-and as much a fact as these matters of fact.

If we listen to 'the dictates of common sense, we must be convinced that there is a real excellence in some things, whatever our feelings or our constitution be', that a thing 'has its excellence from its own constitution, and not from ours'. There are some things that 'ought to please, and others that ought to displease. If they do not, it is owing to some defect in the spectator.'2 The objectivity which Reid is asserting against Hutcheson and Hume is the objectivity of a judgement of value. But he has conducted his argument as though it was the objectivity of a matter of fact judgement which had to be asserted and a linguistic paradox avoided, as though he wanted and was arguing for the admission that in everything that is beautiful or sublime there is something or other, existing independently of us, which causes us to feel certain emotions, and that this, whatever it is, is properly called the thing's beauty or sublimity. It is some excellence or perfection, he adds, but he brings out the significance of this addition obscurely and quite marginally, as though the whole dispute was not over the nature of an excellence or perfection.

Reid selected the wrong feature of the theory of ideas for attention in tracing the effect of the theory on opinions concerning beauty. Preoccupied with the general withdrawal from external reality he saw in the theory, he barely mentions the implications of its conceptual empiricism. ${ }^{3}$ In consequence his real dispute with other philosophers is left in the shadow of a dispute which he could see, when he reflected, was a dispute

Ibid., virr. iii; Works, i. 495 .

2 Ibid., vI. vi; Works, i. 453 .

3importance in this connexion of Locke's ${ }^{3}$ Price, he says brill our ideas. (Intellectual Powers, virr. ii; Works, i. 495.) 
over words. If we have not misunderstood him, what he was really concerned to maintain is that aesthetic judgements (as well as moral judgements) state facts about matters of fact, facts of a unique kind, the nature of which is indicated by the open or concealed presence in these judgements of the word 'ought' or of one of its synonyms.

Is it of any great importance whether or not moral judgements are factual judgements and moral concepts unique? Reid does not appear to regard it as a matter of any practical consequence. Theories which give an account of the "powers of the mind by which we have our moral conceptions, and distinguish right from wrong' are related, he says, to our moral judgements as the theory of vision is to seeing, and 'those who differ most in the theory of our moral powers, agree in the practical rules of morals which they dictate'. Reid does not attempt to give practical application to a common-sense belief, which would otherwise remain purely 'speculative', by suggesting that we might come to think the distinction betwcen right and wrong less important than we had supposed, if we become persuaded that it can be resolved into a difference in our feelings towards different actions.

The consequence which Reid does regard this moral subjectivity as carrying with it is that there can be no immutable morality. If what we call a moral judgement is no real judgement but merely the expression of some feeling that we have, or is a real judgement, but one merely which states that we have that feeling, then all

the principles of morals which we have been taught to consider as an immutable law to all intelligent beings, have no other foundation but an arbitrary structure ... in the constitution of the human mind. So that, by a change in our structure, what is immoral might become moral, virtue might be turned into vice, and vice into virtue. And beings of a different structure, according to the variety of their feelings, may have different, nay opposite, measures of moral good and evil. ${ }^{2}$

The opinion that morality depends upon the arbitrary constitution of our nature has a further consequence, Reid says. It is that we could know nothing whatever of the moral character

$$
\begin{aligned}
& \text { Attive Powers, v. ii; Works, ii. } 642 . \\
& \text { Ibid., v. vii; Works, ii. 678-9. }
\end{aligned}
$$

of God. Indeed this is to state the consequence too weakly: since 'nothing arbitrary or mutable can be conceived to enter into the description of a nature eternal, immutable, and nessarily existent', the consequence is that God has no moral cluracter. ${ }^{1}$

A real judgement has a trivial dependence on the constitution of one's nature and a real independence of it, unless it is a judgement about oneself. We cannot 'judge of visible objects' if the faculty of sight is missing, nor of beauty and deformity if we are without the faculty of taste.

If we suppose a being without any moral faculty in his fabric, I grant that he could not have the sentiments of blame and moral

approbation. The are, therefore, judgand fabric of the mind. But . . . though it depends upon the fabric of a mind, whether it have such a judgment or not, it depends not upon that fabric whether the judgment be true or not. ${ }^{2}$

"True or false in morals . . . is necessarily so.'3 This, Reid thinks, will not be denied by anyone who allows that truth is there at all. What kind of evidence can we have for moral propositions which if true are necessarily true? Locke held that moral truth is capable of demonstration: 'the precise real essence of the things moral words stand for may be perfectly known; and so the congruity and incongruity of the things themselves be certainly discovered; in which consists perfect knowledge'. Locke's examples are the two propositions, that there can be no injustice where there is no property, and no government where there is absolute liberty; propositions 'as certain as any demonstration in Euclid'.4

Neither of these propositions is a demonstrated conclusion, both are true by definition, Reid says; he would not call them moral truths. The propositions which are correctly to be called 'moral' are not 'abstract' propositions-Locke's argument applies only to 'abstract' propositions-but those which affirm 'some moral obligation to be, or not to be incumbent on one or

Ibid.; Works, ii. 679 .

2 Ibid.; Works, ii. 676 .

3 Intellectual Powers, vi. vi; Works, i. 454.

4 Essay, in. xi. 16, rv. iii. 18; Works, ii. 50, 112. 
more individual persons', which affirm 'something to be the duty of persons that really exist'. ${ }^{1}$

The proposition that there is more merit in a generous action than in an action which is no more than just, is an 'abstract' proposition and a moral proposition. (Reid has earlier called it a 'moral axiom'.) It is not the abstractness of Locke's propositions which disqualifies them as moral propositions. Reid's first comment on them indicates their disqualification.

Moral truths divide into two classes. There is the class of principles, of moral axioms; such principles, besides the one already mentioned, as that we ought to be faithful to our engagements, that we ought not to do to others anything which we would regard as unjust if done to ourselves in the same circumstances. No one who cannot see their truth can have it proved to him. Suppose that a man cannot see that he ought to be faithful to his engagements. He cannot see it. How would you reason with him? 'You may possibly convince him by reasoning, that it is his interest to observe this rule; but this is not to convince him that it is his duty.'2 You can no more demonstrate to him that it is his duty than you can argue a blind man into seeing. The 'first principles of morals, into which all moral reasoning may be resolved, are perceived intuitively, and in a manner more analogous to the perceptions of sense than to the conclusions of demonstrative reasoning'. ${ }^{3}$ There is thus no question of demonstrating the first principles of morals. There are no premisses for the demonstration, and these principles are already intuitively self-evident.

The second class of moral truths is constituted by the application of principles to particular cases. This is not Reid's description of this class. The second class of moral truths, he says, consists of those that are deduced by reasoning from those that are self-evident. We shall see in a moment that Reid appears to say that no moral propositions are demonstrable, and then to say that some of them are. The appearance of contradiction is caused by a shift, at least a partial shift, in the meaning of 'demonstrable' and 'demonstrative evidence', and Reid adds to our difficulties by not marking off at the outset (as he does

\footnotetext{
Intellectual Powers, vir. ii; Works, i. 479-81.

2 Active Powers, IIr. iii. 6; Works, ii. $59 \mathrm{r}$.
3 Intellectual Powers, vir. ii; Works, i. $48 \mathrm{r}$.
}

later on implicitly) the conclusions reached by moral reasoning as a sub-class within the class of derivative moral propositions. Are any moral propositions demonstrable, any of the propositions which 'affirm some moral obligation to be, or not to be incumbent on one or more individual persons'?

To such propositions, Mr. Locke's reasoning does not apply, because the subjects of the proposition are not things whose real because the subjects of the perfectly known. They are the creatures of God; their obligation results from the constitution which God hath given them, and the circumstances in which he hath placed them. That an individual hath such a constitution, and is placed in such circumstances, is not an abstract and necessary, but a contingent truth. It is a matter of fact, and, therefore, not capable of demonstrative evidence, which belongs only to necessary truths. ${ }^{\text {I }}$

Is our duty in our actual circumstances ever demonstrable? It is never demonstrable. The 'moral man' is not the abstraction Locke made him out to be-'a corporeal rational creature'.2 The moral man is a man in the particularity of his individual nature, with his duty determined by it and by his concrete circumstances. His duty in the different circumstances in which he finds himself is never demonstrable because it depends upon contingent matters of fact, and these are never demonstrable.

Is Reid maintaining (as Dr. Raphael interprets him) ${ }^{3}$ that we can never 'know for certain' what we ought to do in any particular set of circumstances; that we can never know it for certain, because out obligations are determined partly by the constitution of our nature and partly by the nature of our circumstances, and these are matters of fact about which we may have 'highly probable belief', but can never have 'knowledge'? Or is Reid maintaining merely that our actual duties are incapable of demonstration, in a logician's technical sense of 'demonstration' (sharing with Locke the view which assimilates all demonstration to mathematical demonstration); maintaining this, but not implying by this that they are never certain?

'The evidence which every man hath of his own existence, though it be irresistible, is not demonstrative. And the same thing may be said of the evidence which every man hath, that

Ibid., vr. ii; Works, i. 479 .

2 Essay, uI. xi, 16; Works, ii. 50. $\quad 3$ The Moral Sense, pp. 171-2. 
he is a moral agent, and under certain moral obligations.' This is the beginning of the paragraph which follows the paragraph we are considering. It is not perháps entirely decisive against the first interpretation of that paragraph, since Reid may be meaning by the obligations for which we have evidence as irresistible as the evidence for our own existence, the general obligations which are principles of morality. It is at least a reminder that there are contingent matters which, though formally indemonstrable, can be known with absolute certainty.

If the first interpretation is correct, Reid is about to contradict himself, for on the next page he says:

I apprehend, that, in every kind of duty we owe to God or man ... the obligation of the most general rules of duty is self-evident; that the application of those rules to particular actions is often no less evident; and that, when it is not evident, but requires reasoning, that reasoning can very rarely be of the demonstrative, but must be of the probable kind. Sometimes it depends upon the temper, and talents, and circumstances of the man himself; sometimes upon the character and circumstances of others; sometimes upon both; and these are things which admit not of demonstration.

Here Reid is saying something about uncertainty in moral judgements. When it is not perfectly obvious that a general rule covers a particular case (as it often is, as it often is as evident, for example, that we ought to keep this promise as that we ought in general to keep our promises), where we have to reason out what we should do, taking into consideration our own circumstances and the circumstances of other people, then we can very seldom reach conclusions which have demonstrative evidence and must content ourselves with probabilities. ${ }^{\mathrm{I}}$ Thus a magistrate knows that he ought to promote the good of the community which has put him in office. He will very often be doubtful about the best means to adopt, and 'very rarely' able to resolve his doubts by 'demonstrative evidence', and will have to decide on what 'appears most probable'. But few moral cases require reasoning out. In 'the common occurrences of life, a man of integrity ... sees his duty without reasoning, as he sees the highway'.

In the passage which we have just been considering 'demonI Virtue does not suffer, Reid remarks at the end of the chapter. To act 'agains what appears most probable in a matter of duty, is as real a trespass against the first principles of morality, as to act against demonstration'.
Trative' evidence is contrasted with 'probable' evidence as conclusive with inconclusive evidence. In the earlier passage this contrast is absent; the contrast is between logically different types of evidence. 'Demonstrative evidence' is one type of evidence, and the evidence for the propositions which state our actual duties is never 'demonstrative', but there is no implication that it is never conclusive.

How is it possible for anyone to be morally mistaken when he is not mistaken with regard to any relevant matters of fact? It is not possible, Reid implies, if moral judgements are expressions of some of our feelings or assertions that we have these feelings ; ${ }^{\mathrm{I}}$ for either nothing is asserted, or nothing that could be false unless there is lying. A mistaken moral judgement is logically possible on Reid's view of the nature of a moral judgement, but how could the mistake ever come about? On this Reid has very little to say, and it is not of much use. A man's moral sensitivity depends to a large extent on his moral character. And from 'the varieties of education, of fashion, of prejudices, and of habits', men will come to have conflicting moral opinions. The variety of their moral opinions is not greater but much less than the variety of their opinions on 'speculative' matters, and 'as easily accounted for, from the common causes of error, in the one case as in the other'. ${ }^{2}$ But there is no parallel between the cases Reid is comparing, except where the 'speculative' matters are matters for which the only evidence is self-evidence. And a failure to see what is self-evident is finally inexplicable.

The moral history and moral geography of mankind are altogether misinterpreted, Stewart considers, if they are thought to prove that there is no fundamental unanimity in men's moral opinions. In examining the moral codes of different times and different places, allowance has to be made for the different physical circumstances of peoples and for their different degrees of civilization. When this is done the illusion of fundamental contradiction between moral codes begins to disappear. Thus, for example, where soil and climate are so beneficent that the necessities of life and many of its luxuries are there for the taking, the zights of property will be very contracted. People will think about most things as everyone does about light and air, that
Cf. Hume, Treatise, nIr. ii. 8, p. 547.
2 Active Powers, mi. iii. 5; Works, ii. 587. 
they belong to no one in particular. Theft will not be wrong or will be a trivial offence. But if what is stolen is something that a man has made for himself and values as his own, the offence will assume the proportions that it has everywhere else. As an example of the difference which different degrees of civilization make to moral rules, private vengeance is one thing in a society such as ours, and morally quite another thing in a society where the laws give the individual no adequate protection.

External circumstances modify the application of moral rules, and the external features of an action do not reveal its moral character. The disposition expressed in an action gives it its moral significance. The Indians around Hudson's Bay kill their aged parents, but in filial piety; they are not to be cited as evidence that there are no innate practical principles.

Nature through moral principles prescribes ends to our conduct; it is left to our reason to calculate the best means to attain them. Thus we ought to aim at our own happiness and at the happiness of other men, but this prescription does not define 'the constituents of happiness', nor the way to it. Differing in opinion with regard to the nature of happiness and how it is to be reached, men must often differ in particular moral judgements, while they acknowledge and because they acknowledge the same moral principles.

Stewart is not planing down the content of moral principles until there is no material left in them over which there might be disagreement. He recognizes many moral principles besides those which require us to seek our own and other people's happiness. He thinks vaguely of all of them as prescribing ends to our conduct and leaving the means to our own discovery. He thinks of them as also primary rules of duty. Stewart is no kind of utilitarian. In his view the way to public and private happiness is governed by these rules, and they are to be obeyed not because, or not only because, obedience leads towards happiness and disobedience away from it, but because they are rules of unalterable right and wrong. ${ }^{\mathrm{I}}$

\section{THE PRINCIPLES OF ACTION}

Moral distinctions, Hume argues, cannot be factual distinctions. A statement of fact by itself has no practical implications;

\footnotetext{
I Active and Moral Powers, I. iii.
}

no one does anything or avoids anything simply as a consequence of acknowledging its truth. But men are 'deter'd from some actions by the opinion of injustice, and impell'd to others by that of obligation'. Moral judgements as such have practical consequences, and are therefore not factual judgements; the truth and falsity which belong to factual judgements does not belong to them. They cannot therefore proceed from reason which is concerned with 'truth or falsehood'. Nor could the 'merit' of an action possibly be derived from its 'conformity to reason'; an action cannot be reasonable or unreasonable except in a 'figurative and improper way of speaking'.

Reason has an indirect influence on our actions in two ways. It informs us of the existence of an object which is the 'proper object' of some 'passion', and the passion aroused moves us to action; or it indicates the means to an end dictated by desire ('discovers the connexion of causes and effects, so as to afford us means of exerting any passion'), and because we will the end we will the means. And that an object is an object of a certain kind, and that the means to it are of a certain kind, are both matters of fact about which we may make true or false judgements. False judgements about either might be said figuratively and misleadingly to make the passions and actions connected with them unreasonable. There is no other truth and falsity in morals, no other reasonableness or unreasonableness in actions. ${ }^{\text {I }}$

As mankind have, in all ages, understood reason to mean the power by which not only our speculative opinions, but our actions ought to be regulated, we may say, with perfect propriety, that all vice is contrary to reason; that, by reason, we are to judge of what we ought to do, as well as of what we ought to believe. ... There are other to do, as well ases which heen used on the same side of the question, which I see no reason for adopting, such as-acting contrary to the relations of things-contrary to the reason of things-to the fitness of things-to the truth of things- to absolute fitness. These phrases have not the authority of common use, which, in matters of language, is great. They seem to have been invented by some authors, with a view to explain the nature of vice; but I do not think they answer that end. If intended as definitions of vice, they are improper; because, in the most favourable sense they can bear, they extend to every kind of foolish and absurd conduct, as well as to that which is vicious. ${ }^{2}$

I Treatise, m. i. 1, pp. $456-60$.

2 Active Powers, v. vii; Works, ii. 676. 
Reid has not changed his mind as to the source of our knowledge of moral distinctions in now speaking of reason as the power by which we judge of what we ought to do. 'Conscience', 'the moral faculty', 'moral sense', 'reason'-as far as Reid is concerned, these are all different names for the same thing; all of them sanctioned by common usage. The term 'moral sense', he admits, may need some apology. Shaftesbury and Hutcheson gave it wide currency, but it is 'not new'; at least expressions very similar to it are old, the 'sensus recti et honesti' in Latin and the 'sense of duty' in English. 'The moral faculty was given the name 'moral sense' no doubt because of the evident analogy between it and the external senses. Philosophers made the term 'moral sense' into a term of theory, in Reid's opinion, by abridging the functions of sense, by making it feeling without judgement. Reid would deny that he uses the term in the interests of a theory; it is not putting forward a philosophical theory to oppose a philosophical theory by pointing to the objective implications of the word 'sense'.

The controversy in which it is debated whether 'moral sense' or 'reason' is the proper description of the moral faculty, but in which the question of the objectivity of moral distinctions does not necessarily arise, attracts no more than Reid's casual notice, and only at the point where the rationalists seemed to be attempting explanatory definitions of virtue and vice. Otherwise it is a controversy towards which he shares Butler' ${ }^{2}$ indifference. But if the faculty by which we frame judgements which must be true or false is to have the word 'reason' appropriated to it, then it becomes philosophically important to call the moral faculty 'reason'.

Reid once held much more radically that the whole controversy as to whether moral distinctions are discerned by 'reason or sentiment' was trivial. ${ }^{3}$ It could be settled, and the manner

I Active Powers, m. iii. 6; Works, ii. 589-9o. Reid paid considerable attention to the way in which the word 'reason' was ordinarily used in moral contexts, but none to the ordinary signification of other expressions which he treats as equivalents. (Beattie remarks briefly that 'conscience' is a term applied to a man's moral 'consideration of his own conduct', and that 'moral sense' is a philosopher's term. Elements of Moral Science, 2nd ed., Edinburgh, 1807, ii. 15.)

2 The Analogy, Dissertation II. Reid's moral philosophy and Butler's have a number of points in common. Reid has, however, changed into his own idiom anything he might have taken over from Butler.

${ }^{3}$ Aberdeen MSS. 2131.3. The minute-book of the Literary Society of Glasgow in which it was to be settled showed its triviality. Consider, Reid says, the agreement between the disputants. They agree (i) that there is a power of the mind by which we distinguish in 'speculative' matters between truth and falsehood; (ii) a power 'speculative' matters between tetermine which ends are 'eligible'; (iii) a power of the mind by which we can determine the means appropriate to these ends. They agree that the first and third of these powers are to be called 'reason'. They agree in their moral judgements. What are their disagreements? One says that the second of these powers should be called 'reason' and the other denies that it should. They have the same moral 'perceptions'. 'But, says one, this perception is not feeling but seeing; says the other, it is not seeing but feeling.' Their dispute is to be settled 'not by arguments but by authority', by the authority of customary speech. The truth is that the 'different powers of the mind are not distinct individual beings, nor are the limits that divide one power from another fixed by nature. We divide the powers of the mind as we divide a joynt of meat, as best suits our convenience and occasions'.

Reid came to see that the real point in the dispute was whether or not moral distinctions are sui generis and objective, and it became a matter of importance to him which words were used. Objective words are needed to mark objective distinctions: 'reason' and 'judgement', and not 'sentiment' and 'feeling'.

Stewart does not ever share to any great extent Reid's veneration for common language because it is common language. The words to be used here are any words which keep the recognition of the objectivity and immutability of moral distinctions as clear as possible. It is useful to say that moral distinctions are perceived by 'reason'; the word is an emphatic safeguard. On the other hand, it perhaps suggests that moral discernment is the result of reasoning. 'Moral sense' is a harmless enough expression in itself, although it has come to have dangerous associations. Neither of these terms, nor any other, throws any light on the origin of our moral conceptions and judgements. The unique, unanalysable, and objective conceptions of morality may be legitimately and unilluminatingly ascribed to reason, to the understanding. If we have laid it

has this question against Reid's name for 3 Mar. 1769 . Reid mentions its discussion in the paper in which he speaks of his conversion in moral theory. 
down that every simple idea is to have its origin in some 'sense', we shall have to speak instead of a 'moral sense'. And if the ideas of time, of number, of causation were 'as important as those of right and wrong, or had been as much under the review of philosophers, we might perhaps have had a sense of Time, a sense of Number, and a sense of Causation'. ${ }^{\mathrm{T}}$

The power of moral discernment, in Reid's mature opinion, is a rational power, and a regard for our duty a 'rational principle of action'.

By the 'principles of action' Reid explains that he means 'everything that incites us to act'. When 'moral imputation' is involved, he says, nothing is to be regarded as a man's action unless it is something which he 'previously conceived and willed or determined to do', but in other contexts the words 'a man's action' have a much more general meaning, wide enough to allow us to speak of 'involuntary actions'. Reid is inquiring into the principles of human action in this very general sense. They fall, he thinks, into three classes: 'mechanical', 'animal', and 'rational' principles. ${ }^{2}$

No thought and no intention are required for an action which proceeds from the operation of a mechanical principle. What is done instinctively, and what is done by habit may be done without our even noticing it. Instincts and habits are the two different kinds of mechanical principles. To breathe is 'instinctive', to swallow, to imitate. The habits which are active principles are those which do not merely facilitate an action, but those which incline us towards its repetition.

Animal principles ${ }^{3}$ 'operate upon the will' but do not presuppose any exercise of reason. Animal principles may be divided into 'appetites', 'desires', 'affections' (each of these words being given some arbitrary precision). An appetite is a compound of 'uneasy sensation', always more or less specific, and of a desire which keeps pace with it, and it is periodical in its

I Outlines of Moral Philosophy, n. i. 6, Active and Moral Powers, rv. ii; Works, vi. 24-31, vii. 246

2 Active Powers, ir. i. I.

3 Though Stewart is 'always unwilling to differ' from Reid, he is bound to say that the names which Reid has given to these two classes of active principles are completely indefensible. If any principles are common to animals and men, instincts are, and to make desires and affections sub-classes of the class of animal principles runs Reid into obvious absurdities when the desires and affections are particularized. (Active and Moral Powers, Introduction, I. ii; Works, vi. 125, I3I.) occurrence. In desire, as distinguished from appetite, there is no single sensation as there is, for example, a single sensation of hunger, and there is no cycle of want and satiety.

Desires may have persons or things for their objects. Affections have persons for their objects, and lead us to desire either their good or their hurt; are therefore either benevolent or malevolent affections. (It sounds oddly to speak of 'malevolent ffections', Reid admits, but it is convenient and there is the expression 'ill-affected' as some justification.) Reid appears to regard the difference between 'desires' and 'affections' as conregard the differentere by the difference in the proportions and relations of desire and feeling which are components of both. In affections feeling predominates, and desire takes its rise from feeling. When desires and affections are vehement, tempestuous, obsessive, they are commonly called 'passions'.

Mechanical principles of action operate without our will. Animal principles operate upon our will. There are also rational principles of action in man. Without these, and left simply to appetites, desires, and affections, our life would be without direction. The function of rational principles is to prescribe ultimate ends to our will, and to govern our life accordingly. Reason has

in all ages, among the learned and unlearned, been conceived to have two offices-to regulate our belief, and to regulate our actions and conduct. . . . To act reasonably, is a phrase no less common in all languages, than to judge reasonably.... A way of speaking so universal among men, common to the learned and the unlearned in all nations and in all languages, must have a meaning. To suppose it to be words common sense of mankind.

That it comes within the province of reason to determine means to ends, no philosopher, of course, has denied. But reason is not a principle of action unless it determines 'the ends we ought to pursue, or the preference due to one end above another'. Hume denies that reason has any competence in this matter.

I shall endeavour to shew [Reid says] that among the various ends of human actions, there are some, of which, without reason, we could not even form a conception; and that, as soon as they are conceived, a regard to them is, by our constitution, not only a principle of Active Powers, m. iii. I; Works, ii. 579. 
action, but a leading and governing principle, to which all our animal principles are subordinate, and to which they ought to be subject.

These I shall call rational principles; because they can exist only in beings endowed with reason, and because, to act from these principles, is what has always been meant by acting according to reason."

The ends prescribed to our conduct by reason are our 'good upon the whole' (our general interest) and our moral duty. As ends, inclining the will towards them, they are principles of action; as prescribed by reason, rational principles. We live as reasonable men when these principles in fact govern our conduct, and we act unreasonably when our actions contradict either of them.

The conception of our good upon the whole is plainly a rational conception. Anything in which a man finds any part of his happiness is good to him, and is desired as soon as it is thought of. In the early part of our lives our will is at the disposal of desires which do not look beyond 'particular and present objects', at the disposal of whichever of these desires happens to be the strongest at the time. When we are older, we learn by the exercise of our reason to think of consequences, looking backwards and forwards. We learn to weigh one good against another, present satisfaction against future loss. We form the highly abstract and general conception of our good upon the whole, a conception which is thus clearly the offspring of reason, and can be only in beings endowed with reason. And if this conception gives rise to any principle of action in man, which he had not before, that principle may very properly be called a rational principle of action.'2

There is no doubt that this conception does give rise to a principle of action, does supply a motive to our will. There is a contradiction, Reid is nearly certain, in supposing an intelligent being to have the notion of good and not to desire it. There is at any rate some sort of impossibility in contemplating with complete indifference something which we know to be necessary for our happiness.

The 'sense of duty', declaring our obligations to us and urging them upon us, is an active principle. The moral faculty for

\footnotetext{
2 Active Powers, rr. iii. 1; Works, ii. 580.
}

Reid combines intellectual and active powers. The judgement that this is my duty is a factual judgement; it is true or false. It is a practical judgement; it states what I ought to do. And it is practical again as inclining me to action; moral judgements are not 'dry and unaffecting'. From the constitution of our nature, even if there is no other necessity in the matter-and Reid is inclined to think that there is-we cannot regard something as our duty and regard it with complete indifference. ${ }^{\mathrm{r}}$ The 'sense of duty' is a rational principle of action-by common consent. Reid never adds anything to his statement that to do what we believe to be our duty is part of what has always been meant by 'acting according to reason'.

Since reason prescribes our total good and our duty as ends to our conduct, the passions ought to be under the control of reason, for the passions demand immediate satisfaction with no concern for our general interest and none for right and wrong. At least sometimes in Reid, to oppose 'the common sense of mankind' is simply to oppose 'the common language of mankind'. When Hume asserts

that men ought to be governed by their passions only, and that the use of reason is to be subservient to the passions, this, at first hearing, appears a shocking paradox, repugnant to good morals and to common sense; but, like most other paradoxes, when explained according to his meaning, it is nothing but an abuse of words.

For, if we give the name of passion to every principle of action, in every degree, and give the name of reason solely to the power of discerning the fitness of means to ends, it will be true that the use of reason is to be subservient to the passions. ${ }^{2}$

The rational principles of action have authority over the whole of our conduct. Their requirements, Reid is certain, can never really conflict; in the justice of God, duty is always our interest. In their apparent conflict we do our duty, because it is our duty, and if we need any further reason for doing it, because to do otherwise is to act immediately against our happiness. A prudential virtue will very properly lack the exalted happiness

Ibid.

2 Active Powers, IIr. ii. 6; Works, ii. 572. In a later passage (IIr. iii. 2 ; Works, ii. $5^{81}$ ), which otherwise closely reproduces this passage, Reid speaks as though he thought Hume was maintaining something really paradoxical, which could 'only be defended by a gross and palpable abuse of words'. 
which accompanies disinterested virtue. ${ }^{\mathrm{I}}$ It will at least escape the misery of vice. The man who does what his duty requires is thus, even so far as this world is concerned, looking after his happiness most effectively. If he is looking after his happiness effectively, he will find that he is led to a life of virtue. The principle of enlightened self-interest leads

directly to the virtues of Prudence, Temperance, and Fortitude. And, when we consider ourselves as social creatures, whose happiness or misery is very much connected with that of our fellow-men; when we consider that there are many benevolent affections planted in our constitution, whose exertions make a capital part of our good and enjoyment: from these considerations, this principle leads us also, though more indirectly, to the practice of justice, humanity, and all the social virtues.

It is true, that a regard to our own good cannot, of itself, produce any benevolent affection. But, if such affections be a part of our constitution, and if the exercise of them make a capital part of our happiness, a regard to our own good ought to lead us to cultivate and exercise them, as every benevolent affection makes the good of others to be our own. ${ }^{2}$

Duty and interest prescribe the same conduct. They are both 'reasonable motives to action'. And entirely different. Anyone may be 'satisfied of this who attends to his own conceptions, and the language of all mankind shows it. When I say, This is my interest, I mean one thing; when I say, It is my duty, I mean another thing.' 3

Is it our duty to act with regard to our interest? Reid perhaps seems to hesitate. The principle of a regard to our good upon the whole gives us the conception of $a$ right and wrong in human conduct. There is a 'kind of self-approbation' when we have done right in this way, and, a 'kind of remorse' for folly. ${ }^{4}$ But Reid is not really hesitating. He is saying that we could make these quasi-moral judgements on our conduct independently of any moral judgements we might make upon it; we could make

I Reid shares the widespread eighteenth-century belief in the superlative happiness arising from a consciousness of virtue. It is something which he perhaps owed partly to the instruction of Turnbull, who had learnt it from Shaftesbury. God himself is happy, according to Turnbull, 'from no other source but his absolute moral perfection'. (Principles of Moral Philosophy, i, p. iii.)

2 Active Powers, nIr. iii. 3; Works, ii. 584.

3 Ibid., III. iii. 5; Works, ii. 587 .

4 Ibid., III. iii. 2; Works, ii. 582 . them even if we lacked what is strictly a moral sense. In the Intellectual Powers the principle that we ought to seek our own happiness is mentioned as one of the 'first principles of morals'.

Our duties unmistakably include, Stewart maintains, a duty to ourselves; the neglect of private good is morally wrong. If it does not call for the same indignation as injury to others, that is because it punishes itself, and our indignation is softened by pity. We all think that the man who has recklessly damaged his own interests deserves to suffer for it, and he thinks so himself when he reflects. And his remorse is not merely a regret for lost happiness; he is dissatisfied not only with his 'condition' but with his conduct. Since imprudence is immoral, a belief in rewards and punishments after death makes every bad action worse. ${ }^{2}$

What gives moral worth to an action? Every human action 'takes its denomination and its moral nature from the motive with which it is performed'. An act is not an act of benevolence unless it is done from benevolence, an act of gratitude must be done from a sense of gratitude, an act of obedience from regard to a command. And 'in general, that is an act of virtue which is done from a regard to virtue'. ${ }^{3}$ If we ask 'whether an action deserving moral approbation, must be done with the belief of its being morally good', we are asking, Reid says, a question in 'practical' morals, and therefore a question which is to be referred not to moral theory but to the moral faculty. And any theory which is committed to answering it in a way which conflicts with the answer it unhesitatingly receives from the moral faculty, is in the position of any theory in conflict with fact. An action to have moral worth must be done with the belief that it is morally good. 4

The question, as Reid words it, is ambiguous, and it has been answered ambiguously. Is it enough that the action be done with the belief that it is morally good, or, as Reid's remark on the moral denomination of human actions indicates, must it be done with this belief as its motive?

There is, Reid maintains, a set of self-evident propositions respecting guilt, innocence, and moral worth, 5 and the proposition

vur. ii; Works, i. $4^{80}$.

3 Active Powers, v. vi; Works, ii. 667 .

2 Active and Moral Powers, Iv. iv. I.

5 Ibid.; Works, ii. 646-7.
4 Ibid., v. iv; Works, ii. 646. 
that an action, in order to have moral worth, must be done with the belief that it is morally good takes its place among them. Everything that we do is either right, wrong, or morally indifferent, and in everything that we do our conscience is altogether silent, or it informs us that what we are doing is right, wrong, or morally indifferent. If a man does something that is wrong, without the least suspicion that it is, his conscience either silent or pronouncing the action indifferent, he acts innocently. He does not deserve condemnation or approbation. Would any moralist disagree? Reid is sure that the disagreement would be merely verbal. Reid is considering simply the action and the disposition with which it was done, disregarding previous circumstances. 'If there was any previous culpable negligence or inattention which led him to a wrong judgment, or hindered his forming a right one, that I do not exculpate.' The moralists who will not allow that a man acting with a clear conscience must be acting innocently, take his past and present conduct as a single whole, and in the whole there will perhaps be something to blame. Reid takes his conduct to pieces so as to put the blame where it lies.

If a man does what his conscience condemns, he deserves condemnation, even though his conscience should happen to be misinformed. If he does what his conscience demands, he deserves approbation. Now if he does what his conscience demands, he does it with some regard to the fact that he believes it to be his duty, or with none. The second alternative is 'not supposable'; moral judgements cannot leave the will unaffected. Reid might therefore have claimed that the ambiguity in the proposition we are considering is of no account, since an action done with the belief that it is our duty is unavoidably an action done with this belief as a motive. He claims that he has made it evident that 'those actions only can truly be called virtuous, or deserving of moral approbation, which the agent believed to be right, and to which he was influenced, more or less, by that belief'.

Is it Reid's opinion that a regard for duty is the only motive which has moral worth? Passages which seem to point to one answer have their indications weakened elsewhere. The question of the proper object of moral approbation arose when Reid was comparing the 'affections' with the virtues and vices.
What is the difference between them, between, for example, the affection of benevolence and the virtue of benevolence? 'The virtue of benevolence is a fixed purpose or resolution to do good when we have opportunity, from a conviction that it is right, and is our duty. The affection of benevolence is a propensity to do good, from natural constitution or habit, without regard to rectitude or duty.' One might hesitatingly take this to carry the general implication that a regard for duty is the only motive with moral worth. 'The more weight the rectitude of the action has in determining me to do it, the more I approve of my own conduct.' This remark occurs in the context of Reid's discussion of the proposition that 'an action deserving moral approbation, must be done with the belief of its being morally good.' But when he is defending the proposition against the objection that we approve immediately of 'benevolence, gratitude, and other primary virtues, without inquiring whether they are practised from a persuasion that they are our duty', his curious answer is that we take it for granted that a man practising any of the virtues is doing so 'with a good conscience'. ${ }^{2}$ And this seems to imply that while a man's actions must have the approval of his conscience if they are to have moral worth, conscientiousness is not the only motive having moral worth.

Had Reid been asked then, whether it is better to do an act of charity which we recognize as our duty, from a regard for duty or from charity, we cannot be quite sure how he would have answered.

There is, Hume maintains, a logical absurdity in the view that it is a regard to the virtue of an action which makes the action virtuous. 'Before we can have such a regard, the action must be really virtuous; and this virtue must be deriv'd from some virtuous motive: And consequently the virtuous motive must be different from the regard to the virtue of the action.'3

Reid paraphrases Hume's argument in order to bring out its 'full strength': Our judgement cannot alter the nature of an action. If the action is wrong and we judge otherwise, it is still wrong; nothing becomes true by being believed to be true. A man therefore who does what he mistakenly believes to be right cannot be acting virtuously, nor viciously by doing what he

\footnotetext{
I Active Powers, Ir. iii; Works, ii. 540.

2 Ibid., v.iv; Works, ii. 647 .
} 
thinks is wrong, unless it is wrong-a conclusion which contradicts one of the first principles of morals and the plainest common sense.

How was Reid able to arrive at this interpretation of Hume? One of Hume's sentences seems to have immobilized his attention, and although he quotes versions of Hume's argument from different parts of the Treatise, this sentence is almost all he sees: 'An action must be virtuous, before we can have a regard to its virtue.'

Reid's reply to Hume can be moved across from the substitute argument to Hume's. It amounts to this: Hume has conjured up an illusion of logical vice in the proposition that to be virtuous an action must be done with a regard to its virtue, has conjured it up out of an ambiguity which is present in many of the moral nouns and their corresponding adjectives. The 'goodness' of an action is different from the goodness of the agent. The goodness of an action which is considered 'abstractly' that is, apart from the disposition of the agent who performs it'appears to lie in this ... only, That it is an action which ought to be done by those who have the power and opportunity, and the capacity of perceiving their obligation to do it'. And the action has 'this goodness' whether the agent thinks so or not. The goodness of the agent is a matter of the disposition with which the action is performed, a disposition which at least includes some regard to the fact that what is done is seen as one's duty. ${ }^{2}$

'Those who have denied the reality of moral distinctions, may be ranked among the disingenuous disputants', Hume says. They should be left to themselves. Finding nobody prepared to argue with them, they will in all probability 'from mere weariness, come over to the side of common sense and reason'. 'Let a man's insensibility be ever so great, he must often be touched with the images of Right and Wrong; and let his prejudices be ever so obstinate, he must observe, that others are susceptible of like impressions.' 3 Reid arrived at the opinion that the moral sceptic is not fully restored to common sense until he sees again what he once knew (however inarticulately), that moral

\footnotetext{
I Active Powers, v. iv; Works, ii. 648.

2 Ibid.; Works, ii. 649 .

3 Enquiry Concerning the Principles of Morals, I, pp. 169-70.
}

distinctions are immutable and independent of anyone's 'impressions'. Hume has only to point to the impressions to establish the truth of what he regards as the common-sense belief in the reality of moral distinctions. For Reid, this belief has a metaphysical character, and its evidence is self-evidence.

The philosopher who is accused of rejecting a belief of common sense may properly demand proof that the belief he is rejecting is a belief of common sense. The philosophy of Common Sense has no more than a coarse sensitivity to this demand. With negligible protest from its critics, it took the metaphysical character of the beliefs of common sense for granted as something manifest, and defended their truth with too little reflection upon their interpretation. We distinguished in a previous chapter the different levels which must be present in these beliefs if the philosophy of Common Sense has not wholly mistaken their nature: an 'empirical' level at which they are verifiably true and are never questioned except through misunderstanding-moral distinctions, for example, have at least and indisputably the reality Hume assigns to them-and a 'metaphysical' level at which their truth has come into continual dispute. Never making this duality explicit, never more than half-realizing it, the Common Sense philosophers, Beattie and Oswald especially, frequently defended common-sense beliefs at their metaphysical level against imaginary attacks upon them at their empirical level. And for the same reason, they failed to see that the criterion of 'practice' establishes the truth of these beliefs only at the level at which their truth is not in dispute. Reid's appeal to general consent makes the incidental claim that the beliefs of common sense have God's guarantee - there is 'a great presumption that the judgment of mankind .... is the natural outcome of those faculties which God hath given them'. A Apart from this, it is, like his references to the testimony found in the structure of ordinary language, subsidiary to his appeal to the self-evidence of the beliefs of common sidiary to his appeal to the show that they really are beliefs of common sense, original dictates of the constitution of the human mind.

Priestley gave assurances that Hartley's principles would do great damage to 'the system of common sense'. Mill's attack

1 Intellectual Powers, vi. iv; Works, i. $44^{\circ}$. 
upon it had Hartlian antecedents. There are no truths 'cognizable by the mind's inward light, and grounded upon intuitive evidence', Mill asserts in his essay on Coleridge (1840); all knowledge is experience generalized. Locke was not mistaken, but Reid and 'the German school', in repudiating Locke, raised difficulties to which Locke's principles without Hartley's had no solutions.I Hartley had explained in broad outline for Mill how the a posteriori could take on the features of the a priori, and how in the growth of the mind all our knowledge and beliefs are built up associatively from what Locke had provided as their only materials.

Mill's Examination of Sir William Hamilton's Philosophy is a work in the concrete empiricism to which Hartley had applied himself. In this book Mill attacks the philosophy of Common Sense by attacking the primitiveness of the beliefs of common sense. We cannot, he argues (ch. ix), ascertain the 'original data of consciousness' from 'present consciousness'; they can only emerge as 'residual phaenomena' when hypotheses describing their generation by analogy with the generation of admittedly derivative 'mental facts' have broken down. The primitiveness of anything in the mind is therefore a matter for scientific investigation, for the 'psychological method' of inquiry which Mill opposed to the 'introspective method' of Reid and Hamilton. It would lead, he considered, to an explanation of the origin of beliefs which they maintained to be grounded upon inexplicable discernment into the truth of things, and reveal the way in which what was without evidence had come to appear self-evident.

The philosopher who rejects a belief of common sense is bound, Reid thought, to show that it is mistaken and why it is universal; he has to find 'a cause of the error, as general as the error'.2 In fact, however, if the metaphysical beliefs of common sense are held to be self-evident and incapable of proof, he seems to have done his work sufficiently well when he has shown why the belief is universal. Questions of validity are independent of questions of origin, but not when evidence is self-evidence. But balancing this, when evidence is self-evidence, the beliefs it authenticates are always likely to appear more obviously true

\footnotetext{
'Dissertations and Discussions (London, 1859), i. 404-12.
}

a Intellectual Powers. vi. iv; Works, i. 440. than any account of them which explains away their selfevidence. Self-evidence is always better and worse than other evidence in competition with it.

With Mill's Examination (1865), the philosophy of Common Sense, already old-fashioned, went quite out of date, both for those who thought with Mill and for most of his critics. Those who criticized Mill and wanted Hume answered, with few exceptions no longer wanted him answered in Reid's way, or they wanted Reid's answer taken up into Kant's, or given its modest place in an Hegelian synthesis.

But very little in philosophy is ever finished with, and the philosophy of Common Sense is not finished with. Either there are no 'ideas' in thinking, remembering, and perceiving, or there are only 'ideas'. A crude proposition, and much of Reid's discussion of it is crude, but the problems with which Reid was concerned in his survey of the theory of ideas are perennial, and some of the things he says will always need repeating.

There are questions asked by philosophers and answered by common sense, which therefore contains 'a philosophy prior to philosophy'. ' With the untroubled assumption that the beliefs of common sense show their metaphysical character as they show their authority, the philosophy of Common Sense came into existence in order to make this claim. It is a claim which cannot easily be settled if it can be settled, and as it involves the nature both of philosophy and of common sense, it is one which should be reconsidered and, in spite of its unsophistication, with some care.

I Jouffroy, Melanges philosophiques (2nd ed., Paris, 1838), p. 145. 


\section{INDEX}

Aberdeen Philosophical Society, 1-2,

226-7.

,

Abstract truths, 55, I 17 n., 237-8.

Agency, 136, 209-14, 219

Analogies between the operations of bodies and minds, 27, 33-34, I 31 $133-5,139-40,143,201,214,219$.

Analysis, 29, 80-81, 93-96, 98, 102 , 107-8, 1 30, x 43-5, 149, I 75, 182, 206,

Approbation, moral, 224-5, 230, 234, 237, 251-3.

Aristotle, 10, 114, 132, $214 \mathrm{n}$.

Arnauld, A., 22.

Athanasius, $1 \mathrm{n} ., 7 \mathrm{l}$.

Atomism, 78-80.

Bacon, F., 2, 7, 10, 132, 135, 141, 1478, 159.

Bain, A., 2.

Beattie, J., i-2, 5-6, 8, 10 n., 25, 56-57, $61-62,67-68,70,82-86,89$, 101, 104, I 06-7, I I0, I I 2-13, I I 5, I 19-20, $124-6,132,147$ n., 174 n., 185,187 n., 194,244 n., 255

Beauty, I I I , 154, 225, 230-5, 237

Belief, nature of, $9,24^{-25}, 70-71,75$, 80.

Berkeley, G., 10, 13, 16, 21,23 n., 40$42,53-54,56-61,97,115,15 \mathrm{I}, 154$ $159,170,180,183,188,224$

Blacklock, $T$., 1

Bonald, de, 3

Bonnet, C., 200.

Brougham, H., 2.

Brown, T., 6, 12-13, 20, 22, 109, 144, 182,183 n., $216 \mathrm{n}$

Buffier, G., 8-9, 112 n., 122 n., 214 n. Butler, J., r 94 n., 244.

Campbell, G., 1, 5, 10 n., 79 n., 11718, 145 .

Causation, 7, 9, 53, 79, 103, I I 7 n., I I8, $135-7,148,154,180,205,209^{-1}$, $218-19,246$.

Chalmers, T., 3

Cheselden, W., 17 I.

Clarke, S., 26-27.

Cognitive contact, principle of, $25^{-28}$,

Coleridge, S. T., 256.

Common Sense: appeal to, 1, 7, 110 ,

$112 \mathrm{n}$., I13, I15, 123-4; authority of,
$4-5,86,109,122,158,257$; beliefs of as presupposed in experience, $3,149-$ 50,$196 ;$ and certainty, 87-92, 98, 1 19; and common consent, $107-8,121-3$ 124 n., 255; and common language, see Language; criteria of, $83, \mathrm{IO}^{-5}$ $119,123,130,255$; definition of, 8,84 115,15 , distinction of $116,123,158-9,255$; and the external senses, $110-13,168,180$, 186 foundation of, $151,153,156-9$; limit of, $6,122,124$; metaphysical character of, $4,93,96$, 101 -8, I $16-17,120-1$, $123,150,158-9,196-7,200,226-7$, 255,257 ; and morality, $67,96,158$, 226-8, 230, 236, 249, 254-5; objectivity of, $3,110-12,124-5$ perception, 19-20,128, $184-6$; and philosophy, 97, 130-1, 147-8, 206, 257; principles of, 3, 83, I $14, I_{1} 7^{-19}$, 125, 130, 144, 147-50, $164 \mathrm{n} ., 186$, 209; and proof, 9, 83, 119-23, I30-I, 150-1, 255-6; and reason, 1.1 pas$4-5,8-9,21$ n., 57-59, 82-87, 92-93, 10I-2, I06, I I 9-23, 131, I 50, I83, I $222,230,247,249,254,256$; and selfevidence, 53, $101 n$, $88,116-21,123-$ 6 , 149-51, 201, 223, 255-7; sec also Language.

Conception: abstract general, 40-42; of extra-mental objects, $27,29,31,34$, $39-40,43-49,72,81$; of non-existent objects, 24-26, 33-41, 43, 72; of objects, $24-26,33-41,43,72$, of propositions, 78 ; of universals, $35-$

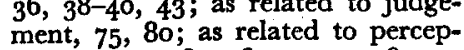
tion, $30,32,161,167,174-5,181$; as tion, $30,3^{2}$, $16 \mathrm{r}, 167,174-5,181$; as
related to possibility, 41 , 77-78; see related to possibility, 4
also Ideas, Imagination.

Conceptualism, 37-38, 40, $4^{1} \mathrm{n}$.

Condillac, $3,6 \mathrm{n}$., 141 .

Conscience, 244, 252-3

Consciousness, 9, 27, 55, 72-73, 116-

$17,122,155,176,19^{1-4}, 197-8,200$, 202, 211,216 n., 256

Cousin, V., I, 3 n., 4, 6-7, $210 \mathrm{n}$.

Democritus, 11 .

Demonstration, 55, 87-88, 89 n., 9091, I 19, I21, 148-50, 237-41.

Descartes, R., 10-11, 26, 116, 120, 132,

I35, I 37, 1 39, 194, 199-200, 224. 
Determinism, see Free Will.

Doubt, 62, 68, 92, 119 ; see also Common Sense, Knowledge.

Dryden, J., 194.

Duncan-Jones, A. E., 97 n.

Duty, see Obligation; and interest, 215 8, 249-5I

Eclecticism, 3-4, $14 \mathrm{I}$.

Edmond, F., $118 \mathrm{n}$.

Empiricism, conceptual, $15^{-16}$, 50-53, $63-64,72,77,97-98,235$

vidence, $87-88,116,126,196,239-$ $41,256-7$; see also Self-evidence.

Fallacies of the senses, $185-9$.

Fearn, J., $170 \mathrm{n}$.

Ferguson, A., 2, 5 .

Ferrier, J. F., 56, 60 n., 129

Flew, A., $86 \mathrm{n}$.

Fraser, A. C., 2 ro $n$

ree Will, VI. 2 passim, 2 n., 82-83,

$85-86,93,97-98,102,134,158,202$.

Galileo, 131.

Generalization, 40-43.

Gerard, A., I, 5 .

Glasgow Literary Society, 227, 244 n.

Glennie, -, 2.

Glennie,,- 2.

God, 5, 26, 46, 58-59, 61, 115,117 n.,

$121,126,131,135-7,139,146-8$, 154, 158-60, 199, 201, 209-10, 237, 239-40, 249, 255

Gregory, J., 7 n., 12, 214 n.

Hamilton, W., 6, 8 n., 21, $3^{1}$ n., 117 , $123,126-9,141,157,174,181,215-$ $16,226,256$.

Happiness, 242, 249-51.

Hartley, D., $\mathrm{I}_{38-9}, 143,200,255^{-6}$.

Henry, J., $5 \mathrm{n}$.

Heraclitus, 125 .

Home, H., see Lord Kames.

Horner, F., 2.

Hume, D., I-2, 4-5, 7-8, 10-12, 19 , $28-30,52-54,61-79,83,85-86,89-$ $91,93,97-98,101,104$, 109, 11 120, $130,140-1,143,145,154,183-5$ I91, 202-7, 212-13,226, $228,229-5$ 230, 235, 24I n., 242, 247, 249, 253-5, 257.

Hutcheson, F., 141, 233, 235, 244.

Hypotheses, $131,135-6,3_{38-40,143}$ 148.

Ideas: abstract, $40-41,46,55,78$; agreements and disagreements of, 55 , 15-16,50, 15 178, 191, 199, 228, 235 n., 245-6;
4, 17 ; as differing in degree, $59,70-76$ fugitive existence of $11,23,29,46$ $59-60,64-67$; identity of act and object in, 20-23, 35, 59, 65-67, 70 73 ; as images, $13-20,26,28-29$, $34-35,44,47,50$; as images in the brain, 13, 17-19; of imagination $22, .28,33,43,59,70-71,73-76$;
innate, 46 , 199 ; as matching iminnate, 46, 199 ; as matching impressions, $15,46,50,52,76-77,191$, 211 ; of memory, 9, II, 22, 24, 27 $29,33,43-44,49-51,71,73-76$; as objects in perception, I. I passim, $24,26-27,43,47,49,7 \mathrm{I}, 73-76,182$; as objects of thought, 9, II, 22, 24-27 31, 33-35, 37, 45-49,51, 54, 63ings of the term, $21-22,44$; as philo sophers' inventions, 12 , 17 ; Platonic 40; privacy of, 24, 57-59; of reflec tion, 10, 15-16, 50, 191 , 11 ; tion, 10, 15-16, 50, 191, 211; of I9I, $211^{\circ}$, $4^{-1} 7,47,5^{0}, 59,163^{-4}$ as separas sensations, $17,169,182$ as separate entities, $20-23$; as signi-
fied by words, $37-38$; simple, $79-$ $8 \mathrm{I}$; supposed mediatorial necessity of, $x$ I, 24-27, 37; as unlike anything external, $14,16-17,56,60,64$; see external, $14,16-17$,
also Theory of Ideas.

Identity, $9,58,194-5$, I97; personal, VI. I passim, 51, 53, 77, 82-85, 93,
Vity, 9, 84 , VI. I passim, 51, 53, 77, 82-8
97, I02-4, II 5 I 19, 149, 227 .

Imagination: and belief, $3^{1-32,44,71}$; distinguished from conception, 31 32,34 n., 43 ; objects of, $20,22,25$, $32-34,43-44,72-73$; as related to memory, 28 , 30-32, 43, 69-76; see also Conception, Ideas.

Immortality, 200

Impressions, see Ideas, Perceptions.

Induction, $68,79,82-83,85,101 \mathrm{n}$.

$117,120,122,131-2,135,137-41$,

$143,146,149,158,160$.

Intensity, scale of, $33,70-76$.

Jeffrey, F., 2, 144 .

essop, T. E., $59 \mathrm{n}$.

Johnson, S., $59 \mathrm{n}$.

Jouffroy, T., 131 n., 141-3, 146, $257 \mathrm{n}$. Judgement, $75,80,111,126,224,229$,
237; aesthetic, 234-6; moral, VII. 1 passim, 243-5, 249-50, 252-3.

Kames, Lord, 2, 137 n., 138 n.

Kant, I., 3, 5, 118, 129, 257

Kemp Smith, N., 61, 63, 67, 74 .

Knowledge, 9, 55, 80, 87, 96, 131, 145; relativity of, 6, 10, 126-9; see also Common Sense, Doubt, Probability, Scepticism.
Lamennais, F. de, $124 \mathrm{n}$.

Language: analogical extension of, sec Natural Signs; Common, 7, 19, 20$21,34,52-53,58,65,69,86-88,92-94$ $96-100,102,105-7,122,132-3,163$ $165,169,195,203,208,225-6,228$, 230, 233, 243-5, 247, 249-50, 255; correct, 99-100, 192; natural and conventional, I51-4, I59-60, 172 ; origin of, $151-3$; structure of, 20, 21n.,65, 105-7, 193, 255; and thought, $42-43$.

W., 206.

Liddell, A. T. W., $227 \mathrm{n}$.

Locke, J., 3, 7-11, 15-16, 18, 25-26, $28-29,40-41,47-48,53-56,60-63$, $79-8 \mathrm{I}, 110,141,169,197-8,224$ $233-4,235$ n., $237-9,256$.

Mackintosh, J, , 109

Maclagan, W. G. $2 \times 7$ n.

Magnitude, real and apparent, $171-2$ $183-6$

Maine de Biran, 3.

Maistre, J. de, 3 .

Malcolm, N., 99-100.

Malebranche, N., I3, 21, 26, $211 \mathrm{n}$.

Mansel, H., 128.

Materialism, 142-3, 200-1.

Mathematical propositions, $117-18$, $14^{8-9}$.

Matter, passivity of, 199, 201, 209-10; substantiality of, $56,126-7,193,198$ -

McCosh, J., 3 n., I18, 126 n., 140-1,

$210 \mathrm{n}$.
Memory: immediacy of, $25,27,29-$ 30, 31 n., 44,48 , 158 ; physiological theor 30 ; as related to imagination, see Imagination; true and false, 24-25, 44; veracity of, 122 ,

The Sense.

Method in the philosophy of the mind IV. 2 passim, 3, 6-7, 10, 200, 256. Mill, J., 3.

Mill, J. S., 94, I28, 256-7.

Milton, J., 194

Mind: corporealization of, $19,133 \mathrm{n}$., 170,201 ; fragmentation of, 61,66 , $76-77,79,202,213$; immateriality of, 1 34-5, 199-201, 203; substantival being of, $76-77,79,126-7,180,193$, 198-9, 203; see also Self, Soul.

Minds, other, $58,82-85,93$, 1or -4 , 108, I I 7, I I 9, I 52-7, I96-7.

Moral codes, diversity of, $241-2$.
Moral distinctions, immutability of $223,227,236-7,245,255$; objectivity of, VII. I passim, 107, 146, 242-5,

Moral sense, 67, I1 1 , 228, 238, 244-6, 25

Moral worth, 251-4.

Motives, 203, 213-1 7, 219, 229, 248, $25 \mathrm{I}-3$.

Natural Signs, V. I-2 passim, $80 \mathrm{n}$. $184,186-8,190-3,197$

Necessary truths, 78, 117-18, 121

146 n., 148, 209, 237, 239

Newton, I., $7,18,26,136,142,147-9$

Obligation, 219-20, 222-3, 228-30, $237-44,246,24^{8-54}$

Occasionalism, 173, $210,211 \mathrm{n}$.

Ontologism, 4-5.
Oswald, J., 5-6, 8, 57 n., 82-86, 104 n., I10, I12, I15, I24, 147 n., 255.

Palmerston, Lord, 3.

Paradigm cases, 86-87, 92, 96

Paradox, philosophical, 8-9, 59, 84-86 $92-93,98-100,102,115,120,169$ 230, 233-5, 249

Passion and reason, 247-9.

Perception, direct, $15,18,20,24-25$, $30,43,56,59$ n., $128,172,177-8$, 181-2, 184-5; distinction of act and object in, $21 \mathrm{n} ., 22-23,165-6,171$ 72 ; mistakes in, $24-25,180-1,186-9$ objectivity of, $14-16,18,20,21 \mathrm{n}$. $43,111-12,128,163-71,175-8,180-$ 9,226 ; original and acquired, $172-3$ $177,180-1,184-5,188$; physiologica antecedents of $17-18$, pho $187-8$; relativity of, $V$. 3 passim, $187-8$ relativity of, 3 passim, 10 24-25, 62; representative, see Theory of Ideas; structure of, V. 2 passim, 3o, 32, 225; see also Com

Perceptions, continued existence of, 65 67; exclusive existence of, 63,70 76 ; separability of, $66-67,77$; see also Ideas.

Phenomenalism, 83, 85, 93, 95-96, 10o, $105,107-8$.

Plato, 40.

Positivism, 83, 85, 93, 97, 105, 107-8.

Possibility, maxim of, 77-78.

Power, 53, 104 n., 128, 208-1 I, 220.

Predictability of behaviour, 203, 212

13, 216-18. 
Price, R., 9-10, 27, 235 n.

Priestiey, J., 5, 12, 13-14, 15 n., 79 n. I 10-1 I, I12 n., 124-6, I38 n., I44 $206,222,255$.

Primary and secondary qualities, 9,103 $128,163,167-9,182,193,198,224$ 23I, 233-4

Principles: of action, VII. 2 passim; of common sense, see Common Sense first, II $117-18,120,125,121-2$ 144, 147-50, $193,238,2400$ 254. 254; Newtonian, 148-9; in the philosophy of the mind, 144, 149

Probability, 87-89, 92, 100 n., 239-40. Probability, $87-89$

Pyrrho, 83.

Raphael, D., 27 n., 230 n., 239.

Reason, 64-68, 188-9, 196; and common sense, see Common Sense; in morality, 238-40, 242-50

Reid, T.: biographical details, I-2; sources of his philosophy, 6-10; opinions, see under particular subjects.

Responsibility, moral, 201-3, 205-6, 21 I n., $212-13,216,219-20,222,246$. Réthoré, F., $6 \mathbf{n}$.

Rosmini, A., 4, 72.

Royer-Collard, P., $3,6 \mathrm{n}$.

Russell, B., 98-99.

Russell, Lord John, 3

Scepticism, 1, 8-9, 14, 53, 56, 57 n., $62-64,67-68,75,83,89-92$, I 10-13, $123,150,254$; see also Theory of Ideas. Scott, Sir Walter, 3 .

Segerstedt, T., 9

Self, $3,5^{1-52}, 83,85,93,102-4,108$, $134,157,190-6,198,201-3,213,227$; see also Mind, Personal Identity, Soul. Self-evidence, and common sense, see Common Sense; and moral discernment, 238, 240-1, 251, 255.

Sensation: characteristics of, 14-16, 162 , 165-6; location of, $161-2$; meaning of the term, 15-16, 164-5; no physical archetypes of, 14-16, 134, $162,164,166 \mathrm{n}$.; significatory powers of, V. 2 passim, $156-7,187-8$, I 90-1, 193-4; see also Ideas, Natural Signs, Perception.

Sergeant, J., 26.

Shaftesbury, Earl of, 7, 244, 250 n.

Simple apprehension, 78,80 .

Smith, Adam, 2.

Smith, Sydney, 2.
Soul, I8, 26-27, 56, 142, 200-1; see so Mind, Self

Stewart, D., 2, 5-6, 12, 17 n., 27, 31$33,36 \mathrm{n} ., 37,40-43,63,83,84 \mathrm{n}$ 86-88, 102 n., 104 n., $113-19,122-3$ 124 n., 126,131 , 132 n., 133 n., 134 $124 ., 126,131,132$ n., 169-7o, I 74 n., $176-7$, 180 , 191-4 $196,199-200,216,218-19,231 \mathrm{n}$ 196, tilling, $24,2,245$

Stirlingleet, E.s 25

Stirling, J. H.,

Sublimity, I54, 232-3, 235

Sutance, 106, 126-8, 190, 192$98-9,202$; see also Matter, Mind,

Suggestion, I 78-81.

Sympathetic Imitation, 144 n., 156 .

Theory of Ideas: double aspect of, $9^{-10}$ 12, I 5-16, 50,63, 77-79; explanatory aims of, $25^{-27}, 33,45,136$; explanatory failure of, $27-28,136$; 'gross' and 'subtle' forms of, 21-24; logical incoherence of when fully general ized, 29, 45-46, 48-49, 64; moral implications of, $11,224-7$; old and new forms of, 16-17, 50; persuasive towards, I1, 24-27, 62, I 33,183 sceptical consequences of, II passim 9-12,16-17,30,33, III II 110,134 $224-5,235,257$; as a theory of memory, as a theory of perception I I passim as a theory of 64 , $82-4 ;$ see $24-25,49,60,64,111,182-4$; see Thought, see Conception, Language. Time, $6-7$

Tume, 146-7. $6-7,10,107$ n., $250 \mathrm{n}$.

Universals, see Conception, Conceptualism.

Veitch, J., 128.

Vice, 222, 229-30, 236, 243-4, 250, 253 .

Virtue, to n., II, 202, 222, 226, 2293o, 236, 240 n., 244, 249-54.

Visible Figure, $169-72,177,181-2$, I84-5, 193 n.

Wight, $\vec{P}, 227$.

Winch, P. G., i $78-80$.

Wittgenstein, L., $232 \mathrm{n}$

Woozley, A. D. $96 \mathrm{n}$.
PRINTED IN GREAT BRITAIN

AT THE UNIVERSITY PRESS, OXFORD BY VIVIAN RIDLER

PRINTER TO THE UNIVERSIT 